WESLEY BECARI

\title{
DESENVOLVIMENTO DE SENSORES EM FREQUÊNCIAS DE MICRO-ONDAS PARA CARACTERIZAÇÃO DE ETANOL COMBUSTÍVEL
}

São Paulo 
WESLEY BECARI

\section{DESENVOLVIMENTO DE SENSORES EM FREQUÊNCIAS DE MICRO-ONDAS PARA CARACTERIZAÇÃO DE ETANOL COMBUSTÍVEL}

Tese apresentada à Escola Politécnica da Universidade de São Paulo para obtenção do Título de Doutor em Ciências.

Área de Concentração: Microeletrônica

Orientadora: Prof. ${ }^{a}$ Dr. ${ }^{\text {a }}$ Fatima Salete Correra

São Paulo 
Este exemplar foi revisado e corrigido em relação à versão original, sob responsabilidade única do autor e com a anuência de seu orientador.

São Paulo,13 de Abril de 2017

Assinatura do autor:

Assinatura do orientador:

\section{Catalogação-na-publicação}

\section{Becari, Wesley}

Desenvolvimento de Sensores em Frequências de Micro-ondas para Caracterização de Etanol Combustível / W. Becari -- versão corr. -- São Paulo, 2017.

$246 \mathrm{p}$.

Tese (Doutorado) - Escola Politécnica da Universidade de São Paulo. Departamento de Engenharia de Sistemas Eletrônicos.

1.Sensores de micro-ondas. 2.Caracterização eletromagnética de materiais. 3.Análise de combustíveis. 4.Sensores de líquidos e gases. I.Universidade de São Paulo. Escola Politécnica. Departamento de Engenharia de Sistemas Eletrônicos II.t. 


\section{AGRADECIMENTOS}

À Deus, sobre todas as coisas. À prof. ${ }^{a}$ Fatima Salete Correra, pela orientação, dedicação, empenho e paciência. À Andréia, mulher amada, pelo seu carinho. À Maria Clara, minha filha, por toda a alegria do mundo. Aos meus pais, Heloísa e Waldir, bem como aos meus irmãos, Willy e Christiane, e minha avó Luiza, por todo apoio, vivência e afeto. Aos amigos Molina, José Augusto, Maurício, Márcio, Luqueze, Matteo, Sandro, Mara, Carlos, Teresa, Herval, Anísio, Nelson, Raimundo, Dilma, Adriano, Silvano, Luís, Latife (in memoriam), Rosane, Rita, prof. ${ }^{\text {a }}$ Pilar, prof. ${ }^{a}$ Bete, prof. $^{\text {o }}$ Javier, prof. ${ }^{o}$ Roberto, prof..$^{o}$ Justo, prof. ${ }^{\circ}$ Vitor, prof. ${ }^{\circ}$ Wang, prof. ${ }^{\circ}$ Kléber, prof. ${ }^{a}$ Inés, prof. ${ }^{\mathrm{o}}$ Fernando, prof. ${ }^{\mathrm{O}}$ Vieira, prof. ${ }^{\mathrm{o}}$ Marius, prof. ${ }^{\mathrm{o}}$ Walter, prof. ${ }^{\mathrm{o}}$ Ronaldo, que dividem comigo as alegrias e angústias do trabalho na Universidade de São Paulo.

Ao Henrique por todo esforço, colaboração e parceria ao longo dos anos. Ao Jair pelas soluções criativas nas montagens e por todas as instruções na realização de medidas.

Iniciei o trabalho no departamento de Engenharia de Sistemas Eletrônicos (PSI) no grupo de Sensores Integráveis e Microssistemas (GSIM) no primeiro ano de graduação da Escola Politécnica da Universidade de São Paulo. Tão logo formado, iniciei os trabalhos junto ao grupo de Micro-ondas, Optoeletrônica e Onda Milimétricas (GMOO). Desde então, percorro um caminho de aprendizagens, vivências e experiências.

Num instante foram as graduações, mestrado e, agora, doutorado. De fato, como nos lembra o apóstolo Marcos no seu evangelho, a vida "é como um homem que lançou a semente na terra: ele dorme e acorda, de noite e de dia, mas a semente germina e cresce, sem que ele saiba como. A terra por si mesma produz fruto: primeiro a erva, depois a espiga e, por fim, a espiga cheia de grãos. Quando o fruto está no ponto, imediatamente se lhe lança a foice, porque a colheita chegou".

Por fim, agradeço à Universidade de São Paulo por tão generosamente ter me dado tudo que tenho e feito tudo que sou. 


\section{RESUMO}

Etanol é um dos principais combustíveis na matriz energética brasileira. Embora tenha uma fiscalização rigorosa, é comum sua adulteração com água. Este trabalho propõe o desenvolvimento de sensores planares de micro-ondas para a qualificação de etanol combustível. São apresentados dois conjuntos de sensores, sendo um voltado para a análise da fase vapor e outro para a fase líquida do etanol combustível. Foram projetados dois sensores para a fase vapor, sendo um deles uma antena de microfita e o outro uma antena de fenda em cavidade de guia de ondas integrada ao substrato, ambos recobertos com nanotubos de carbono e operando em 5,8 GHz. As antenas foram utilizadas como ressoadores e não como elementos radiantes. Os dois sensores para a fase líquida foram projetados em tecnologia de guia de ondas integrado ao substrato, sendo um deles a antena de fenda em cavidade, sem cobertura de nanotubos de carbono, e o outro um guia de ondas operando na faixa de 3,95 a $6 \mathrm{GHz}$ contendo uma seção no substrato. Foram implementadas as técnicas de perturbação da cavidade ressonante e de transmissão/reflexão para a extração dos valores de permissividade elétrica complexa dos materiais sob teste, a partir da resposta em frequência dos sensores propostos. Foram caracterizadas amostras de álcool etílico absoluto 99,5\%, água deionizada e misturas desses materiais em diferentes frações. Todos os sensores propostos demonstraram capacidade de discriminação de frações volumétricas de etanol em água de $2 \%(\mathrm{v} / \mathrm{v})$ na faixa especificada pela legislação. Os nanotubos de carbono viabilizaram o desenvolvimento dos sensores de fase vapor, sendo que o sensor empregando a antena com fenda apresentou sensibilidade 5,1 vezes maior comparado ao sensor com antena de microfita. O sensor de fase líquida usando a antena com fenda apresentou a maior sensibilidade entre os sensores ressonantes - 30,9 vezes maior do que o obtido com a antena de microfita com nanotubos de carbono. O sensor com guia de ondas integrado ao substrato apresentou incerteza máxima de 3,4\% para medidas de etanol em água nas frações permitidas pela legislação. Dessa forma, este trabalho contribui de forma original no desenvolvimento de sensores para caracterização eletromagnética de materiais e para qualificação de etanol combustível.

Palavras Chaves: Sensores de micro-ondas. Caracterização de materiais. Análise de combustíveis. Sensores de líquidos e gases. Nanomateriais. 


\begin{abstract}
Ethanol is one of the main fuels in the Brazilian energy matrix. Despite going through rigorous inspection, it is usually altered with water. This work proposes different planar microwave sensors for qualifying ethanol fuel. Two sets of sensors are presented: one for analyzing the vapor phase of ethanol and the other for the liquid phase of ethanol. Two sensors were designed for the vapor phase: a microstrip antenna and a cavity-backed slot antenna based on the substrate integrated waveguide technology, both coated with carbon nanotubes and operating at $5.8 \mathrm{GHz}$. The antennas were used as resonators and not as radiation elements. The sensors for the liquid phase were also designed based on the substrate integrated waveguide technology. The first sensor is a cavity-backed slot antenna, without carbon nanotubes, and the second sensor is a waveguide containing a section in the substrate, which operates at frequencies from 3.95 to $6 \mathrm{GHz}$. The cavity perturbation technique and the transmission/reflection method were implemented to extract the complex permittivity values from the materials under test, from the frequency response of the sensors. Samples of ethanol $99,5 \%$ pure, deionized water, and mixture with different proportions of these two materials were characterized. All the proposed sensors demonstrated capacity to differentiate $2 \%(\mathrm{v} / \mathrm{v})$ of volumetric fraction of ethanol in water within the range specified by the legislation. Carbon nanotubes allowed the development of the vapor phase sensors. The vapor phase sensor using the cavitybacked slot antenna presented 5.1 times higher sensitivity compared to the sensor employing the microstrip antenna. The liquid phase sensor using the cavity-backed slot antenna presented the highest sensitivity among the resonant sensors - 30.9 times higher than the microstrip antenna with carbon nanotubes. The sensor with substrate integrated waveguide presented uncertainty $3.4 \%$ for fractions of ethanol in water allowed by the legislation. Thus, this work provides an original contribution to the development of electromagnetic sensors for the characterization of materials and for qualifying ethanol fuel.
\end{abstract}

Keywords: Microwave sensors. Characterization of materials. Fuel analysis. Ethanol fuel analysis. Gas and liquid sensors. Nanomaterials. 


\section{LISTA DE ILUSTRAÇÕES}

Figura 2.1 - Tangente de perdas dielétricas e magnéticas...................................... 32

Figura 2.2 - Efeitos da polarização na espectroscopia dielétrica...............................38

Figura 2.3 - Espectroscopia dielétrica da água destilada modelada pelos parâmetros de Debye à temperatura ambiente $\left(25^{\circ} \mathrm{C}\right)$.

Figura 2.4 - Diagrama Cole-Cole da água destilada modelada pelos parâmetros de Debye à temperatura ambiente $\left(25^{\circ} \mathrm{C}\right)$.

Figura 2.5 - Medida utilizando a técnica da transmissão/reflexão, (a) ondas refletidas e transmitidas na amostra de comprimento $l$, (b) esquema de equipamentos para caracterização do material. 48

Figura 2.6 - Medida utilizando a da linha de transmissão terminada em aberto, (a) onda refletida na interface entre a linha e o material, (b) esquema de equipamentos para caracterização do material.

Figura 2.7 - Medida utilizando a técnica do espaço livre, (a) ondas refletidas e transmitidas na amostra de comprimento $l$, (b) esquema de equipamentos para caracterização do material em espaço livre.

Figura 2.8 - Equipamentos utilizados para caracterização de materiais através da técnica ressonante.

Figura 2.9 - Resposta típica de do parâmetro $\mathrm{S}_{11}$ em função da frequência para perturbação de uma cavidade ressonante. Coeficiente de reflexão com variação da frequência de ressonância e do índice de mérito. Essa mesma análise pode ser realizada com o coeficiente de transmissão.

Figura 2.10 - Valores experimentais da parte real da permissividade complexa da mistura etanol e água.

Figura 2.11 - Valores experimentais da parte imaginária da permissividade complexa da mistura etanol e água. 
Figura 3.1 - Sensores propostos para qualificação de etanol combustível e etapas de projeto.

Figura 3.2 - Estrutura e dimensões de uma antena de microfita com plaqueta retangular e alimentação indentada.

Figura 3.3 - Topologia básica de um guia de ondas em SIW e sua equivalência com um guia de ondas retangular.

Figura 3.4 - Comparação entre as diferentes tecnologias de ressoadores em RF quanto a custo, tamanho e perdas.

Figura 3.5 - Dimensões de um guia SIW genérico, levando em consideração seus valores efetivos e casamento de impedância através de taper.

Figura 3.6 - Condições para desenvolvimento de uma estrutura SIW.

Figura 3.7 - Transições entre a estrutura SIW e circuitos planares: (a) linha taper, (b) guia de onda coplanar com plano terra e extremidade aterrada e (c) guia de onda coplanar com plano terra com cavidade interna ao SIW

Figura 3.8 - Cavidades e antenas SIW. (a) cavidade ressonante com uma porta (b) cavidade ressonante com duas portas, (c) antena com fenda no plano terra e (d) antena com fenda no plano radiador.

Figura 3.9 - Representação esquemática dos SWCNT e MWCNT.

Figura 3.10 - Ilustração do arranjo experimental para sensores da fase vapor de etanol combustível.

Figura 3.11 - Aparato experimental para ensaio de sensores de fase vapor. 91

Figura 3.12 - Câmara de ensaio de gases com um sensor internamente alocado...... 91

Figura 3.13 - Aparato para ensaio de líquidos com a antena SIW com fenda traseira.

Figura 3.14 - Aparato para ensaio de líquidos com o guia de ondas integrado ao substrato. 94

Figura 4.1 - Antena de microfita: (a) modelo de simulação; e (b) protótipo da antena de microfita com plaqueta retangular. 101 
Figura 4.2 - Distribuição do campo elétrico [V/m] na antena de microfita com plaqueta retangular.

Figura 4.3 - Antena de microfita com depósito de nanotubos de carbono: (a) SWCNT diluído em água, (b) MWCNT diluído em água.

Figura 4.4 - (a) modelo de simulação da antena SIW com alimentação indentada e fenda traseira para projeto e simulação; (b) protótipo desenvolvido. 121

Figura 4.5 - Distribuição do campo elétrico [V/m] na antena com cavidade ressonante SIW com alimentação indentada e fenda traseira. 121

Figura 4.6 - Antena com cavidade ressonante em SIW e fenda traseira com depósito de nanotubos de carbono: SWCNT diluído em água.

Figura 4.7 - (a) Visão geral da amostra de SWCNT com magnificação de 30.000 vezes; (b) detalhe da amostra de SWCNT com magnificação de 150.000 vezes.

Figura 4.8 - (a) Visão geral da amostra de MWCNT com magnificação de 6.000 vezes; (b) detalhe da amostra de MWCNT com magnificação de 100.237 vezes. 137

Figura 4.9 - Antena SIW com amostra do material sob teste aplicada sobre sua fenda traseira. 138

Figura 4.10 - Guia de ondas SIW: (a) modelo de simulação, (b) protótipo desenvolvido. 146

Figura 4.11 - Distribuição do campo elétrico [V/m] no guia de ondas em SIW para a frequência de 5,8 GHz.

Figura 4.12 - Fabricação da fenda no guia SIW: (a) detalhe da fenda de $1 \mathrm{~mm}$ transversal ao guia; (b) guia com tampa e furação para inserção dos líquidos.149

Figura A.1 - Rede de duas portas caracterizada pelos parâmetros S 183

Figura C.1 - Primeiros modos de propagação TE em um guia de onda retangular. 191

Figura C.2 - Distribuição de campo elétrico dos modos $\mathrm{TE}_{10}$ e $\mathrm{TE}_{20}$ em um guia de onda retangular. 194 
Figura D.1 - Técnica da transmissão/reflexão: medida dos coeficientes de reflexão e transmissão nos planos do material em teste.

Figura E.1 - Circuito equivalente da linha de transmissão em aberto para o modelo capacitivo. 200

Figura E.2 - Circuito equivalente da linha de transmissão em aberto para o modelo de radiação. 203

Figura E.3 - (a) Aparato para caracterização de amostras de etanol combustível através de linha coaxial em aberto; (b) perspectiva da transição coaxial/microfita SMA.

Figura F.1 - Painel frontal da interface com o analisador de redes vetorial Fieldfox. 208

Figura F.2 - Diagrama em blocos da interface com o analisador de redes vetorial Fieldfox. 209

Figura H.1 - Painel frontal do sistema de controle dos MFCs. 212

Figura H.2 - Diagrama em blocos do sistema de controle de MFCs

Figura P.1 - Aparato experimental para ensaio do sensor de fase líquida (antena SIW com fenda) para caracterização de água DI em diferentes temperaturas 228 


\section{LISTA DE TABELAS}

Tabela 2.1 - Métodos para caracterização eletromagnética de materiais (KRUPKA, 2006).

Tabela 3.1 - Amostras de etanol em água utilizadas para testes a $25^{\circ} \mathrm{C}$. ..................6 65

Tabela 4.1 - Parâmetros do modelo de dispersão de Debye para etanol e água......... 95

Tabela 4.2 - Dimensões otimizadas da antena de microfita na frequência de 5,8 GHz.

Tabela 4.3 - Valores de permissividade elétrica complexa com os parâmetros de sensibilidade obtidos na antena de microfita.

Tabela 4.4 - Dimensões otimizadas da antena com cavidade ressonante SIW com fenda traseira.

Tabela 4.5 - Valores de permissividade elétrica complexa e parâmetros de sensibilidade experimentais obtidos na antena SIW com SWCNT. 133

Tabela 4.6 - Valores de permissividade elétrica complexa e parâmetros de sensibilidade experimentais na antena SIW.

Tabela 4.7 - Dimensões otimizadas do guia de ondas em SIW

Tabela 5.1 - Comparativo entre métodos de medida e sensibilidade para a caracterização e qualificação de etanol combustível.

Tabela P.1 - Valores de permissividade elétrica complexa com os parâmetros de sensibilidade obtidos na antena SIW para as diferentes temperaturas analisadas.

Tabela A.1 - Especificações do álcool combustível. 236

Tabela B.1 - Faixas de frequências de micro-ondas. 239

Tabela B.2 - Guias de ondas padrão. 240 


\section{LISTA DE GRÁFICOS}

Gráfico 4.1 - Modelamento do espectro da parte real da permissividade complexa da mistura etanol e água. 98

Gráfico 4.2 - Modelamento do espectro da parte imaginária da permissividade complexa da mistura etanol e água.

Gráfico 4.3 - Coeficiente de reflexão da antena de microfita e das antenas com CNTs em ambiente com $\mathrm{N}_{2}$ seco.

Gráfico 4.4 - Comparação da resposta a vapor de água DI dos sensores com SWCNT, MWCNT e antena de referência sem depósito de CNT.

Gráfico 4.5 - Sensibilidade da frequência de ressonância da antena de microfita com SWCNT para diferentes proporções de umidade relativa (\%). 106

Gráfico 4.6 - Relação entre os picos da sensibilidade da frequência de ressonância da antena de microfita com SWCNT em função da umidade relativa (\%)..... 107

Gráfico 4.7 - Caracterização da repetitividade da sensibilidade da frequência de ressonância da antena de microfita com $\mathrm{N}_{2}$ saturado com água DI. 109

Gráfico 4.8 - Resposta dinâmica da sensibilidade da frequência de ressonância da antena de microfita com $\mathrm{N}_{2}$ saturado com água DI.

Gráfico 4.9 - Coeficiente de reflexão da antena de microfita para as amostras de água DI e etanol 99,5\% em comparação com as curvas de referência.

Gráfico 4.10 - Sensibilidade da frequência de ressonância da antena de microfita com SWCNT para caracterização de etanol combustível.

Gráfico 4.11 - Sensibilidade normalizada do índice de mérito da antena de microfita com SWCNT para caracterização de etanol combustível. 113

Gráfico 4.12 - Relação entre os picos da sensibilidade da frequência de ressonância da antena de microfita com SWCNT e a fração volumétrica de etanol e água. ... 115 
Gráfico 4.13 - Relação entre os picos da sensibilidade da frequência de ressonância e a parte real da permissividade elétrica para a antena de microfita com SWCNT.

Gráfico 4.14 - Relação entre os picos da variação do índice de mérito e a parte imaginária da permissividade elétrica para a antena de microfita com SWCNT.

Gráfico 4.15 - Comparação entre os coeficientes de reflexão simulado e medido da antena com cavidade ressonante com alimentação indentada e fenda traseira em função da frequência.

Gráfico 4.16 - Sensibilidade da frequência de ressonância da antena SIW com SWCNT para diferentes proporções de umidade relativa (\%).

Gráfico 4.17 - Relação entre a sensibilidade da frequência de ressonância da antena SIW com SWCNT em função da umidade relativa (\%). 126

Gráfico 4.18 - Caracterização da repetitividade da sensibilidade da frequência de ressonância da antena SIW com $\mathrm{N}_{2}$ saturado com água DI 127

Gráfico 4.19 - Resposta dinâmica da sensibilidade da frequência de ressonância da antena SIW com $\mathrm{N}_{2}$ saturado com água DI. 128

Gráfico 4.20 - Coeficiente de reflexão medido da antena SIW com SWCNT para as amostras de água DI e etanol 99,5\% em comparação com as curvas de referência.

Gráfico 4.21 - Sensibilidade da frequência de ressonância da antena SIW com SWCNT para caraterização de etanol combustível. 130

Gráfico 4.22 - Variação do índice de mérito da antena SIW com SWCNT para caracterização de etanol combustível.

Gráfico 4.23 - Relação entre a sensibilidade da frequência de ressonância da antena SIW com SWCNT e a fração volumétrica de etanol e água. 132

Gráfico 4.24 - Relação entre a sensibilidade da frequência de ressonância e a parte real da permissividade elétrica para a antena SIW com SWCNT 
Gráfico 4.25 - Relação entre a sensibilidade normalizada do índice de mérito e a parte imaginária da permissividade elétrica para a antena SIW com SWCNT

Gráfico 4.26 - Coeficiente de Reflexão da antena SIW com fenda traseira para as amostras de água DI e etanol 99,5\% em comparação com as curvas de referência.

Gráfico 4.27 - Sensibilidade da frequência de ressonância da antena SIW para a caracterização de etanol combustível. 140

Gráfico 4.28 - Variação do índice de mérito normalizado da antena SIW para a caracterização de etanol combustível. 140

Gráfico 4.29 - Relação entre a sensibilidade da frequência de ressonância da antena SIW e a fração volumétrica de etanol e água.

Gráfico 4.30 - Relação entre a sensibilidade da frequência de ressonância e a parte real da permissividade elétrica para a antena SIW.

Gráfico 4.31 - Relação entre a variação do índice de mérito e a parte imaginária da permissividade elétrica para a antena SIW.

Gráfico 4.32 - Coeficientes de reflexão e transmissão do guia de ondas em SIW do modelo simulado e do protótipo medido. 148

Gráfico 4.33 - Perda de retorno $\left(\mathrm{S}_{11}\right)$ do guia de ondas em SIW em função da frequência para as amostras de etanol em água, (a) magnitude (b) fase. 151

Gráfico 4.34 - Perda de inserção $\left(\mathrm{S}_{21}\right)$ do guia de ondas em SIW em função da frequência para as amostras de etanol em água, (a) magnitude (b) fase.

Gráfico 4.35 - Valores medidos da parte real da permissividade elétrica das amostras de etanol e água comparados com os valores de referência (BAO et al., 1996). 153

Gráfico 4.36 - Valores medidos da parte imaginária da permissividade elétrica das amostras de etanol e água comparados com os valores de referência (BAO et al., 1996). 154

Gráfico E.1 - Parte real da permissividade complexa de amostras de etanol combustível. 
Gráfico E.2 - Parte imaginária da permissividade complexa de amostras de etanol combustível. .....

Gráfico G.1 - Curva da frequência de ressonância ao longo do tempo para água DI. 210

Gráfico G.2 - Curva do índice de mérito ao longo do tempo para água DI. 211

Gráfico P.1 - Parte real da permissividade elétrica complexa em função da frequência para água deionizada em diferentes temperaturas. 227

Gráfico P.2 - Parte imaginária da permissividade elétrica complexa em função da frequência para água deionizada em diferentes temperaturas. 227

Gráfico P.3 - Parte real da permissividade elétrica em função da sensibilidade da frequência de ressonância para diferentes temperaturas. 230

Gráfico P.4 - Parte imaginária da permissividade elétrica em função da sensibilidade da frequência de ressonância para diferentes temperaturas. 


\section{LISTA DE ABREVIATURAS}

AC Corrente Alternada (Alternative Current)

ADS $\quad$ Advanced Design System

ANP Agência Nacional do Petróleo, Gás Natural e Biocombustíveis

ANATEL Agência Nacional de Telecomunicações

CNTs Nanotubos de carbono (Carbon Nanotubes)

CVD Deposição química a vapor (Chemical Vapor Deposition)

DC Corrente Contínua (Direct Current)

EAC Etanol Anidro Combustível

EHC Etanol Hidratado Combustível

EHCP Etanol Hidratado Combustível Premium

EIA Electronic Industries Alliance

GND Terra (Ground)

ISM Industrial Scientific and Medical

LME Laboratório de Microeletrônica

LSI Laboratório de Sistemas Integráveis

MEV Microscopia eletrônica de varredura

MFC Controlador de fluxo (Mass Flow Controller)

MWCNT Nanotubos de carbono de paredes múltiplas (Multi-Walled Carbon Nanotubes)

PCs Computadores pessoais (Personal Computers)

PCI Placa de circuito impresso

PID Proporcional-Integral-Derivativo (Proportional Integrative Derivative)

Pró-Álcool Programa Nacional do Álcool 
PTFE Politetrafluoretileno (Teflon ${ }^{\circledR}$, marca comercial da Dupond)

RF Rádio frequência

RSS Root Sum Square

SAR Taxa de Absorção Específica (Specific Absorption Rate)

SCCM Standard Cubic Centimeters per Minute

SIW Guia de ondas integrado ao substrato (Substrate Integrated Waveguide)

SWCNT Nanotubos de carbono de parede única (Single Walled Carbon Nanotubes)

TDR Reflectometria no domínio do tempo (Time Domain Reflectrometry)

TE Modo Transversal Elétrico (Transverse Electric mode)

TM Modo Transversal Magnético (Transverse Magnetic mode)

TEM Modo Transversal Elétrico Magnético (Transverse Electric and Magnetic mode)

VI Instrumento virtual (Virtual Instrument)

VNA Analisador de Rede Vetorial (Vector Network Analyzer)

VSWR Razão de onda estacionária (Voltage Standing Wave Ratio) 


\section{LISTA DE SÍMBOLOS}

\begin{tabular}{|c|c|}
\hline$h$ & Espessura do substrato \\
\hline$a_{i}$ & Onda incidente na porta $i$ \\
\hline$b_{i}$ & Onda refletida na porta $i$ \\
\hline$S_{i j}$ & Parâmetro de espalhamento \\
\hline$\varepsilon_{0}$ & Permissividade elétrica do espaço livre $\left(\varepsilon_{0}=8,8542 \times 10^{-12} F . m^{-1}\right)$ \\
\hline$\mu_{0}$ & Permeabilidade magnética do espaço livre $\left(\mu_{0}=4 \pi \times 10^{-7} H . m^{-1}\right)$ \\
\hline$\varepsilon^{*}$ & Permissividade elétrica complexa $\varepsilon^{*}=\varepsilon_{0}\left(\varepsilon^{\prime}-j \varepsilon^{\prime \prime}\right)[\mathrm{F} / \mathrm{m}]$ \\
\hline$\mu^{*}$ & Permeabilidade magnética complexa $\mu^{*}=\mu_{0}\left(\mu^{\prime}-j \mu^{\prime \prime}\right)$ \\
\hline$\varepsilon_{r}^{*}$ & Permissividade elétrica complexa relativa $\varepsilon_{r}^{*}=\frac{\varepsilon^{*}}{\varepsilon_{0}}=\varepsilon^{\prime}-j \varepsilon^{\prime \prime}$ \\
\hline \multicolumn{2}{|c|}{ (adimensional) } \\
\hline$\varepsilon_{s}$ & Permissividade estática, para $f \rightarrow 0$ \\
\hline$\varepsilon_{\infty}$ & Permissividade infinita, para $f \rightarrow \infty$ \\
\hline$\mu_{r}^{*}$ & Permeabilidade magnética complexa relativa $\mu_{r}^{*}=\frac{\mu^{*}}{\mu_{0}}=\mu^{\prime}-j \mu^{\prime \prime}$ \\
\hline \multicolumn{2}{|c|}{ (adimensional) } \\
\hline$\varepsilon^{\prime}$ & Parte real da permissividade elétrica complexa $[\mathrm{F} / \mathrm{m}]$ \\
\hline$\mu^{\prime}$ & Parte real da permeabilidade magnética complexa $[\mathrm{H} / \mathrm{m}]$ \\
\hline$\varepsilon^{\prime \prime}$ & Parte imaginária da permissividade elétrica complexa $[\mathrm{F} / \mathrm{m}]$ \\
\hline$\mu^{\prime \prime}$ & Parte imaginária da permeabilidade magnética complexa [H/m] \\
\hline$\sigma$ & Condutividade elétrica $[\mathrm{S}]$ \\
\hline
\end{tabular}


Elétrico) $\left[\mathrm{C} / \mathrm{m}^{2}\right]$

\begin{tabular}{|c|c|}
\hline$\vec{E}$ & Campo Elétrico $[\mathrm{V} / \mathrm{m}]$ \\
\hline$\vec{H}$ & Campo Magnético $[\mathrm{A} / \mathrm{m}]$ \\
\hline$\vec{J}$ & Densidade Superficial de Corrente Elétrica $\left[\mathrm{A} / \mathrm{m}^{2}\right]$ \\
\hline$\vec{J}_{c}$ & Densidade Superficial de Corrente Elétrica de Condução $\left[\mathrm{A} / \mathrm{m}^{2}\right]$ \\
\hline$\vec{J}_{i}$ & Densidade Superficial de Corrente Elétrica Impressa $\left[\mathrm{A} / \mathrm{m}^{2}\right]$ \\
\hline$\rho$ & Densidade Volumétrica de Carga Elétrica $\left[\mathrm{C} / \mathrm{m}^{3}\right]$ \\
\hline$\omega$ & Frequência angular correspondente a $\omega=2 \pi f[\mathrm{rad} / \mathrm{s}]$ \\
\hline$f$ & Frequência da onda eletromagnética $[\mathrm{Hz}]$ \\
\hline$k_{0}$ & Número de onda no espaço livre \\
\hline$m$ e $n$ & Modos de propagação. \\
\hline$j$ & Unidade imaginária $j=\sqrt{-1}$ \\
\hline$\Gamma$ & Coeficiente de reflexão da onda eletromagnética (adimensional) \\
\hline $\mathrm{T}$ & Coeficiente de transmissão da onda eletromagnética (adimensional) \\
\hline$c$ & Velocidade da luz no espaço livre $\left(c=1 / \sqrt{\mu_{0} \varepsilon_{0}}=2,9979 \times 10^{8} \mathrm{~m} \cdot \mathrm{s}^{-1}\right)$ \\
\hline$\tau$ & Tempo de relaxação dielétrica $[\mathrm{s}]$ \\
\hline$f_{r}$ & Frequência de relaxação $\left(f_{r}=\frac{1}{2 \pi \tau}\right)[\mathrm{Hz}]$ \\
\hline$\lambda$ & Comprimento de onda $[\mathrm{m}]$ \\
\hline
\end{tabular}




\begin{tabular}{|c|c|}
\hline$\lambda_{0}$ & Comprimento de onda no espaço livre $[\mathrm{m}]$ \\
\hline$\lambda_{c}$ & Comprimento de onda correspondente à frequência de corte $[\mathrm{m}]$ \\
\hline$\lambda_{g}$ & Comprimento de onda guiado $[\mathrm{m}]$ \\
\hline$t$ & Tempo $[\mathrm{s}]$ \\
\hline $\tan \delta_{d}$ & Tangente de perdas dielétrica \\
\hline $\tan \delta_{e}$ & Tangente de perdas elétrica \\
\hline $\tan \delta_{m}$ & Tangente de perdas magnética \\
\hline$Z$ & Impedância elétrica $[\Omega]$ \\
\hline$Z_{0}$ & Impedância característica da linha de alimentação $[\Omega]$ \\
\hline$Z_{i}$ & Impedância na porta $i[\Omega]$ \\
\hline$V_{i}$ & Tensão na porta $i[\mathrm{~V}]$ \\
\hline
\end{tabular}




\section{SUMÁRIO}

1. INTRODUÇÃO ..................................................................................... 20

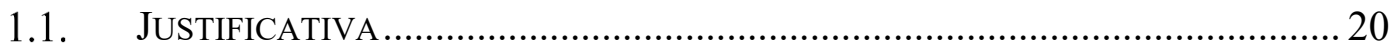

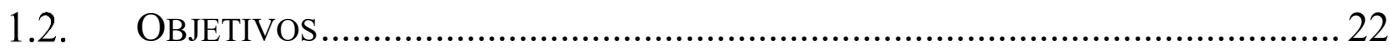

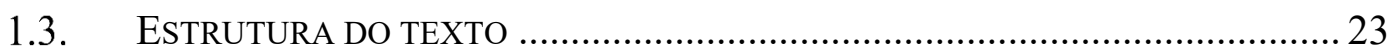

2. CARACTERIZAÇÃO ELETROMAGNÉTICA DE MATERIAIS... 26

2.1. CARACTERIZAÇÃo ELETROMAGNÉTICA DE MATERIAIS E SUAS APLICAÇÕES26

2.2. FÍSICA DOS MATERIAIS MODELADOS ELETROMAGNETICAMENTE ……..........2 27

2.2.1. Materiais condutores, dielétricos e magnéticos................................. 29

2.3. POLARIZAÇÃO EM MATERIAIS DIELÉTRICOS.................................................... 34

2.4. MECANISMOS DE POLARIZAÇ̃̃o EM MATERIAIS DIELÉTRICOS ....................... 36

2.5. Processos de RELAXAÇão dielÉtrica e Modelos .................................... 39

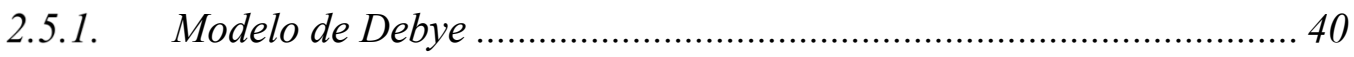

2.5.2. Modelos de Cole-Cole e Cole-Davidson............................................. 44

2.5.3. Modelo Havriliak-Negami ............................................................... 46

2.6. TÉCNICAS PARA CARACTERIZAÇÃo ELETROMAGNÉTICA DE MATERIAIS ..... 46

2.6.1. Técnicas no dominio da frequência ……………………………........ 47

2.6.2. Técnicas no domínio do tempo............................................................ 54

2.7. ADULTERAÇ̃̃o DE COMBUSTÍVEIS.......................................................... 55

2.7.1. Etanol combustivel ........................................................................... 55

2.7.1.1. Características e regulamentação ………………………………….... 56

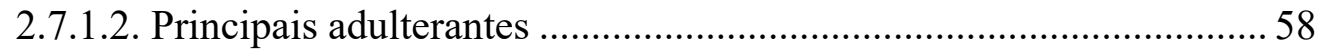

2.7.1.3. Características de permissividade elétrica complexa do etanol combustível 60 
3. DESENVOLVIMENTO

DE

SENSORES

PARA

CARACTERIZAÇÃO DE ETANOL COMBUSTÍVEL:

TECNOLOGIAS E ESTRUTURAS EM FREQUENCIAS DE

MICRO-ONDAS....................................................................................63

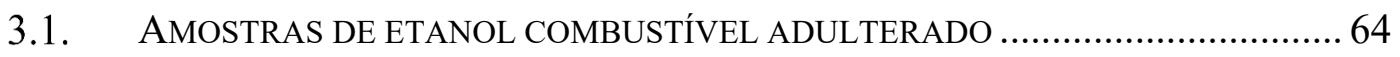

3.2. FERRAMENTAS PARA SIMULAÇÃO E CARACTERIZAÇÃO DE CIRCUITOS DE

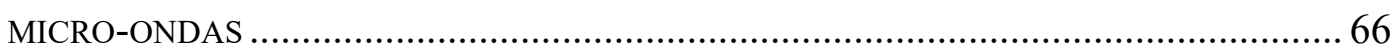

3.2.1. Softwares para simulação 3 D eletromagnética ................................ 66

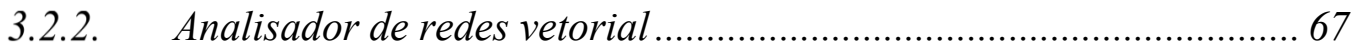

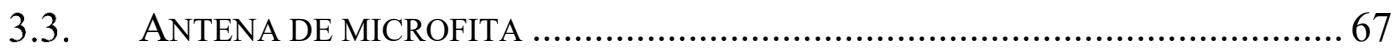

3.4. GUIAS DE ONDAS INTEGRAdOS AO SUBSTRATO (SIW) .............................. 72

3.5. PROJETO DE UM GUIA DE ONDAS EM SIW ............................................... 75

3.5.1. Integração à tecnologia planar: transições entre a tecnologia SIW e

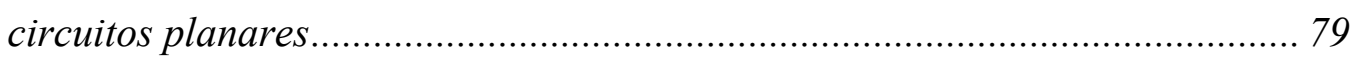

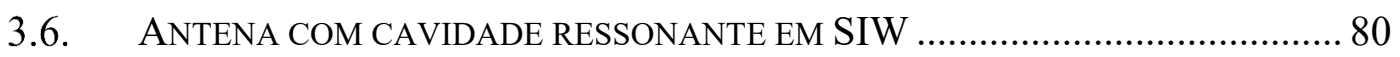

3.7. MATERIAIS NANOESTRUTURAdOS: NANOTUBOS DE CARBONO.................... 82

3.7.1. Processos de obtenção de materiais nanoestruturados ..................... 84

3.7.2. Processos de adsorção e dessorção em materiais nanoestruturados 85

3.7.3. Técnicas para deposição de materiais nanoestruturados.................. 86

3.8. DESENVOLVIMENTO DE SENSORES PARA CARACTERIZAÇÃO DA FASE VAPOR

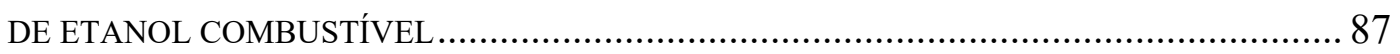

3.8.1. Deposição de materiais nanoestruturados via gotejamento.............. 88

3.8.2. Ambiente de ensaio para sensores de gases ................................. 88

3.8.2.1. Plataforma para ensaio dos sensores da fase vapor......................... 90

3.9. DESENVOLVIMENTO DE SENSORES PARA CARACTERIZAÇÃO DA FASE LÍQUIDA

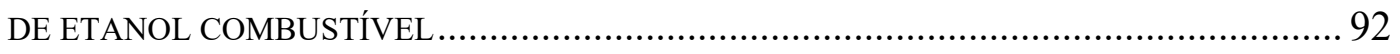


3.9.1. Ambiente de ensaio para sensor de líquido: antena SIW com fenda traseira

3.9.2. Ambiente de ensaio para sensor de líquido: guia de onda integrado ao substrato 93

4. RESULTADOS E DISCUSSÕES 95

4.1. MODELAMENTO DA PERMISSIVIDAdE ELÉTRICA COMPLEXA DO ETANOL LÍQUIDO COMBUSTÍVEL ATRAVÉS DOS SEUS MODELOS DE RELAXAÇÃO E DE REGRAS DE DILUIÇÃO 95

4.2. PROJETO, SIMULAÇÃO E CARACTERIZAÇÃO DOS SENSORES PARA ANÁLISE DA FASE VAPOR DE ETANOL COMBUSTÍVEL 99

4.2.1. Antena de microfita com plaqueta retangular. 100

4.2.1.1. Sensibilidade da antena de microfita como sensor 104

4.2.1.2. Ensaios para teste da repetitividade e dinâmica da resposta da antena de microfita 109

4.2.1.3. Ensaios de qualificação de misturas de etanol combustível 110

4.2.2. Antena com cavidade ressonante em SIW e fenda traseira 119

4.2.2.1. Sensibilidade da antena SIW com SWCNT 124

4.2.2.2. Ensaios para teste da repetitividade e dinâmica da resposta da antena SIW com SWCNT 126

4.2.2.3. Ensaios de qualificação de misturas de etanol combustível 129

4.2.3. Análise morfológica dos materiais nanoestruturados 135

4.3. PROJETO, SIMULAÇÃO E CARACTERIZAÇÃO DE SENSORES PARA ANÁLISE DA FASE LÍQUIDA DE ETANOL COMBUSTÍVEL

4.3.1. Antena SIW com fenda traseira para análise da fase líquida. 137

4.3.1.1. Ensaios de qualificação de misturas de etanol combustível. 138

4.3.2. Guia de ondas integrado em substrato 145

5. 
5.1. CONCLUSÕES 156

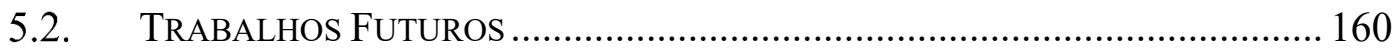

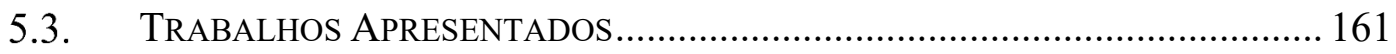

5.3.1. Artigos submetidos em jornais e periódicos ................................... 162

5.3.2. Trabalhos em simpósios e congressos internacionais .................... 162

5.3.3. Trabalhos em simpósios e congressos nacionais............................ 163

REFERÊNCIAS BIBLIOGRÁFICAS .......................................................... 164 APÊNDICE A - TEORIA DE REDES E PARÂMETROS DE

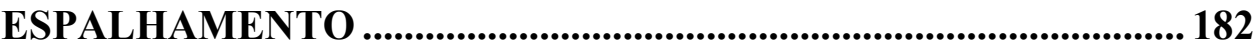

APÊNDICE B - TEORIA DA PERTURBAÇÃO RESSONANTE ..................... 185 APÊNDICE C - ONDAS GUIADAS E MODOS DE PROPAGAÇÃO ............. 190 APÊNDICE D - TÉCNICA DA TRANSMISSÃO/REFLEXÃO_........................ 196 APÊNDICE E - TÉCNICA DA LINHA COAXIAL EM ABERTO ................... 200 APENNDICE F - INSTRUMENTO VIRTUAL PARA INTERFACE COM O ANALISADOR DE REDES VETORIAL FIELDFOX N9912A....... 208 APÊNDICE G - CURVAS DE FREQUÊNCIA DE RESSONÂNCIA E ÍNDICE DE MÉRITO EM FUNÇÃO DO TEMPO COM SWCNT DEPOSITADO SOBRE ANTENA DE MICROFITA .......................210

APÊNDICE H - INSTRUMENTO VIRTUAL PARA CONTROLE DO FLUXO DE MASSA (MFC) 212

APÊNDICE I - PERMISSIVIDADE ELÉTRICA COMPLEXA DA ÁGUA DESTILADA UTILIZANDO O MODELO DE DEBYE DE UMA E DUAS RELAXAÇÕES DIELÉTRICAS 214

APÊNDICE J - CÁLCULO DOS VALORES DE PERMISSIVIDADE ELÉTRICA COMPLEXA ATRAVÉS DOS MODELOS DE DEBYE PARA MISTURA - SCRIPT EM MATLAB 215 
APÊNDICE K - CARACTERIZAÇÃO DE MATERIAIS ATRAVÉS DE LINHAS EM ABERTO - SCRIPT EM MATLAB .216

APÊNDICE L - PROJETO DA ANTENA DE MICROFITA COM PLAQUETA RETANGULAR - SCRIPT EM MATLAB 221

APÊNDICE M - CÁLCULO DAS DIMENSÕES DO GUIA DE ONDAS EM SIW - SCRIPT EM MATLAB 223

APÊNDICE N - CÁLCULO DAS DIMENSÕES DA CAVIDADE RESSONANTE EM SIW - SCRIPT EM MATLAB .............................224

APÊNDICE O - CÁLCULO DAS DIMENSÕES DO TAPER PARA O PROJETO DE GUIA DE ONDAS EM SIW E DA ANTENA COM CAVIDADE RESSONANTE EM SIW - SCRIPT EM MATLAB 225

APÊNDICE P - PERMISSIVIDADE ELÉTRICA EM FUNÇÃo DA TEMPERATURA PARA ANÁLISE DA FASE LÍQUIDA 226

APÊNDICE Q - ALGORITMO NRW PARA CARACTERIZAÇÃo DE AMOSTRAS COM O GUIA DE ONDAS SIW - SCRIPT EM MATLAB 232

ANEXO A - ESPECIFICAÇÕES DO ÁLCOOL COMBUSTÍVEL 236 ANEXO B - BANDAS DE OPERAÇÃO NAS FAIXAS DE FREQUÊNCIAS DE MICRO-ONDAS E GUIAS DE ONDAS PADRÃO 239 


\section{INTRODUÇÃ O}

\subsection{Justificativa}

O etanol proveniente da cana-de-açúcar é utilizado como combustível automotivo no Brasil desde a década de 1930 (MILANEZ; FILHO, 2008) (UNICA, 2015). Para garantir qualidade e padronização, a Agência Nacional do Petróleo, Gás Natural e Biocombustíveis (ANP) estabelece e fiscaliza os combustíveis no Brasil. Entretanto, a qualidade desses produtos pode ser alterada em função das condições inadequadas de manuseio, transporte e estocagem bem como por práticas ilegais de adulteração. Nesse sentido, para além dos métodos atuais de qualificação, que são basicamente químicoanalíticos, há uma demanda pelo desenvolvimento de sensores que permitam qualificar o etanol combustível, discriminando as frações de seus compostos, contribuindo para inibir a prática irregular de sua adulteração. Ressalta-se também que o etanol é uma questão nacional. Em outras palavras, o estudo do etanol como combustível atende a uma especificidade do Brasil.

Além disso, sensores são dispositivos fundamentais para a monitoramento de linhas de produção; análise de materiais e processos; e para qualificação de misturas, entre outras aplicações (FRADEN, 1996). Uma das linhas de pesquisas que mais crescem nesse campo é o desenvolvimento de sensores que operam na faixa de rádio frequência e micro-ondas ${ }^{1}$. Dessa forma, o uso de sensores em frequências de micro-ondas possibilita uma aplicação para além do seu uso comum em sistemas de comunicações e/ou sistemas de radares. Portanto, explorar as possibilidades de desenvolvimento de sensores físicos ou químicos em altas frequências oferece oportunidades de inovação no desenvolvimento de sensores, dado o caráter não canônico dessa aplicação.

Ao se trabalhar em frequências de micro-ondas, outra importante questão diz respeito aos diferentes modos de polarização aplicados aos materiais em teste. Ao se excitar um material em frequências de micro-ondas, é possível obter maior sensibilidade, ou seja, maior variação das propriedades físicas e/ou químicas do sensor quando exposto

\footnotetext{
${ }^{1}$ Considera-se a faixa de micro-ondas as ondas eletromagnéticas no ar com comprimentos de onda variando entre $1 \mathrm{~m}$ (300 MHz de frequência) até $1 \mathrm{~mm}$ (300 GHz de frequência).
} 
ao elemento analisado. Além disso, aumenta-se sua seletividade para caracterização, em outras palavras, a capacidade do sensor em discriminar uma ou mais espécies em uma mistura. Tal fato se deve aos diferentes mecanismos de polarização que ocorrem nas ligações inter e intra moleculares. Dessa forma, diferenciando-se de uma caracterização elétrica (resistência, capacitância ou indutância) em corrente contínua (DC) ou de uma espectroscopia de impedâncias em baixas frequências (até $10 \mathrm{MHz}$ ).

Uma das tecnologias emergentes na pesquisa em circuitos planares de micro-ondas é a estrutura SIW (Substrate Integrated Waveguide ${ }^{2}$ ). A partir dessa tecnologia, circuitos de micro-ondas são fabricados empregando guias de onda em substrato dielétrico planar de baixas perdas. Furos metalizados periódicos interligando as duas faces do substrato substituem as paredes laterais dos tradicionais guias de ondas retangulares (DESLANDES; WU, 2001).

Atualmente, existem diversas aplicações de componentes SIW passivos e ativos. Dentre eles: filtros; antenas; amplificadores; divisores e combinadores de potência; acopladores; e osciladores. Contudo são poucos os estudos que utilizam essa tecnologia para a caracterização eletromagnética de materiais. Para tanto, este trabalho também apresenta o desenvolvimento de diferentes topologias planares usando tecnologia SIW para o desenvolvimento de aplicações de sensoriamento, contribuindo, assim, para o desenvolvimento de dispositivos de baixo custo, pequenas dimensões, facilidade de fabricação e possibilidade de integração com placas de circuito impresso. As amostras de etanol combustível são analisadas utilizando-se sensores de gases na fase vapor da amostra. Para esses sensores, podem ser utilizados materiais que variam suas propriedades elétricas através do processo de adsorção de gases na superfície.

Existem diferentes materiais capazes de modificarem sua estrutura, bem como sua condutividade e permissividade elétrica, ao adsorverem um gás. A literatura apresenta, em larga medida, óxidos metálicos, tais como: $\mathrm{SnO}_{2}$ (dióxido de estanho) (ZHANG et al., 2008), $\mathrm{SrTiO}_{3}$ (perovskita), $\mathrm{TiO}_{2}$ (dióxido de titânio) (FRANCIOSO et al., 2008), $\mathrm{ZnSO}_{4}$ (sulfato de zinco), $\mathrm{ZnO}$ (óxido de zinco) (WAN et al., 2004) e $\mathrm{ZrO}_{2}$ (óxido de

\footnotetext{
${ }^{2}$ Neste trabalho será denominado como "Guia de Ondas Integrado ao Substrato", tradução direta da língua inglesa.
} 
zircônio ou zircônia). Dentre os materiais mais estudados e utilizados, atualmente, encontram-se os filmes e compósitos à base de nanotubos de carbono (CNTs). Estes materiais possuem alta velocidade na transferência de carga, elevada área superficial e a presença de grupos funcionais que permitem o desenvolvimento de sensores de gás. Contudo, são poucos os trabalhos que apresentam a aplicação de CNTs em circuitos de micro-ondas. Dessa forma, sua utilização para aplicações de sensoriamento em altas frequências representa uma importante contribuição para o desenvolvimento de novos métodos de qualificação de materiais, entre eles, combustíveis.

As amostras de etanol também são analisadas por meio de sensores para amostras líquidas. Esses sensores podem ser de imersão, quando o sensor é totalmente imerso no material em teste, ou apenas, sensibilizados por uma pequena quantidade da amostra depositada sobre o sensor.

\subsection{Objetivos}

O objetivo principal deste trabalho é estabelecer uma metodologia para a caracterização e qualificação de materiais, em específico, etanol combustível, através de sensores planares de micro-ondas.

Dentre os objetivos específicos estão:

- Analisar os principais métodos e técnicas para caracterização da permissividade elétrica complexa dos materiais analisados.

- Projetar, simular e construir circuitos passivos planares de micro-ondas que permitam analisar tanto a fase gasosa como a fase líquida do etanol combustível;

- Correlacionar os modelos de caracterização eletromagnética dos materiais com as respostas obtidas com os sensores planares de micro-ondas;

- Integrar circuitos planares de micro-ondas e materiais nanoestruturados para análise da fase vapor e de possíveis adulterações de etanol combustível;

- Avaliar o desempenho de diferentes materiais nanoestruturados, em específico nanotubos de carbono, para a qualificação de adulterantes em combustíveis; 
- Desenvolver infraestrutura laboratorial para caracterização de amostras de combustíveis;

- Propor e demonstrar a potencialidade da tecnologia SIW para caracterização de materiais, em especial, para análise da fase gasosa e líquida do etanol combustível;

- Propor a permissividade elétrica complexa como parâmetro de qualificação de etanol combustível.

\subsection{Estrutura do texto}

Este primeiro capítulo apresenta uma introdução ao problema, à justificativa de escolha e ao recorte dado para o projeto. São destacados os objetivos principais e específicos da tese e a metodologia que foi utilizada no trabalho.

No segundo capítulo é feita uma revisão dos princípios da física dos materiais modelados eletromagneticamente, bem como as propriedades e fenômenos que ocorrem com os mesmos em altas frequências. Também são apresentados os mecanismos de polarização dos materiais, além dos conceitos de relaxação dielétrica. No subitem “Técnicas para caracterização eletromagnética de materiais" são destacados os principais métodos para obtenção dos parâmetros eletromagnéticos dos materiais. Além disso, são discutidas as vantagens e desvantagens de cada técnica. São apresentados algoritmos de extração das propriedades eletromagnéticas dos materiais a partir dos parâmetros de espalhamento (parâmetros S). Um maior detalhamento e descrição desses algoritmos é realizado nos apêndices. Ao fim do capítulo são apresentados os aspectos químicos e eletromagnéticos envolvendo a adulteração de combustíveis, em específico do etanol.

O terceiro capítulo apresenta os materiais e métodos utilizados no desenvolvimento de sensores para caracterização de combustíveis. São descritos os procedimentos de projeto, de simulação computacional e de caracterização dos sensores planares propostos: uma antena de microfita com frequência de ressonância em 5,8 GHz e uma antena usando cavidade SIW na mesma frequência de ressonância, ambos os sensores utilizados para caracterização da fase vapor de etanol combustível. Para tanto, são utilizados nanotubos de carbono de parede única (SWCNT) como elemento sensor. 
Nessa condição, utiliza-se o gotejamento desse nanomaterial como método de deposição, devido à sua baixa complexidade.

Também é descrita a instrumentação utilizada para caracterizar os circuitos e realizar os experimentos, sendo detalhado o aparato para inserção e controle de gases.

Ainda no capítulo três é apresentado o procedimento de projeto dos sensores de amostras líquidas de etanol combustível propostos. Dentre eles, um guia de onda SIW e a cavidade SIW. São referenciados os algoritmos de extração que possibilitam a caracterização eletromagnética dos materiais. $O$ aparato empregado para a caracterização da fase líquida das misturas de etanol e água também é descrito nesse capítulo.

No quarto capítulo é apresentado o projeto dos sensores propostos, bem como a aplicação dos mesmos na caracterização dos materiais analisados. Os protótipos foram construídos, sendo caracterizados através das medidas dos parâmetros $\mathrm{S}$ com intuito de validar os resultados obtidos nas etapas de projeto e simulação. Para a validação dos sensores de gases foi realizada a caracterização morfológica dos materiais depositados. Além disso, realizou-se uma análise dos parâmetros como sensibilidade, estabilidade e tempo de resposta dos sensores, entre outros. Os testes com diferentes concentrações de adulterantes de etanol (água deionizada) são realizados e seus resultados são demonstrados ao longo do capítulo.

O quinto capítulo apresenta as conclusões do trabalho, discutindo a aplicabilidade dos resultados obtidos, seus benefícios e limitações, demonstrando-se a potencialidade da aplicação de sensores de micro-ondas para a caracterização de combustíveis. São destacados os pontos de inovação apresentados por esse trabalho, caracterizando o fator inédito da aplicação de estruturas de micro-ondas para sensoriamento de adulteração em combustíveis, fornecendo-se sugestões para trabalhos futuros. Encerrando esse capítulo, são relacionados os trabalhos publicados em jornais especializados, periódicos, simpósios e congressos durante o período do doutorado e decorrentes dos seus resultados.

Vale realçar que, pela interdisciplinaridade do tema sensores de micro-ondas, foram acrescidos apêndices ao final, que auxiliam o leitor na compreensão de alguns conceitos envolvidos ao longo do texto, como é o caso de: teoria de redes e parâmetros 
de espalhamento; ondas guiadas e modos de propagação; teoria da perturbação ressonante; e equacionamento dos métodos de extração das características eletromagnéticas dos materiais através das técnicas de linha coaxial em aberto e transmissão/reflexão. 
2. CARACTERIZAÇÃO

ELETROMAGNÉTICA

DE

\section{MATERIAIS}

Este capítulo inicia com uma introdução ao estudo das características eletromagnéticas dos materiais, apresentando os fundamentos físicos e destacando os materiais dielétricos e os métodos de representação da permissividade elétrica complexa. Além disso, são destacadas as principais técnicas para caracterização dos materiais, dentre elas as técnicas no domínio da frequência (ressonantes e não ressonantes) e no domínio do tempo. O capítulo destaca os parâmetros do etanol combustível e de sua adulteração, foco do trabalho.

\subsection{Caracterização eletromagnética de materiais e suas aplicações}

O interesse das propriedades eletromagnéticas dos materiais sempre esteve vinculado ao desenvolvimento de dispositivos, circuitos e equipamentos elétricos (NELSON, 1999). Contudo somente a partir do século XIX, o conhecimento acerca das propriedades eletromagnéticas dos materiais apareceu como campo de estudo. Dessa forma, foram desenvolvidos métodos para análise não destrutiva a fim de reconhecer as propriedades físicas e químicas dos materiais. Tal fato, tornou-se fundamental no desenvolvimento de novos materiais, além de aplicações industriais, médicas e químicas.

Inicialmente as pesquisas concentravam-se em baixas frequências (abaixo de $100 \mathrm{MHz}$ ). Somente após a Segunda Guerra Mundial, as aplicações com frequências até $10 \mathrm{GHz}$ foram desenvolvidas, em larga medida pelo avanço da tecnologia de micro-ondas (STUCHLY; STUCHLY, 1990).

Na década de 1920, foram apresentados os primeiros modelos de relaxação dielétrica, baseados em estudos teóricos sobre propriedades dielétricas de células em suspensão (FOSTER, 2002).

Em 1929, Debye propôs o primeiro modelo para representar a relaxação dielétrica (DEBYE, 1929). Já na década de 1930, K. S. Cole e R. H. Cole propuseram um diagrama para analisar a impedância de um circuito equivalente de um material submetido a estímulos elétricos com frequência variável. Através desse diagrama, 
representado no plano complexo, tornou-se possível analisar os processos de relaxação dielétrica para alguns materiais.

Em 1948, C. L. Liskow utilizou frequências de micro-ondas para a caracterização de materiais industriais. Contudo, o interesse na caracterização de materiais em frequências de $300 \mathrm{MHz}$ a $300 \mathrm{GHz}$, teve grande impulso com a publicação dos livros de Arthur R. von Hippel no início dos anos 50 (von HIPPEL, 1954a) (von HIPPEL, 1954b). Esses trabalhos tornaram-se referências na caracterização de materiais dielétricos. Pode-se considerar que os livros de von Hippel (1954) são os mais completos e amplamente conhecidos padrões e procedimentos para caracterização de materiais em frequências de micro-ondas. Com isso, estabeleceu-se um campo de pesquisa para caraterizações de materiais através de espectroscopia dielétrica.

Trabalhos posteriores permitiram a tabulação dos valores obtidos nas caracterizações eletromagnéticas dos materiais. Enquadra-se nessa afirmação o trabalho de Durney et al. (1986), que tabelou diferentes medidas de propriedades dielétricas em líquidos e materiais biológicos. Na atualidade são diversos os trabalhos que utilizam os métodos de caracterização eletromagnética de materiais para novas aplicações, dentre eles: imageamento humano para detecção de anomalias e diagnósticos médicos (GOLIO, 2003); caracterização de líquidos e qualificação de produtos; processamento de alimentos, plásticos, cerâmicas e borrachas (KRASZEWSKI, 1996); desenvolvimento de produtos farmacêuticos; análise e qualificação de grãos na agricultura; entre outros (SAEED et al., 2012) (SOTODEH, 2014) (PONGSUWAN et al., 2014) (CHEN et al., 2004) (BARTLEY; BEGLEY, 2010).

\subsection{Física dos materiais modelados eletromagneticamente}

As propriedades eletromagnéticas dos materiais são evidenciadas pela resposta ao campo eletromagnético, que de maneira macroscópica pode ser descrito por duas das equações de Maxwell: Lei de Gauss da Eletricidade e a Lei de Ampère Generalizada. Essas equações na forma integral e diferencial podem ser descritas por 2.1 a 2.2, respectivamente. 


$$
\begin{aligned}
& \oint_{\Sigma} \vec{D} \cdot d \vec{S}=\int_{\tau} \rho \cdot d \tau \Leftrightarrow \nabla \cdot \vec{D}=\rho \text { (Lei de Gauss da Eletricidade) } \\
& \oint_{C} \vec{H} \cdot d \vec{l}=\int_{S}\left(\vec{J}+\frac{\partial \vec{D}}{\partial t}\right) \cdot d \vec{S} \Leftrightarrow \nabla \times \vec{H}=\vec{J}+\frac{\partial \vec{D}}{\partial t} \text { (Lei de Ampère) }
\end{aligned}
$$

A Lei de Gauss da Eletricidade indica que a densidade de fluxo elétrico, $\vec{D}$, que diverge de um ponto é igual a Densidade Volumétrica de Carga Elétrica, $\rho$. Esse conceito é fundamental para a compreensão do parâmetro de permissividade elétrica e será detalhado.

A Lei de Ampère Generalizada (ou Ampère-Maxwell) descreve a relação do rotacional do Campo Magnético, $\vec{H}$, com a Densidade Superficial de Corrente Elétrica, $\vec{J}$, e a variação da Densidade de Fluxo Elétrico, $\vec{D}$, no tempo, indicando que um campo magnético pode ser gerado pelo movimento de cargas e/ou pelo efeito da variação do campo elétrico no tempo. Essa equação apresenta o conceito de permeabilidade magnética e será detalhada posteriormente.

A relação entre as grandezas vetoriais $\vec{D}$ e $\vec{E}, \vec{B}$ e $\vec{H}$, e $\vec{J}$ e $\vec{H}$ são descritas pelas Relações Constitutivas ou Equações Constitutivas, respectivamente, nas equações 2.3 a 2.5. Através delas é realizada a associação entre os campos eletromagnéticos e a matéria física que constitui o meio material.

$$
\begin{aligned}
& \vec{D}=\varepsilon \vec{E} \quad \text { (Relação Constitutiva Elétrica) } \\
& \vec{B}=\mu \vec{H} \quad \text { (Relação Constitutiva Magnética) } \\
& \vec{J}=\sigma \vec{E} \quad \text { (Lei de Ohm Pontual) }
\end{aligned}
$$

no qual $\varepsilon, \mu$ e $\sigma$, propriedades constitutivas, são, respectivamente, a Permissividade Elétrica $[\mathrm{F} / \mathrm{m}]$, a Permeabilidade Magnética $[\mathrm{H} / \mathrm{m}]$ e a Condutividade Elétrica $[\mathrm{S} / \mathrm{m}]$ do material. Esses parâmetros descrevem as propriedades físicas dos materiais excitados por campos eletromagnéticos externos. 
As propriedades constitutivas dos materiais são dependentes da intensidade e direção dos campos aplicados, da posição dentro do meio, da frequência de operação e da penetração da onda eletromagnética no material (CHEN et al., 2004). Dessa forma, assume-se uma classificação de acordo com as características macroscópicas do material, tais como: linearidade, homogeneidade, isotropia e dispersão.

É dito como linear, o meio cujas propriedades constitutivas não dependem da intensidade do campo aplicado. Materiais cujas propriedades constitutivas não dependem da sua posição são ditos homogêneos. As propriedades constitutivas também são dependentes da temperatura (SADIKU, 2012).

Materiais isotrópicos são aqueles em que as propriedades constitutivas não são função da direção do campo aplicado. Do contrário são designados como materiais não isotrópicos ou anisotrópicos. As equações 2.3, 2.4 e 2.5 já levam em conta o caráter isotrópico do material, pois de outra forma, considerar-se-iam as propriedades constitutivas descritas como tensores: $\vec{\varepsilon}, \vec{\mu}$ e $\vec{\sigma}$. Uma vez sendo isotrópicos, reduzem-se esses tensores à ordem zero, ou seja, a uma grandeza escalar (SADIKU, 2012).

Por último, os materiais que variam suas propriedades constitutivas com a frequência são ditos dispersivos (CHEN et al., 2004). Vale ressaltar que os materiais analisados neste trabalho são dispersivos, pois com a variação da frequência, modificam-se seus parâmetros constitutivos. O próximo item esclarece com detalhes o mecanismo de polarização intrínseco aos materiais, que permite compreender o comportamento microscópico do material polarizado.

\subsubsection{Materiais condutores, dielétricos e magnéticos}

Os materiais podem ser divididos em três classes: condutores, dielétricos e magnéticos. Para os condutores, pode-se resumir sua operação pela presença, no material, de elétrons livres, fracamente ligados à camada externa do átomo. Quando submetidos a um campo elétrico externo, os elétrons livres migram entre os átomos, originando a corrente elétrica. 
Os materiais dielétricos são caracterizados através da sua permissividade elétrica, $\varepsilon$, que tem origem na lei de Gauss da Eletrostática, equação 2.1. Essa lei demonstra que as linhas de campo elétrico por uma superfície fechada variam proporcionalmente com a quantidade de cargas elétricas no seu interior. Essa proporcionalidade é dada por $1 / \varepsilon$ e depende do material.

Um dielétrico pode ser modelado com um arranjo de átomos e moléculas no espaço livre, que podem ser polarizados por um campo elétrico. O campo força as cargas a se separarem em oposição às suas forças de Coulomb de atração, sem, entretanto, arrancar as cargas dos átomos ou moléculas. Isso resulta em uma cadeia de dipolos microscópicos. Ao se aplicar um campo harmônico no tempo que se propaga como uma onda pelo material, surgirão momentos de dipolos oscilatórios, que estabelecem uma onda de polarização que se propaga pelo material.

De maneira simplificada, esses dipolos oscilantes podem ser modelados como antenas microscópicas (HAYT; BUCK, 2013), que reirradiam campos que se propagam conjuntamente com o campo aplicado. Conforme a frequência, haverá uma defasagem entre o campo incidente e o campo radiado. Esse campo resultante interage com os próximos dipolos sucessivamente. As defasagens acumuladas, para cada posição, ocasionam em uma diminuição da velocidade de fase da onda resultante, ocorrendo atenuação do campo.

Para os materiais magnéticos, realiza-se uma divisão entre: diamagnéticos, paramagnéticos e ferromagnéticos. Para os diamagnéticos, a magnetização ocorre de forma oposta ao campo magnético aplicado. Já nos paramagnéticos e ferromagnéticos, o sentido de magnetização é o mesmo do campo magnético aplicado. Entretanto, os ferromagnéticos apresentam os efeitos de magnetização muito maiores do que os paramagnéticos e diamagnéticos.

Os materiais magnéticos são caracterizados através da sua permeabilidade magnética, $\mu$. Essa tem origem na lei circuital de Ampère, equação 2.2, em que a circuitação (integral de linha num contorno fechado) do vetor campo magnético é diretamente proporcional a quantidade de corrente concatenada com o contorno sobre o qual foi efetuada a circuitação. Essa proporcionalidade é dada por $\mu$ e depende do material. 
Os valores $\mu_{0}=4 \pi \times 10^{-7} H \cdot m^{-1}$ e $\varepsilon_{0}=\frac{1}{\mu_{0} c^{2}} \approx 8,854 \times 10^{-12} F \cdot m^{-1}$ representam a permeabilidade magnética e a permissividade elétrica do espaço livre, respectivamente, sendo $c$ a velocidade da luz no vácuo. Esses valores servem como referência para a comparação entre diferentes materiais, posto que são os menores valores possíveis, exceto para materiais diamagnéticos. Dessa forma, atribui-se valores relativos, $\varepsilon_{r}$ e $\mu_{r}$, denominados respectivamente, permissividade elétrica relativa e permeabilidade magnética relativa, descritos pelas equações 2.6 e 2.7 .

$$
\begin{gathered}
\varepsilon_{r}=\frac{\varepsilon}{\varepsilon_{0}} \\
\mu_{r}=\frac{\mu}{\mu_{0}}
\end{gathered}
$$

no qual, $\varepsilon$ e $\mu$ corresponde à permissividade elétrica e à permeabilidade magnética do material.

Das equações 2.3 e 2.4, que relacionam $\vec{D}$ e $\vec{E}, \vec{B}$ e $\vec{H}$, respectivamente, pode-se constatar que, embora os vetores $\vec{D}$ e $\vec{E}$ tenham mesma direção, eles podem estar defasados no tempo. O mesmo ocorre com os vetores $\vec{B}$ e $\vec{H}$. Dessa forma os valores de permissividade e permeabilidade devem ser descritos através de um valor complexo que permita relacionar diferenças de amplitude e fase. As equações 2.8 e 2.9 descrevem o comportamento complexo desses parâmetros.

$$
\begin{aligned}
& \varepsilon_{r}^{*}=\varepsilon_{r}^{\prime}-j \varepsilon_{r}^{\prime \prime} \\
& \mu_{r}^{*}=\mu_{r}^{\prime}-j \mu_{r}^{\prime \prime}
\end{aligned}
$$

no qual as propriedades constitutivas dos materiais são descritas por $\varepsilon_{r}^{*}$ e $\mu_{r}^{*}$, respectivamente, a permissividade elétrica relativa complexa e a permeabilidade 
magnética relativa complexa, sendo que a parte real da permissividade elétrica relativa e da permeabilidade magnética relativa, $\varepsilon_{r}^{\prime}$ e $\mu_{r}^{\prime}$, indicam quanto de energia dos campos elétrico e magnético é armazenada no material, respectivamente. Já a parte imaginária da permissividade elétrica relativa e da permeabilidade magnética relativa, $\varepsilon_{r}^{\prime \prime}$ e $\mu_{r}^{\prime \prime}$, representa o quanto de energia é transferida dos campos elétricos e magnéticos ao material de maneira dissipativa através de calor, respectivamente.

Para descrever a dissipação de energia no material, utiliza-se a representação da tangente de perdas (fator de dissipação). As equações 2.10 e 2.11 descrevem, respectivamente, a tangente de perdas dielétricas e a tangente de perdas magnéticas. A Figura 2.1 representa graficamente a tangente de perdas.

$$
\begin{gathered}
\operatorname{tg} \delta_{d}=\frac{\varepsilon_{r}^{\prime \prime}}{\varepsilon_{r}^{\prime}} \\
\operatorname{tg} \delta_{m}=\frac{\mu_{r}^{\prime \prime}}{\mu_{r}^{\prime}}
\end{gathered}
$$

Figura 2.1 - Tangente de perdas dielétricas e magnéticas.
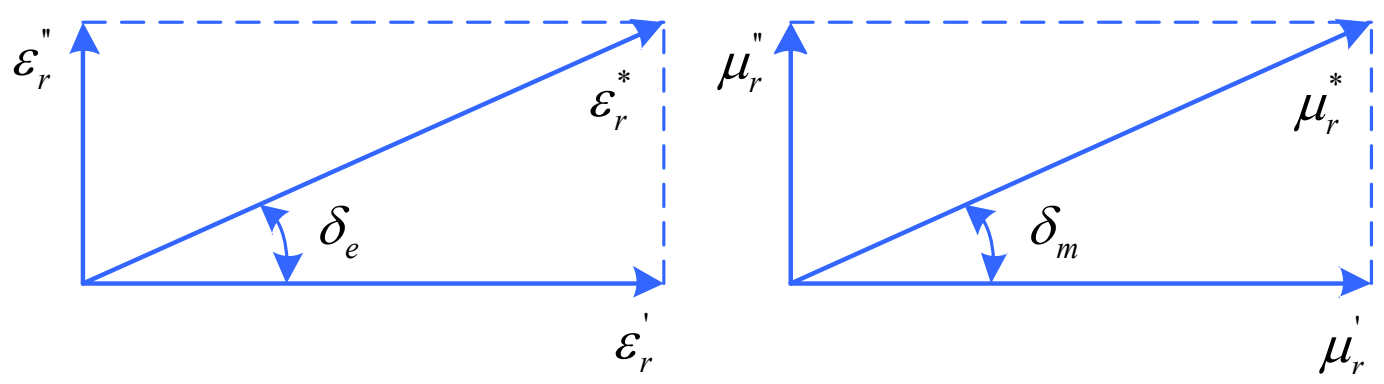

Fonte: o autor ${ }^{3}$.

\footnotetext{
${ }^{3}$ Todas as figuras e gráficos que não possuírem fonte explícita devem ser consideradas do autor.
} 
Em campos elétricos harmônicos vale a relação $\frac{\partial \vec{D}}{\partial t}=j \omega \vec{D}$. Considerando a equação 2.2 e as relações dadas pelas equações 2.6 e 2.8, obtém-se:

$$
\nabla \times \vec{H}=\sigma \vec{E}+j \omega \varepsilon^{*} \vec{E}
$$

Isolando $\vec{E}$ e conhecendo as relações complexas da permissividade elétrica, obtém-se a equação 2.13:

$$
\begin{aligned}
\nabla \times \vec{H} & =\left(\sigma+j \omega \varepsilon^{*}\right) \vec{E} \\
& =\left[\sigma+j \omega\left(\varepsilon^{\prime}-j \varepsilon^{\prime \prime}\right)\right] \vec{E} \\
& =j \omega\left(\frac{\sigma}{j \omega}+\varepsilon^{\prime}-j \varepsilon^{\prime \prime}\right) \vec{E} \\
\nabla \times \vec{H} & =\left[\left(\sigma+\omega \varepsilon^{\prime \prime}\right)+j \omega \varepsilon^{\prime}\right] \vec{E}
\end{aligned}
$$

Dessa forma, nota-se que o termo relacionado $\left(\sigma+\omega \varepsilon^{\prime \prime}\right)$ é relacionado a uma perda devido à condutividade e por uma perda devido à polarização do material. Pode-se, portanto, considerar uma condutividade efetiva, descrita pela equação 2.15:

$$
\sigma_{e f}=\sigma+\omega \varepsilon^{\prime \prime}
$$


sendo $\sigma$ a condutividade devido às correntes de condução, $\omega=2 \pi f$ a frequência angular e $f$ a frequência do campo aplicado. O valor da tangente de perdas dielétricas, equação 2.10 , é reescrito pela equação $2.16^{4}$ (WENTWORTH, 2006).

$$
\operatorname{tg} \delta_{e}=\frac{\sigma_{e f}}{\omega \varepsilon^{\prime}}=\frac{\sigma+\omega \varepsilon^{\prime \prime}}{\omega \varepsilon^{\prime}}=\frac{\sigma}{\omega \varepsilon^{\prime}}+\frac{\varepsilon^{\prime \prime}}{\varepsilon^{\prime}}
$$

As teorias que permitem determinar os parâmetros da permissividade elétrica complexa, $\varepsilon^{\prime}$ e $\varepsilon^{\prime \prime}$, em função da frequência do campo aplicado, fundamentam-se nas relações entre tais propriedades, intrínsecas ${ }^{5}$ aos materiais, e os mecanismos de polarização. Os itens 2.3 e 2.4 apresentam, detalhadamente, os modelos de permissividade elétrica complexa em função da frequência.

\subsection{Polarização em materiais dielétricos}

Materiais com comportamento dielétrico são aqueles que apresentam simultaneamente os processos de condução $\left(\sigma_{e f}=\sigma+\omega \varepsilon^{\prime \prime}\right)$ e polarização elétrica $\left(\varepsilon^{\prime}\right)$. A distribuição de cargas das moléculas desses materiais muda em relação à condição de equilíbrio quando sujeitos a um campo elétrico externo. Dessa forma, de uma distribuição neutra, formam-se duas regiões com cargas positivas e negativas, $\pm q$, separadas por uma distância finita $\vec{d}$. Esse dipolo elétrico pode ser representado por um momento de dipolo elétrico dado por $\vec{p}=|q| \vec{d}[C \cdot m]$.

4 Cabe ressaltar que algumas referências bibliográficas (SADIKU, 2012) desconsideram a condutividade devido às correntes de condução e indicam somente a tangente de perdas dielétricas, conforme equação 2.10 .

${ }^{5}$ Propriedade intrínseca está relacionada a propriedade de material que independe do seu tamanho ou de sua geometria externa. Já uma propriedade extrínseca está ligada diretamente a sua geometria e tamanho. 
O momento de dipolo elétrico é diretamente proporcional ao campo elétrico externo $\vec{E}$, de modo que $\vec{p}=\alpha \vec{E}$. A razão de proporção $\alpha$ correspondente a polarizabilidade, relativa à natureza das ligações químicas, sejam elas moleculares e/ou atômicas.

Durante a orientação das cargas o dipolo armazena energia no campo, sendo que em uma região com o volume $\Delta v$ de um meio dielétrico polarizado haverá $N$ momentos de dipolo $\vec{p}$. Dessa forma, o vetor polarização $\vec{P}$ é definido como o momento de dipolo por unidade de volume $(\Delta v \rightarrow 0)$, de acordo com a equação 2.17 , que corresponde a uma distribuição contínua e sem singularidades de momento de dipolo elétrico através do volume.

$$
\vec{P}=\lim _{\Delta v \rightarrow 0} \frac{\sum_{k=1}^{N} \vec{p}}{\Delta v}
$$

Macroscopicamente, a polarização $\vec{P}$ descreve o aumento na densidade de fluxo elétrico, $\vec{D}$, oriundo da polarizabilidade do meio, conforme equação 2.18 .

$$
\vec{D}=\varepsilon_{0} \vec{E}+\vec{P}
$$

A ação do campo elétrico sobre o material dielétrico pode originar dipolos induzidos ou orientação de dipolos elétricos permanentes. Para os campos elétricos estáticos, descreve-se o vetor polarização elétrica, $\vec{P}$, como uma grandeza proporcional ao vetor campo elétrico, $\vec{E}$. Para um material isotrópico homogêneo, essas grandezas estão relacionadas pela equação 2.19 .

$$
\vec{P}=\varepsilon_{0} \chi_{E} \vec{E}
$$


no qual $\chi_{E}$ é a susceptibilidade elétrica do material, que indica a medida de quanto um material dielétrico é sensível aos campos elétricos.

Substituindo as equações 2.18 na equação 2.19 , obtém-se a equação 2.20 .

$$
\vec{D}=\varepsilon_{0}\left(1+\chi_{E}\right) \vec{E}
$$

\subsection{Mecanismos de polarização em materiais dielétricos}

As propriedades dielétricas de um material estão intrinsicamente ligadas à distribuição de cargas no seu interior devido a ação de um campo elétrico externo. A polarização total que ocorre nesses materiais pode ser dada pela soma dos vários mecanismos de polarização envolvidos (GEYER, 1990).

Dado um campo elétrico com sentido periodicamente variável, os dipolos são forçados a segui-lo, contra suas propensões naturais de tomarem direções aleatórias, o que causa agitação térmica. Essa movimentação age como força restauradora. A amplitude de polarização enfraquecerá com o aumento da frequência, pois não existirá um tempo longo o suficiente para completar o alinhamento de cada ciclo, o que indica uma descrição do mecanismo de relaxação dielétrica.

Esse fenômeno ocorre quando há mudança no arranjo espacial de partículas eletricamente carregadas de um dielétrico. Desta forma, diz-se que o intervalo de tempo necessário para que os mecanismos de polarização respondam ao campo elétrico aplicado é dado pelo tempo de relaxação, $\tau$.

Podem ocorrer dois tipos de polarização na escala atômica ou molecular. O primeiro tipo, reconhecido como polarização induzida, ocorre nas substâncias formadas por moléculas não polares. Na presença de um campo elétrico externo, produz-se uma polarização através do deslocamento de elétrons em um átomo relativamente à posição do núcleo, o que representa uma deformação das camadas eletrônicas em relação ao núcleo. 
O segundo tipo de polarização é conhecido como polarização orientacional, que ocorre nas substâncias formadas por átomos ou moléculas polares. A polarização resulta na orientação dos dipolos permanentes na direção preferencial do campo.

Dessa maneira, compreende-se por polarização eletrônica, $P_{e}$, aquela que ocorre em todos os átomos e íons, em especial, dielétricos (GEYER, 1990). Ocorre, como já mencionado, devido a um pequeno deslocamento da nuvem eletrônica em relação ao núcleo do átomo num intervalo de tempo inferior a $10^{-15} \mathrm{~s}$.

Já a polarização atômica, $P_{a}$, conhecida também por polarização iônica ou molecular, é o resultado de um deslocamento mútuo entre íons constituintes da molécula, sejam eles átomos ou conjuntos de átomos agregados (GEYER, 1990). São verificáveis em intervalos de tempo da ordem de $10^{-13}$ a $10^{-12} \mathrm{~s}$.

Também é possível descrever a polarização dipolar, $P_{d}$, conhecida por polarização orientacional, que é formada pela orientação dos dipolos permanentes na direção do campo externo aplicado em moléculas polares (GEYER, 1990). Materiais como água e álcool são exemplos de dipolos sensíveis a esse tipo de polarização. O intervalo de resposta desse processo é da ordem de $10^{-8}$ a $10^{-10} \mathrm{~s}$, dependendo da estrutura do material e das variações de temperatura. Além disso, a polarização dipolar é relacionada por sua natureza com a agitação térmica das moléculas ${ }^{6}$, e, portanto, a temperatura pode exercer um efeito nesse tipo de polarização.

Para misturas, impurezas e materiais heterogêneos com descontinuidade, seja por formação de aglomerados ou materiais insolúveis, pode-se considerar a polarização interfacial, $P_{i}$, denominada de efeito Maxwell-Wagner (GEYER, 1990). Nesses materiais é possível encontrar regiões com diferentes permissividades elétricas e/ou condutividades. Os portadores, íons ou elétrons, ficam livres para se deslocarem em função de um campo elétrico, acumulando-se na superfície de separação, originando momentos de dipolos. Essa forma de polarização contribui para tempos de relaxação menores, da ordem de $10^{-7} \mathrm{~s}$.

\footnotetext{
${ }^{6}$ Moléculas de água, que são dipolos, rotacionam em decorrência do campo elétrico alternado. Esse mecanismo possui altas perdas, o que explica o aquecimento de alimentos em um forno de micro-ondas.
} 
Os tipos de polarização respondem em diferentes faixas de frequência à excitação por um campo elétrico externo alternado. A Figura 2.2 apresenta esquematicamente, através de um gráfico de espectroscopia dielétrica genérica, os diferentes mecanismos de polarização em função da frequência do campo elétrico para um material hipotético, no qual estão presentes diferentes mecanismos de polarização.

Fica clara a dependência das partes real e imaginária da permissividade elétrica complexa com a frequência. Pois, microscopicamente, a resposta dielétrica de um material sob um campo elétrico externo variável está ligada à eficiência com que os dipolos respondem às variações temporais do campo.

Figura 2.2 - Efeitos da polarização na espectroscopia dielétrica.

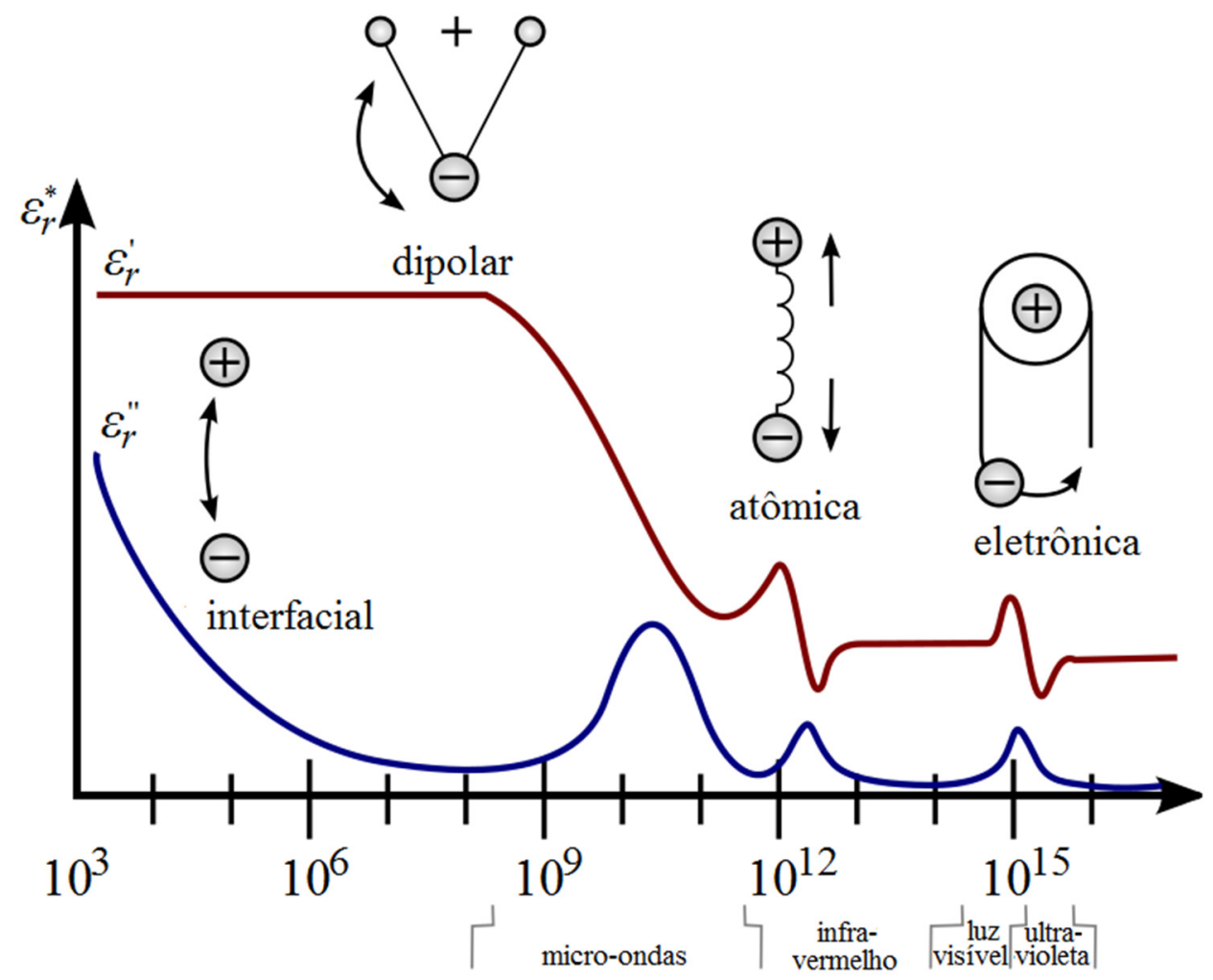

Frequência $(\mathrm{Hz})$

Fonte: Adaptado de (RAMO et al., 1994).

Para as caracterizações realizadas em frequências de micro-ondas $(300 \mathrm{MHz}$ a $300 \mathrm{GHz}$ ), têm-se as polarizações atômicas e dipolares. Abaixo dessa faixa de 
frequências, o mecanismo interfacial é predominante. Dessa forma, a caracterização em frequências de micro-ondas, foco deste trabalho, permite realçar diferentes características de um material em detrimento de medidas estáticas realizadas em corrente contínua $(\mathrm{CC})$, ou medidas de espectroscopia de impedância feitas em corrente alternada (CA) com frequência máxima de $100 \mathrm{MHz}$, ou medidas realizadas por sensores ópticos com frequências maiores do que $1 \mathrm{THz}$.

\subsection{Processos de relaxação dielétrica e modelos}

O mecanismo de relaxação dielétrica é descrito em termos da permissividade elétrica em função da frequência. Todos os modelos que aproximam o comportamento de relaxação dielétrica possuem três parâmetros fundamentais. São eles: a permissividade estática, $\varepsilon_{s}$, também conhecida como permissividade em baixas frequências; o limite da permissividade em altas frequências, $\varepsilon_{\infty}$; e o tempo de relaxação $\tau$.

O valor $\varepsilon_{s}$ corresponde ao valor da permissividade relativa do material para uma polarização estática, ou seja, quando a frequência tende a zero. Usualmente é conhecido como constante dielétrica do material ${ }^{7}$. Esse valor é um número real, pois nas condições estáticas não há diferença de fase entre a polarização e o campo elétrico. Para altas frequências, o período do campo elétrico é menor do que o tempo de relaxação do material, com isso, a orientação dos dipolos não varia com o campo elétrico, permanecendo no seu estado original. Dessa forma, o valor de $\varepsilon_{\infty}$ é real, representando, principalmente, os fenômenos da polarização atômica e eletrônica do material.

\footnotetext{
${ }^{7}$ Dielétricos podem ser diferenciados em quatro diferentes categorias (KRASZEWSKI, 1996): baixo valor de constante dielétrica e baixas perdas $\left(\varepsilon_{r}{ }^{\prime}<10\right.$ e $\left.\operatorname{tg} \delta<0,001\right)$; alto valor de constante dielétrica e baixas perdas $\left(\varepsilon_{r}^{\prime} \geq 10\right.$ e $\left.\operatorname{tg} \delta<0,001\right)$; alto valor de constante dielétrica e baixíssimas perdas $\left(\varepsilon_{r}^{\prime}>100 \mathrm{e}\right.$ $\operatorname{tg} \delta<0,0002)$; e material com altas perdas $(\operatorname{tg} \delta>0,1)$.
} 
A constante de relaxação descreve o tempo necessário para que os dipolos se orientem com o campo elétrico. Também é possível relacionar essa constante com o tempo para reequilíbrio de um material depois que cessa a perturbação do campo elétrico.

$\mathrm{Na}$ literatura são apresentados diferentes modelos, ou seja, funções capazes de representar a fenomenologia física do comportamento de materiais dielétricos, bem como descrever o comportamento dielétrico de alguns materiais (DEBYE, 1929) (FUOSS; KIRKWOOD, 1941) (HAVRILIAK; NEGAMI, 1966) (WILLIAMS; WATTS, 1970) (DISSADO; HILL, 1984). Os parâmetros dessas funções foram, na maioria das situações, ajustados de modo a fornecer uma representação otimizada dos resultados obtidos experimentalmente. Podem-se citar, em específico, os modelos de: Debye, Cole-Cole, Cole-Davidson e de Havriliak-Negami.

\subsubsection{Modelo de Debye}

A função de Debye (1929) é considerada como o primeiro modelo para a descrição da polarização de materiais. Ela é aplicada para materiais homogêneos que apresentam pouca interação entre seus dipolos ${ }^{8}$. Esse modelo permite analisar, principalmente, a polarização orientacional, que é um tipo de polarização lenta.

O modelo pode ser deduzido, a partir de uma polarização inicial $P_{0}$ que retorna para uma polarização $P_{\infty}$ após um período $\tau$. Pode-se descrever esse processo através de uma equação diferencial de primeira ordem, 2.21.

$$
\frac{d P(\mathrm{t})}{d t}=\frac{P_{0}-P_{\infty}}{\tau}
$$

\footnotetext{
${ }^{8}$ Debye considerou que nos materiais formados por moléculas com momentos de dipolo permanentes, as moléculas permanecem afastadas umas das outras, não apresentando forte interação entre si. Sem a aplicação de campo elétrico, a orientação e a posição das moléculas são aleatórias, devido à agitação térmica do sistema. Com a aplicação de um campo elétrico ocorre orientação na distribuição, originando uma polarização resultante. Nesse caso, o processo de relaxação dielétrica pode ser modelado, segundo Debye, por uma equação diferencial de primeira ordem.
} 
Portanto, do ponto de vista macroscópico, a solução da equação 2.21 pode ser descrita por $P(t)=\left[P_{0}-P_{\infty}\right] e^{\frac{-t}{\tau}}+P_{\infty}$. A solução estacionária de $P(t)$, que leva em consideração a frequência angular, é apresentada na equação 2.22 .

$$
P(\omega)=P_{\infty}+\frac{P_{0}-P_{\infty}}{1+j \omega \tau}
$$

no qual, $P_{\infty}$ e $P_{0}$ são os valores assintóticos de $P(\omega)$ para os limites de frequência superior $(\omega \rightarrow \infty)$ e inferior $(\omega \rightarrow 0)$, respectivamente. Da equação 2.19 , pode-se relacionar a susceptibilidade complexa de um dielétrico com o tempo de relaxação do material, como apresentado na equação 2.23.

$$
\chi^{\prime}(\omega)-j \chi^{\prime \prime}(\omega)=\chi_{\infty}+\frac{\chi_{0}-\chi_{\infty}}{1+j \omega \tau}
$$

Dessa forma, através da relação direta entre susceptibilidade e permissividade elétrica, pode-se reescrever a equação 2.23 pela equação 2.24 .

$$
\varepsilon_{r}^{\prime}(\omega)-j \varepsilon_{r_{p o l}}^{\prime \prime}(\omega)=\varepsilon_{\infty}+\frac{\varepsilon_{0}-\varepsilon_{\infty}}{1+j \omega \tau}
$$

Através desse procedimento, Debye chegou ao modelo mais simples de relaxação, que pode ser expresso em um modelo de primeira ordem pela equação 2.25.

$$
\varepsilon_{r}^{*}(\omega)=\varepsilon_{\infty}+\frac{\varepsilon_{s}-\varepsilon_{\infty}}{1+j \omega \tau}
$$


sendo que $\varepsilon_{r}^{*}(0)=\varepsilon_{s}$ representa a permissividade estática para $\omega=0$ e $\varepsilon_{r}^{*}(\infty)=\varepsilon_{\infty}$ representa a permissividade infinita para $\omega \rightarrow \infty$.

Alguns estudos sobre relaxação de materiais (BUCHNER; STAUBER, 1999) demonstraram que, para frequências maiores do que $40 \mathrm{GHz}$, o comportamento de materiais, como é o caso da água, pode ser descrito por um modelo que considera uma sobreposição de duas equações de Debye. Dessa forma é possível expandir a representação em frequência para materiais com dois processos de perdas de acordo com a equação 2.26, que representa duas relaxações dielétricas $\tau_{1}$ e $\tau_{2}$, e dois valores de permissividade elétrica para frequências intermediárias $\varepsilon_{s_{1}}$ e $\varepsilon_{s_{2}}$ :

$$
\varepsilon_{r}^{*}(\omega)=\varepsilon_{\infty}+\frac{\varepsilon_{s_{1}}-\varepsilon_{s_{2}}}{1+j \omega \tau_{1}}+\frac{\varepsilon_{s_{2}}-\varepsilon_{\infty}}{1+j \omega \tau_{2}}
$$

Também pode-se considerar múltiplos mecanismos de relaxações de um material através de uma formulação genérica representada na equação 2.27.

$$
\varepsilon_{r}^{*}(\omega)=\varepsilon_{\infty}+\sum_{n} \frac{\varepsilon_{s}-\varepsilon_{n}}{1+j \omega \tau_{n}}
$$

A título de exemplo, pode-se mostrar o modelamento por Debye da água destilada. Como é sabido, esse material possui altos valores da parte real da permissividade elétrica e baixos valores de perdas. Bao et al. (1996) apresentam um modelo para a água destilada à temperatura ambiente $\left(25^{\circ} \mathrm{C}\right)$ entre as frequências de $100 \mathrm{MHz} \mathrm{e}$ $26,5 \mathrm{GHz}$. Os parâmetros do ajuste da equação 2.25 são dados por: $\varepsilon_{s}=77,11$, $\varepsilon_{\infty}=4,55$ e $\tau=7,37$ ps. Para um modelo com duas relaxações, pode-se utilizar os trabalhos de Buchner et al. (1999), que caracterizaram água destilada entre as frequências de $100 \mathrm{MHz}$ até $150 \mathrm{GHz}$ em temperatura ambiente. Os parâmetros de 
ajuste para a equação 2.26 obtidos são dados por: $\varepsilon_{s_{1}}=78,32, \varepsilon_{s_{2}}=6,32, \varepsilon_{\infty}=4,57$, $\tau_{1}=8,38$ ps e $\tau_{2}=1,1$ ps .

A Figura 2.3 apresenta o comportamento da permissividade elétrica da água empregando o modelo de Debye com um e dois mecanismos de relaxação. A linha contínua, apresenta o comportamento da parte real da permissividade elétrica complexa da água, enquanto que, a linha tracejada, apresenta a parte imaginária, nas frequências entre $100 \mathrm{MHz}$ e $150 \mathrm{GHz}$ (APÊNDICE I).

Figura 2.3 - Espectroscopia dielétrica da água destilada modelada pelos parâmetros de Debye à temperatura ambiente $\left(25^{\circ} \mathrm{C}\right)$.

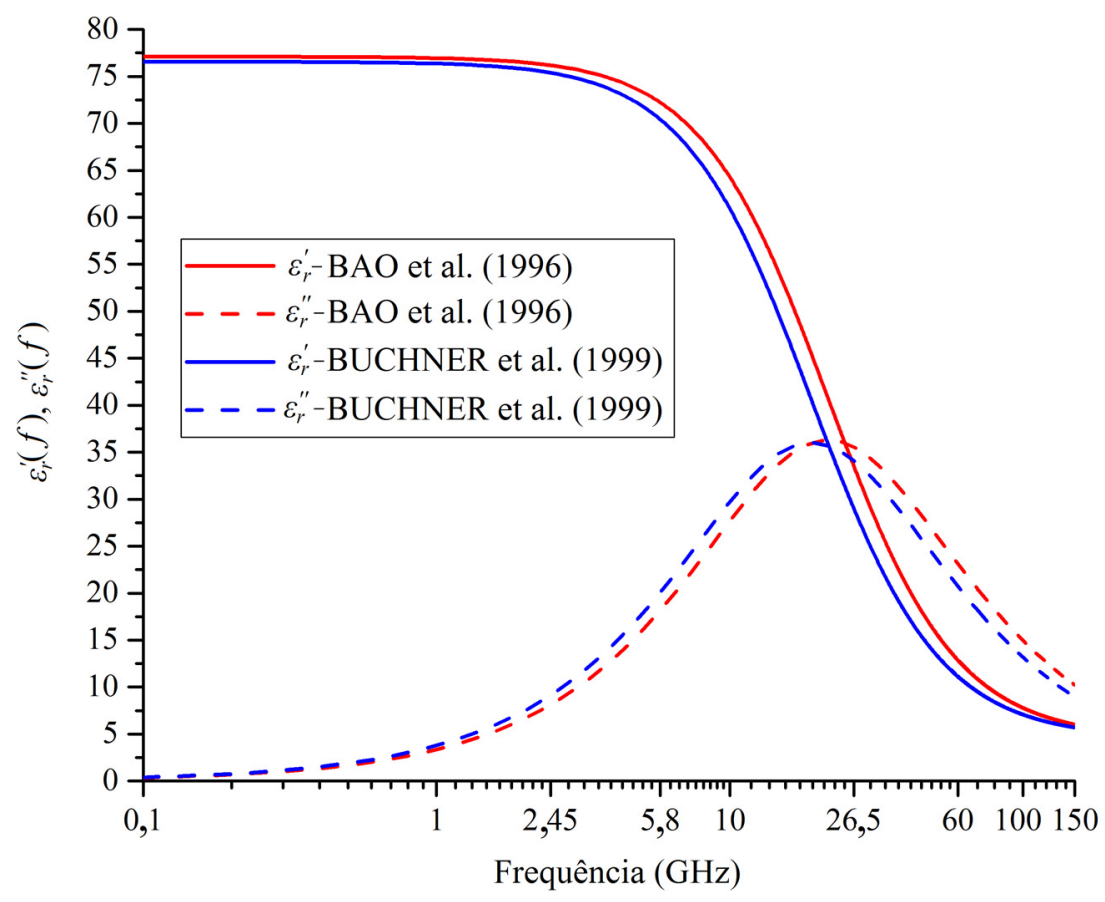

Da espectroscopia dielétrica, é possível verificar boa conformidade entre os modelos com uma e duas relaxações dielétricas. A título de comparação, o modelo de Bao et al. (1996) foi extrapolado para frequências até $150 \mathrm{GHz}$. Para a água destilada, nota-se o fenômeno da polarização dipolar, que implica numa relaxação nas frequências acima 
de $1 \mathrm{GHz}$. Além disso, nota-se que nas frequências próximas a $20 \mathrm{GHz}^{9}$ há o valor máximo de $\varepsilon_{r}^{\prime \prime}$.

\subsubsection{Modelos de Cole-Cole e Cole-Davidson}

O modelo de Debye permite representar o comportamento da resposta dielétrica de algumas substâncias, em especial, líquidos. Entretanto, o modelo não é capaz de descrever de forma adequada o comportamento de substâncias sólidas, materiais poliméricos e cerâmicos.

Os modelos de Cole-Cole (COLE; COLE, 1941) e Cole-Davidson (COLE; DAVIDSON, 1952), representados nas equações 2.28 e 2.29, ajustam empiricamente suas funções para representar o comportamento dielétrico de materiais que não são bem ajustados pela representação de Debye.

$$
\begin{aligned}
& \varepsilon_{r}^{*}(\omega)=\varepsilon_{\infty}+\frac{\varepsilon_{s}-\varepsilon_{\infty}}{1+(j \omega \tau)^{1-\alpha}} \\
& \varepsilon_{r}^{*}(\omega)=\varepsilon_{\infty}+\frac{\varepsilon_{s}-\varepsilon_{\infty}}{1+(j \omega \tau)^{\beta}}
\end{aligned}
$$

no qual os parâmetros $\alpha$ e $\beta$ são valores compreendidos nos intervalos $0 \leq \alpha<1 \mathrm{e}$ $0<\beta \leq 1$. Eles são escolhidos de forma a proporcionar um melhor ajuste com os dados experimentais das partes real e imaginária da permissividade elétrica. São pequenas as

${ }^{9}$ É usualmente conhecida a ideia de que o forno de micro-ondas opera com seu magnetron na frequência de 2,45 GHz, pois essa seria a frequência de ressonância das moléculas de água. Contudo essa frequência não é a frequência de ressonância desse material. Utiliza-se essa frequência por ter um compromisso entre a profundidade de penetração da onda eletromagnética (considerada ótima) no material e absorção média para os diferentes materiais que constituem o alimento (WENTWORTH, 2006). 
diferenças entre um modelo e outro, cabendo ao pesquisador optar por uma das representações.

É possível recuperar o modelo de Debye a partir do modelo de Cole-Cole atribuindo valor limite $\alpha=0$. O mesmo vale para o modelo de Cole-Davidson através do valor limite $\beta=1$.

Cole-Cole (1941) também propuseram um diagrama que permite a análise gráfica do comportamento da parte imaginária em função da parte real em coordenadas cartesianas, obtendo assim uma curva semelhante a um arco de círculo, como demonstrado na Figura 2.4.

Ressalta-se que todos os modelos são desenvolvidos de modo a representar os valores da permissividade elétrica complexa obtidos experimentalmente. Nesse sentido, a parte imaginária da permissividade elétrica complexa obtida nesses modelos considera tanto a contribuição das perdas por condução como por polarização do material, tal como descrito na equação 2.16 .

Figura 2.4 - Diagrama Cole-Cole da água destilada modelada pelos parâmetros de Debye à temperatura ambiente $\left(25^{\circ} \mathrm{C}\right)$.

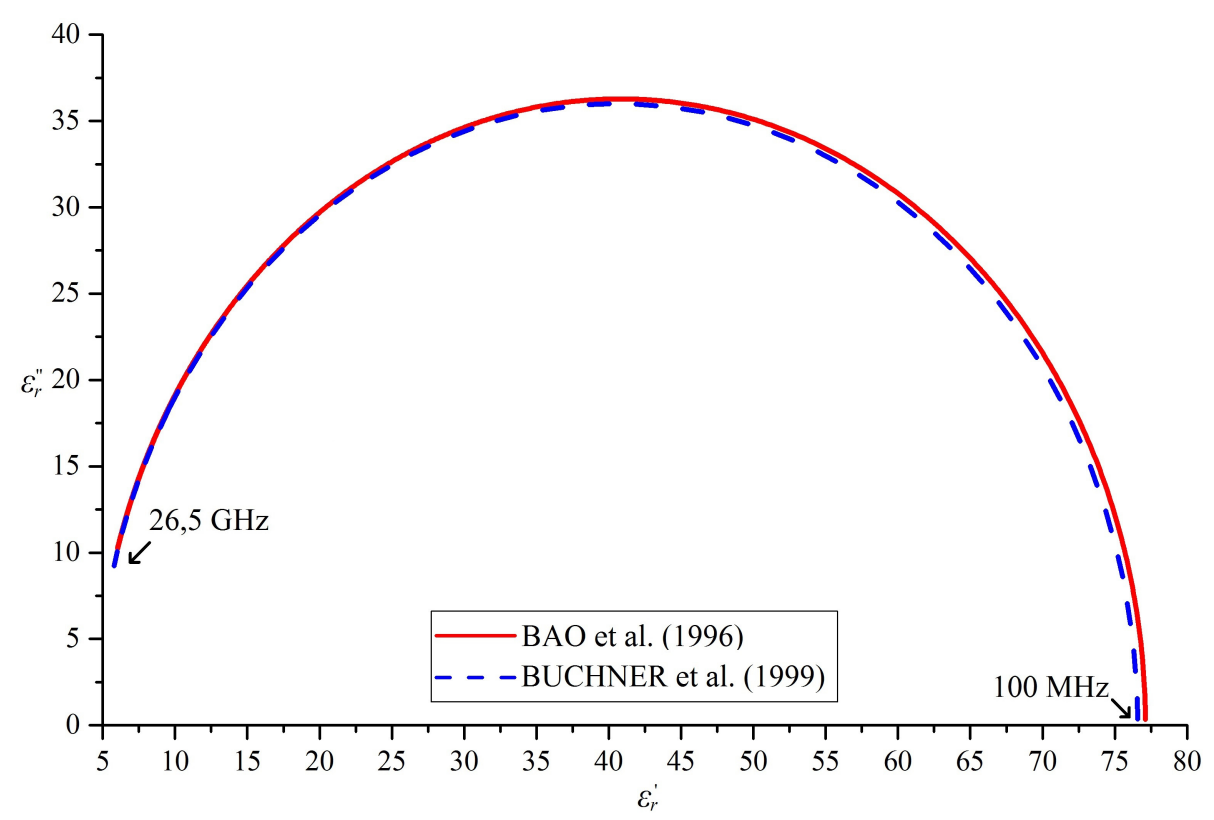




\subsubsection{Modelo Havriliak-Negami}

O modelo Havriliak-Negami considera a assimetria e a amplitude da relaxação dielétrica através da equação 2.30. Esse modelo foi primeiramente utilizado para representação da relaxação dielétrica de polímeros (HAVRILIAK; NEGAMI, 1966).

$$
\varepsilon_{r}^{*}(\omega)=\varepsilon_{\infty}+\frac{\varepsilon_{s}-\varepsilon_{\infty}}{\left[1+(j \omega \tau)^{\alpha_{H N}}\right]^{\beta_{H N}}}
$$

no qual $\alpha_{H N}$ e $\beta_{H N}$ são parâmetros entre $0<\alpha_{H N} \leq 1$ e $0<\beta_{H N} \leq 1$.

\subsection{Técnicas para caracterização eletromagnética de materiais}

Existem vários métodos para obter os valores da permissividade elétrica e de permeabilidade magnética em materiais através dos parâmetros de espalhamento ou parâmetros S (ver APÊNDICE A). Sua escolha depende da aplicação desejada, das propriedades eletromagnéticas do material, das frequências de operação e do nível de incerteza desejado. Além disso, o tipo de material a ser analisado é fundamental, seja ele líquido, sólido, em pó, ou em grão.

A caracterização eletromagnética de materiais é feita através de técnicas no domínio da frequência, por meio de métodos ressonantes ou métodos não ressonantes, ou por técnicas no domínio do tempo. Para o domínio da frequência, os métodos não ressonantes são utilizados para análise em uma determinada faixa de frequências. Os métodos ressonantes são aptos para obter maior precisão na medida em valores de frequência específicos. Para o domínio do tempo, é utilizada a técnica de reflectometria no domínio do tempo TDR (Time Domain Reflectrometry). Essa técnica permite a análise em uma banda larga de frequências. 


\subsubsection{Técnicas no domínio da frequência}

Como mencionado anteriormente, no domínio da frequência os materiais podem ser analisados através dos métodos não ressonantes e ressonantes. Para o método não ressonante, caracterizam-se os materiais através de sua impedância e da velocidade de propagação da onda no material, bem como da transição da onda entre dois materiais. Isso é possível, pois ao atravessar uma interface entre dois meios, uma parcela da onda eletromagnética é refletida e outra parcela é transmitida. Dessa forma ao irradiar uma onda eletromagnética sobre o material, pode-se deduzir seus parâmetros a partir da fração refletida e/ou transmitida. Com isso é possível obter a relação dos valores de permissividade elétrica relativa e da permeabilidade magnética relativa entre os dois materiais. A literatura apresenta diferentes técnicas a partir desse método, dentre elas as técnicas de reflexão e/ou transmissão/reflexão (KRASZEWSKI, 1996) (CHEN et al., 2004) (AGILENT, 2006) (LOBATO-MORALES ET AL., 2010).

A técnica da transmissão/reflexão é usualmente realizada por meio de um guia de ondas ou linha coaxial. Uma amostra do material caracterizado é inserida no interior dessas estruturas preenchendo-as total ou parcialmente. Através de um analisador de redes vetorial, VNA (Vector Network Analyzer), são realizadas medidas dos parâmetros de espalhamento $\mathrm{S}_{11}$ e $\mathrm{S}_{21}$ (ver APÊNDICE D). A Figura 2.5 apresenta esquematicamente a disposição da amostra sob teste alocada de maneira a preencher totalmente o espaço alocado.

Cabos coaxiais de alta precisão conectam as portas do VNA à estrutura sob teste. Os planos de referência de medida dos parâmetros $\mathrm{S}$ são definidos nas extremidades desses cabos, por meio de procedimentos de calibração. Para realizar a extensão desses planos para a superfície da amostra podem ser utilizados dois métodos. O primeiro método é realizado manualmente deslocando a fase até o plano de calibração da amostra. $\mathrm{O}$ segundo método envolve a função de-embedding do analisador de redes vetorial. Nesse método são realizadas medidas dos parâmetros de espalhamento sem amostras após a calibração do VNA no plano de seus conectores. 
Figura 2.5 - Medida utilizando a técnica da transmissão/reflexão, (a) ondas refletidas e transmitidas na amostra de comprimento $l,(b)$ esquema de equipamentos para caracterização do material.

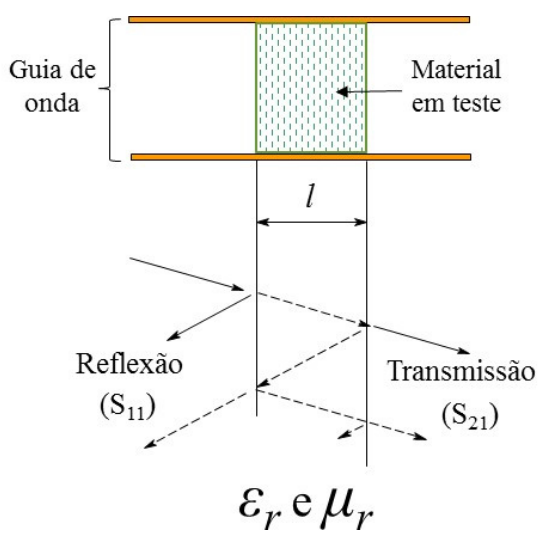

(a)

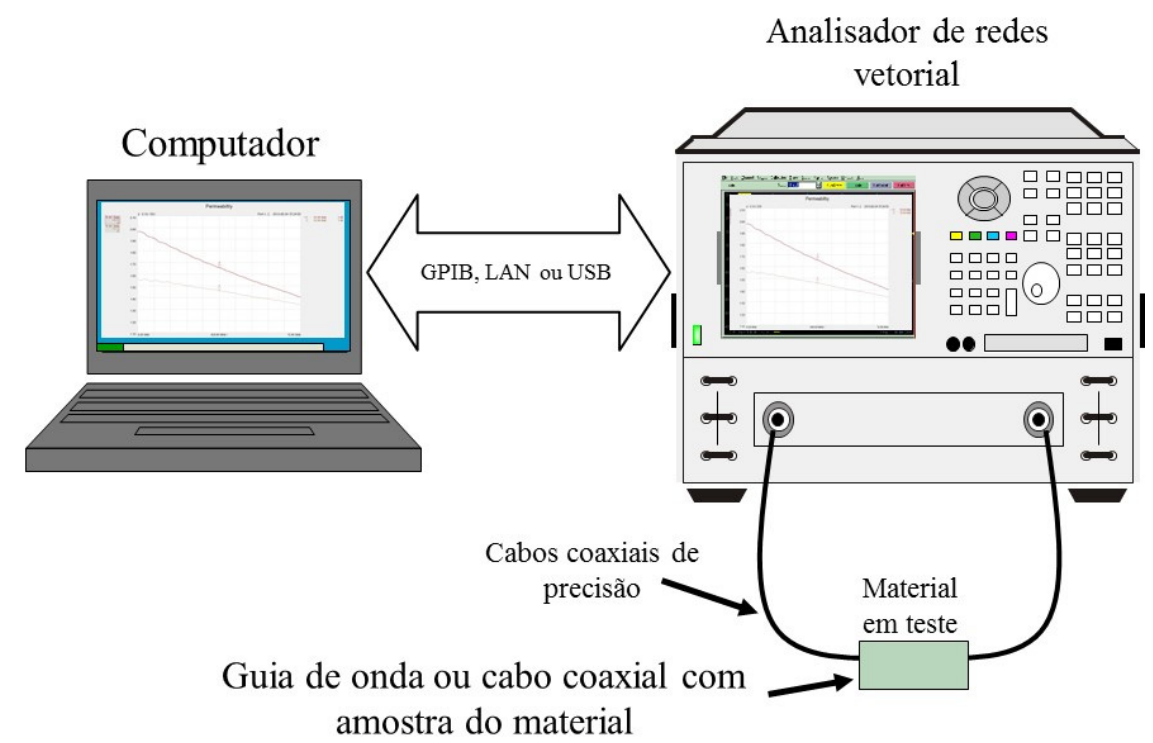

(b)

Fonte: Adaptado de (BEGLEY, 2009).

A técnica da transmissão/reflexão é útil para medidas da permissividade elétrica e/ou permeabilidade magnética em materiais com médias e altas perdas. A incerteza dessa técnica está vinculada aos efeitos de preenchimento do material na linha, tanto devido à presença de espaços vazios, como pelo tamanho da amostra que não pode ser múltiplo de $1 / 4$ do comprimento de onda. 
Na técnica da linha de transmissão terminada em aberto, a onda eletromagnética é direcionada para a amostra posicionada na extremidade em aberto da linha coaxial. A Figura 2.6 apresenta esquematicamente a técnica.

Figura 2.6 - Medida utilizando a da linha de transmissão terminada em aberto, (a) onda refletida na interface entre a linha e o material, (b) esquema de equipamentos para caracterização do material.

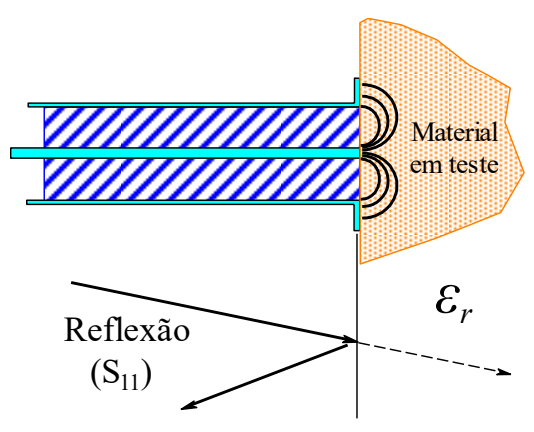

(a)

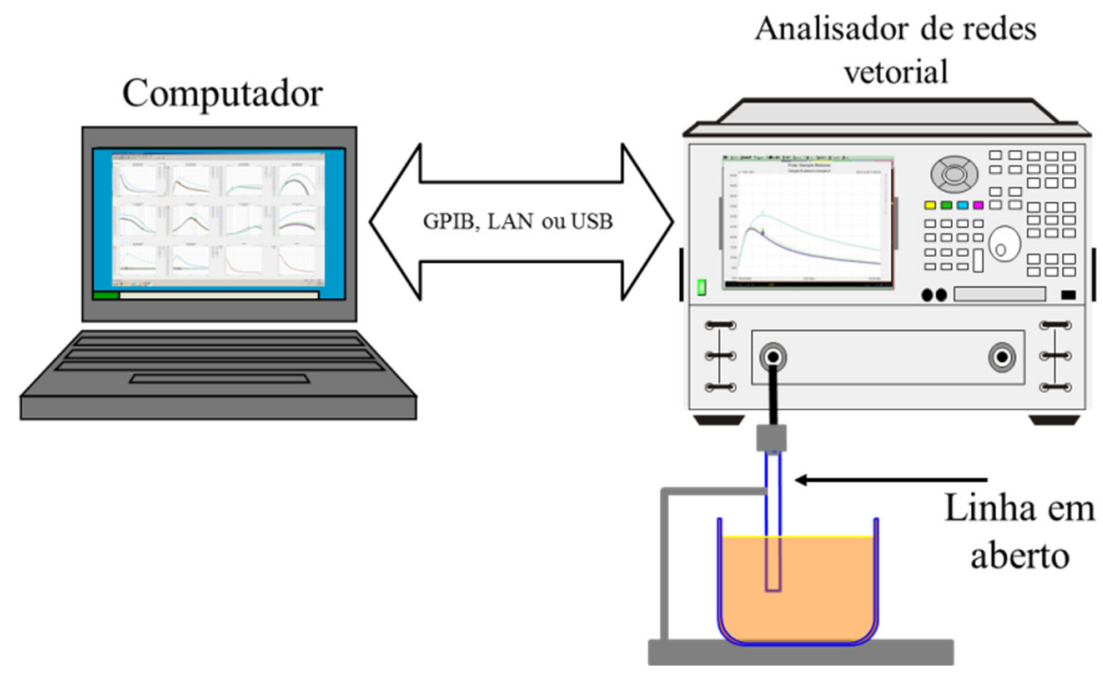

(b)

Fonte: Adaptado de (BEGLEY, 2009).

A partir do coeficiente de reflexão, mede-se o valor de permissividade elétrica do material (ver APÊNDICE E). O coeficiente de reflexão também é obtido com auxílio de um analisador de redes vetorial, previamente calibrado no plano do conector. Para 
obter essa calibração, utiliza-se uma amostra referência: por exemplo, no caso de líquidos, água deionizada, ou etanol; no caso de sólidos, teflon. Esses materiais de referência são utilizados por terem valores de permissividade elétrica conhecidos e tabelados. As linhas em aberto, tipicamente são terminadas com flange para garantir capacitância adequada (LI; CHEN, 1995) (STUCHLY; STUCHY, 1980).

Para a obtenção de resultados precisos usando essa técnica, a espessura dos materiais analisados deve ser maior do que o diâmetro do cabo coaxial. Além disso, o material deve ter baixas perdas para garantir a viabilidade dos modelos. Nesse método, é usual alocar a ponta de prova imersa no líquido ou pressionada contra o material, se sólido. Através dessa técnica é possível obter rapidamente valores de permissividade elétrica e/ou permeabilidade magnética complexa sem a necessidade de preparação das amostras. Além disso, ficam facilitadas as modificações dos parâmetros dos materiais analisados, como temperatura, concentração da mistura, entre outros.

As linhas terminadas em curto são utilizadas para medir materiais magnéticos (GUILLOM, 1995). Nesses casos, o valor da permissividade elétrica é desconsiderado.

A técnica do espaço livre possibilita a caracterização de amostras em altas temperaturas ou em ambientes hostis. Outra vantagem dessa técnica é a medição das propriedades eletromagnéticas de materiais em estado sólido, líquido ou plasma de maneira não destrutiva. A Figura 2.7 apresenta esquematicamente a infraestrutura para testes. Nela são utilizadas duas antenas conectadas a um analisador de redes vetorial. Dessa forma, são medidos os parâmetros de espalhamento com e sem o material, com intuito de minimizar a influência do suporte da amostra. Ao final os valores da permissividade elétrica podem ser determinados através das medidas dos coeficientes de transmissão e reflexão.

Embora esse método permita operar em altas frequências, há necessidade que o material sob teste esteja devidamente alinhado com a polarização das antenas em câmara anecoica eletromagnética de modo a minimizar os efeitos das múltiplas reflexões (BARTLEY; BEGLEY, 2005).

Para a medição em espaço livre, deve-se considerar que a amostra está na região de campo distante das antenas. 
Figura 2.7 - Medida utilizando a técnica do espaço livre, (a) ondas refletidas e transmitidas na amostra de comprimento $l$, (b) esquema de equipamentos para caracterização do material em espaço livre.

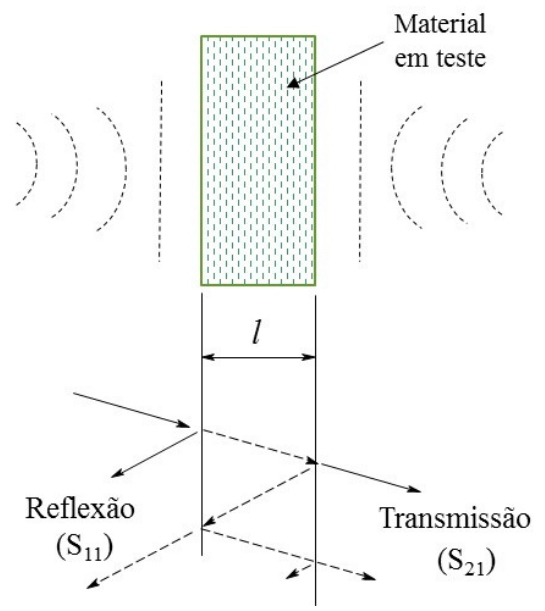

(a)

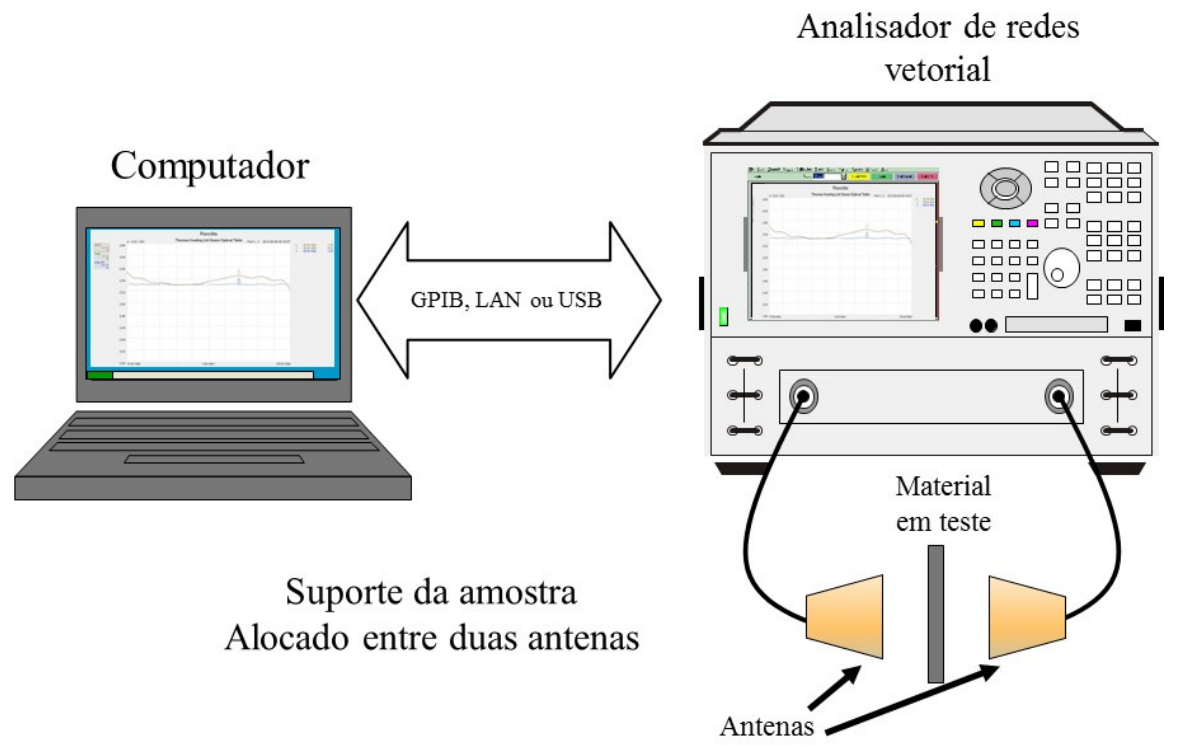

(b)

Fonte: Adaptado de (BEGLEY, 2009).

Na técnica ressonante é possível encontrar os valores mais exatos da permissividade elétrica ou permeabilidade magnética. Contudo, há limitação para análises em banda larga e para materiais com altas perdas. Há dois tipos de métodos ressonantes com 
diferentes aplicações. O método ressonante por perturbação é adequado para materiais com perdas médias e altas. Já o método ressonante em cavidades é utilizado para analisar materiais com baixas perdas.

Para a cavidade ressonante, são realizadas as medidas iniciais utilizando o dispositivo sem amostra. O passo seguinte é repetir a medida com a amostra preenchendo totalmente a cavidade (KOBAYASHI; TANAKA, 1980). Os parâmetros de permissividade elétrica e permeabilidade magnética podem ser calculados através da frequência de ressonância, volume da amostra e índice de mérito ${ }^{10}(Q)$ da cavidade ressonante medido. A Figura 2.8 apresenta um diagrama esquemático dessa medida empregando uma cavidade ressonante com dois acessos.

Figura 2.8 - Equipamentos utilizados para caracterização de materiais através da técnica ressonante.

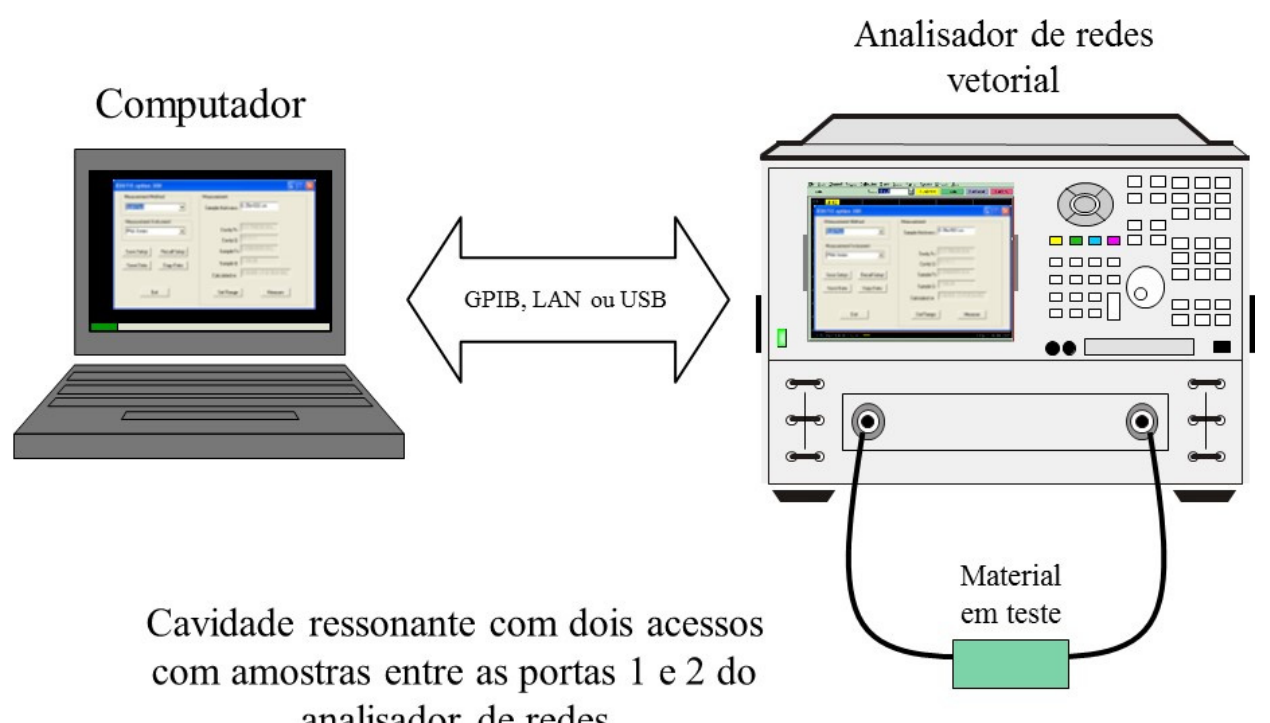
analisador de redes

Fonte: Adaptado de (BEGLEY, 2009).

${ }^{10}$ Compreende-se índice de mérito, ou fator de mérito, como a razão entre frequência de ressonância e a largura de banda $B W$ definida pela diferença entre as duas frequências em $-3 \mathrm{~dB}\left(B W=f_{\mathrm{a}}-f_{\mathrm{b}}\right)$. Desta forma, sendo dada por: $Q=f_{0} / B W$. 
Já o método da perturbação ressonante, o material sob teste é alocado no interior de uma cavidade sem que haja seu total preenchimento. Nessa condição também ocorre variação dos valores da frequência de ressonância e do índice de mérito (Figura 2.9). Sendo que os materiais dielétricos ou magnéticos são alocados, preferencialmente, nas posições de maior campo elétrico e maior campo magnético, respectivamente.

Figura 2.9 - Resposta típica de do parâmetro $\mathrm{S}_{11}$ em função da frequência para perturbação de uma cavidade ressonante. Coeficiente de reflexão com variação da frequência de ressonância e do índice de mérito. Essa mesma análise pode ser realizada com o coeficiente de transmissão.

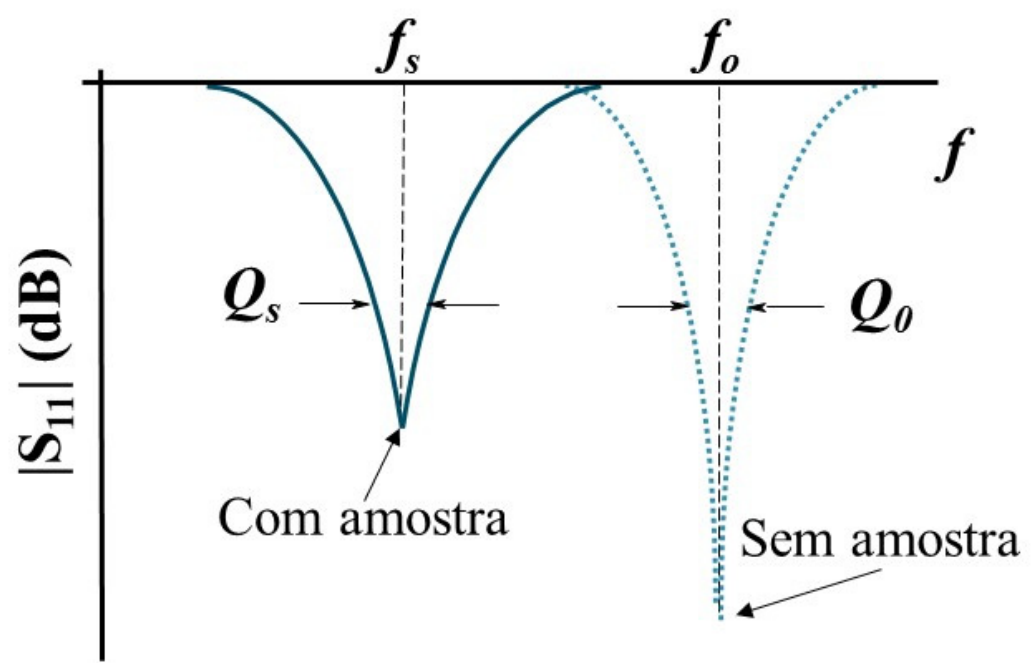

Fonte: Adaptado de (BEGLEY, 2009).

A Tabela 2.1 apresenta sucintamente as principais características das técnicas de caracterização eletromagnética de materiais, dentre elas: técnica da transmissão/reflexão, técnica da linha de transmissão em aberto, técnica em espaço livre, técnica ressonante através de cavidades. 
Tabela 2.1 - Métodos para caracterização eletromagnética de materiais (KRUPKA, 2006).

\begin{tabular}{|c|c|c|c|c|c|}
\hline Técnica & $\begin{array}{c}\text { Parâmetros } \\
\text { S }\end{array}$ & $\begin{array}{c}\text { Modo de } \\
\text { propagação }\end{array}$ & $\begin{array}{l}\text { Parâme- } \\
\text { tros }\end{array}$ & Vantagens & Dificuldades \\
\hline $\begin{array}{l}\text { Transmissão } \\
\text { / Reflexão }\end{array}$ & $\mathrm{S}_{11}$ e $\mathrm{S}_{21}$ & $\begin{array}{l}\text { Modo TEM } \\
\text { em linhas } \\
\text { coaxiais e } \\
\text { modo TE em } \\
\text { guias de onda }\end{array}$ & $\varepsilon_{r} \mathrm{e} \mu_{r}$ & $\begin{array}{l}\text { Medidas em banda } \\
\text { larga; adequado para } \\
\text { materiais com } \\
\text { baixas e altas } \\
\text { perdas; semi-sólidos } \\
\text { e líquidos. }\end{array}$ & $\begin{array}{l}\text { Problemas de } \\
\text { preenchimento } \\
\text { do material. }\end{array}$ \\
\hline $\begin{array}{l}\text { Linha de } \\
\text { transmissão } \\
\text { terminada } \\
\text { em aberto }\end{array}$ & $\mathrm{S}_{11}$ & $\begin{array}{l}\text { Modo TEM } \\
\text { ou modo TE }\end{array}$ & $\varepsilon_{r}$ & $\begin{array}{l}\text { Medidas em altas } \\
\text { frequências; } \\
\text { adequado para } \\
\text { materiais com } \\
\text { baixas e altas } \\
\text { perdas; sólidos e } \\
\text { líquidos. }\end{array}$ & $\begin{array}{l}\text { Limitações em } \\
\text { frequências } \\
\text { baixas (menores } \\
\text { do que } \mathrm{GHz} \text { ). }\end{array}$ \\
\hline Espaço livre & $\mathrm{S}_{11}$ e $\mathrm{S}_{21}$ & Modo TEM & $\varepsilon_{r} \mathrm{e} \mu_{r}$ & $\begin{array}{l}\text { Medidas em banda } \\
\text { larga; sem contato } \\
\text { com a amostra; } \\
\text { adequado para } \\
\text { materiais com } \\
\text { baixas e altas } \\
\text { perdas; utilizado } \\
\text { para amostras em } \\
\text { altas temperaturas. }\end{array}$ & $\begin{array}{l}\text { Problemas no } \\
\text { preparo da } \\
\text { amostra. }\end{array}$ \\
\hline $\begin{array}{l}\text { Cavidade } \\
\text { ressonante }\end{array}$ & $\begin{array}{l}\text { Frequências } \\
\text { de } \\
\text { ressonância e } \\
\text { índice de } \\
\text { mérito } Q \\
\text { extraídas de } \\
\mathrm{S}_{11} \text { e } \mathrm{S}_{21} \text {. }\end{array}$ & $\begin{array}{l}\text { Modo TE ou } \\
\text { modo TM }\end{array}$ & $\varepsilon_{r} \mathrm{e} \mu_{r}$ & $\begin{array}{l}\text { Método com melhor } \\
\text { exatidão; adequado } \\
\text { para materiais com } \\
\text { baixas perdas; } \\
\text { amostras sólidas e } \\
\text { líquidas. }\end{array}$ & $\begin{array}{l}\text { Medidas em } \\
\text { frequência } \\
\text { única. }\end{array}$ \\
\hline
\end{tabular}

\subsubsection{Técnicas no domínio do tempo}

A principal técnica para caracterização eletromagnética de materiais no domínio do tempo é a reflectometria no domínio do tempo, TDR (Time Domain Reflectrometry). A técnica TDR consiste em aplicar um degrau de tensão em uma linha de transmissão 
e analisar a resposta de tensão em função do tempo. Seu funcionamento é baseado em princípios de linhas de transmissão, na qual pelo descasamento de uma carga com a impedância característica da linha, há uma reflexão parcial ou total da energia injetada. As medidas através da técnica TDR não são capazes de apresentar os valores exatos da permissividade complexa de um material. Contudo são capazes de fornecer com precisão a constante dielétrica dos materiais (valor estático da parte real da permissividade elétrica) a partir do tempo de reflexão da onda e do comprimento da linha de transmissão (TOPP et al., 1980).

\subsection{Adulteração de combustíveis}

A adulteração de combustíveis consiste em realizar qualquer adição de substâncias, usualmente com a finalidade de baratear o produto, resultando num combustível de qualidade inferior, ou com especificação em desacordo com o permitido por lei. A adulteração possui inúmeras consequências, como danos ambientais (devido à queima de solventes tóxicos), danos ao veículo, danos econômicos (decorrentes da evasão fiscal) e danos legais (decorrentes da concorrência desleal).

No Brasil, a produção de combustíveis é realizada por refinarias - centrais petroquímicas e usinas de processamento de cana de açúcar. A distribuição é feita por cerca de 277 distribuidoras, conforme dados de Dias et al. (2007). Cabe à rede de postos de revendas fornecerem o produto aos consumidores finais. Essa estrutura é regulada e fiscalizada pela Agência Nacional do Petróleo, Gás Natural e Biocombustíveis (ANP), autarquia federal criada pela Lei $n^{0} 9.478 / 1997$, vinculada ao Ministério das Minas e Energia.

\subsubsection{Etanol combustível}

Os álcoois são substâncias orgânicas oxigenadas caracterizadas pela presença de moléculas do grupo hidroxila (-OH). Dois exemplos de álcoois são o etanol ou álcool etílico $\left(\mathrm{CH}_{3} \mathrm{CH}_{2} \mathrm{OH}\right)$ e o metanol $\left(\mathrm{CH}_{3} \mathrm{OH}\right)$. Além do uso como combustível automotivo, o etanol pode ser utilizado como solvente na fabricação de tintas, vernizes 
e perfumes; na preparação de produtos farmacêuticos; como produtos de limpeza; em bebidas; entre outros.

O uso de álcool combustível teve impulso no Brasil, principalmente, com o programa Pró-Álcool (Programa Nacional do Álcool) a partir do ano de 1975, tendo como objetivo reduzir a dependência do petróleo importado durante os sucessivos "choques do petróleo". Apesar do aumento do preço internacional do petróleo, o etanol não era economicamente competitivo. Com isso foram necessários subsídios para garantir sua viabilidade. Contudo esses incentivos duraram até meados de 1984. Tal fato culminou na crise de abastecimento no início da década de 1990, o que reduziu drasticamente a venda de carros a álcool. Somente a partir de 2003, com os veículos flex-fuel, o setor ganhou novo impulso.

\subsubsection{Características e regulamentação}

De acordo com a resolução ANP no 19 de 15/04/2015 são produzidos três tipos de etanol combustível: Etanol Anidro Combustível (EAC), destinado para mistura com gasolina A na formulação da gasolina C; Etanol Hidratado Combustível (EHC) ${ }^{11}$, destinado à utilização direta em motores de combustão interna; e Etanol Hidratado Combustível Premium (EHCP), com massa específica entre 799,7 e $802,8 \mathrm{~kg} / \mathrm{m}^{3}$ a $20^{\circ} \mathrm{C}$ (ANP, 2015).

No regulamento proposto pela ANP (ver ANEXO A), são descritas as características que o etanol deve possuir para comercialização, dentre elas seu aspecto, cor, massa específica, teor alcoólico, potencial hidrogeniônico $(\mathrm{pH})$, condutividade elétrica, entre outras.

11 É comum mencionar as denominações Etanol Anidro Combustível (EAC) e Etanol Hidratado Combustível (EHC) como, respectivamente, álcool etílico anidro combustível e álcool etílico hidratado combustível. 
Segundo especificações da ANP é chamado EAC o etanol de alta pureza (mínimo de 99,3 ${ }^{\circ} \mathrm{INPM}^{12}$ ). Esse é utilizado como componente da gasolina automotiva, a permitir maior taxa de compressão (octanagem) do combustível resultante. Por sua vez, o EHC possui teor alcoólico entre 92,5 a 94,6 ${ }^{\circ} \mathrm{INPM}$, ou seja, aproximadamente 7\% de sua massa total é composta por água. Já os combustíveis que possuem teor alcoólico entre 95,5 a 96,5 ${ }^{\circ} \mathrm{INPM}$ podem ser vendidos como EHCP.

Para a obtenção desses álcoois combustíveis, utiliza-se a fermentação de açúcares de vegetais seguida de sucessivas destilações. No Brasil, a extração é preponderantemente feita a partir da cana-de-açúcar. Em países como Estados Unidos e Japão são utilizados vegetais como o milho e a beterraba (MINTEER, 2006).

Por meio da fermentação, pode-se obter uma mistura de teor alcoólico entre 7,0 e 10,0 ${ }^{\circ}$ INPM. Esse teor é baixo para ser utilizado como etanol combustível. Dessa forma é necessário um processo de destilação com intuito de reduzir a concentração de água. Ao longo do processo de destilação, obtêm-se no máximo um etanol de $96{ }^{\circ} \mathrm{GL}$ ou $93,2^{\circ} \mathrm{INPM}$ (KISTER, 1992).

Maiores teores não são alcançados através desse método, pois a mistura de $95 \%$ de álcool e 5\% de água é azeotrópica. Ou seja, numa temperatura denominada temperatura azeotrópica a composição da fase líquida da mistura e da fase gasosa é a mesma. Isto inviabiliza a separação da mistura por destilação simples (MINTEER, 2006). Dessa forma, para obter o EAC é realizado o processo de desidratação. Para tanto são adicionados à mistura um ciclohexano que origina um novo azeótropo. Esse

\footnotetext{
${ }^{12} \mathrm{O}$ grau alcoólico ${ }^{\circ} \mathrm{INPM}$ (Instituto Nacional de Pesos e Medidas) corresponde à quantidade em gramas de álcool absoluto contida em 100 gramas de mistura hidroalcoólica. Ou seja, uma amostra de álcool com 99,3 ${ }^{\circ}$ INPM possui 99,3\% de massa de álcool e 0,7\% de massa de água. Também é conferido grau alcoólico através da escala ${ }^{\circ} \mathrm{GL}\left({ }^{\circ} \mathrm{Gay}\right.$ Lussac) que corresponde à quantidade em mililitros de álcool absoluto contida em 100 mililitros de mistura hidroalcoólica a $25^{\circ} \mathrm{C}$. Dessa forma, uma amostra de álcool com $90{ }^{\circ} \mathrm{GL}$ tem $90 \%$ em volume de álcool e $10 \%$ em volume de água.

Opta-se pelo grau ${ }^{\circ} \mathrm{INPM}$, pois medidas em ${ }^{\circ} \mathrm{GL}$ são sensíveis à variação de temperatura devido à dilatação dos líquidos. Para realizar as diluições de álcool combustível são utilizados os procedimentos descritos na norma ABNT 5992 “Álcool etílico e suas misturas com água - Determinação da massa específica e do teor alcoólico".
} 
possui ponto de ebulição inferior ao álcool, permitindo a remoção da água (KEYES, 1928). Ao final do processo, pode-se chegar a um etanol de $99,7^{\circ} \mathrm{GL}$.

\subsubsection{Principais adulterantes}

Os principais adulterantes utilizados no etanol combustível são água e metanol. Posto que o etanol é facilmente miscível em água, sua adulteração é facilitada, pois o aspecto da mistura resultante não sofre modificações. Em relação ao metanol, verifica-se que esse possui similaridade de suas propriedades físico-químicas com o etanol, o que também facilita a adulteração. Contudo o metanol é extremamente tóxico e, em altas concentrações, pode causar cegueira e morte (DIAS et al., 2015).

Ambos adulterantes do etanol combustível não são visualmente verificáveis. No entanto, um dos testes realizados nos postos de combustíveis é o da densidade, realizado através de densímetros de vidro (ABNT NBR 5992, 2008). Quando o etanol apresenta um aumento do teor de água, sua densidade aumenta. Tal fato pode ser verificado através dos densímetros alocados nas bombas de combustível. Esse tipo de análise é incapaz de detectar a fraude realizada pela adição de metanol, pois, como dito anteriormente, suas propriedades físico-químicas, dentre elas a densidade, são similares às do etanol. Cabe ressaltar que os densímetros também podem ser fraudados o que impede qualquer tipo de análise inicial do etanol combustível.

A adulteração com água ocorre, especialmente no EAC, para a comercialização como EHC. Essa mistura é conhecida como “álcool molhado”. Como o EAC não sofre tributação direta quando adquirido para ser adicionado à gasolina (DELGADO et al, 2007), os fraudadores realizam a sua diluição para ser vendido como $\mathrm{EHC}^{13}$. Além disso, outra prática comum é a adição de água a EHC em quantidade superior à permitida pela legislação vigente.

Uma forma de identificar o uso de adulterantes é através de densímetros, outra é através da medida de condutividade elétrica (ABNT NBR 10547, 2012). Tanto para o

\footnotetext{
${ }^{13}$ A resolução ANP n³6 estipula o uso de corante laranja ao álcool anidro. Dessa forma o consumidor tem como identificar, pela cor, adulterações desse álcool, uma vez que o AEHC deve ser incolor.
} 
EHC como para o EAC, foi limitado o valor de condutividade elétrica em $300 \mu \mathrm{S} / \mathrm{m}$. Com a adição de água de torneira, aumenta-se o valor dessa condutividade devido aos íons presentes na água. Com isso, uma medida de condutividade de álcool molhado pode chegar a valores de até $2000 \mu \mathrm{S} / \mathrm{m}$. Cabe ressaltar que, uma das maneiras de burlar essa medida é através da adição de água destilada ou até mesmo água deionizada (DI), que, possuindo menores condutividades elétricas, mascaram as medidas realizadas pelo condutivímetro.

A adulteração através do metanol tem como objetivo mascarar a adulteração por água. Com a adição de metanol, os fraudadores são capazes de adicionar uma significativa quantidade de água, sem que a mistura resultante seja afetada no ensaio do teor específico.

Cabe à ANP regulamentar os métodos para testes de qualidade dos combustíveis. Esses devem ser realizados mediante o emprego de Normas Brasileiras (NBR) da Associação Brasileira de Normas Técnicas (ABNT) e/ou normas internacionais da American Society for Testing \& Materials (ASTM), do Comitté Européen de Normalisation (CEN) ou da International Organization for Standartization (ISO). Vale ressaltar que tais métodos envolvem o uso de equipamentos laboratoriais de bancada com alto custo e complexidade. Além disso, os testes são, usualmente, destrutivos às amostras.

Dentre eles, estão os testes de pH (ABNT NBR 10891, 2013), que devem garantir aos três tipos de etanol combustível valores dentro dos limites de 6,0 a 8,0. Além disso, outro processo utilizado é o de cromatografia gasosa (ABNT NBR 16041, 2012), que consiste na técnica de separação e análise de misturas de substâncias voláteis. Nesse processo a amostra é vaporizada e transportada por um fluxo de gás inerte (fase móvel ou gás de arraste) tipicamente hidrogênio, argônio, hélio ou nitrogênio até a coluna cromatográfica. Como os compostos mais voláteis e de menor peso molecular são detectados primeiramente, obtém-se um cromatograma, cujos valores indicam os componentes da amostra e suas respectivas concentrações. 
2.7.1.3. Características de permissividade elétrica complexa do etanol combustível $\mathrm{Na}$ literatura são fornecidos resultados tabelados provenientes de caracterizações da permissividade elétrica de líquidos e suas misturas, bem como de alguns sólidos (BUCKLEY; MARYOTT, 1958) (GREGORY; CLARKE, 2006) (ELLISON, 2007). Em específico, as misturas de etanol com água são descritas através de três métodos: leis empíricas que ponderam os valores de permissividade elétrica e as frações em volume das misturas; gráficos de espectroscopia dielétrica; ou através dos parâmetros de relaxação dielétrica apresentados no item 2.5 (BAO et al., 1996) (MEGRICHE et al., 2012) (OLMI et al., 2007).

As moléculas de etanol ao se misturarem com outros líquidos polares, a exemplo de água, interagem microscopicamente. Devido a essa interação, torna-se difícil modelar o valor da permissividade elétrica complexa das soluções através da simples ponderação entre os volumes de etanol e de água e dos valores de permissividade elétrica desses materiais. Dessa forma, para analisar o comportamento das misturas desses materiais em diferentes frequências, utiliza-se a análise experimental através de gráficos de espectroscopia dielétrica.

O trabalho de Bao et al. (1996) apresenta detalhadamente medidas de permissividade elétrica complexa de soluções binárias de etanol e água, representadas nas figuras 2.10 e 2.11 , ambas caracterizadas a temperatura de $25^{\circ} \mathrm{C}$. Tais medidas foram realizadas utilizando o método da linha coaxial em aberto, com faixas de frequência entre $45 \mathrm{MHz}$ a 26,5 GHz para as frações de etanol apresentadas nas figuras 2.10 e 2.11.

Os valores de permissividade elétrica não apresentam variação uniforme com as diferentes diluições. Isto ocorre pois, em geral, as propriedades físicas de misturas binárias não variam linearmente com as frações em volume.

Os mecanismos de relaxação dielétrica de duas moléculas de álcool podem interagir formando agregados moleculares (BAO et al., 1996), dessa maneira tendo uma interação linear. Por outro lado, as misturas entre etanol e água não se comportam como misturas de álcoois, a exemplo do etanol e metanol.

Como as moléculas de água são pequenas em comparação às moléculas de álcool, tendem a possuir maiores frequências de dispersão. Dessa forma, tendo diferentes 
relaxações dielétricas, a mistura, ao interagir com um campo elétrico, tende a apresentar um valor de relaxação intermediário entre os de água e etanol.

Figura 2.10 - Valores experimentais da parte real da permissividade complexa da mistura etanol e água.

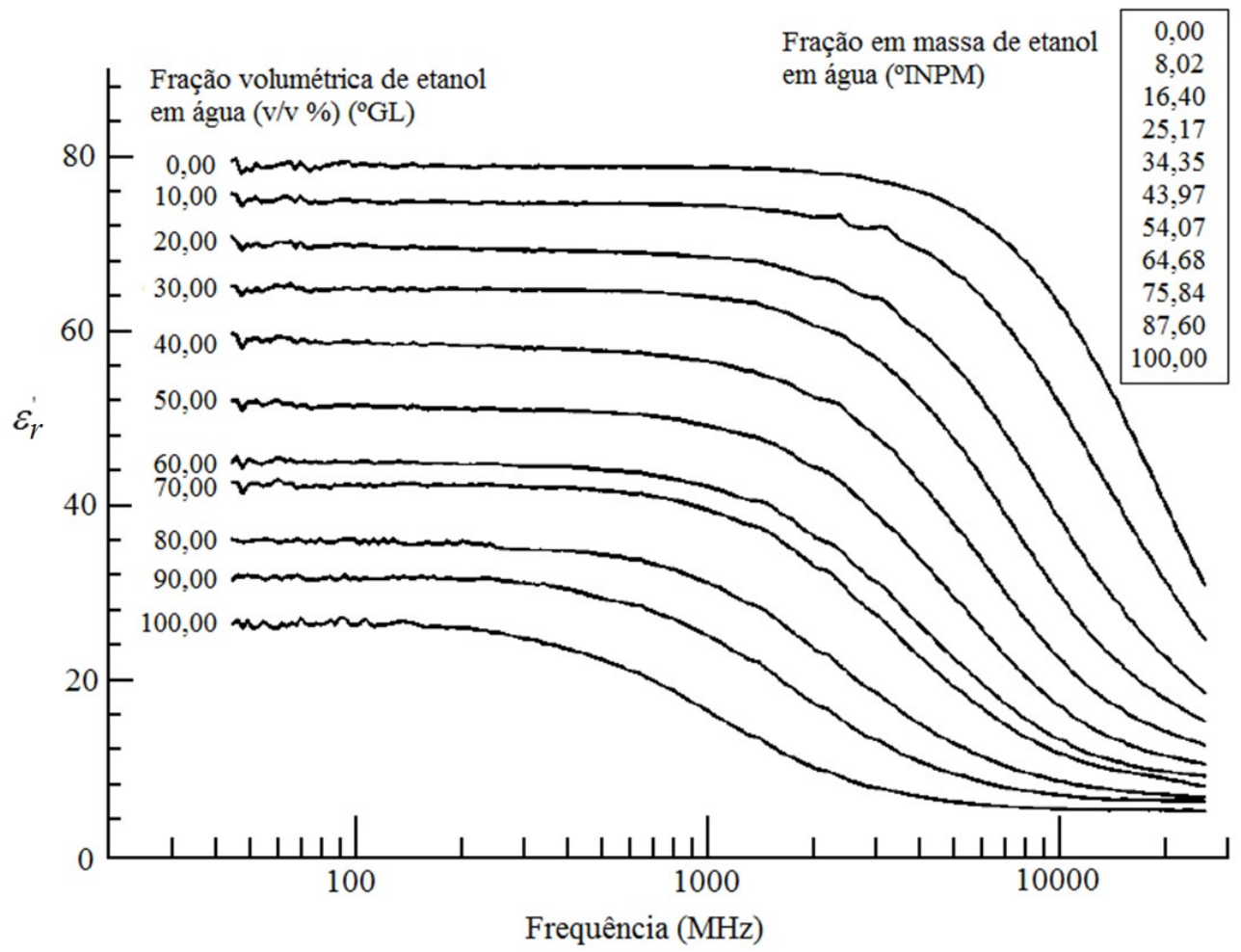

Fonte: Adaptado de Bao et al. (1996).

As curvas da parte real da permissividade das misturas entre etanol e água são bem distinguíveis, principalmente, entre as frequências de $45 \mathrm{MHz}$ e $6 \mathrm{GHz}$ para passos de 10\% na diluição volumétrica de etanol em água, conforme apresentado na Figura 2.10. A Figura 2.11, permite identificar que as curvas da parte imaginária das mesmas soluções são melhores discriminadas a partir de $1 \mathrm{GHz}$ até $26,5 \mathrm{GHz}$. Portanto, através da permissividade elétrica complexa é possível diferenciar amostras de etanol combustível diluídas com água. Dessa forma, o desenvolvimento de sensores de baixo custo que analisem esse parâmetro permite qualificar as diferentes adulterações desse álcool combustível. 
Figura 2.11 - Valores experimentais da parte imaginária da permissividade complexa da mistura etanol e água.

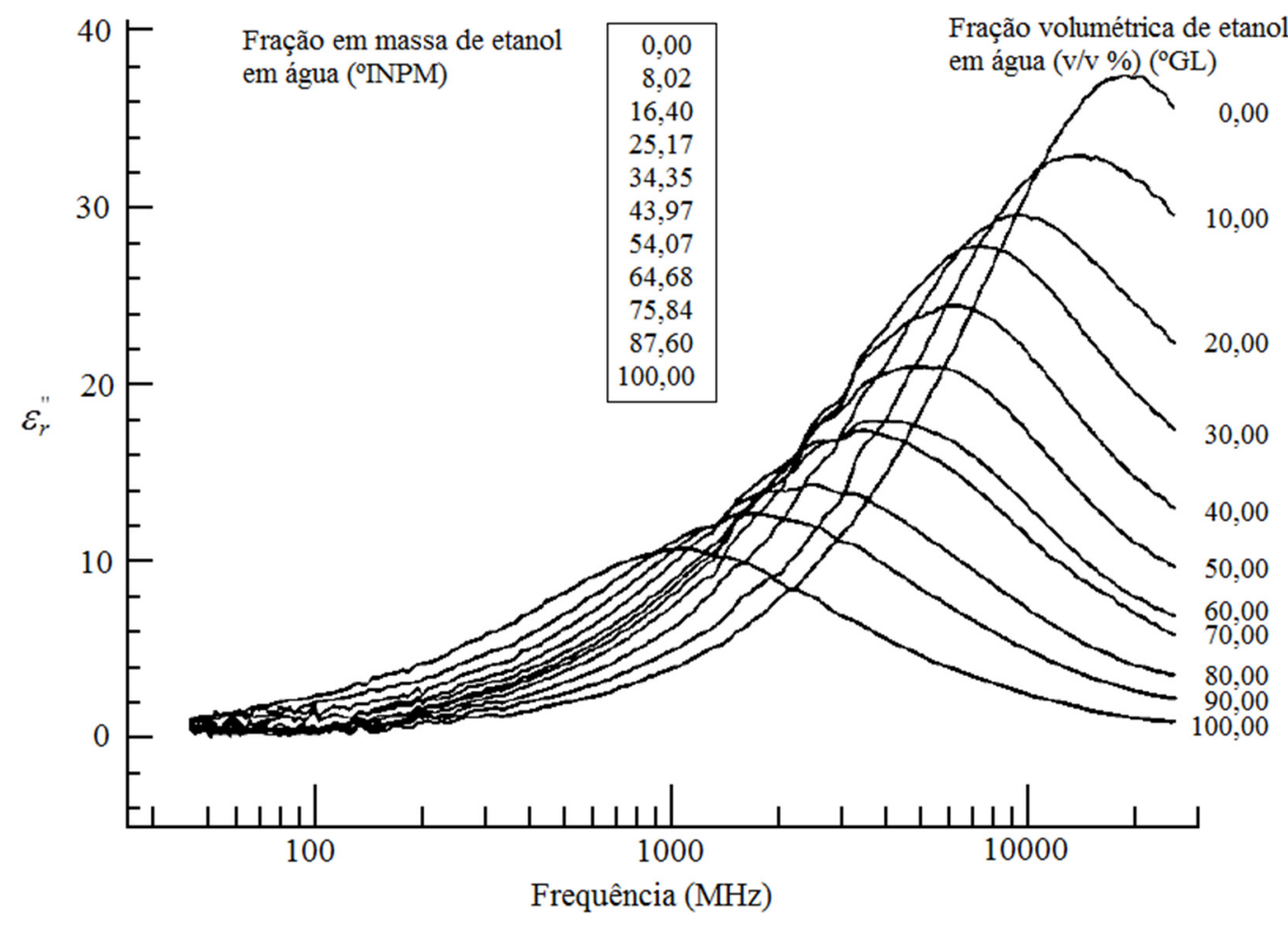

Fonte: Adaptado de Bao et al. (1996). 


\section{DESENVOLVIMENTO \\ DE SENSORES \\ PARA \\ CARACTERIZAÇÃO DE ETANOL COMBUSTÍVEL: TECNOLOGIAS E ESTRUTURAS EM FREQUENCIAS DE MICRO-ONDAS}

Neste capítulo são delimitados os materiais, tecnologias e estruturas utilizadas para desenvolvimento de sensores em micro-ondas. Os sensores propostos nesta tese são descritos, conforme Figura 3.1, através de dois conjuntos: sensores da fase vapor e sensores da fase líquida do etanol combustível. Na mesma figura são listadas as etapas de desenvolvimento dos sensores.

Para o primeiro bloco, são propostos dois tipos de sensores: uma antena de microfita com plaqueta retangular e uma antena com fenda desenvolvida com tecnologia SIW. As antenas foram utilizadas como ressoadores e não como elementos radiantes. Em ambos sensores é utilizado o método da perturbação ressonante, sensibilizado por meio de nanotubos de carbono, CNTs, depositados na superfície do substrato. O uso da antena de microfita tem como objetivo realizar uma prova de conceito da metodologia proposta.

Figura 3.1 - Sensores propostos para qualificação de etanol combustível e etapas de projeto.

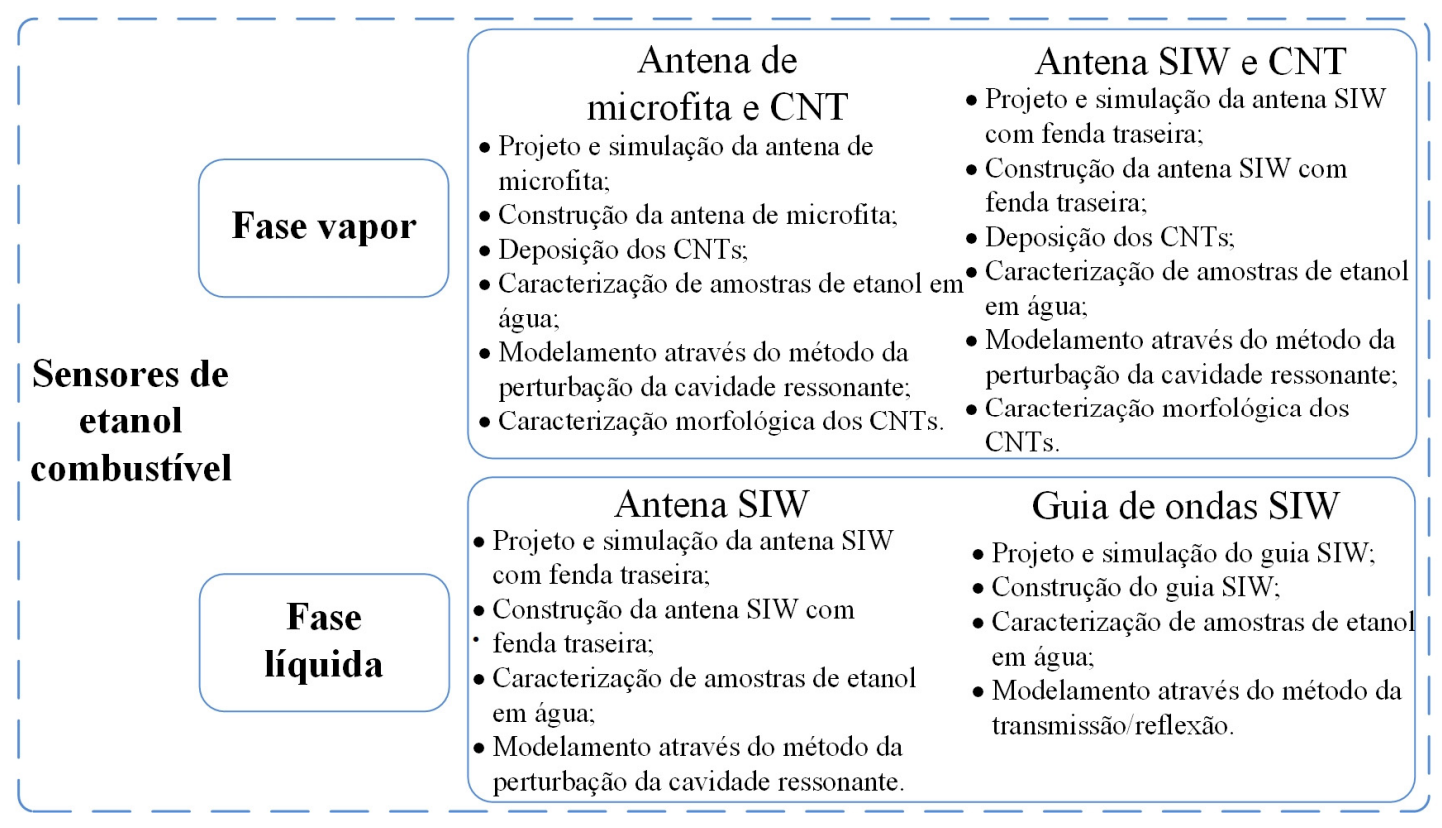


As equações de projeto da antena de microfita são apresentadas no item 3.3. A técnica de deposição de CNTs por gotejamento é descrita no subitem 3.8.1 e o ambiente de ensaio para os sensores de gases, bem como os instrumentos de medida, são descritos no subitem 3.8.2. As equações de projeto da antena SIW com fenda traseira são descritas no item 3.6. A deposição de CNTs por gotejamento é detalhada no subitem 3.8.1, tal como a antena de microfita. $\mathrm{O}$ ambiente de ensaios é apresentado no subitem 3.8.2. As características e aplicações do CNT em sensoriamento para os sensores de fase vapor são detalhadas no subitem 3.7.2.

Para o etanol combustível na sua fase líquida são propostos dois sensores planares. $\mathrm{O}$ primeiro, a antena SIW com fenda traseira, sem CNT, é utilizado diretamente em contato com uma pequena quantidade do material sob teste. Com isso, a presença da amostra sob teste causa variação dos mesmos parâmetros - frequência de ressonância e índice de mérito. O segundo sensor de fase líquida é constituído por um guia de ondas em SIW, que através do método da transmissão/reflexão permite analisar diretamente uma pequena quantidade do material que é inserida no interior do guia.

Para a antena SIW com fenda traseira, detalham-se as equações de projeto no item 3.6 e a metodologia de caracterização do sensor e das amostras de etanol em água no subitem 3.9.1. As equações de projeto do guia de ondas em SIW são apresentadas no item 3.5 e a infraestrutura de caracterização tanto do sensor como das amostras é descrita no subitem 3.9.2. Para todos os sensores, são detalhadas as metodologias de projeto. Para tanto são indicados, sucintamente, os princípios teóricos de funcionamento de cada estrutura de micro-ondas.

\subsection{Amostras de etanol combustível adulterado}

Para os testes com os sensores, foram preparados diferentes tipos de amostras binárias, utilizando-se diferentes proporções de etanol com água, típicas soluções de álcool combustível adulterado, como demonstrado no capítulo 2. 
As amostras foram preparadas a partir de etanol $99,5^{\circ} \mathrm{GL}$ (grau analítico) do fabricante Synth $^{14}$. Todas as diluições foram realizadas através de misturas em massa, como determinado pela ANP. Para o preparo das amostras foi utilizada uma balança de precisão analítica Marte Al 500. Além disso, foram utilizados outros utensílios químicos como: bureta, proveta e béquer, além de seringas descartáveis.

A caracterização entre etanol e água foi realizada através de 8 amostras, a partir das faixas de teor alcóolico padronizadas pela ANP. As amostras de etanol com água foram preparadas nas proporções apresentadas nas Tabela 3.1. As amostras com 99,36, 94,96 e $87,60^{\circ}$ INPM estão em torno dos valores permitidos para EHC - entre 92,5 e 94,46 ${ }^{\circ}$ INPM. Dessa forma, pode-se aferir valores para adulterações próximas aos valores permitidos.

Tabela 3.1 - Amostras de etanol em água utilizadas para testes a $25^{\circ} \mathrm{C}$.

\begin{tabular}{ccc}
\hline \multicolumn{3}{c}{ Amostras de etanol em água } \\
\hline Amostra & $\begin{array}{c}\text { Fração em volume } \\
{[\%(\mathrm{v} / \mathrm{v})] \text { ou }{ }^{\circ} \mathrm{GL}}\end{array}$ & $\begin{array}{c}\text { Fração em massa } \\
{[\%(\mathrm{~m} / \mathrm{m})] \text { ou }^{\circ} \mathrm{INPM}}\end{array}$ \\
\hline 1 (etanol anidro) & 99,50 & 99,36 \\
2 & 96,00 & 94,96 \\
3 & 90,00 & 87,60 \\
4 & 80,00 & 75,84 \\
5 & 60,00 & 54,07 \\
6 & 30,00 & 25,17 \\
7 & 10,00 & 8,02 \\
8 (água DI) & 0,00 & 0,00 \\
\hline
\end{tabular}

\footnotetext{
${ }^{14}$ Labsynth - Matérias-primas e reagentes analíticos para laboratórios: http://www.labsynth.com.br/

15 Os valores de densidade, à temperatura de $25^{\circ} \mathrm{C}$, da água $(d=0,9989 \mathrm{~kg} / \mathrm{l})$ e do etanol $(d=0,7839 \mathrm{~kg} / \mathrm{l})$ possibilitam apresentar os valores das amostras tanto através de frações de volume, com pela sua fração em massa.
} 


\subsection{Ferramentas para simulação e caracterização de circuitos de micro-ondas}

\subsubsection{Softwares para simulação 3D eletromagnética}

Os circuitos de micro-ondas foram otimizados e simulados utilizando os softwares eletromagnéticos comerciais Advanced Design System (ADS) ${ }^{16} 2015$ da Keysight Technologies e CST Microwave Studio ${ }^{17}$.

$\mathrm{O} \operatorname{ADS}^{18}$ possui maior velocidade de simulação, contudo não permite a simulação de estruturas com formato arbitrário. Nesses casos é utilizado o CST, posto que esse possibilita interface de modelagem geométrica tridimensional. Muito embora com velocidade de simulação menor em comparação ao $\mathrm{ADS}$, o $\mathrm{CST}^{19}$ realiza análise de equação de onda completa utilizando o Método dos Elementos Finitos para a solução numérica das Equações de Maxwell.

Além disso, o CST permite atribuir constantes de dispersão dielétrica diretamente nos materiais e blocos. Dentre os modelos possíveis estão: Debye de $1^{\mathrm{a}}$ ordem, Debye de $2^{\mathrm{a}}$ ordem, Drude, Lorentz, entre outros. Empregando esse recurso é possível utilizar os parâmetros relativos a etanol, metanol e água para simular a interação dos materiais com os sensores. Dessa forma, utiliza-se, preferencialmente, o CST para realizar as simulações eletromagnéticas tridimensionais, sendo o ADS ferramenta auxiliar de projeto.

\footnotetext{
16 Keysight Advanced Design System: http://www.keysight.com/en/pc-1297113/advanced-designsystem-ads

${ }^{17}$ Computer Simulation Technology: https://www.cst.com/

${ }^{18}$ O ADS possui dois simuladores eletromagnéticos: Momentum e FEM. Para a solução numérica das Equações de Maxwell, o Momentum utiliza o Método dos Momentos, enquanto o FEM emprega o Método dos Elementos Finitos. Momentum e FEM são otimizados para simulação de estruturas planares e só permitem que formas geométricas sejam definidas por camadas sobrepostas.

${ }^{19}$ O CST possui diferentes algoritmos de otimização. Nesse trabalho foram utilizados: Trust Region Framework, Nelder-Mead Simplex, Genetic Algorithm e Particle Swarm Optimization.
} 


\subsubsection{Analisador de redes vetorial}

Para a caracterização dos circuitos e sistemas de micro-ondas desenvolvidos foram utilizados: o analisador de redes Fieldfox N9912A ${ }^{20}$ da Keysight, operando entre $10 \mathrm{MHz}$ e $6 \mathrm{GHz}$; o analisador de redes vetorial HP8722D, operando entre $50 \mathrm{MHz}$ e $40 \mathrm{GHz}$; e o analisador de redes escalar HP8710B, operando entre $45 \mathrm{MHz}$ e $26,5 \mathrm{GHz}$, conectado ao gerador de sinal HP83650L entre $10 \mathrm{MHz}$ e $50 \mathrm{GHz}$, equipamentos estes da Hewlett-Packard ${ }^{21}$.

\subsection{Antena de microfita}

Antenas planares de micro-ondas são estruturas que utilizam radiadores em forma laminar (DESCHAMP, 1953), com espessura muito menor do que o comprimento de onda no espaço livre, $\lambda$. São quatro as categorias principais dessas antenas: antenas de microfita, antenas com plaqueta suspensa, antenas planares em L-invertido/F-invertido e antenas monopolos planares (SEKO, 2013). Essas antenas têm elementos condutores (elemento condutor radiante e plano terra) e um substrato plano de material dielétrico com valores de constante dielétrica $\varepsilon_{r}$ entre 1,96 e 12 , e espessura entre $0,2 \mathrm{~mm}$ e $2 \mathrm{~mm}$. Antenas de microfita possuem pequenas dimensões e são largamente utilizadas em comunicações sem fio, desde aparelhos móveis de rádio frequência até aeronaves, espaçonaves, satélites e mísseis.

Diversas são as maneiras de projetar analiticamente uma antena de microfita (GARG, 2001) (JAMES; HALL, 1989). Dentre elas, utilizam-se os modelos de linha de

\footnotetext{
${ }^{20} \mathrm{O}$ Fieldfox foi utilizado por sua portabilidade e facilidade para aquisição de dados via rede Ethernet. Outra característica do VNA N9912A é sua excelente resolução em frequência - 2,5 kHz na faixa de 2 $\mathrm{MHz}$ a $1,6 \mathrm{GHz}, 5 \mathrm{kHz}$ na faixa de $1,6 \mathrm{GHz}$ a $3,2 \mathrm{GHz}$ e $10 \mathrm{kHz}$ na faixa de 3,2 GHz a $6 \mathrm{GHz}$.

21 Os manuais de todos os equipamentos citados estão disponíveis no site do fabricante: http://www.keysight.com/
} 
transmissão e/ou de cavidade ressonante ${ }^{22}$. Dessa forma, a antena apresentará modos ressonantes com frequência de ressonância bem definida, usualmente com a operação no modo ressonante fundamental.

As perdas de uma antena de microfita podem ser dadas por: perdas condutivas, devida à dissipação térmica na plaqueta radiante e no plano terra; perdas dielétricas, devida à dissipação térmica no substrato; perdas por ondas de superfície, devidas ao espalhamento de energia eletromagnética no substrato; e perdas por radiação, devida ao mecanismo de radiação (SEKO, 2013). Este último mecanismo é desejável em sistemas de comunicação, sendo responsável pela operação de radiação da antena. Ressalta-se, contudo, que neste trabalho as antenas de microfita são utilizadas como cavidade ressonante, portanto a radiação da antena é um aspecto secundário para o projeto dos sensores.

Outro ponto fundamental no projeto de antenas planares de micro-ondas é a estrutura de alimentação. A transição que ocorre entre a linha de alimentação e o elemento radiante influencia a impedância de entrada da antena e, como consequência, a sua banda. As alimentações mais comuns são: sonda coaxial, linha de microfita, acoplamento por proximidade e acoplamento por abertura.

A alimentação via linha de microfita indentada possibilita o casamento de impedância através da alocação adequada da posição de inserção, conhecida como reentrância (inset-fed), no elemento radiador.

A Figura 3.2 apresenta esquematicamente a estrutura e as dimensões de uma antena de microfita com plaqueta retangular com alimentação via linha de microfita indentada. O projeto de uma antena de microfita alimentada por inset-fed é realizado através do cálculo das dimensões de $W_{p}$ e $L_{p}$ (largura e o comprimento da plaqueta, respectivamente); $W_{f}$ e $L_{f}$ (largura e comprimento da linha de microfita, respectivamente); $x_{0}$ e $y_{0}$ (parâmetros da reentrância) para um determinado substrato dielétrico com espessura $h$ com constante dielétrica $\varepsilon_{r}$.

\footnotetext{
${ }^{22}$ Vale ressaltar que uma antena, ao ser modelada como cavidade ressonante, possibilita sua aplicação através da técnica da perturbação da cavidade ressonante, tal como apresentado nos métodos de caracterização eletromagnética de materiais.
} 
Figura 3.2 - Estrutura e dimensões de uma antena de microfita com plaqueta retangular e alimentação indentada.

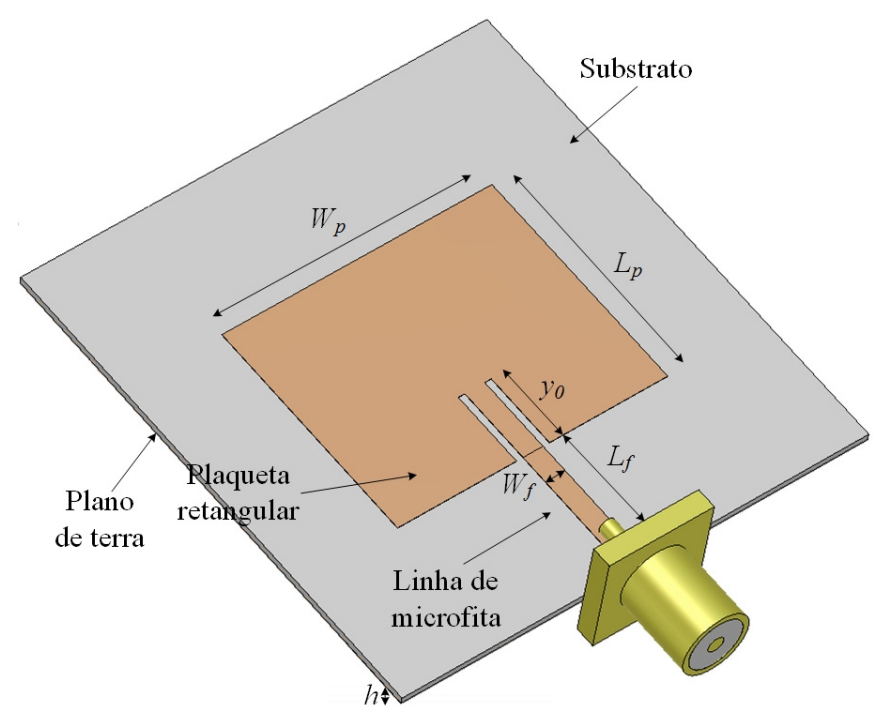

Fonte: Adaptado de (SEKO, 2013).

Várias aproximações analíticas podem ser feitas para modelar o projeto de uma antena de microfita (BALANIS, 1997) (KUMAR, 2003). Em específico, pode-se utilizar a formulação obtida através do modelo de linha de transmissão (Transmission-Line Model), no qual as dimensões da antena são calculadas através das equações 3.1 a 3.5. Sendo, inicialmente, o valor de $W_{p}$ calculado com o objetivo de obter um radiador eficiente.

$$
W_{p}=\frac{c}{2 f_{r}} \sqrt{\frac{2}{\varepsilon_{r}+1}}
$$

no qual, $f_{r}$ é a frequência de ressonância da antena de microfita com plaqueta retangular e $\varepsilon_{r}$ é a constante dielétrica do substrato.

Para considerar a combinação das características eletromagnéticas do substrato e do ar, além dos efeitos de franjamento do campo eletromagnético (fringing fields), relativos à deformação dos campos nas bordas da plaqueta, deve-se calcular o valor da 
permissividade elétrica efetiva. Esse valor é calculado com base na permissividade elétrica do dielétrico e na geometria da microfita. Para a condição em que $W_{p} / h>1 \mathrm{o}$ valor da permissividade elétrica efetiva é obtido pela equação 3.2 .

$$
\varepsilon_{e f f}=\frac{\varepsilon_{r}+1}{2}+\frac{\varepsilon_{r}-1}{2} \frac{1}{\sqrt{1+12 h / W_{p}}}
$$

Devido ao efeito de franjamento do campo eletromagnético, o comprimento da plaqueta é maior do que seu comprimento físico. Esse fenômeno é representado pela extensão da plaqueta $\Delta L$, que é função de $\varepsilon_{e f f}$ e da relação entre a largura da plaqueta e a espessura do substrato $(W p / h)$ dada pela equação 3.3 .

$$
\Delta L=h(0,412) \frac{\left(\varepsilon_{e f f}+0,3\right)\left(W_{p} / h+0,264\right)}{\left(\varepsilon_{e f f}-0,258\right)(h+0,8)}
$$

O valor do comprimento físico da plaqueta, considerando o efeito de franjamento pode ser calculado pela equação 3.4 .

$$
L_{p}=\frac{c}{2 f_{r} \sqrt{\varepsilon_{e f f}}}-2 \Delta L
$$

A distância do ponto de inserção da alimentação da plaqueta em relação a sua borda $\left(y_{0}\right)$ para casar a impedância da linha com o elemento radiante é aproximado através das equações 3.5, 3.6 e 3.7 (RAMESH, 2003) (BALANIS, 1997): 


$$
\begin{aligned}
R_{i n}\left(y=y_{0}\right) & =R_{i n}(y=0) \cos ^{2}\left(\frac{\pi}{L_{p}} y_{0}\right) \\
& =\frac{1}{2\left(G_{1} \pm G_{12}\right)} \cos ^{2}\left(\frac{\pi}{L_{p}} y_{0}\right)
\end{aligned}
$$

no qual $R_{\text {in }}(y=0)$ é a impedância de entrada na extremidade do elemento radiador e $R_{\text {in }}\left(y=y_{0}\right)$ é a impedância à distância $y_{0}$ da borda da plaqueta, no centro da largura da mesma. Projeta-se $y_{0}$ de modo a determinar uma impedância de entrada desejada igual a $R_{\text {in }}=50 \Omega$. Os valores $G_{1}$, condutância na abertura radiante, e $G_{12}$, condutância mútua entre as fendas de radiação, são obtidos através das equações 3.6 e 3.7 (DERNERYD, 1978).

$$
\begin{gathered}
G_{1}=\frac{1}{120 \pi^{2}} \int_{0}^{\pi}\left[\frac{\operatorname{sen}\left(\frac{k_{0} W_{p}}{2} \cos \theta\right)}{\cos \theta}\right]^{2} \operatorname{sen}^{3} \theta \cdot d \theta \\
G_{12}=\frac{1}{120 \pi^{2}} \int_{0}^{\pi}\left[\frac{\operatorname{sen}\left(\frac{k_{0} W_{p}}{2} \cos \theta\right)}{\cos \theta}\right]^{2} \mathrm{~J}_{0}\left(k_{0} L_{p} \operatorname{sen} \theta\right) \operatorname{sen}^{3} \theta \cdot d \theta,
\end{gathered}
$$

sendo $J_{0}$ a função de Bessel de primeira ordem e $k_{0}$ o número de onda no espaço livre. Por último, para o cálculo da linha de microfita com impedância de $50 \Omega$, utiliza-se a equação 3.8, fórmula de síntese, que calcula o valor de $W_{f}$, tal como apresentado na Figura 3.2. 


$$
\frac{W_{f}}{h}=\left\{\begin{array}{l}
\frac{8 \cdot e^{A}}{e^{2 A}-2}, \operatorname{para} \frac{W_{f}}{h} \leq 2 \\
\frac{2}{\pi} \cdot\left[B-1-\ln (2 B-1)+\frac{\varepsilon_{r}-1}{2 \varepsilon_{r}}\left\{\ln (B-1)+0,39-\frac{0,61}{\varepsilon_{r}}\right\}\right], \text { para } \frac{W_{f}}{h}>2
\end{array}\right.
$$

no qual A e B são dados pelas equações apresentadas em 3.9.

$$
\begin{gathered}
A=\frac{Z_{0}}{60} \cdot \sqrt{\frac{\varepsilon_{r}+1}{2}}+\frac{\varepsilon_{r}-1}{\varepsilon_{r}+1} \cdot\left(0,23+\frac{0,11}{\varepsilon_{r}}\right) \\
B=\frac{377 \pi}{2 Z_{0} \sqrt{\varepsilon_{r}}}
\end{gathered}
$$

Ressalta-se que existem softwares que já realizam o cálculo da largura de uma linha de microfita. Exemplos como o Advanced Design System (ADS) através de sua ferramenta LineCalc e do CST Studio, através de seus macros.

\subsection{Guias de ondas integrados ao substrato (SIW)}

Guia de ondas são dispositivos amplamente utilizados nas frequências de micro-ondas devido à sua baixa dissipação de potência e elevado índice de mérito. Contudo possuem alto custo de fabricação e sua integração com outras tecnologias, como é o caso de circuitos planares, depende de transições complexas.

Como alternativa para esses problemas foram propostas estruturas planares que possuem as características similares às de guias de ondas em circuitos planares. Essa tecnologia foi denominada como guia de ondas integrado ao substrato (SIW) (DESLANDES; WU, 2001). Nela, as estruturas são fabricadas diretamente no substrato de baixas perdas. As paredes laterais dos guias de ondas retangulares são realizadas através de furos periódicos metalizados. Dessa forma, confina-se a onda eletromagnética (EM) no substrato, tal como uma estrutura de guia de ondas. A Figura 3.3 apresenta esquematicamente a topologia de um guia em SIW. 
Distintos componentes SIW passivos e ativos foram desenvolvidos, incluindo guias de ondas, ressoadores, filtros, antenas, amplificadores, divisores e combinadores de potência, acopladores e osciladores (CHEN; WU, 2014) (XU; WU, 2005) (DESLANDES; WU, 2001). Dentre as vantagens dessas aplicações estão o baixo custo, a redução de tamanho e a repetitividade de construção de leiautes.

Figura 3.3 - Topologia básica de um guia de ondas em SIW e sua equivalência com um guia de ondas retangular.

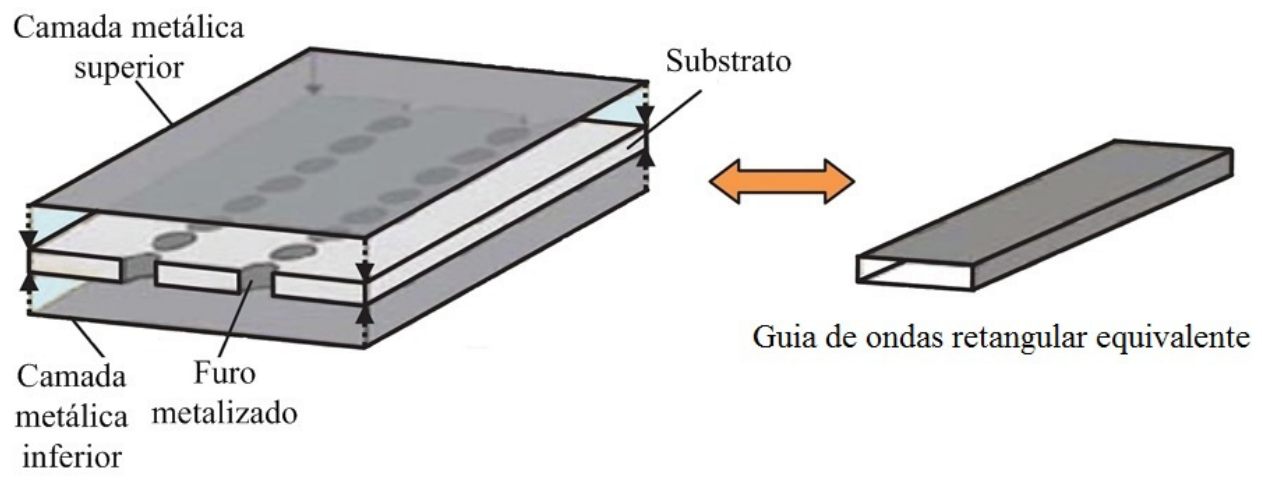

Fonte: Adaptado de (CHEN; WU, 2014).

Uma característica fundamental da tecnologia SIW é a não propagação de fluxo de corrente longitudinal. Dessa forma, o SIW suporta exclusivamente a propagação do modo transversal elétrico (TE) (ver APÊNDICE C ${ }^{23}$ ). Para o modo TE10, o SIW tornase equivalente a um guia de ondas retangular. Com isso, pode-se calcular a frequência de corte através da dimensão de sua seção transversal.

Para os circuitos desenvolvidos com a tecnologia SIW é necessário considerar as perdas no dielétrico e nos condutores, posto que as perdas por radiação e indução eletromagnética decorrentes de radiações externas são praticamente desprezíveis, uma

23 O Apêndice C apresenta uma revisão bibliográfica dos conceitos de propagação de ondas eletromagnéticas, bem como de guias de ondas retangulares, suas características e modos de propagação. 
vez que a onda está praticamente confinada no interior do guia. Vale ressaltar que as perdas afetam o índice de mérito $(Q)$ dos guias de ondas.

Nesse sentido, outra característica importante da tecnologia SIW é seu índice de mérito relativamente maior do que outros circuitos projetados com linhas de transmissão planares.

A Figura 3.4 apresenta a tecnologia SIW em comparação com outras tecnologias, como é o caso da linha de transmissão em microfita, ressoador dielétrico e guia de ondas. Nota-se que a tecnologia SIW é uma solução intermediária entre os requisitos custo, tamanho e perdas, sendo uma tecnologia planar com elevado índice de mérito, o que permite um melhor desempenho no desenvolvimento de cavidades ressonantes.

Figura 3.4 - Comparação entre as diferentes tecnologias de ressoadores em RF quanto a custo, tamanho e perdas.

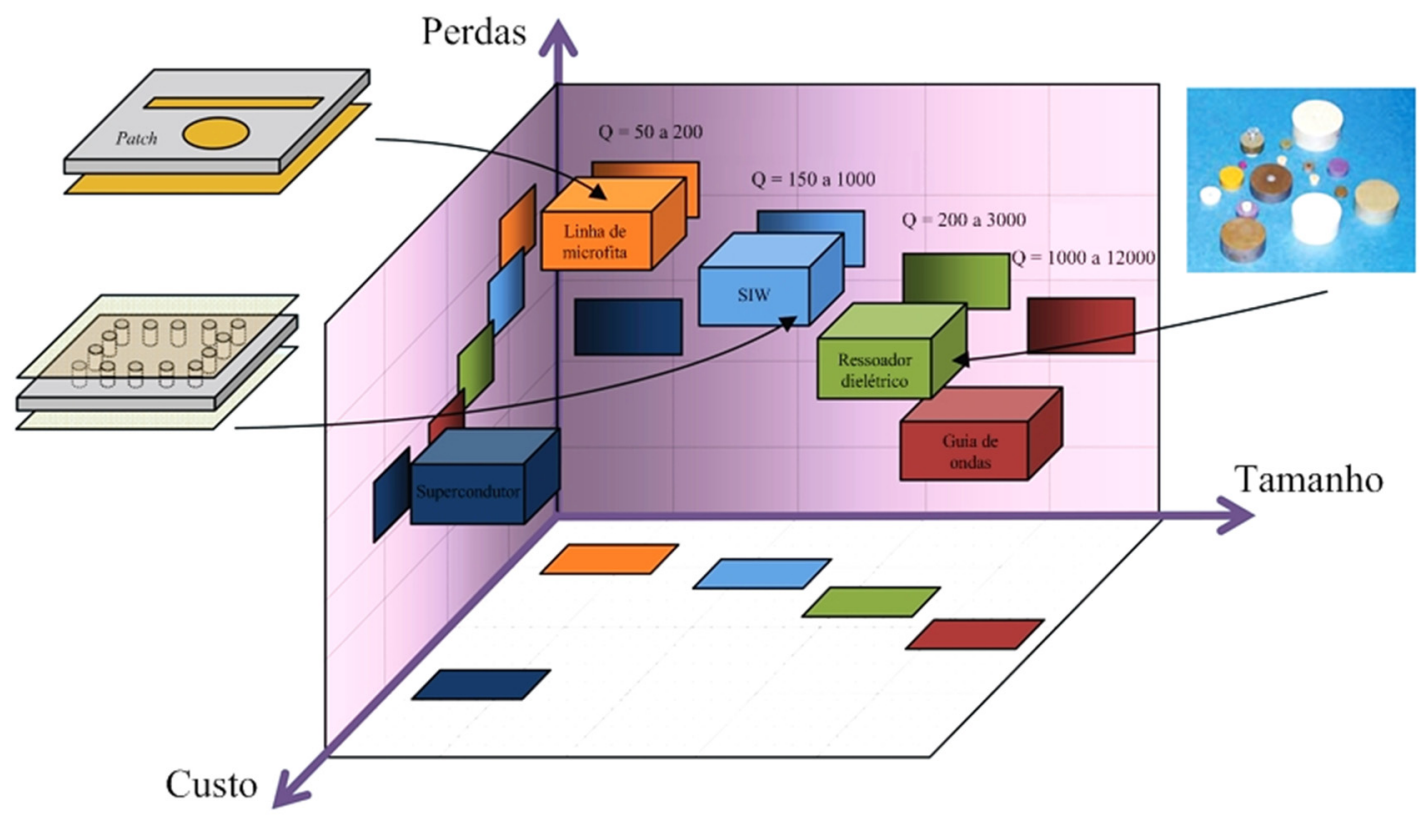

Fonte: Adaptado de (CHEN; WU, 2014). 


\subsection{Projeto de um guia de ondas em SIW}

Como apresentado anteriormente, a geometria do SIW não possibilita o fluxo de corrente longitudinal, portanto os modos TM não se propagam, restando somente aos modos $\mathrm{TE}^{24}$. Assim como ocorre nos guias de ondas retangulares, os guias SIW são projetados para operar no modo TE10, que é o modo fundamental de propagação. Para tanto, limita-se a frequência superior da faixa superior do guia, de modo a evitar o surgimento de modos de propagação superiores.

Conforme apresentado por Wu e Kishk (2010), o procedimento para projeto de um guia de ondas em SIW, inicia-se pela frequência de corte do guia com objetivo de determinar suas dimensões geométricas. De maneira análoga a um guia de ondas retangular convencional, calcula-se a maior dimensão da seção transversal do guia a partir da frequência de corte do modo fundamental. No caso do SIW, tal como em um guia de ondas retangular (Figura 3.5), o valor de $a_{\text {eff }}$ define a frequência de corte do guia. Esse valor efetivo considera a distância $a$, o diâmetro dos postes metálicos $d$ e o espaçamento periódico entre postes metálicos $p$. A equação 3.10 apresenta a frequência de corte do SIW para os modos TEmo, no qual $m$ é um número inteiro que corresponde ao modo de propagação.

Figura 3.5 - Dimensões de um guia SIW genérico, levando em consideração seus valores efetivos e casamento de impedância através de taper.

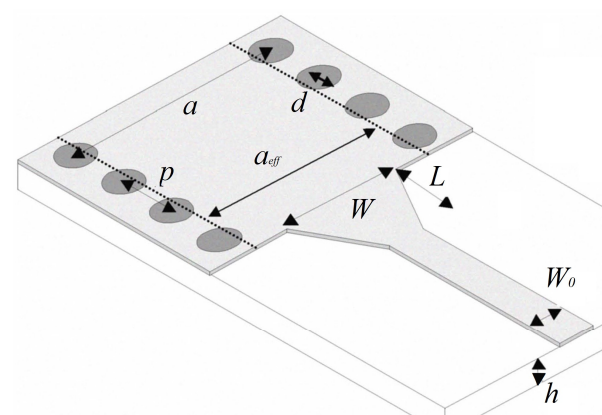

Fonte: Adaptado de (DESLANDES, 2001).

\footnotetext{
${ }^{24}$ Vale ressaltar que em guias de ondas retangulares os modos TE e TM estão presentes, conforme apresentado no (APÊNDICE B)
} 


$$
f_{c_{m_{0}}}=\frac{1}{2 \sqrt{\mu \varepsilon}}\left(\frac{m}{a_{e f f_{m 0}}}\right)
$$

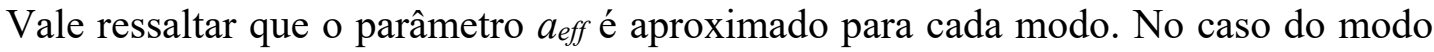
TE10, as equações 3.11 e 3.12 podem ser utilizadas, sendo que a segunda garante melhor aproximação para o parâmetro (CASSIVI et al., 2002) (BOZZI et al., 2007) (CALEFFO, 2016).

$$
\begin{aligned}
& a_{e f f_{10}}=a-\frac{d^{2}}{0,95 p} \\
& a_{e f f_{10}}=a-1,08 \frac{d^{2}}{p}+0,1 \frac{d^{2}}{a}
\end{aligned}
$$

Já para o modo $\mathrm{TE}_{20}$ a largura efetiva é descrita pela equação 3.13 (CASSIVI et al., 2002). A faixa de operação recomendada para a operação do guia SIW pode ser definida como $1,25 f_{c_{T E_{10}}} \leq f \leq 0,95 f_{c_{T E_{20}}}$.

$$
a_{e f f_{20}}=a-\frac{d^{2}}{1,1 p}-\frac{d^{3}}{6,6 p^{2}}
$$

Os valores de $d$ e $p$, devem ser escolhidos a partir das condições dadas pelas inequações 3.14 a 3.15 (BOZZI et al., 2007).

$$
\begin{gathered}
p>d \\
0,05<\frac{p}{\lambda_{c}}<0,25,
\end{gathered}
$$


no qual, $\lambda_{c}$ representa o comprimento de onda guiado, na frequência de corte do modo fundamental. Cada condição possui um significado físico. A equação 3.14 determina que a distância entre os postes metálicos deve ser superior ao diâmetro desses furos, caso contrário haveria sobreposição de furos. Já a equação 3.15, fundamental para análise, apresenta a condição para que seja calculada a distância entre postes, sem que haja os efeitos de electronic bandgap que geram faixas de rejeição na banda de operação do modo. O valor limite para o número de postes metalizados por comprimento de onda deve ser inferior a 20 para não fragilizar o substrato.

Outro parâmetro é a perda devido ao vazamento da onda eletromagnética pelos espaços entre os postes condutores. A equação 3.16 apresenta a condição para que essa perda possa ser desconsiderada.

$$
\frac{\alpha_{S I W}}{k_{0}}<10^{-4},
$$

no qual $\alpha$ SIW são as perdas totais no SIW e $k_{0}$ é o número de onda no espaço livre.

Todos os critérios são resumidos através da Figura 3.6, que apresenta as condições para desenvolvimento de uma estrutura SIW a partir das condições de $p / \lambda_{c}$ e $d / \lambda_{c}$. Na região de interesse o SIW se comportará tal como um guia de ondas retangular, pois ambas as tecnologias possuem propriedades de dispersão equivalentes.

Para o SIW, deve-se considerar as perdas dielétricas do substrato, dado que estas afetam a propagação da onda eletromagnética. Para o guia de ondas retangular, essas perdas podem ser desconsideradas pois o meio dielétrico é, usualmente, o $\operatorname{ar}^{25}$. A constante de propagação, $\gamma$ SIW, do guia em SIW é dada através de uma parte real, descrita pelas perdas totais e uma parte imaginária relacionada a constante de fase, $\beta$.

\footnotetext{
${ }^{25}$ Costuma-se considerar a tangente de perdas do ar igual a zero. Já para substratos construídos com Teflon ${ }^{\circledR}$, podem ser assumidos valores de tangente de perdas de, aproximadamente, 0,001 .
} 
Figura 3.6 - Condições para desenvolvimento de uma estrutura SIW.

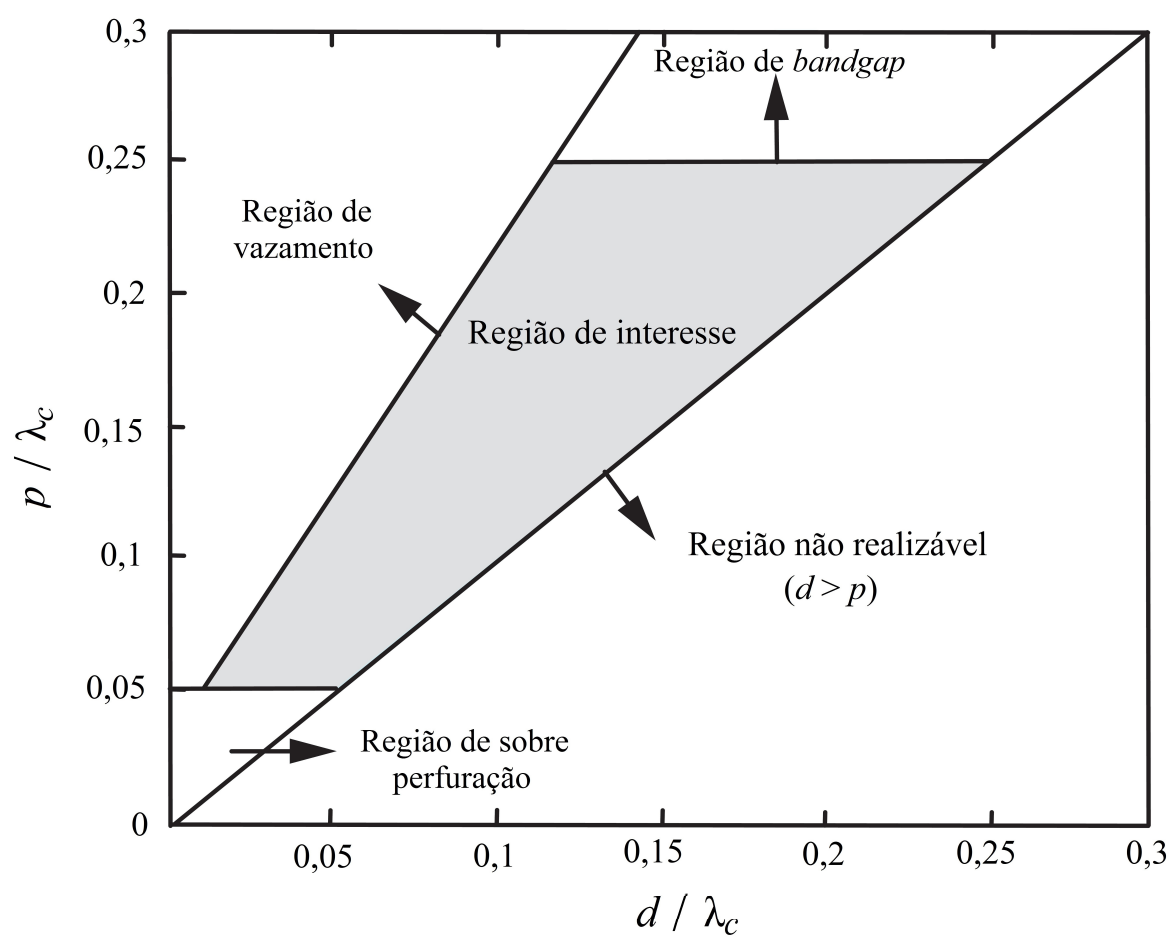

Fonte: Adaptado de (CHEN; WU, 2014).

A equação 3.17 descreve a relação entre esses parâmetros.

$$
\gamma_{S I W}=\alpha_{S I W}+j \beta
$$

As perdas totais são descritas por três componentes: $\alpha_{l}, \alpha_{d}$ e $\alpha_{c}$, respectivamente, perdas por vazamento, perdas no dielétrico e perdas no condutor.

A constante de fase, representado na equação 3.18, assemelha-se à utilizada para modos TE $E_{m 0}$ em um guia de ondas retangular, com diferença na dimensão $a_{e f f}$ ao invés da maior largura da seção transversal.

$$
\beta=\sqrt{k^{2}-\left(\frac{m \pi}{a_{e f f}}\right)^{2}}
$$


Como as perdas de um guia de ondas SIW são maiores do que a de um guia de ondas retangular, seu índice de mérito tende a ser menor. Contudo, um guia de ondas SIW possui índice de mérito maior do que outros circuitos planares, tal como apresentado na Figura 3.4.

\subsubsection{Integração à tecnologia planar: transições entre a tecnologia SIW e circuitos planares}

Atualmente, são propostas três estruturas de transição entre circuitos SIW e circuitos planares, em específico, microlinhas de transmissão (BOZZI et al., 2011). A Figura 3.7 apresenta, esquematicamente, esses métodos. Na Figura 3.7 (a) é detalhado o método mais simples realizado por meio de uma linha taper ou cônica. Essa linha tem como objetivo casar a impedância do guia de ondas, com a microlinha de transmissão (usualmente linha de $50 \Omega$ ). Por sua simplicidade esse método é utilizado no projeto de guias. Por sua vez, a Figura 3.7 (b) apresenta uma transição através de um guia de onda coplanar com plano terra e extremidade aterrada. Nessa estrutura o fluxo de corrente gera um campo magnético no interior do guia de ondas SIW.

Figura 3.7 - Transições entre a estrutura SIW e circuitos planares: (a) linha taper, (b) guia de onda coplanar com plano terra e extremidade aterrada e (c) guia de onda coplanar com plano terra com cavidade interna ao SIW.

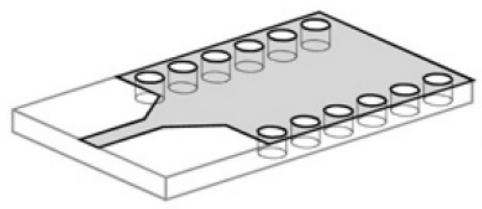

(a)

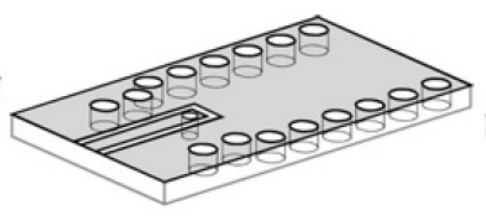

(b)

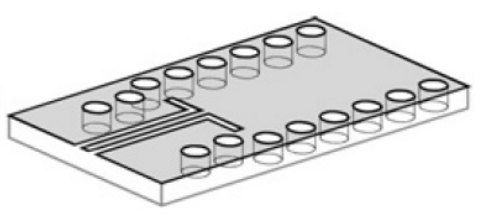

(c)

Fonte: Adaptado de (BOZZI et al., 2011).

A Figura 3.7 (c) descreve outra estrutura de guia de onda coplanar com plano terra, terminada por fendas no interior do guia SIW. Tal topologia atua como sonda de tensão, excitando o campo elétrico dentro do guia de ondas. 
Em específico, as transições realizadas por taper permitem o casamento de impedância da linha de microfita com o guia de ondas por meio de uma largura variável com o comprimento da linha. Uma expressão analítica proposta para modelar as dimensões do taper é apresentada na equação 3.19 , que permite obter o valor de $W$, relativo à largura do taper. A equação 3.20 apresenta os critérios para cálculo do comprimento $L$ do taper, usualmente ajustado para múltiplos de $\lambda / 4$ da frequência central (NAWAZ; HUILING, 2014).

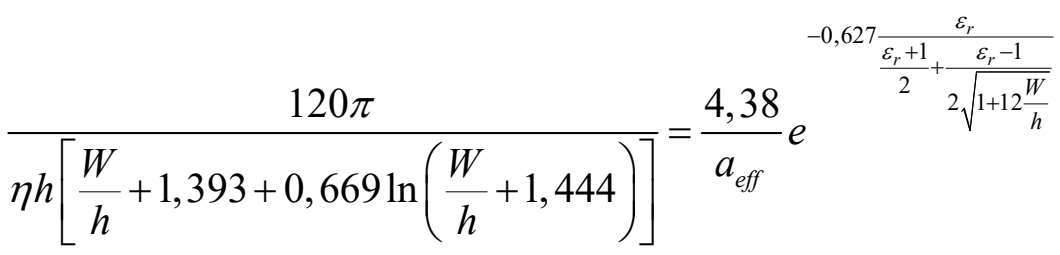

$$
\begin{aligned}
& L=\frac{n \lambda_{c}}{4}, n=1,2,3,4 \ldots
\end{aligned}
$$

no qual $W, L, h$, e $a_{e f f}$ correspondem à Figura 3.5. O parâmetro $\eta$ é a impedância intrínseca do meio dielétrico.

Após o cálculo inicial, $W$ e $L$ são otimizados usando simulação eletromagnética, de modo a melhorar o casamento de impedância entre o SIW e a linha de microfita.

\subsection{Antena com cavidade ressonante em SIW}

Como demonstrado no capítulo 2, uma das técnicas para caracterização da permissividade elétrica complexa em materiais é realizada através de cavidades ressonantes. A amostra sob teste, com caráter dielétrico, é alocada na posição com máximo campo elétrico, provocando uma pequena perturbação que se reflete na frequência de ressonância e no índice de mérito de acordo com as propriedades da amostra. 
Através da tecnologia SIW é possível construir estruturas ressonantes com baixo custo, alto índice de mérito e excelente sensibilidade. Comprovando sua funcionalidade, alguns trabalhos apresentam o uso dessa tecnologia (LOBATO-MORALES et al., 2010) para a caracterização de matérias sólidos, como teflon, acrílico, nylon, madeira e quartzo.

O projeto de uma antena com cavidade ressonante em SIW pode ser realizado através de diferentes estruturas. A Figura 3.8 (a) apresenta uma cavidade ressonante de uma porta, já a Figura 3.8 (b) apresenta uma cavidade ressonante com duas portas, tipicamente utilizada para o projeto de osciladores, a Figura 3.8 (c) apresenta uma antena com fenda no plano terra, e a Figura 3.8 (d) descreve uma antena com cavidade com fenda no plano radiador.

Figura 3.8 - Cavidades e antenas SIW. (a) cavidade ressonante com uma porta (b) cavidade ressonante com duas portas, (c) antena com fenda no plano terra e (d) antena com fenda no plano radiador.

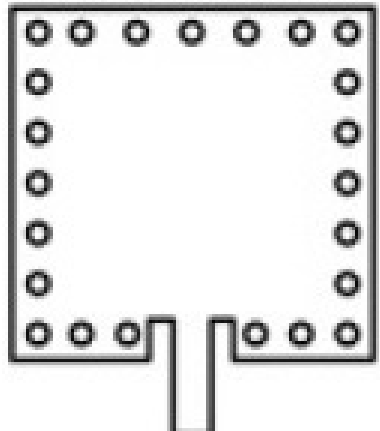

(a)

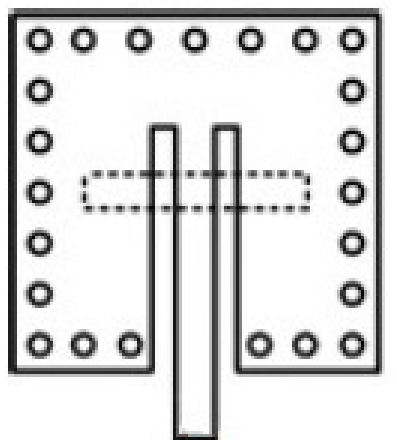

(c)

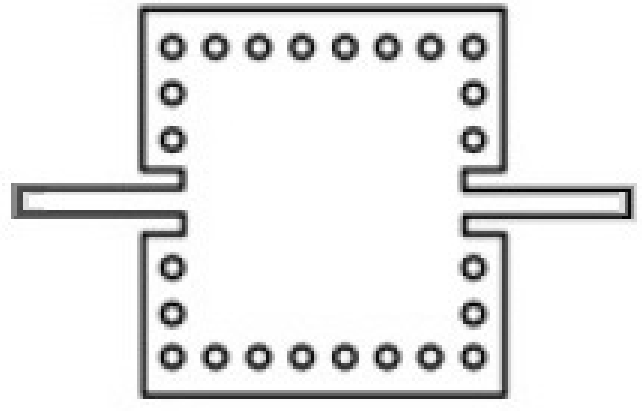

(b)

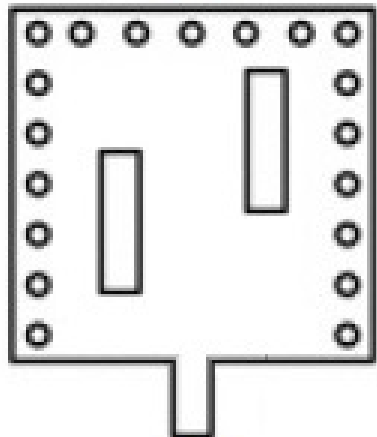

(d)

Fonte: Adaptado de (BOZZI et al., 2011). 
A fenda da antena SIW funciona com elemento radiante (MORO et al., 2012). Nela há um campo elétrico transverso à fenda, o que faz com que a energia possa se irradiar pelo espaço através dessa fenda (BOHORQUEZ et al., 2009). O principal uso de antenas com fenda traseira se dá em arranjo de antenas com controle de fase (phased arrays antennas) devido à sua propagação unidirecional e ao baixo acoplamento mútuo entre seus elementos.

A cavidade ressonante SIW apresentada na Figura 3.8 (a) opera nos modos TEm0n, cujas frequências de ressonância obedecem a equação 3.21 .

$$
f_{r}=\frac{c}{2 \sqrt{\varepsilon_{r} \mu_{r}}} \sqrt{\left(\frac{m}{a_{\text {eff }}}\right)^{2}+\left(\frac{n}{b_{\text {eff }}}\right)^{2}},
$$

no qual $a_{e f f}$, como demonstrado anteriormente, é a largura efetiva e $b_{\text {eff }}$ é o comprimento efetivo, $m$ e $n$ correspondem ao modo ressonante e $f_{r}$ é a respectiva frequência de ressonância da cavidade. Para o primeiro modo de operação, o valor de

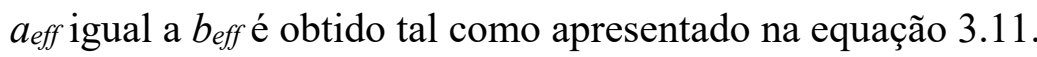

\subsection{Materiais nanoestruturados: nanotubos de carbono}

Desde sua proposta (IJIMA, 1991), os nanotubos de carbono - CNTs, têm sido estudados em diversas áreas do meio científico, dentre elas a física, a química e a engenharia de materiais. Devido às suas propriedades estruturais, mecânicas e elétricas, esses materiais proporcionaram avanços em nanotecnologia. Dentre suas potencialidades, as pesquisas com nanotubos de carbono já exploraram suas propriedades de supercondutividade (TANG et al., 2001) e supercapacitância (AN et al., 2001) e como dispositivos de emissão de campo (DE HEER et al., 1995) e dispositivos nanoeletrônicos (TANS et al., 1998).

CNTs são compostos por átomos de carbono ligados entre si, cuja estrutura tem perfil tubular (cilíndrico) e seu comprimento pode variar de unidades até centenas de micrômetros. A classificação típica desse material nanoestruturado é dada de acordo 
com o número de paredes: nanotubos de carbono de parede única, Single Walled Carbon Nanotubes (SWNTs), ou nanotubos de carbono de paredes múltiplas (multiparedes), Multi Walled Carbon Nanotubes (MWNTs), conforme Figura 3.9.

Figura 3.9 - Representação esquemática dos SWCNT e MWCNT.
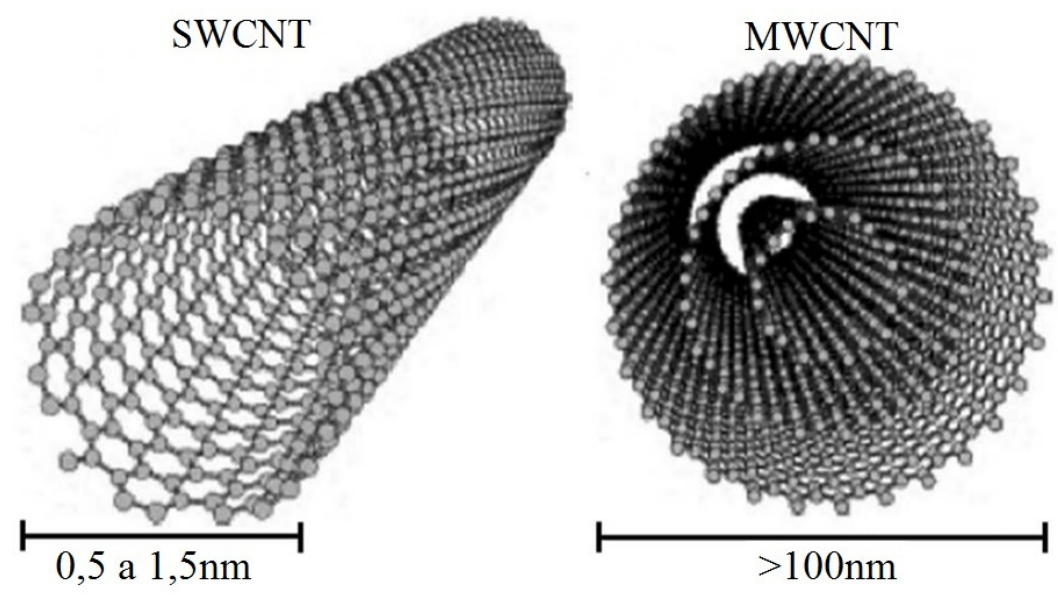

Fonte: Adaptado de (ZARBIN, 2007).

Da Figura 3.9, nota-se que o SWCNT é formado por um único enrolamento da folha de grafeno $^{26}$, enquanto que o MWCNT é composto por vários tubos concêntricos dessas mesmas folhas. As dimensões típicas dos SWCNTs são dadas por diâmetros entre 0,5 a 1,5 nm e comprimentos maiores do que $100 \mathrm{~nm}$ até dezenas de micrômetros (BONARD et al., 2001). Já os MWCNTs têm diâmetros em torno de $100 \mathrm{~nm} \mathrm{e}$ comprimentos entre 0,1 e $50 \mu \mathrm{m}$ (IIJIMA; ICHIHASHI, 1993) (JOURNET et al., 1997). Tal variação implica em diferenças de propriedades.

As propriedades dos nanotubos dependem do seu arranjo atômico, do diâmetro, do comprimento do tubo, da simetria e de sua morfologia. Tais propriedades influenciam nas características elétricas dos CNTs. As estruturas dos CNTs podem ser: ziguezague, poltrona (armchair) e quiral. Em relação às características elétricas, os CNTs são

\footnotetext{
${ }^{26} \mathrm{O}$ grafeno consiste em uma folha plana de átomos de carbono com ligação do tipo sp2 e com espessura de apenas um átomo, reunidos em uma estrutura cristalina hexagonal.
} 
divididos, preferencialmente, em: CNTs metálicos; CNTs semicondutores e CNTs mistos. A classe de CNTs do tipo ziguezague e quiral podem apresentar propriedades metálicas ou de semicondutor, de acordo com o diâmetro da sua estrutura. Já a classe do tipo armchair apresenta características elétricas de um material metálico à temperatura ambiente (SAITO et al., 1992).

As principais propriedades dos CNTs são: capacidade de condução de altos níveis de corrente elétrica (BANDARU, 2007), baixa reatividade, elevada condutividade térmica $^{27}$ e elevada resistência mecânica ${ }^{28}$. Além disso, os CNTs, devido à sua morfologia, apresentam alta polarizabilidade. Nesse sentido, dada uma matriz não orientada, ao se aplicar um potencial externo, origina-se um momento de dipolo orientado ao longo do eixo central dos CNTs.

Para o uso como elemento sensor, as propriedades específicas dos CNTs são: suporte de alta densidade de corrente elétrica, alta condutividade elétrica ${ }^{29}$ e elevada área ativa. Devido a essa última característica, as paredes laterais do CNT e as regiões próximas às ligações incompletas das extremidades atuam como regiões ativas, as quais ocorrem as reações de adsorção e absorção de átomos e moléculas gasosas. Dessa forma, garante-se o uso de CNTs no desenvolvimento de novos dispositivos de sensoriamento de gases (BAUGHMAM et al., 2002).

\subsubsection{Processos de obtenção de materiais nanoestruturados}

Os CNTs podem ser obtidos através de diferentes métodos, dentre eles: descarga de arco, ablação à laser e CVD (Chemical Vapor Deposition). Os CNTs podem ser

\footnotetext{
${ }^{27}$ Para um CNT de parede única metálico de 2,6 $\mu \mathrm{m}$ de comprimento e 1,7 nm de diâmetro, uma medida empírica de condutividade térmica é de $3500 \mathrm{Wm}^{-1} \mathrm{~K}^{-1}$ (AMORIM, 2009).

${ }^{28} \mathrm{O}$ módulo de Young para um CNT multiparede de diâmetro 32,9 nm é de 1,26 TPa, grandeza semelhante a encontrada no diamante de 1,22 TPa (AMORIM, 2009).

${ }^{29}$ Para os CNTs metálicos sua resistividade está na ordem de $10^{-6} \Omega . \mathrm{cm}$ à temperatura ambiente, valor igual ou menor do que os metais de mais baixa resistividade como a prata ( $\rho_{\text {prata }}=1,47 \times 10^{-6} \Omega$.cm), o cobre $\left(\rho_{\text {cobre }}=1,72 \times 10^{-6} \Omega . \mathrm{cm}\right)$ e o alumínio ( $\left.\rho_{\text {alumínio }}=2,75 \times 10^{-6} \Omega . \mathrm{cm}\right)($ AMORIM, 2009).
} 
funcionalizados por meio de interações químicas e físicas. Em outras palavras, é possível adicionar ou extrair diferentes átomos ou grupos funcionais na sua estrutura, tornando-o mais eficiente em suas aplicações mecânicas, físicas ou químicas.

\subsubsection{Processos de adsorção e dessorção em materiais nanoestruturados}

Como apresentado anteriormente, por possuírem elevada área ativa, os CNTs podem realizar processos de absorção e adsorção nas suas ligações incompletas, originando estados de energia de superfície e/ou algum tipo de ligação química.

Adsorção é o fenômeno de ligação entre átomos, íons ou moléculas na superfície de um determinado material. O processo inverso, no qual ocorrem quebras das ligações entre partículas e moléculas em uma determinada superfície é denominado dessorção. A ligação pode ter diferentes graus de estabilidade e energia. Essas características variam conforme o tamanho das espécies (átomos e íons) envolvidos, eletronegatividade, entre outros (JANATA, 2009) (SPICHIGER-KELLER, 1998) (DIAMOND, 1998).

Por isso os processos de adsorção são comumente classificados em: fisissorção (adsorção física) para processos que envolvem ligações fracas, como as forças de van der Waals; ou quimissorção para descrever processos de adsorção que envolvem ligações covalentes, que sabidamente são mais fortes e estáveis do que a ligação anteriormente apresentada (JANATA, 2009).

No caso dos CNTs depositados sobre dispositivos de micro-ondas, os processos de adsorção e dessorção de partículas e moléculas gasosas possibilitam a transferência de cargas entre o vapor do ambiente e os materiais (MARLIERE et al., 1999). Para tanto, a molécula de gás tende a reagir com a superfície de maneira gradativa, até que, finalmente, seja adsorvida. Esse tipo de adsorção pode ser facilmente desfeito, restabelecendo assim, a condição inicial do sensor. Essa transferência altera os parâmetros de condutividade elétrica e permissividade elétrica do material nanoestruturado, afetando assim os parâmetros do sensor de micro-ondas (SNOW et al., 2006) (SNOW et al., 2005) (KONG et al., 2000) (COLLINS et al., 2000). 


\subsubsection{Técnicas para deposição de materiais nanoestruturados}

A deposição de materiais nanoestruturados sobre substratos pode ocorrer de diferentes maneiras: gotejamento (casting), eletroforese, dieletroforese, deposição química a vapor (CVD), entre outras. Cada uma delas possui suas restrições e especificidades na fabricação de sensores (MORRIS; INIEWSKI, 2013).

$\mathrm{Na}$ técnica de gotejamento, utiliza-se o material nanoestruturado disperso em uma solução líquida (água deionizada ou etanol anidro), usualmente volátil e quimicamente inerte. A solução é gotejada sobre a superfície do substrato utilizando uma seringa. Ao final do processo, o solvente é evaporado, restando assim, somente um filme de material nanoestruturado sobre a superfície do substrato. Para acelerar o processo, pode-se aumentar a temperatura ou deixar a amostra em ambiente de vácuo. Essa técnica é simples e de baixo custo. Contudo é difícil controlar a espessura e a região do substrato no qual é depositado o material nanoestruturado (HASHIM et al., 2015).

A eletroforese é uma técnica de deposição baseada na força de atração entre uma partícula eletricamente carregada e sua carga oposta (MORRIS; INIEWSKI, 2013). Essa técnica garante homogeneidade e elevada densidade do material presente no substrato. Para realizar a deposição por eletroforese, a suspensão preparada com material nanoestruturado é funcionalizada e inserida em um recipiente (BOCCACCINI et al., 2006). Nesta suspensão são mergulhados dois eletrodos metálicos, sendo um desses eletrodos a própria estrutura do sensor no qual será depositado o filme de material nanoestruturado, e o outro o contra eletrodo. Entre esses eletrodos é aplicado um campo elétrico constante. Dessa forma, o material nanoestruturado é atraído para o eletrodo de interesse através de forças eletroforéticas e suas partículas são depositadas na superfície através das forças de van der Waals.

O método de dieletroforese ocorre devido à força que atua sobre uma partícula polarizável, quando imersa em solução adequada e submetida a um campo elétrico desuniforme e variável. Por meio desse campo, os CNTs tendem a se mover e serem depositados de acordo com seu dipolo devido à força dieletroforética (BOCCACCINI et al., 2006).

Por último, a deposição química a vapor (CVD) é realizada através do crescimento orientado do material nanoestruturado sobre substrato com material catalisador 
(KUMAR; ANDO, 2010). Através do CVD é possível obter um filme homogêneo e com alta densidade de material nanoestruturado. Esse método depende de um reator operando à pressão ambiente e temperaturas entre $600^{\circ} \mathrm{C}$ e $1200^{\circ} \mathrm{C}$, tendo um fluxo controlado de gás fonte de carbono, em geral, gases de hidrocarbonetos $\left(\mathrm{CH}_{4}, \mathrm{C}_{2} \mathrm{H}_{2} \mathrm{e}\right.$ $\left.\mathrm{C}_{2} \mathrm{H}_{4}\right)$.

A espessura do filme pode ser controlada de acordo com o tempo de exposição. Embora alinhado e controlado, o processo CVD adiciona impurezas, em larga medida devido à presença das partículas catalisadoras e dos subprodutos das reações.

\subsection{Desenvolvimento de sensores para caracterização da fase vapor de etanol combustível}

A Figura 3.1, já descrita, apresenta um diagrama de blocos dos sensores desenvolvidos para caracterização de álcool combustível. Nele são descritos uma antena de microfita e uma antena com cavidade ressonante empregando tecnologia SIW em 5,8 GHz. Essa frequência foi escolhida devido às dimensões reduzidas para aplicação dos materiais nanoestruturados e por ser liberada ${ }^{30}$ para uso, pois se trata de uma das bandas ISM (Industrial, Scientific and Medical).

Além disso, ao analisar o valor da permissividade elétrica complexa do álcool combustível, verifica-se que, embora não seja a frequência com maior passo de variação de $\varepsilon_{r}^{\prime}$ e $\varepsilon_{r}$ " em relação às frações de etanol em água, há um compromisso entre esse parâmetro e o tamanho dos sensores. Dessa forma a escolha de uma frequência intermediária permite o desenvolvimento de sensores pequenos para a análise de adulteração de álcool combustível. Ressalta-se que todos os testes e caracterizações foram realizados à temperatura ambiente de $25^{\circ} \mathrm{C}$.

Todos os sensores foram desenvolvidos com o substrato RT Duroid ${ }^{\circledR} 5880$, da Rogers Corporation. Embora esse material tenha maior custo, laminados de alta frequência possuem baixa absorção de umidade. A exemplo do RT Duroid®, no

\footnotetext{
${ }^{30}$ No Brasil, o espectro eletromagnético é regulamentado e licenciado pela ANATEL (Agência Nacional de Telecomunicações).
} 
politetrafluoretileno (PTFE) esse parâmetro fica em uma faixa entre $0,02 \%$ a $0,01 \%$. Por outro lado, um substrato de FR4 pode absorver uma quantidade considerável de umidade, sendo que em sua especificação há indicação de 0,50\% de absorção. Esse alto valor pode interferir no sensoriamento, uma vez que as características de permissividade elétrica e de tangente de perdas do substrato serão afetadas.

\subsubsection{Deposição de materiais nanoestruturados via gotejamento}

As antenas foram recobertas por uma pequena camada de CNTs, capaz de adsorver o vapor e consequentemente alterar as propriedades elétricas das antenas. Os materiais nanoestruturados foram depositados por gotejamento. Foram depositados dois grupos de CNTs funcionalizados de elevado grau de pureza, um SWCNT (Sigma Aldrich ${ }^{31}$ com diâmetro de 1,2 a 1,5 nm e comprimento de 2 a $5 \mu \mathrm{m}$ ) e um MWCNT (Sigma Aldrich com diâmetro de 6 a $9 \mathrm{~nm}$ e comprimento de $5 \mu \mathrm{m}$ ), funcionalizados e diluídos em água deionizada (DI). A funcionalização foi realizada com base no procedimento químico descrito em Wang (2014).

A solução foi mantida em banho de ultrassom durante 30 minutos para homogeneização dos materiais nanoestruturados. Antes da deposição, o substrato foi limpo com etanol $70 \%$ e água deionizada. O gotejamento foi realizado através de seringa preenchida com cerca de $5 \mathrm{ml}$ do material nanoestruturado solubilizado, suficiente para preencher toda a área desejada do substrato. Após a deposição, os sensores permaneceram durante 24 horas em ambiente atmosférico para evaporação da suspensão dos CNTs.

\subsubsection{Ambiente de ensaio para sensores de gases}

Para a realização dos testes foi utilizada uma câmara de ensaios de vidro com volume de 100 ml. Essa câmara permite a alocação dos sensores, a entrada do fluxo de gás e

\footnotetext{
${ }^{31}$ Sigma-Aldrich Corporation: https://www.sigmaaldrich.com/
} 
posteriormente sua saída. Utiliza-se como gás inerte (de referência) o nitrogênio ${ }^{32}$ $\left(\mathrm{N}_{2}\right)$, posto que o ar atmosférico é suscetível a flutuações de umidade relativa e pode apresentar particulados. A Figura 3.10 apresenta o diagrama em blocos para caracterização dos sensores de gases de micro-ondas.

Figura 3.10 - Ilustração do arranjo experimental para sensores da fase vapor de etanol combustível.

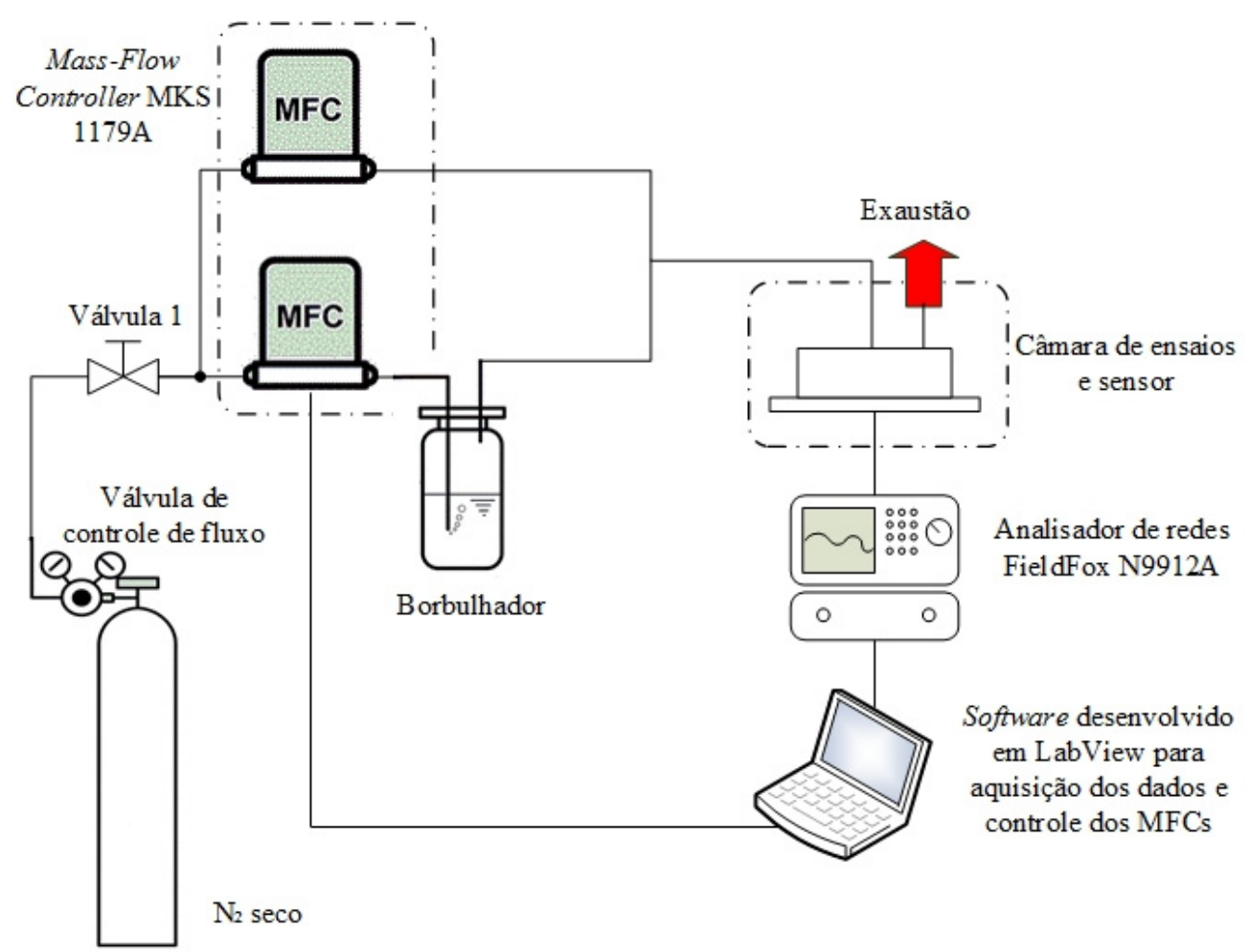

$\mathrm{O} \mathrm{N}_{2}$ entra em dois controladores de fluxo de massa - Mass Flow Controllers (MFC), $\mathrm{MKS}^{33}$ 1179A. Um deles é ligado diretamente à câmara de ensaios, enquanto outro é ligado a um borbulhador, que armazena a amostra de etanol a ser analisado. Através de um software desenvolvido em LabVIEW (APÊNDICE H) é controlado o fluxo do

\footnotetext{
${ }^{32} \mathrm{O} \mathrm{N}_{2}$ é o tradicional ambiente inerte de referência.

${ }^{33}$ MKS Instruments: https://www.mksinst.com
} 
gás em ambos $\mathrm{MFCs}^{34}$. Ou seja, com o sistema é possível alternar o gás referência e o gás referência borbulhado na amostra líquida que se deseja analisar. Dessa forma, é possível limpar a câmara com o gás inerte e injetar o gás teste, saturado com a fase vapor da amostra. Toma-se cuidado para manter o fluxo total fixo, assegurando repetitividade dos ensaios, para analisar dentre outros elementos, a sensibilidade do sensor, sua deriva e estabilidade.

O MFC mede e controla o fluxo de gás de acordo com um valor configurado. A faixa de variação está entre 2 a $100 \%$ do fundo de escala, com incerteza de 1\%. Para as medidas o software de controle do MFC foi ajustado para uma receita com 5 rotinas repetidas de injeção de $1000 \mathrm{sccm}$ (standard cubic centimeters per minute) de $\mathrm{N}_{2}$ seco durante $400 \mathrm{~s}$ alternando com a injeção de $\mathrm{N}_{2}$ borbulhado através do material sob análise, com os mesmos $1000 \mathrm{sccm}$, durante $80 \mathrm{~s}$. Dessa forma, garantiu-se com o maior tempo de $\mathrm{N}_{2}$ que o sensor fosse totalmente seco e voltasse às suas condições iniciais. Além disso, optou-se pela escolha de um tempo menor para a injeção do $\mathrm{N}_{2}$ borbulhado para que não ocorresse deriva ou envenenamento dos sensores.

\subsubsection{Plataforma para ensaio dos sensores da fase vapor}

O esquema para montagem leva em consideração o uso de dois MFCs controlados, um borbulhador e uma câmara de ensaios. A Figura 3.11 apresenta o aparato experimental para ensaios dos sensores de fase vapor do etanol combustível. Dá-se destaque ao analisador de redes Fieldfox N9912A e ao computador que amostra os valores da frequência de ressonância e do índice de mérito (calculado a partir do valor de referência de $-3 \mathrm{~dB}$ ). Esses valores são obtidos através dos marcadores do analisador de redes, a cada 1,5 s, correspondente ao tempo de latência entre uma varredura do analisador, os cálculos e sua posterior comunicação via barramento Ethernet (APENNDICE F).

\footnotetext{
34 Para medir o fluxo, o MFC utiliza o princípio da diferença de temperatura entre dois sensores simetricamente alocados no início e fim do tubo, que correlaciona o fluxo com o calor específico de um gás. O controle do MFC é realizado através de um algoritmo PID (Proportional-Integral-Derivative), aumentando ou reduzindo o fluxo conforme o erro do sinal.
} 
Figura 3.11 - Aparato experimental para ensaio de sensores de fase vapor.

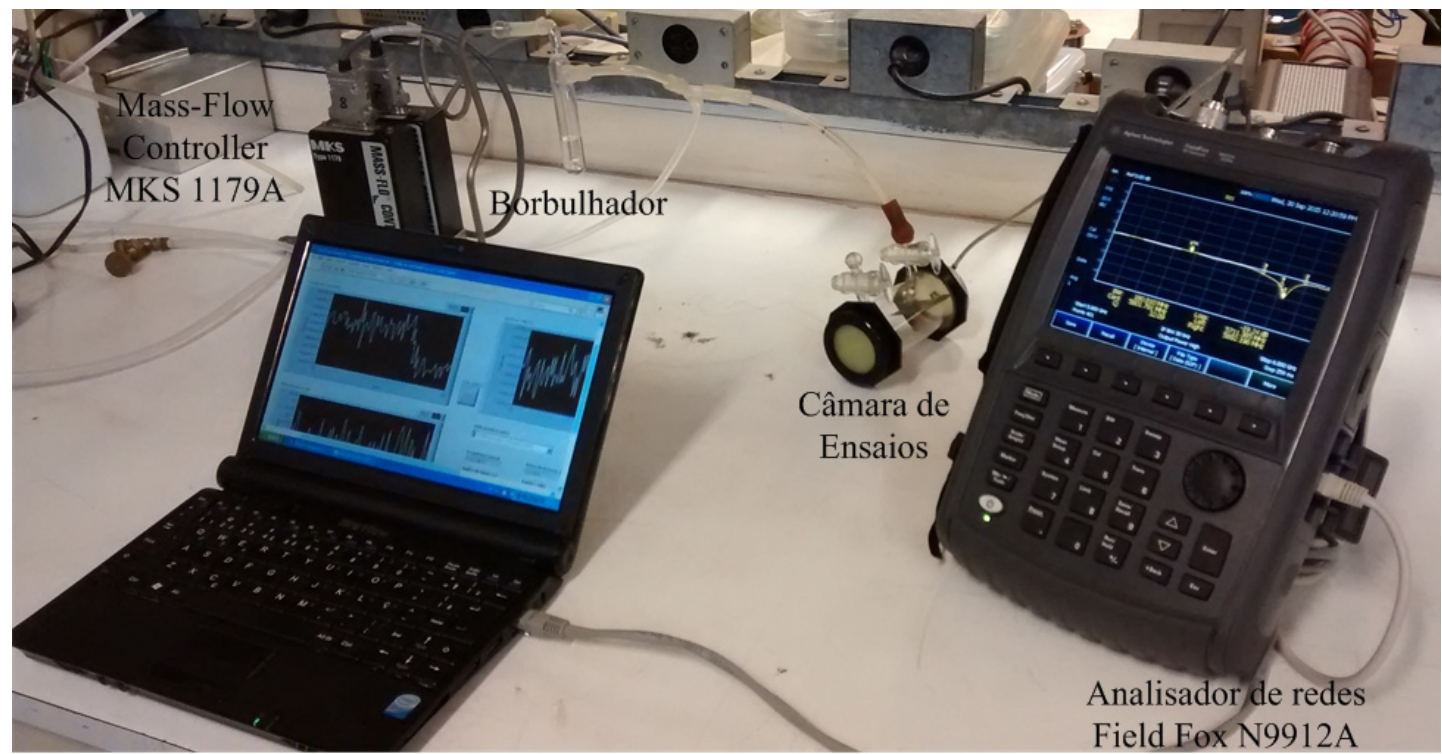

A Figura 3.12 apresenta, em detalhe, a câmara de ensaios de gases. Nota-se que a antena com material nanoestruturado depositado fica alocada internamente à câmara. Vale ressaltar que a própria inserção da antena em um ambiente confinado modifica, ligeiramente, os parâmetros das medidas de $\mathrm{S}_{11}$. Contudo, pode-se desconsiderar essas pequenas flutuações, posto que o objetivo é verificar a variação da frequência de ressonância e do índice de mérito em relação aos seus valores de referência em $\mathrm{N}_{2}$ seco.

Figura 3.12 - Câmara de ensaio de gases com um sensor internamente alocado.

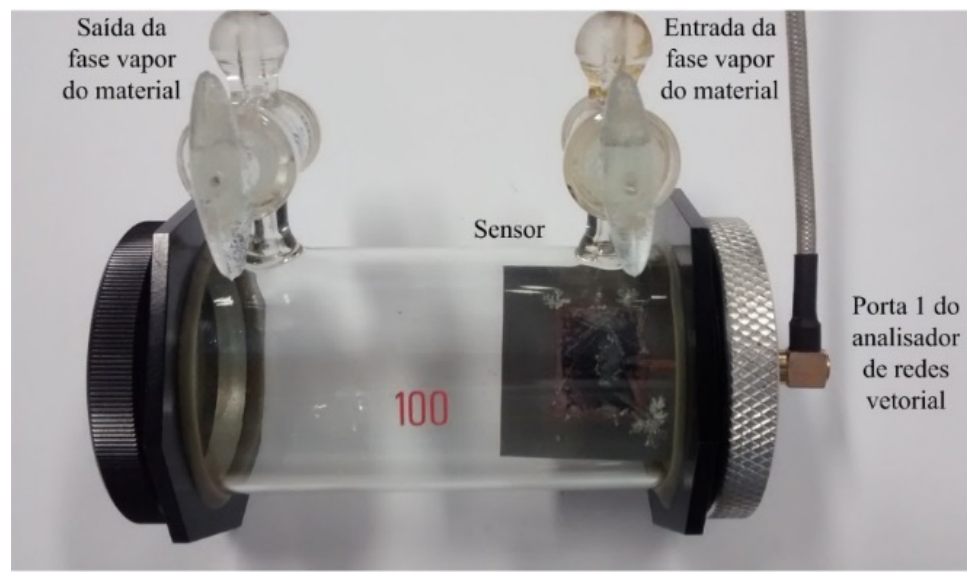




\subsection{Desenvolvimento de sensores para caracterização da fase líquida de etanol combustível}

Para além da fase vapor de misturas de etanol adulterado, também foram propostos sensores para caracterização das amostras líquidas. Os circuitos planares foram projetados com a tecnologia SIW. Para tanto foram projetados uma antena SIW com fenda traseira, conforme apresentado na Figura 3.8 (c), e um guia de onda integrado ao substrato. Os resultados da antena foram modelados pelo método da perturbação da cavidade ressonante para caracterização de materiais. Os resultados do guia foram analisados através dos algoritmos do método de transmissão/reflexão. Dentre as vantagens estão a possibilidade, para essas estruturas, de utilizar somente uma fração mínima da amostra do combustível. Todos os testes e caracterizações foram realizados à temperatura ambiente de $25^{\circ} \mathrm{C}$.

\subsubsection{Ambiente de ensaio para sensor de líquido: antena SIW com fenda traseira}

A Figura 3.13 apresenta o aparato para caracterização das amostras de etanol em água através da antena SIW com fenda traseira. Para realizar os ensaios são depositadas pequenas amostras da mistura etanol em água diretamente na fenda traseira da antena. Esse processo é realizado utilizando uma seringa de $1 \mathrm{ml}$ que permite inserir amostras de $0,04 \mathrm{ml}$ sobre a antena. Utilizando o software de aquisição desenvolvido em LabVIEW $^{35}$ (APÊNDICE G) são tomadas 50 medidas ao longo de $100 \mathrm{~s}$ dos valores da frequência de ressonância e do índice de mérito, com o sensor inicialmente seco utilizando o analisador de redes vetorial FieldFox N9912A. Em sequência as amostras das misturas são depositadas. $\mathrm{O}$ instrumento virtual realiza mais 45 medidas obtidas do analisador de redes ao longo de $90 \mathrm{~s}$, com o intuito de verificar o comportamento da perturbação da cavidade e da evaporação do material depositado. Ao final, limpase a antena SIW com fenda traseira com papel toalha e com um jato de $\mathrm{N}_{2}$, permitindo à antena SIW com fenda traseira voltar às suas condições iniciais.

\footnotetext{
${ }^{35}$ LabVIEW System Design Software - National Instruments: www.ni.com/labview/
} 
Figura 3.13 - Aparato para ensaio de líquidos com a antena SIW com fenda traseira.

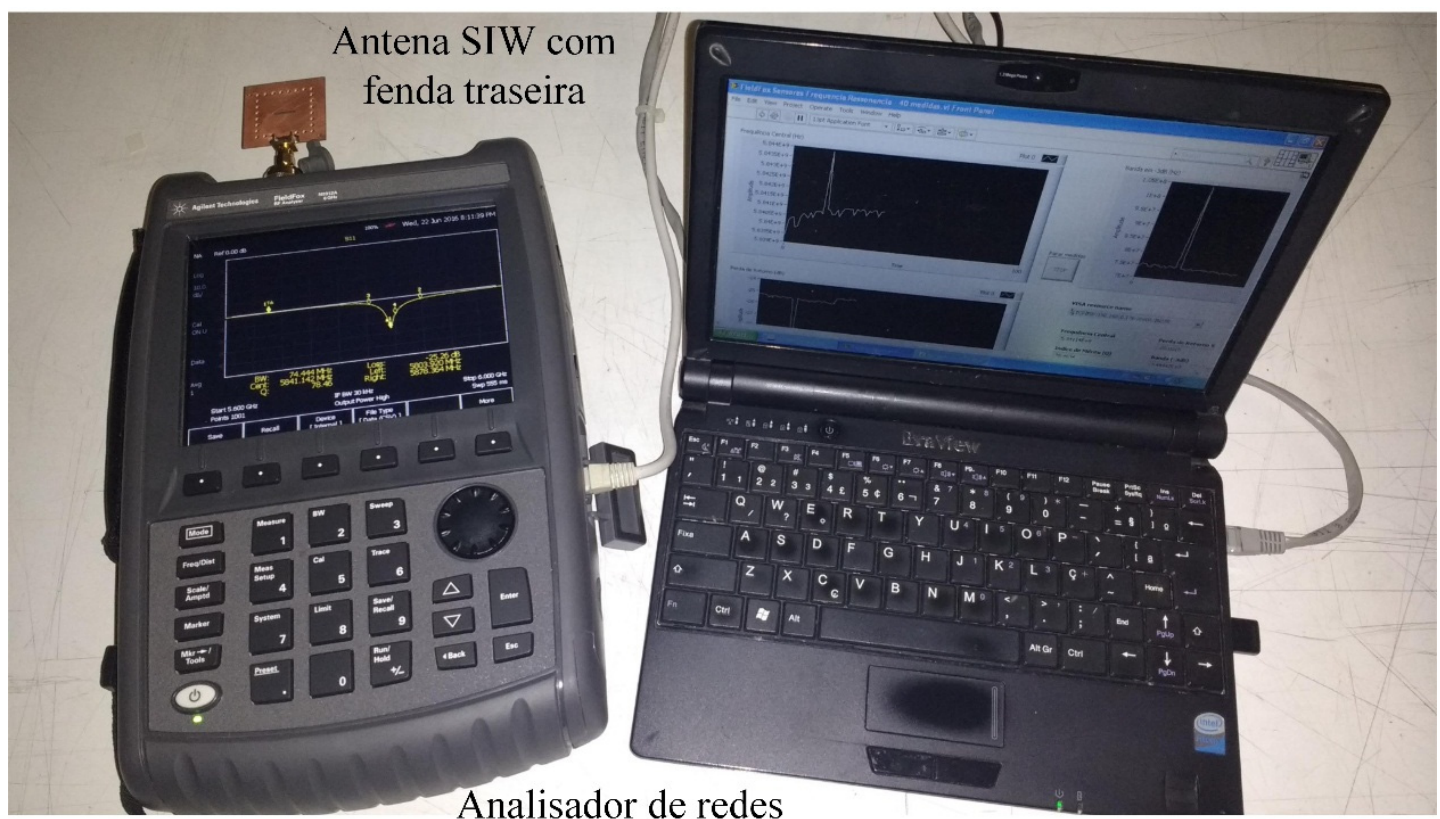

Fieldfox N9912A

\subsubsection{Ambiente de ensaio para sensor de líquido: guia de onda integrado ao substrato}

Os ensaios realizados com o guia de ondas integrado ao substrato podem ser descritos através do aparato apresentado na Figura 3.14. O guia de ondas é ligado entre as portas 1 e 2 do analisador de redes vetorial HP8722D. O uso desse analisador de redes em detrimento ao Fieldfox deve-se a sua maior banda de operação.

Utilizando uma seringa de $1 \mathrm{ml}$, as amostras de etanol em água são inseridas em uma fresta construída dentro do guia através de dois pequenos furos. Quantidades menores do que $0,015 \mathrm{ml}$ são capazes de preencher a fresta do guia. As curvas dos parâmetros S são amostradas utilizando uma interface em LabVIEW. Através desse instrumento virtual é possível obter as curvas $S_{11}, S_{21}, S_{12}$ e $S_{22}$ antes e depois de cada injeção de amostra. Os parâmetros de espalhamento são armazenados e posteriormente analisados utilizando a ferramenta matemática Matlab ${ }^{36}$ (Matrix Laboratory) por meio

\footnotetext{
${ }^{36}$ MATLAB - MathWorks: https://www.mathworks.com/products/matlab.html
} 
dos algoritmos do método de transmissão/reflexão (APÊNDICE Q). Após a aquisição de uma amostra, o guia de ondas é limpo passando $\mathrm{N}_{2}$ através da cavidade interna do guia de ondas, voltando a suas condições iniciais.

Figura 3.14 - Aparato para ensaio de líquidos com o guia de ondas integrado ao substrato.

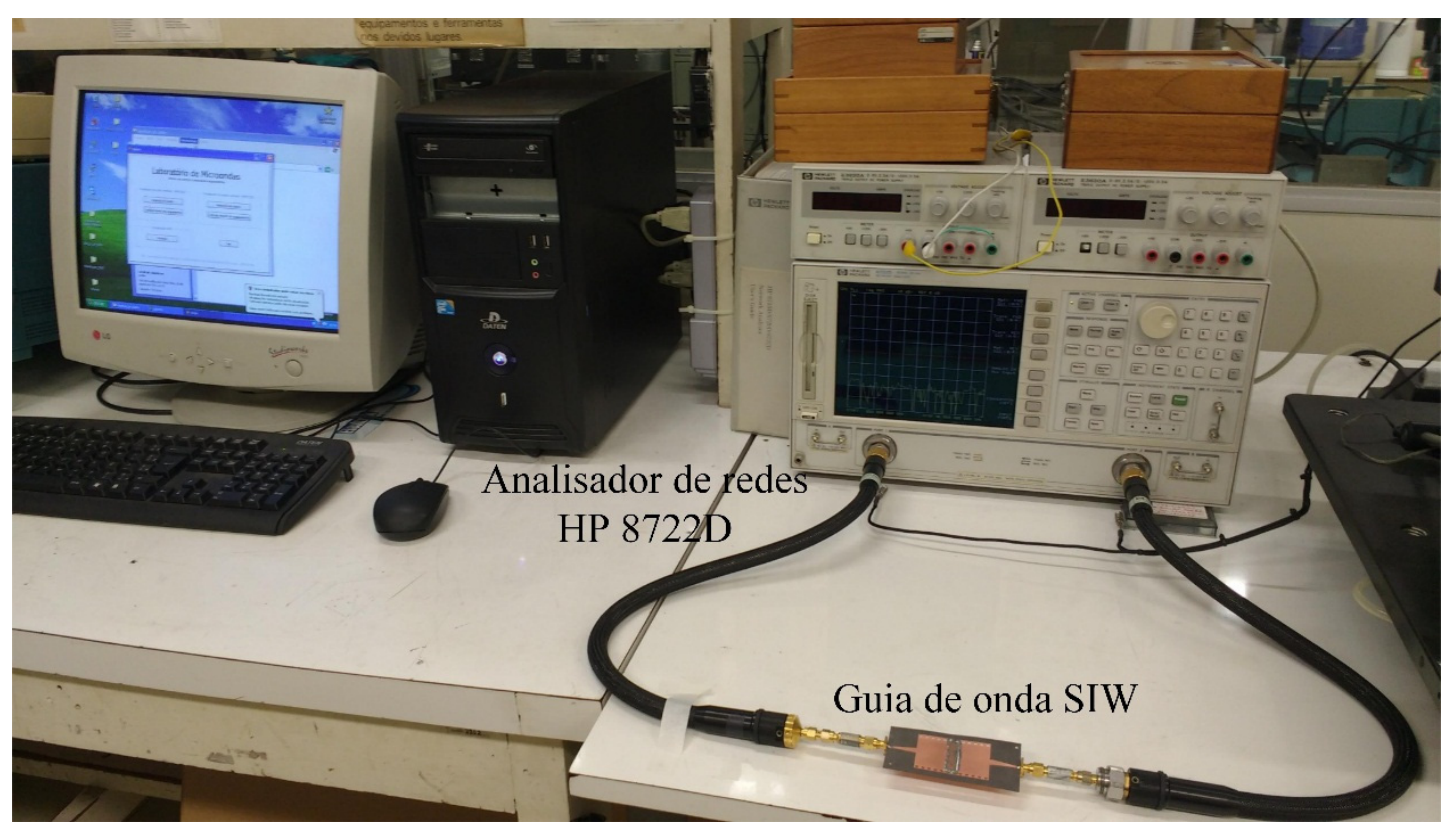




\section{RESULTADOS E DISCUSSÕES}

Neste capítulo são apresentados os resultados do desenvolvimento de sensores planares para caracterização de etanol combustível. Inicialmente é feito um modelamento dos valores de permissividade elétrica complexa a partir das regras de mistura encontradas na literatura. Dessa forma, estabelece-se uma referência a ser utilizada pelos outros sensores desenvolvidos.

Para os sensores são destacados: os resultados da otimização, simulação e, posteriormente, as caracterizações de etanol feitas através dos protótipos desenvolvidos tanto para o etanol em fase vapor, como em fase líquida.

\subsection{Modelamento da permissividade elétrica complexa do etanol líquido combustível através dos seus modelos de relaxação e de regras de diluição}

Através das curvas experimentais de permissividade elétrica complexa, alguns autores parametrizaram os modelos de dispersão de Debye de primeira ordem para amostras puras de etanol, água e metanol (BAO et al., 1996) (KINDT; SCHMUTTENMAER, 1996) (YANG et al., 2010) (BERTOLINI et al., 1991) (TINGA, 1992). A Tabela 4.1 apresenta os parâmetros de dispersão de $1^{\mathrm{a}}$ ordem dos materiais citados.

Tabela 4.1 - Parâmetros do modelo de dispersão de Debye para etanol e água.

\begin{tabular}{cccc}
\hline \multicolumn{4}{c}{ Experimental $\left(25^{\circ} \mathrm{C}\right)$} \\
\hline Amostras & $\varepsilon_{\infty}$ & $\varepsilon_{\mathrm{s}}$ & $\tau(\mathrm{ps})$ \\
\hline Água et al. $(1996)$ & $4,55 \pm 0,39$ & $77,11 \pm 0,81$ & $7,37 \pm 0,45$ \\
Etanol & $4,68 \pm 0,09$ & $25,25 \pm 0,77$ & $143,18 \pm 5,01$ \\
\hline
\end{tabular}

Os valores intermediários dos parâmetros do modelo de dispersão de Debye para as misturas de etanol e água não estão disponíveis na literatura. Contudo foram propostas diferentes formulações empíricas para estimar a permissividade elétrica de misturas a partir da fração em volume de cada amostra na solução (LANDAU et al., 1984). 
Usualmente, não é possível definir uma regra geral para todas as possíveis soluções. Os trabalhos de Bao et al. (1996), Yang et al. (2009), Bertolini et al. (1991) propõem "regras de mistura" especificamente para as soluções utilizadas neste trabalho.

Para a modelagem do valor de permissividade elétrica estática $(f \rightarrow 0)$ de uma mistura de dois materiais, pode-se utilizar, em primeira aproximação, a equação 4.1, desenvolvida por Bruggeman (YANG et al., 2010) (GREFFE; GROSSE, 1992):

$$
\left(\frac{\varepsilon_{s_{\text {mix }}}-\varepsilon_{s_{1}}}{\varepsilon_{s_{2}}-\varepsilon_{s_{1}}}\right)\left(\frac{\varepsilon_{s_{2}}}{\varepsilon_{s_{\text {mix }}}}\right)^{1 / 3}=1-x
$$

no qual $\varepsilon_{s_{\text {mix }}}$ corresponde à permissividade elétrica estática, $\varepsilon_{s_{1}}$ e $\varepsilon_{s_{2}}$ relacionam a permissividade elétrica estática das amostras 1 e 2 e $x$ corresponde à fração em volume da mistura ${ }^{37}$.

De acordo com a equação 4.1, uma relação analítica é esperada entre as diferentes frações da mistura. Contudo, os valores experimentais podem ser melhor ajustados através da equação 4.2, que leva em consideração o fator de ajuste numérico $a$ (PURANIK et al., 1994).

$$
\left(\frac{\varepsilon_{s_{\text {mix }}}-\varepsilon_{s_{1}}}{\varepsilon_{s_{2}}-\varepsilon_{s_{1}}}\right)\left(\frac{\varepsilon_{s_{2}}}{\varepsilon_{s_{\text {mix }}}}\right)^{1 / 3}=1-[a-(a-1) x] x
$$

O valor $a=1$ corresponde à mistura ideal de Bruggeman. Valores que desviam ligeiramente da unidade indicam maior interação entre os solventes na mistura. Pequenos valores de $a$ indicam aumento significativo do volume efetivo do solvente,

\footnotetext{
${ }^{37}$ A fração em volume $x$ corresponde à relação entre o volume $v_{1}$ do material $1 \mathrm{e}$ o volume total da mistura $v_{1}+v_{2}$, sendo dado pela fórmula $x=\frac{v_{1}}{v_{1}+v_{2}}$.
} 
assim como fraca interação entre os materiais. Dessa forma, a equação 4.2 permite corrigir singularidades das misturas.

$\mathrm{O}$ valor de permissividade dielétrica da mistura em altas frequências, $\varepsilon_{\infty}$, pode ser calculado a partir da equação 4.3 (YANG et al., 2009).

$$
\varepsilon_{\infty_{\text {mix }}}=\frac{\varepsilon_{\infty_{1}}}{x}+\frac{\varepsilon_{\infty_{2}}}{1-x}
$$

no qual, $\varepsilon_{\infty_{\text {mix }}}$ representa a permissividade dielétrica em altas frequências da mistura, e $\varepsilon_{\infty_{1}}$ e $\varepsilon_{\infty_{2}}$ indicam a permissividade dielétrica em altas frequências das amostras $1 \mathrm{e}$ 2 , respectivamente.

Por último, a equação 4.4 descreve o tempo de relaxação dielétrica, $\tau_{m i x}$, da mistura a partir dos trabalhos de Lou et al. (1997) e Yang et al. (2009).

$$
\ln \tau_{\text {mix }}=x \ln \tau_{1}+(1-x) \ln \tau_{2}
$$

na qual, $\tau_{\text {mix }}$ representa a tempo de relaxação dielétrica da mistura, e $\tau_{1}$ e $\tau_{2}$ indicam o tempo de relaxação dielétrica das amostras 1 e 2 , respectivamente.

A modelagem das misturas foi realizada, selecionando-se o melhor grupo de equações para representação das características dielétricas das frações de etanol em água. Os resultados do modelamento da permissividade elétrica estática foram realizados otimizando o parâmetro $a$ para cada fração. Através das regras de mistura e dos parâmetros da Tabela 4.1 foi possível modelar as espectroscopias dielétricas das misturas de etanol em água utilizando os valores modelados na equação de Debye (2.25). Dessa forma, pode-se obter para cada frequência e fração, os valores das partes real e imaginária da permissividade elétrica da mistura.

Dentre as vantagens desse modelamento estão: a possibilidade de obter valores de permissividade relativa complexa para frações intermediárias, que não constam na 
literatura; a utilização desses mesmos dados nas simulações eletromagnéticas dos sensores; e a comparação entre os dados oriundos dos sensores desenvolvidos com os valores presentes na literatura. Com isso, a modelagem proposta, utilizando em conjunto as equações 4.2, 4.3 e 4.4, é uma das contribuições significativas deste trabalho.

Para as misturas de etanol e água, foram calculados os espectros da parte real e imaginária, representados nos Gráficos 4.1 e 4.2 (ver APÊNDICE J), respectivamente. Esses gráficos representam o modelamento dos valores experimentais obtidos em Bao et al. (1996), apresentados nas Figuras 2.10 e 2.11, respectivamente. Para todos os gráficos modelados, obteve-se incerteza máxima de 3\%, correspondente à comparação entre a leitura visual dos valores experimentais apresentados em Bao et al. (1996) e os valores obtidos através das regras de mistura.

Os valores obtidos no modelamento das frações analisadas neste trabalho foram comparados com medidas experimentais realizadas utilizando a técnica da linha coaxial em aberto (APÊNDICE E), demonstrando boa concordância.

Gráfico 4.1 - Modelamento do espectro da parte real da permissividade complexa da mistura etanol e água.

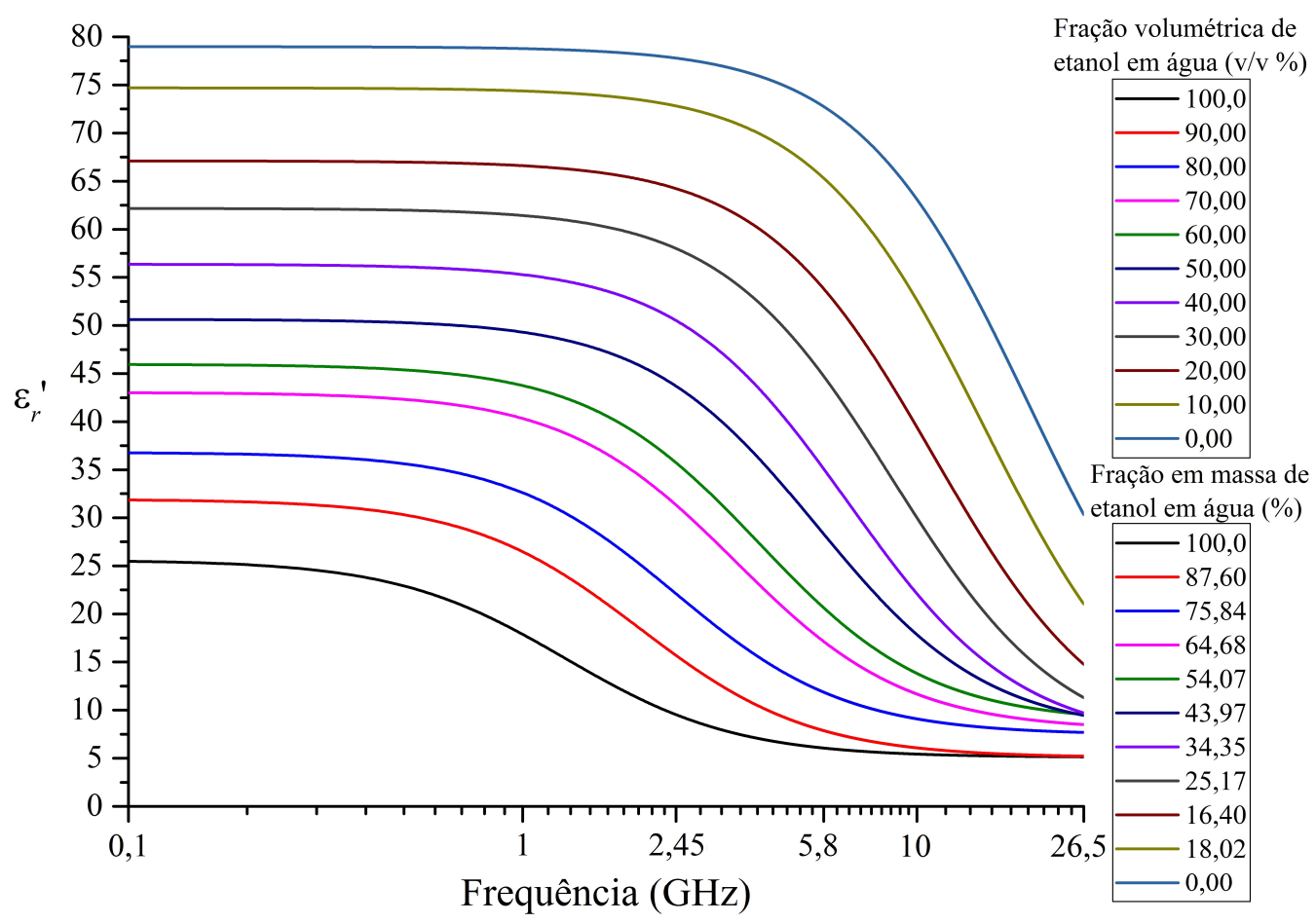


Gráfico 4.2 - Modelamento do espectro da parte imaginária da permissividade complexa da mistura etanol e água.

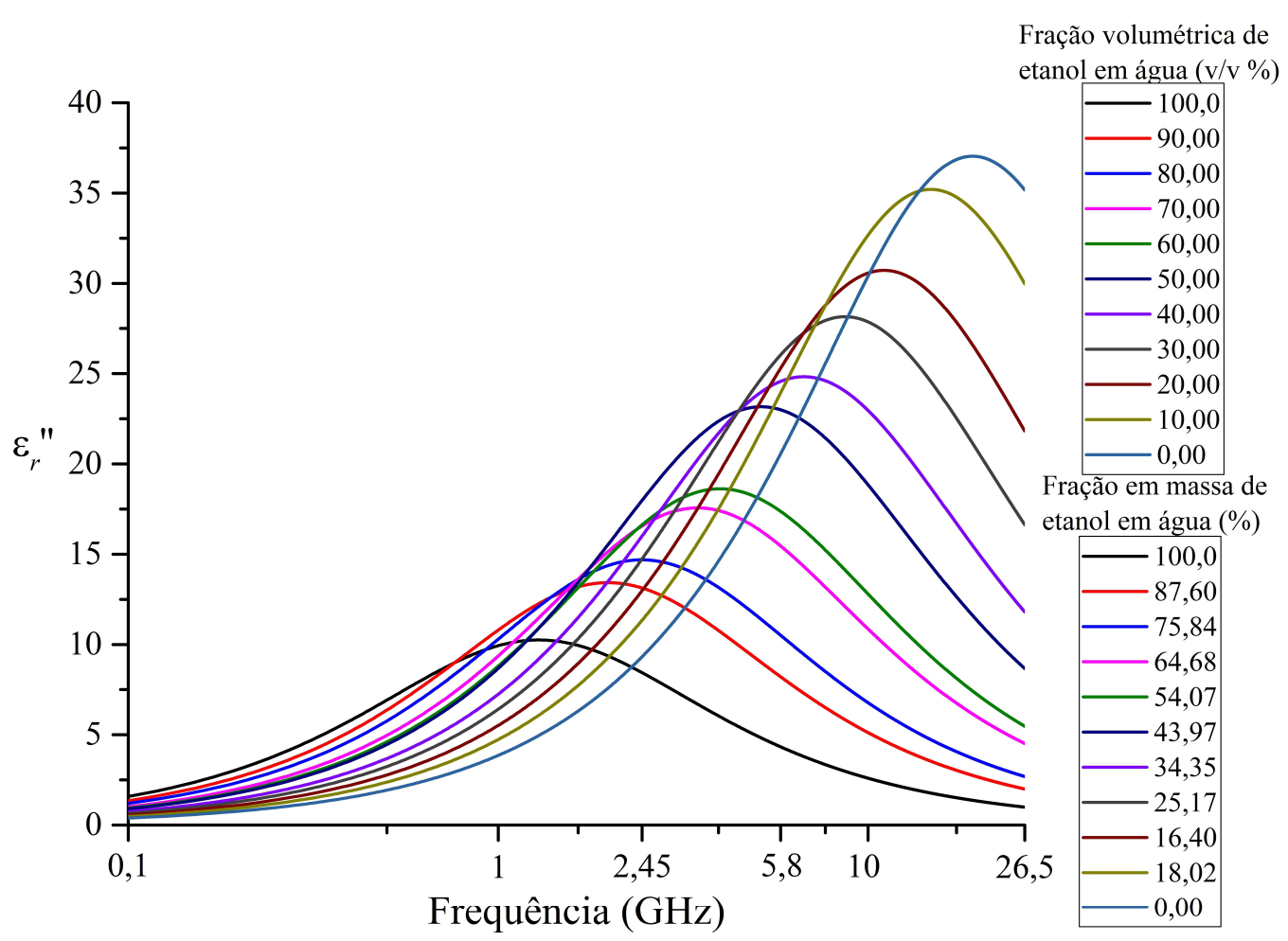

\subsection{Projeto, simulação e caracterização dos sensores para análise da fase vapor de etanol combustível}

Foram dois os sensores projetados para análise da fase vapor de etanol combustível. O primeiro sensor utiliza uma antena de microfita e o segundo sensor emprega uma antena com cavidade ressonante na tecnologia SIW, operando em frequências de micro-ondas. Foram depositados materiais nanoestruturados em ambos os sensores. Esses materiais, em especial o SWCNT, permitiram o deslocamento da frequência de ressonância e a variação do índice de mérito das antenas de micro-ondas quando inseridas em vapor de misturas de etanol combustível. Para todos os casos foram desenvolvidas equações de ajuste de curva, relacionando a permissividade elétrica complexa da amostra com a resposta em frequência do sensor. Além disso, os CNTs depositados foram caracterizados morfologicamente, o que permitiu analisar o arranjo dos materiais nanoestruturados depositados. 


\subsubsection{Antena de microfita com plaqueta retangular}

A partir das equações descritas no item 3.3 foi projetada, simulada e caracterizada uma antena de microfita (APÊNDICE L). Como apresentado no capítulo materiais e métodos, optou-se pela frequência de operação de $5,8 \mathrm{GHz}$. Os valores do projetado otimizado são apresentados na Tabela 4.2.

Os valores apresentados nessa tabela descrevem as características do substrato e os parâmetros relativos ao formato da antena, conforme indicados na Figura 3.2, ajustados após o projeto e simulação. Ressalta-se que a dimensão total da antena foi de $32 \times 45 \mathrm{~mm}$.

Tabela 4.2 - Dimensões otimizadas da antena de microfita na frequência de 5,8 GHz.

\begin{tabular}{lc}
\hline \multicolumn{1}{c}{ Parâmetro de projeto } & Especificação após otimização \\
\hline Frequência de operação $\left(f_{r}\right)$ & $5,8 \mathrm{GHz}$ \\
Constante dielétrica do substrato $\left(\varepsilon_{r}\right)$ & $2,2(\mathrm{RT}$ Duroid® 5880$)$ \\
Tangente de perdas do substrato & 0,0009 \\
Espessura do substrato $(h)$ & $0,508 \mathrm{~mm}$ \\
Condutividade elétrica do cobre $(\sigma)$ & $5,8 \times 10^{7} \mathrm{~S} / \mathrm{m}$ \\
Espessura do cobre $(t)$ & $35 \mu \mathrm{m}$ \\
Comprimento efetivo do patch $\left(L_{p}\right)$ & $17,08 \mathrm{~mm}$ \\
Largura do patch $\left(W_{p}\right)$ & $20,60 \mathrm{~mm}$ \\
Comprimento da reentrância $\left(y_{0}\right)$ & $5,54 \mathrm{~mm}$ \\
Largura da fenda da reentrância $\left(x_{0}\right)$ & $0,5 \mathrm{~mm}$ \\
Largura da linha de microfita $\left(W_{f}\right)$ & $1,52 \mathrm{~mm}$ \\
Comprimento da linha de microfita $\left(L_{f}\right)$ & $30 \mathrm{~mm}$ \\
\hline
\end{tabular}

A Figura 4.1 (a) apresenta o modelo de simulação da antena de microfita no CST Studio Suite. Nota-se que nessa simulação foi realizado o conector foi modelado e 
projetado, o que possibilitou melhor ajuste da frequência de ressonância da antena e das perdas inerentes ao conector. A Figura 4.1 (b) apresenta um dos três protótipos de antenas construídas por meio de uma microfresadora de precisão ${ }^{38} 39$.

Um parâmetro importante para o depósito dos materiais nanoestruturados é a localização das regiões de máximo campo elétrico dentro da estrutura. A Figura 4.2 apresenta a distribuição do campo elétrico na antena de microfita extraída do simulador eletromagnético CST Studio. Como é esperado, a máxima distribuição é obtida nas bordas da plaqueta e na linha de alimentação indentada.

Figura 4.1 - Antena de microfita: (a) modelo de simulação; e (b) protótipo da antena de microfita com plaqueta retangular.

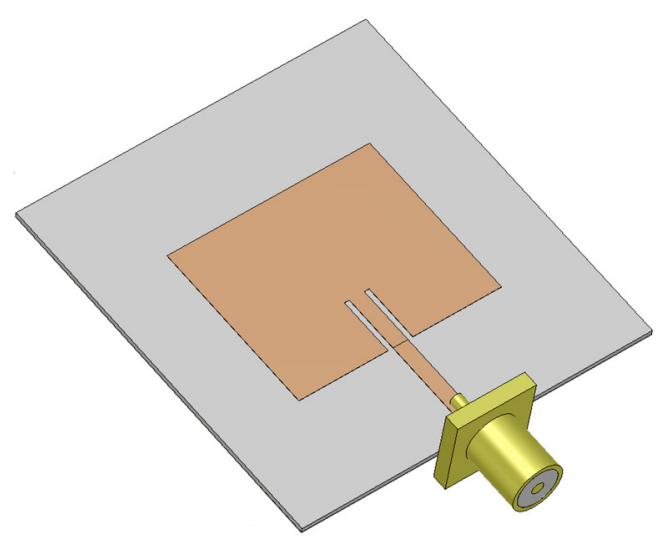

(a)

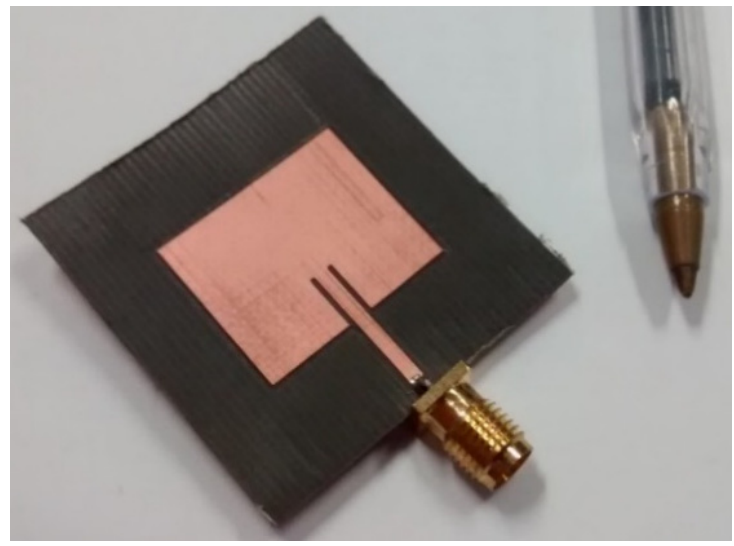

(b)

Sabendo-se que o máximo campo elétrico está nas regiões próximas às bordas do elemento radiante e na reentrância da linha de alimentação indentada, foram depositados os dois grupos de CNTs funcionalizados: SWCNT e MWCNT. Devido à tensão superficial da água e ao processo de secagem, as amostras de CNT tendem a se concentrar, majoritariamente, na parte central da plaqueta retangular. A Figuras 4.3 (a)

\footnotetext{
${ }^{38}$ Protomat S62, da LPKF Laser \& Electronics.

39 Todos os conectores SMA utilizados nesse trabalho foram adquiridos na Amphenol RF (http://www.amphenolrf.com).
} 
e (b) apresentam as antenas de microfita com plaqueta retangular com SWCNT e MWCNT, respectivamente.

Figura 4.2 - Distribuição do campo elétrico [V/m] na antena de microfita com plaqueta retangular.
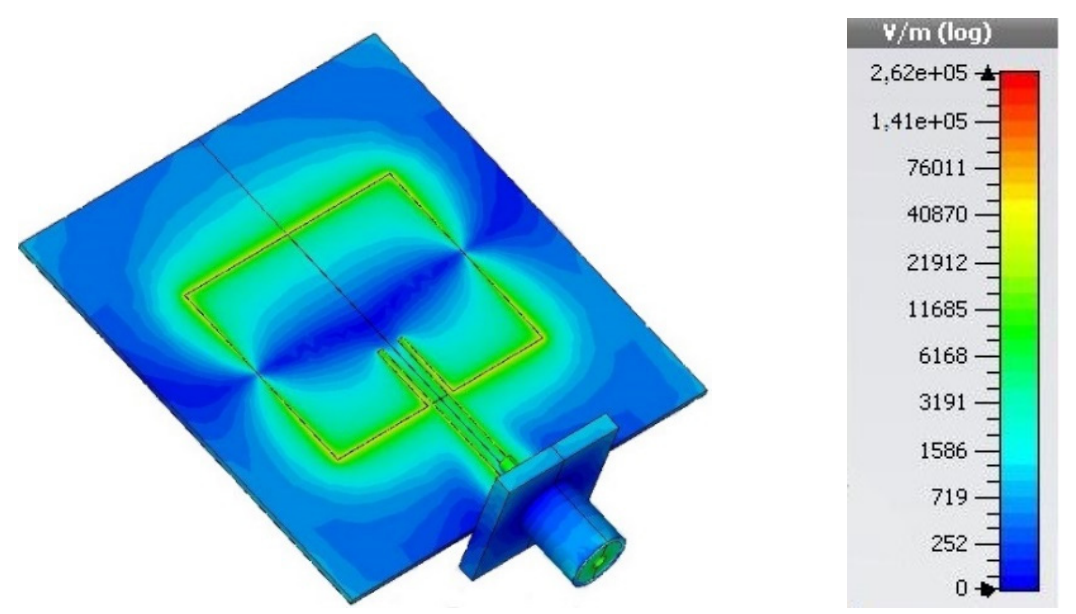

Figura 4.3 - Antena de microfita com depósito de nanotubos de carbono: (a) SWCNT diluído em água, (b) MWCNT diluído em água.

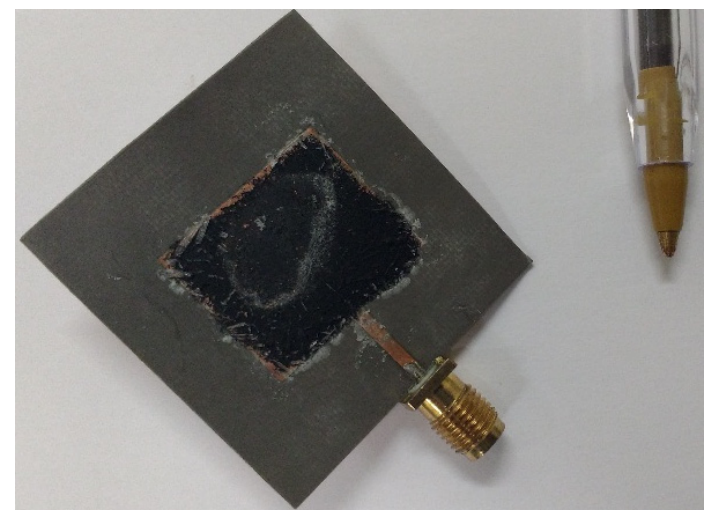

(a)

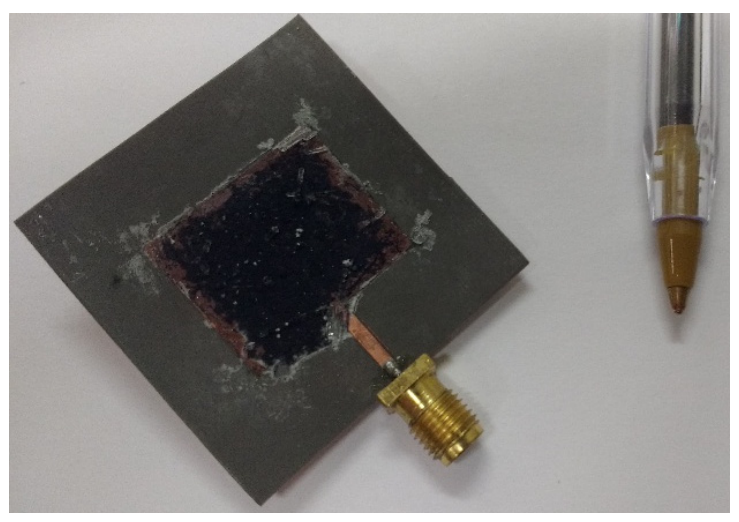

(b)

Uma vez preparadas, os protótipos foram caracterizados através da medida do seu coeficiente de reflexão (parâmetro $\mathrm{S}_{11}{ }^{40}$. O Gráfico 4.3 apresenta o coeficiente de

\footnotetext{
${ }^{40}$ Primeiramente é feita uma calibração no plano do conector do analisador de redes vetorial. Nesse procedimento são utilizados os métodos usuais de calibração padrão (aberto, curto e carga de $50 \Omega$ ).
} 
reflexão versus frequência da antena de microfita simulada e medida em protótipos em três condições distintas: sem CNT, com depósito de SWCNT e com depósito de MWCNT. As medidas foram realizadas em ambiente de $\mathrm{N}_{2}$ seco. Nota-se que os resultados da simulação e da antena de referência, protótipo da antena sem CNT, estão coerentes. A frequência de ressonância está em $5,8 \mathrm{GHz}$ e o valor mínimo para o coeficiente de reflexão da antena simulada é de $-42,28 \mathrm{~dB}$, maior do que o valor de -35,65 dB para o protótipo da antena sem CNT. Ressalta-se que tanto as simulações como as medidas do coeficiente de reflexão são discretizadas, portanto os valores mínimos correspondem à interpolação dos valores obtidos, o que justifica a diferença entre esses valores. $\mathrm{O}$ índice de mérito para essas antenas é de, aproximadamente, 58.

Gráfico 4.3 - Coeficiente de reflexão da antena de microfita e das antenas com CNTs em ambiente com $\mathrm{N}_{2}$ seco.

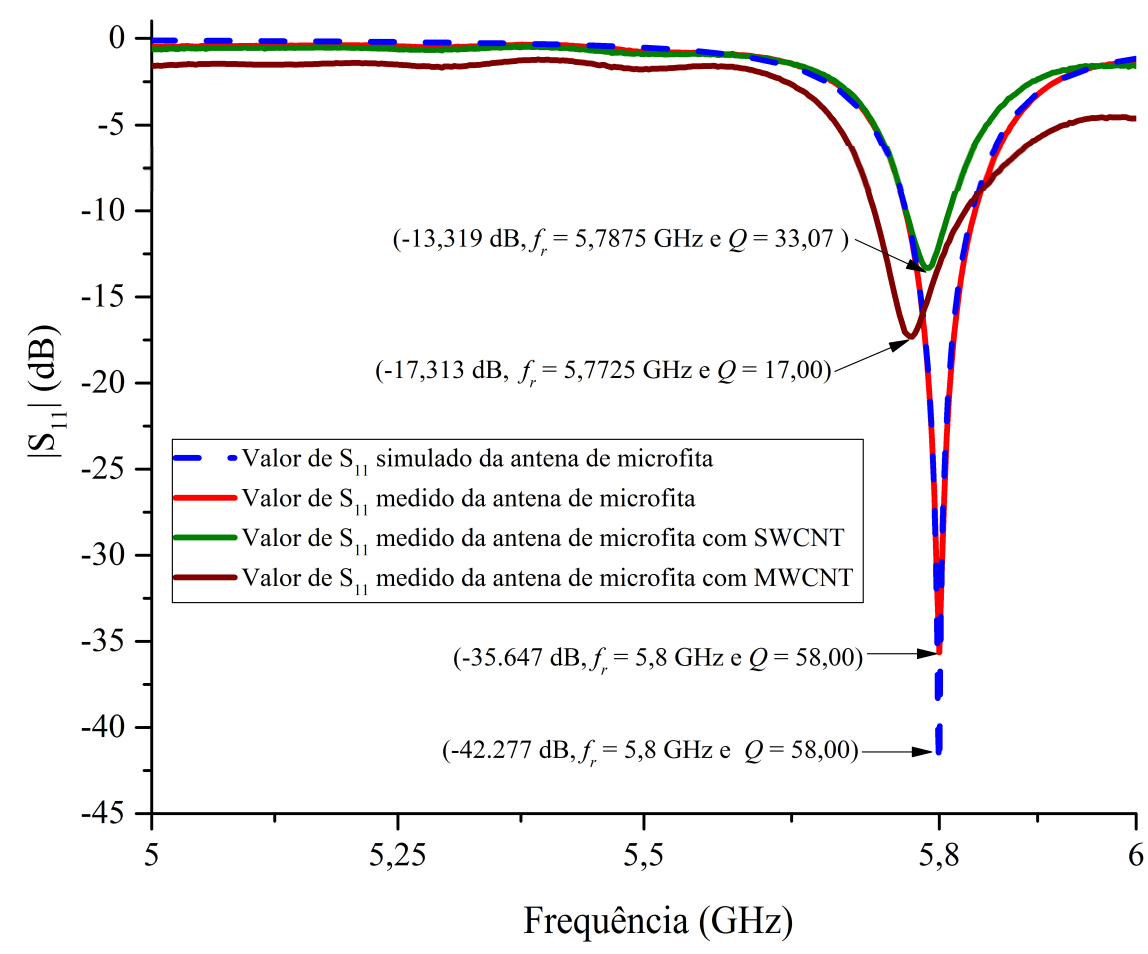

Para essa calibração, foi utilizado o kit de calibração de 3,5 mm do fabricante Maury Microwave (https://www.maurymw.com). 
As antenas com depósito de CNT apresentaram uma variação da sua frequência de ressonância e no seu índice de mérito, quando comparadas com a antena sem CNT. Para a antena com SWCNT, a frequência de ressonância medida foi de 5,7875 GHz e o mínimo valor do coeficiente de reflexão ficou em -13,32 dB. O índice de mérito nessa condição foi calculado em 33,07. Para a antena com MWCNT, a frequência de ressonância medida foi de $5,7725 \mathrm{GHz}$ e o mínimo valor do coeficiente de reflexão ficou em -17,31 dB. O índice de mérito calculado foi de, aproximadamente, 17,00.

Concluída a etapa de caracterização em ambiente de $\mathrm{N}_{2}$ seco, foram realizados os ensaios de qualificação do sensor em relação às misturas de etanol combustível.

\subsubsection{Sensibilidade da antena de microfita como sensor}

O primeiro teste realizado comparou a resposta ao vapor de água para as antenas com SWCNT, MWCNT e a antena de referência, ou seja, sem depósito de CNT. Essa medida teve como objetivo verificar o comportamento dessas estruturas para água DI, que possui o maior valor de permissividade elétrica entre as amostras testadas.

Para reduzir a influência de possíveis flutuações da medida e do material foram utilizadas como resposta os parâmetros de sensibilidade apresentados nas equações 4.5 e 4.6, respectivamente, a sensibilidade da frequência de ressonância e a sensibilidade normalizada do índice de mérito. Dessa forma, mede-se um valor de frequência $f_{s}$ que é comparado e normalizado com a frequência inicial $f_{0}$, medido em ambiente de $\mathrm{N}_{2}$ seco. O mesmo procedimento vale para o índice de mérito, no qual se compara e normaliza o índice $Q_{s}$ em relação a um índice $Q_{0}$.

$$
\begin{gathered}
S_{f}=\frac{\left|f_{s}-f_{0}\right|}{f_{0}}=\frac{\Delta f}{f_{0}}(\%) \\
\frac{S_{Q}}{Q_{s}}=\frac{\left|Q_{s}-Q_{0}\right|}{Q_{s} \cdot Q_{0}}=\frac{\Delta Q}{Q_{s} \cdot Q_{0}}(\%)
\end{gathered}
$$


O Gráfico 4.4 apresenta a variação da sensibilidade da frequência de ressonância. Como descrito no subitem 3.8.2.1 os dados são coletados a cada 1,5s. O Apêndice G apresenta os dados crus coletados para os primeiros ensaios de sensibilidade. Fica evidenciado que não há deriva, nem envenenamento do sensor. Além disso, fica evidente o patamar de saturação do sensor. Esses valores foram condicionados utilizando um filtro digital FIR (Finite Impulse Response) passa baixas do tipo média móvel de 8 elementos. No gráfico, observa-se um comportamento atípico para a primeira inserção da fase vapor de água. Esse comportamento é usual para sensores de gases. A partir da segunda amostra, o sensor se comporta de maneira repetitiva e sem deriva. Com os resultados obtidos, demonstra-se que não houve reação química irreversível entre os materiais nanoestruturados e o ambiente oxidante durante os ensaios.

Gráfico 4.4 - Comparação da resposta a vapor de água DI dos sensores com SWCNT, MWCNT e antena de referência sem depósito de CNT.

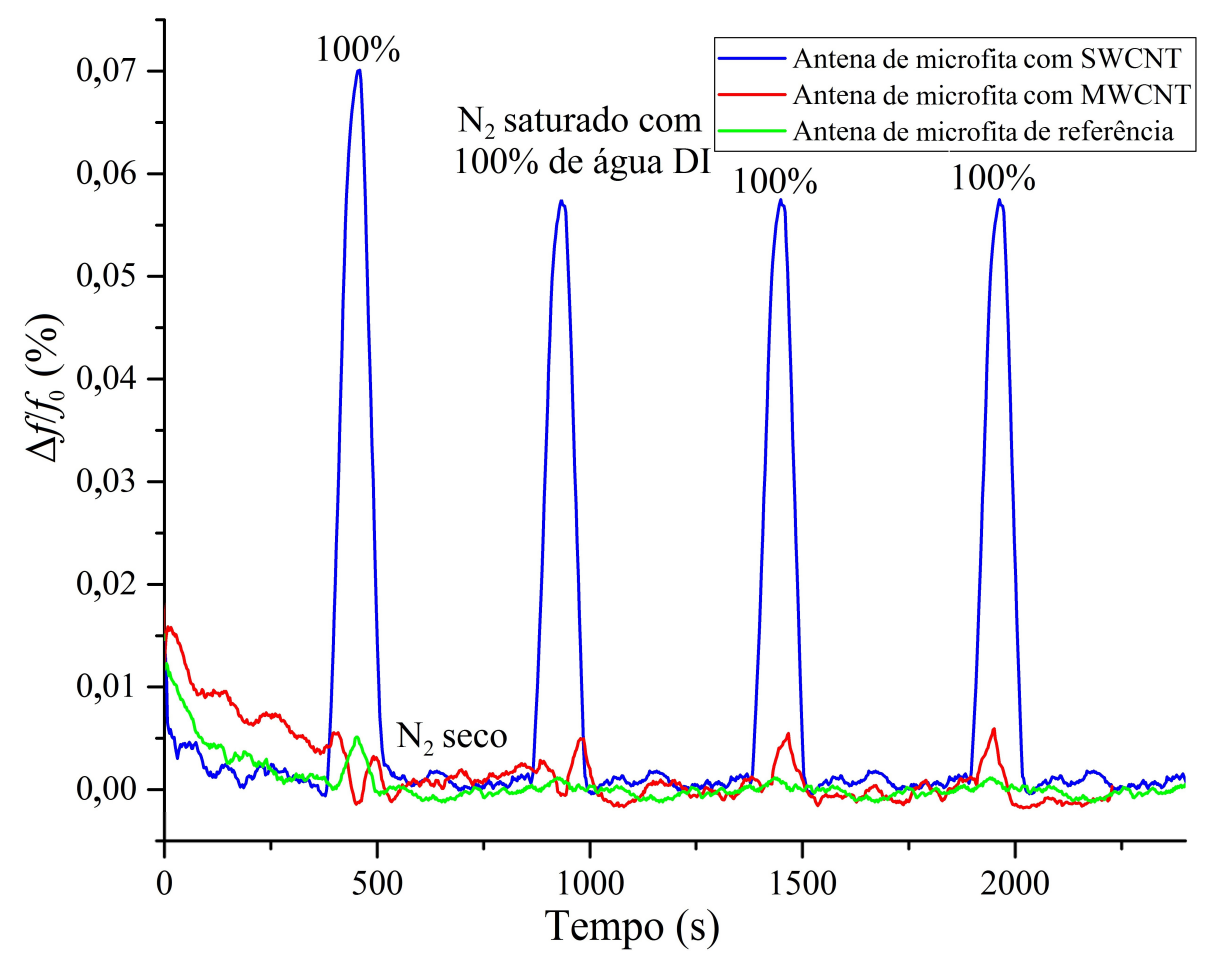

Do Gráfico 4.4, nota-se que a antena com SWCNT possuiu a maior sensibilidade. Tal comportamento não foi verificado com o MWCNT. Outro ponto importante que se 
conclui a partir do gráfico é que a antena sem nenhum material não sofre influência de vapor de umidade na sua superfície. Com isso, toda a variação da ressonância deve-se exclusivamente à mudança das características elétricas do SWCNT depositado sobre o substrato do sensor, quando submetido ao ambiente úmido.

Nos testes preliminares, procurou-se avaliar a resposta do sensor variando-se a umidade relativa. Para verificar essa influência, realizou-se um teste ponderando um fluxo de $\mathrm{N}_{2}$ seco e fluxo de $\mathrm{N}_{2}$ borbulhado em água deionizada (vapor d'água).

Configurou-se como teto o fluxo total de $1000 \mathrm{sccm}$ nos MFCs. Dessa forma para uma umidade relativa de $60 \%$, tem-se $600 \mathrm{sccm}$ no MFC com $\mathrm{N}_{2}$ borbulhado em água DI e 400 sccm no MFC com N2 seco. O Gráfico 4.5 apresenta a variação da sensibilidade da frequência de ressonância para diferentes proporções de umidade relativa. Para as medidas com diferentes umidades relativas, variou-se a injeção nos valores de $20 \%$, $40 \%, 60 \%, 80 \%$ e $100 \%$. Após atingir o valor máximo de $100 \%$, foram repetidas as medidas com os valores de $80 \%, 60 \%, 40 \%$ e $20 \%$, com objetivo de analisar um possível comportamento de histerese do sensor.

Gráfico 4.5 - Sensibilidade da frequência de ressonância da antena de microfita com SWCNT para diferentes proporções de umidade relativa (\%).

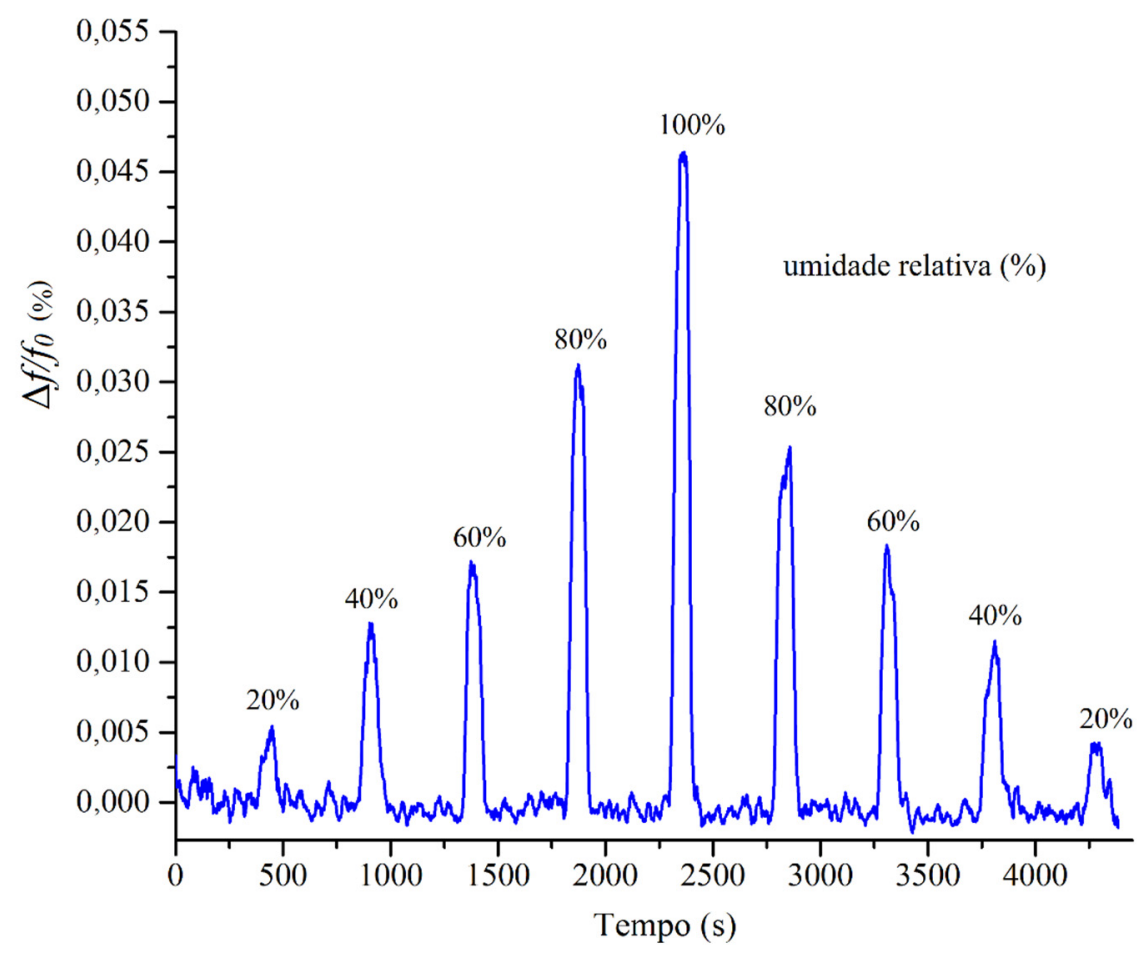


O Gráfico 4.6 apresenta os resultados experimentais do valor de umidade relativa em função da sensibilidade da frequência de ressonância do sensor, constituído pela antena de microfita com SWCNT. Esses resultados foram representados juntamente com as curvas mostradas no Gráfico 4.6, obtidas através dos ajustes linear e polinomial de $2^{\mathrm{a}}$ ordem pelo método dos mínimos quadrados expressas nas equações 4.7 e 4.8, respectivamente. Essas expressões permitem descrever o comportamento da umidade relativa do ar em termos da sensibilidade $\Delta f / f_{0}$ do sensor proposto.

Gráfico 4.6 - Relação entre os picos da sensibilidade da frequência de ressonância da antena de microfita com SWCNT em função da umidade relativa (\%).

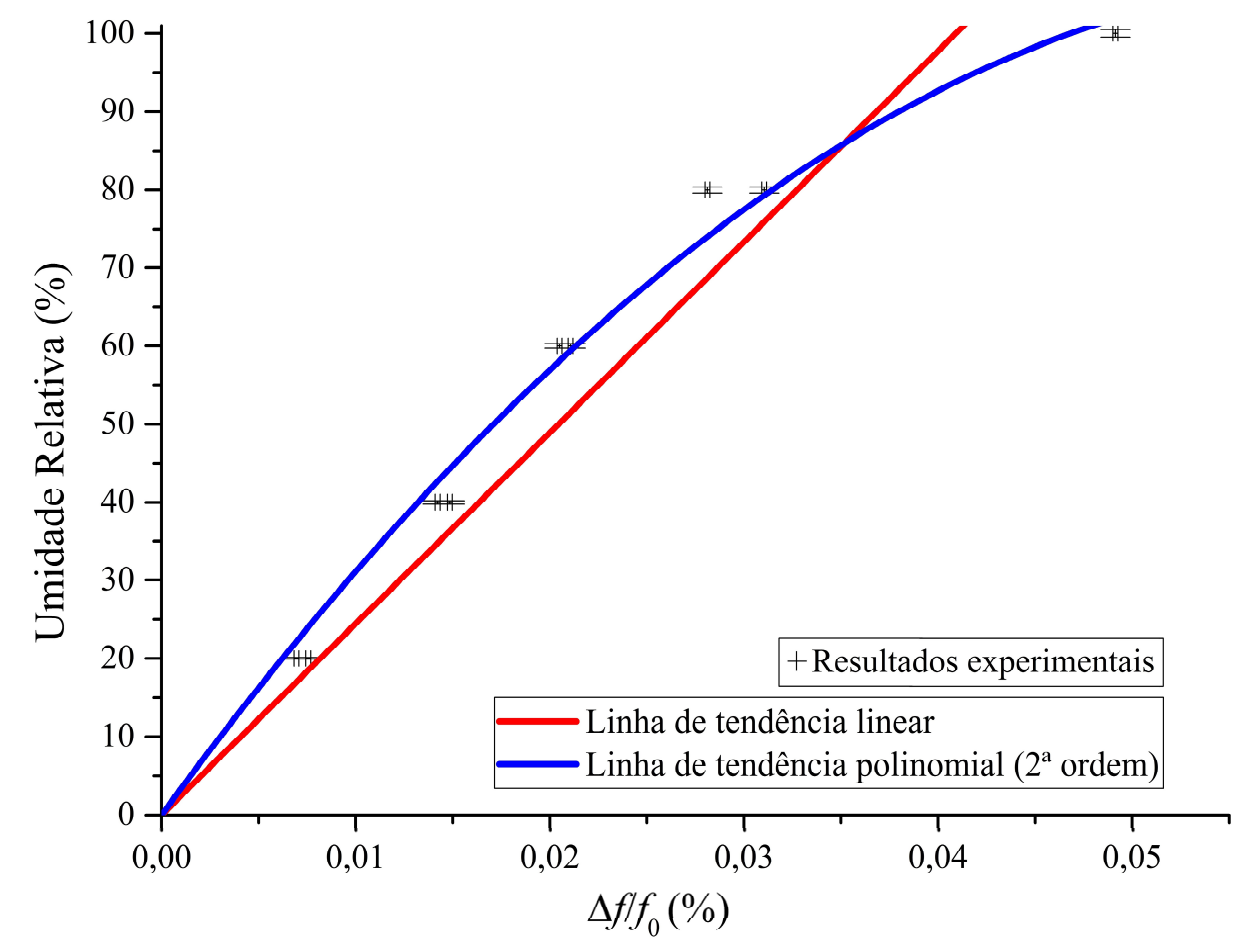

Verifica-se que o sensor responde gradualmente aos diferentes níveis de umidade relativa. A condição de umidade relativa $100 \%$ apresenta a maior sensibilidade. Dessa forma todas as análises posteriores para caracterização de etanol combustível, sempre utilizaram o máximo fluxo $(1000 \mathrm{sccm})$ do material borbulhado. Nota-se pequena variação no valor da sensibilidade da frequência de ressonância para o valor de umidade relativa de $80 \%$. Tal fato sugere que o sensor possui uma pequena deriva de seu comportamento. 
Como resultado secundário, tal comportamento permitiu extrapolar o uso desse sensor para medida de umidade relativa do ar.

$$
\begin{gathered}
\text { Umidade relativa }(\%)=B \frac{\Delta f}{f_{0}}=2444,28 \frac{\Delta f}{f_{0}}(\%) \\
\text { Umidade relativa }(\%)=C \frac{\Delta f}{f_{0}}+D\left(\frac{\Delta f}{f_{0}}\right)^{2}=3376,76 \frac{\Delta f}{f_{0}}-26501,97\left(\frac{\Delta f}{f_{0}}\right)^{2}(\%)
\end{gathered}
$$

Para o ajuste de primeira ordem, obteve-se $B=2444,28$. Do ajuste linear também é possível extrair o parâmetro de qualidade ${ }^{41} R^{2}$ de 0,9886 , o que garante bom ajuste da curva analítica obtida na regressão. Para o ajuste polinomial de $2^{\mathrm{a}}$ ordem, obteve-se $C=3376,76$ e $D=-26501,97$. O parâmetro de qualidade, $R^{2}$ de 0,9967 , garante um ajuste mais refinado do que a função de $1^{\mathrm{a}}$ ordem. Outras ordens de polinômios foram testadas a título de comparação com os polinômios descritos. Para um polinômio de $3^{\mathrm{a}}$ ordem, obteve-se $R^{2}$ de 0,9987 . Já para um polinômio de $4^{\text {a }}$ ordem o valor de $R^{2}$ igual a 0,9987 . Os valores de $R^{2}$ mostram que a aproximação de $2^{\text {a }}$ ordem fornece um bom compromisso entre qualidade de ajuste e baixa complexidade.

Em relação à curva de sensibilidade do índice de mérito, não há percepção de alteração que permita correlacionar a umidade relativa com esse dado. Notaram-se variações de $2 \%$ constantes para todas as proporções de umidade relativa.

\footnotetext{
${ }^{41}$ A qualidade do ajuste é medida através do coeficiente de determinação, $R^{2}$. Em geral, o valor de $R^{2}$ descreve como a variabilidade dos dados é explicada pelo modelo de regressão ajustado. Esse parâmetro varia entre 0 e 1 . Considera-se que a tendência dos dados é fortemente representada por uma função se $R^{2} \geq 0,9$. Caso contrário, diz-se que a relação não é bem descrita pelo modelo.
} 
4.2.1.2. Ensaios para teste da repetitividade e dinâmica da resposta da antena de microfita

O terceiro teste realizado levou em conta a repetitividade das medidas ao longo do tempo, analisando a variação da sensibilidade da frequência de ressonância da antena com SWCNT para várias medidas de uma mesma amostra. Dessa forma, a antena de microfita com SWCNT foi exposta repetidas vezes a $\mathrm{N}_{2}$ 100\% saturado com água, obtendo-se os resultados apresentados no Gráfico 4.7.

Do Gráfico 4.7, nota-se que, excetuando-se a primeira amostra, usualmente diferenciada, todas as outras injeções apresentaram valores máximos de sensibilidade muito próximas (desvio padrão de 0,0022). Portanto, não há evidências de degradação dos sensores nem oxidação permanente do cobre. Cabe também destacar que os sensores não necessitam de aquecimento nem exposição a ambientes de vácuo para realizar a dessorção de água. Este fato evidencia uma das vantagens do uso de CNT como elemento sensor.

Gráfico 4.7 - Caracterização da repetitividade da sensibilidade da frequência de ressonância da antena de microfita com $\mathrm{N}_{2}$ saturado com água DI.

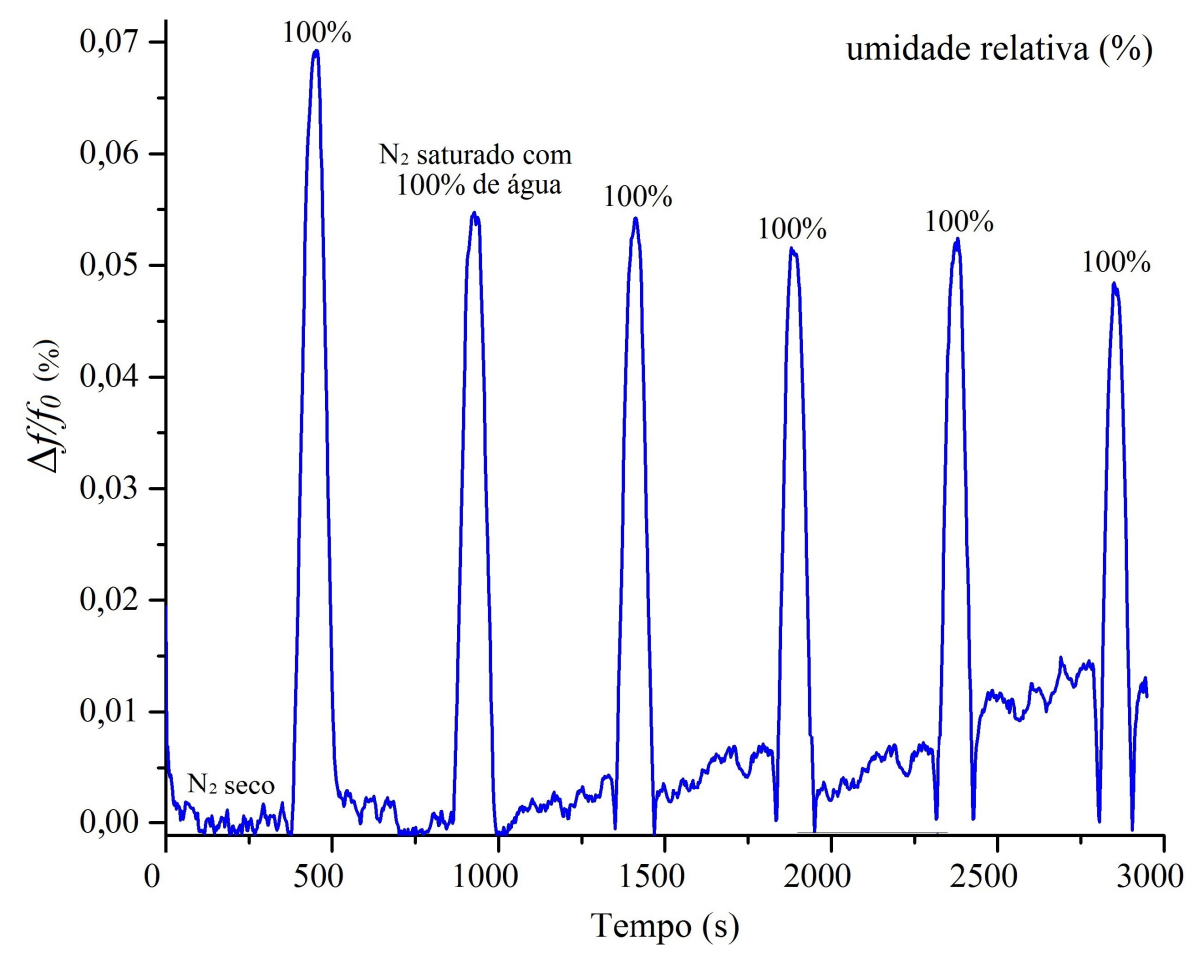


A resposta dinâmica do sensor é apresentada no Gráfico 4.8. O tempo de resposta é de aproximadamente $40 \mathrm{~s}$, isto é, o tempo para alcançar $90 \%$ do pico da variação da sensibilidade da frequência de ressonância. O tempo de restabelecimento, tempo para retornar a $10 \%$ do valor de pico foi de $45 \mathrm{~s}$.

Esse resultado indica que a interação entre o vapor de água e o CNT é devido a processos de fisissorção com ligações fracas. Como é esperado, é necessário um determinado tempo para que essas ligações se rompam, sugerindo que as moléculas de água ficam armadilhadas aos aglomerados de CNT. Além disso, esse resultado indica que pode haver relação entre a quantidade de CNT depositado e a dinâmica da resposta do sensor.

Gráfico 4.8 - Resposta dinâmica da sensibilidade da frequência de ressonância da antena de microfita com $\mathrm{N}_{2}$ saturado com água DI.

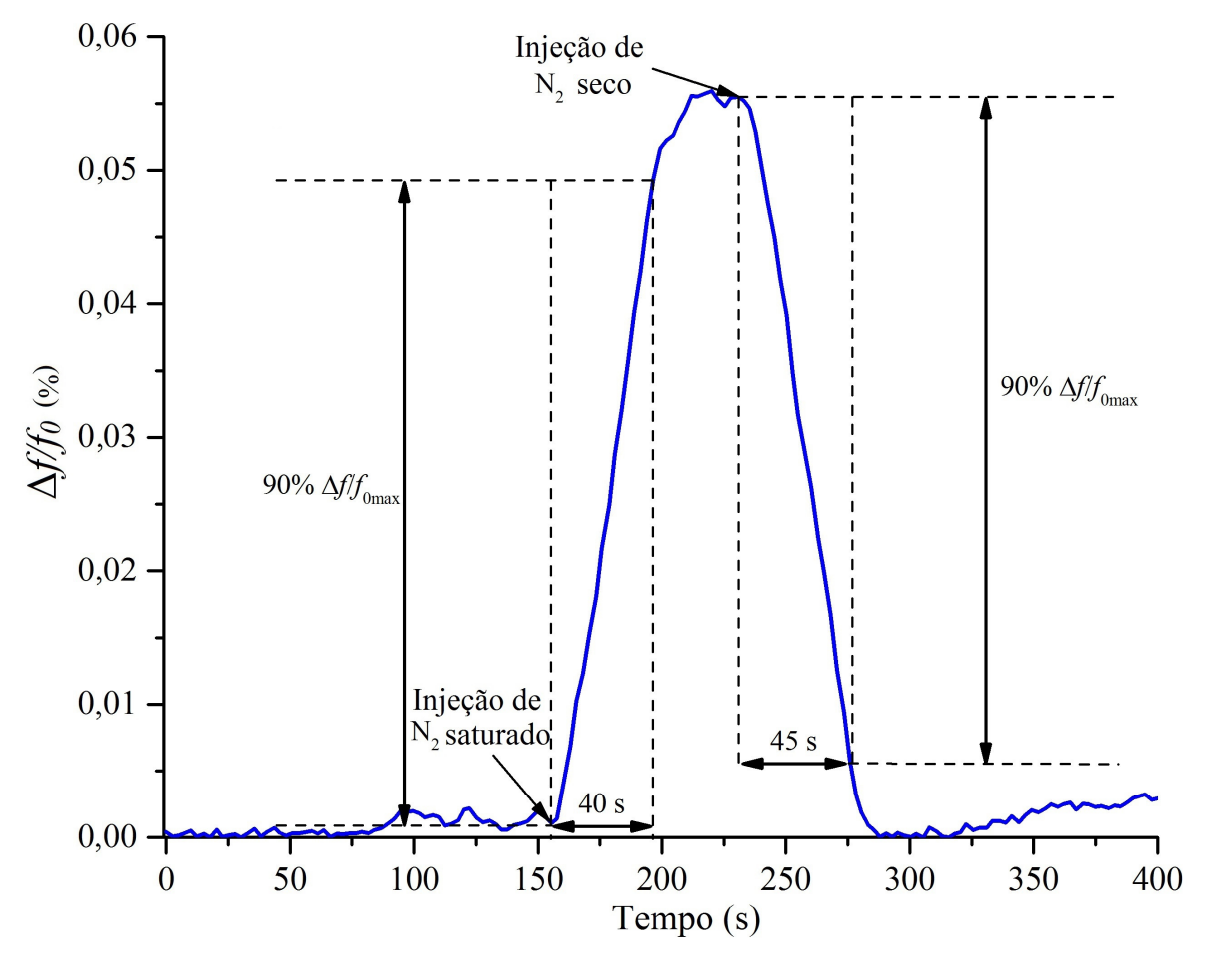

4.2.1.3. Ensaios de qualificação de misturas de etanol combustível

Baseado nos resultados preliminares, foram caracterizadas as amostras de etanol com água. Como a antena com MWCNT foi praticamente insensível à variação com água, 
somente se caracterizou a antena com SWCNT. Inicialmente foram medidos os coeficientes de reflexão da antena com SWCNT para as amostras de água DI e etanol 99,5\%, que correspondem às variações máxima e mínima na resposta em frequência da antena, respectivamente. O Gráfico 4.9 apresenta a comparação entre os coeficientes de reflexão, indicando a faixa de variação da frequência de ressonância e do índice de mérito da antena com SWCNT para as amostras descritas. Para realizar a medida do coeficiente de reflexão, o analisador de redes foi calibrado na faixa de frequências entre 5 e $6 \mathrm{GHz}$. A medida foi realizada com 401 pontos.

Gráfico 4.9 - Coeficiente de reflexão da antena de microfita para as amostras de água DI e etanol 99,5\% em comparação com as curvas de referência.

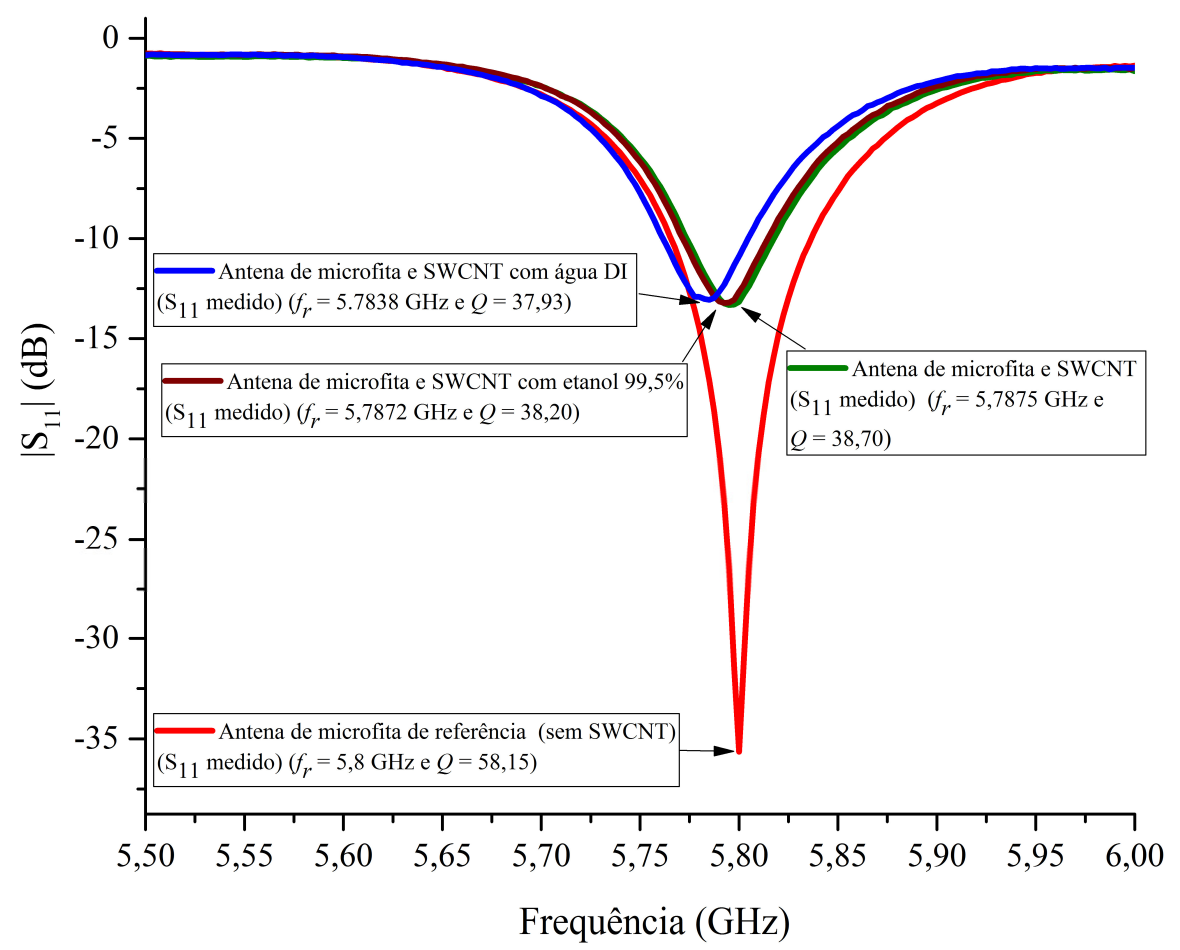

Nota-se que a antena de microfita com SWCNT varia ligeiramente sua resposta em frequência para a inserção de etanol anidro, enquanto que para a água DI, material com maior permissividade elétrica, essa variação fica mais evidente. Como já citado no subitem 3.7.2, o comportamento da resposta em frequência da antena de microfita com SWCNT na presença de vapores ocorre devido a dois processos físico-químicos transferência de cargas elétricas e polarização do SWCNT — que afetam a 
condutividade elétrica e a permissividade elétrica do material nanoestruturado, respectivamente (SNOW et al., 2005).

A variação da condutividade elétrica se deve à transferência de cargas entre o SWCNT e as moléculas da mistura de etanol e água adsorvidas na superfície do sensor (MARLIERE et al., 1999) (COLLINS et al., 2000) (ESEN et al., 2007) (HINES ET AL., 2005). Dessa maneira, há um decréscimo do número de portadores elétricos disponíveis, causando um decréscimo no valor da condutividade elétrica do meio. Esse comportamento pode ser verificado através do índice de mérito das antenas com depósito de SWCNT. O valor desse índice tende a diminuir conforme o tipo e a quantidade de material adsorvido. Como é possível verificar no Gráfico 4.9, a transferência de cargas é mais acentuada quando a antena de microfita com SWCNT é submetida ao vapor de água DI, do que quando submetida ao vapor de etanol 99,5\%. Os efeitos de polarização ocorrem devido à formação de uma camada de moléculas do material sob teste no SWCNT (SNOW et al., 2005). Com isso, aumenta-se o valor da permissividade elétrica do material nanoestruturado. Com o aumento dos efeitos de polarização, há uma redução da frequência de ressonância das antenas. Como verificado no Gráfico 4.9, a frequência de ressonância é menor quanto maior é a adsorção do material na antena de microfita com SWCNT. Dessa forma, a antena de microfita apresenta uma frequência de ressonância menor quando submetida a água DI, comparado a inserção de etanol 99,5\%.

Ao invés de obter o gráfico do coeficiente de reflexão em função da frequência, a interface de aquisição descrita no Apêndice G é capaz de tomar as medidas da frequência de ressonância (frequência do ponto de mínimo da curva de coeficiente de reflexão) e do índice de mérito, ambos determinados automaticamente pelo analisador vetorial de redes.

Os ensaios descritos nos gráficos 4.10 e 4.11 apresentam o comportamento dos parâmetros de frequência de ressonância e índice de mérito normalizados em função do tempo.

O Gráfico 4.10 apresenta a variação da sensibilidade da frequência de ressonância para diferentes frações volumétricas de etanol em água, conforme descrito no capítulo 3. Observa-se a maior sensibilidade para a condição de $0 \%$ de etanol, ou seja, água pura. 
Gráfico 4.10 - Sensibilidade da frequência de ressonância da antena de microfita com SWCNT para caracterização de etanol combustível.

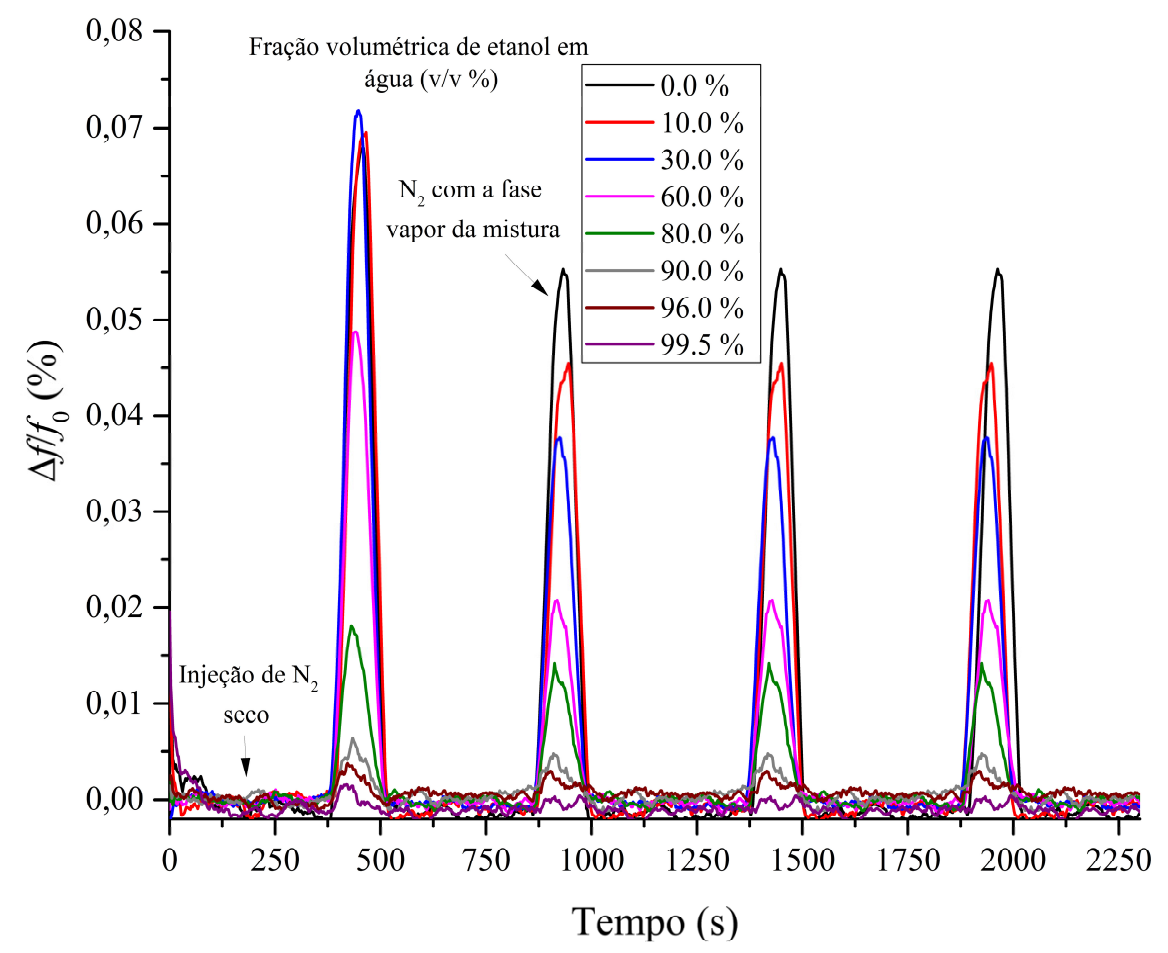

Gráfico 4.11 - Sensibilidade normalizada do índice de mérito da antena de microfita com SWCNT para caracterização de etanol combustível.

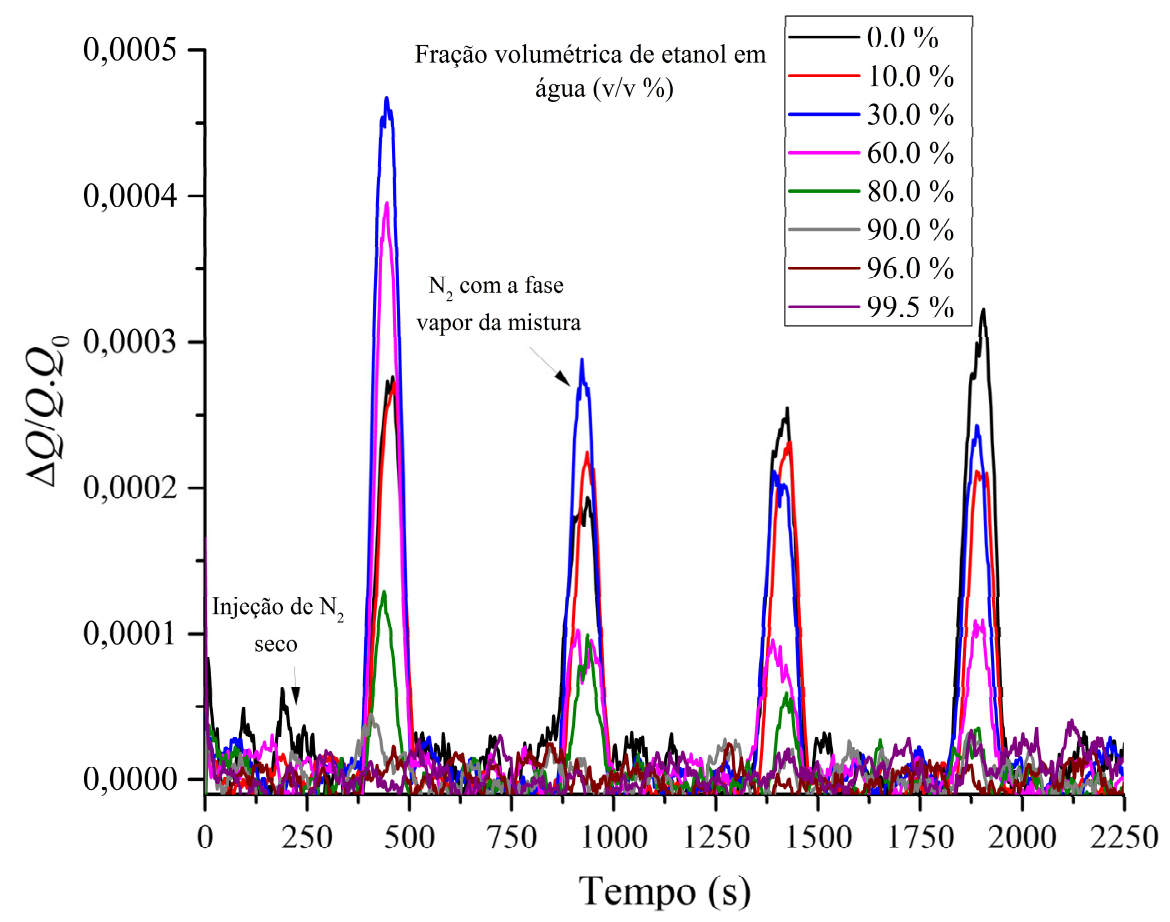


Essa variação fica cada vez menor com a adição de etanol em detrimento à água, indicando uma proporcionalidade inversa entre o teor de água no etanol e a sensibilidade de frequência de ressonância do sensor.

O mesmo procedimento foi realizado para a medida do índice de mérito. O Gráfico 4.11 apresenta a variação da sensibilidade desse parâmetro para a antena com SWCNT. Desse gráfico, é nítido que somente a partir da segunda inserção de gás é obtido um comportamento estável do sensor. Além disso, há uma sobreposição de curvas para diferentes concentrações, o que dificulta correlacionar isoladamente o teor de água em etanol com a sensibilidade normalizada do índice de mérito do sensor. Ressalta-se que tal fato não ocorre com a sensibilidade da frequência de ressonância.

O Gráfico 4.12 apresenta a relação entre a fração volumétrica da mistura de etanol em água com a sensibilidade da frequência de ressonância da antena com SWCNT. Ou seja, verifica-se uma forte correlação entre a porcentagem de diluição com a variação da frequência de ressonância do sensor. Para as medidas com o analisador de redes, calculou-se, através de propagação de incertezas, um valor máximo de 1,2\% de incerteza relativa.

Através dos pontos obtidos experimentalmente, pode-se ajustar uma linha de tendência linear, que possibilita calcular pontos intermediários de diluição. Além disso, verificase boa concordância entre os pontos e a curva do ajuste linear, como mostrado no Gráfico 4.12.

O valor dos coeficientes da curva de ajuste linear, apresentado pela equação 4.9, são: $A=99,35$ e $B=-1884,07$. Do ajuste linear também é possível extrair o parâmetro de qualidade $R^{2}$ igual a 0,9912 , o que indica boa qualidade da curva analítica obtida a partir da regressão. Ou seja, o sensor tem resposta proporcional à variação da mistura de etanol, o que é conveniente para aplicações práticas de análise e qualificação dessa substância.

$$
\text { Fração em volume de etanol }\left({ }^{\circ} \mathrm{GL}\right)=A+B \frac{\Delta f}{f_{0}}=99,35-1884,07 \frac{\Delta f}{f_{0}}(\%)
$$


Gráfico 4.12 - Relação entre os picos da sensibilidade da frequência de ressonância da antena de microfita com SWCNT e a fração volumétrica de etanol e água.

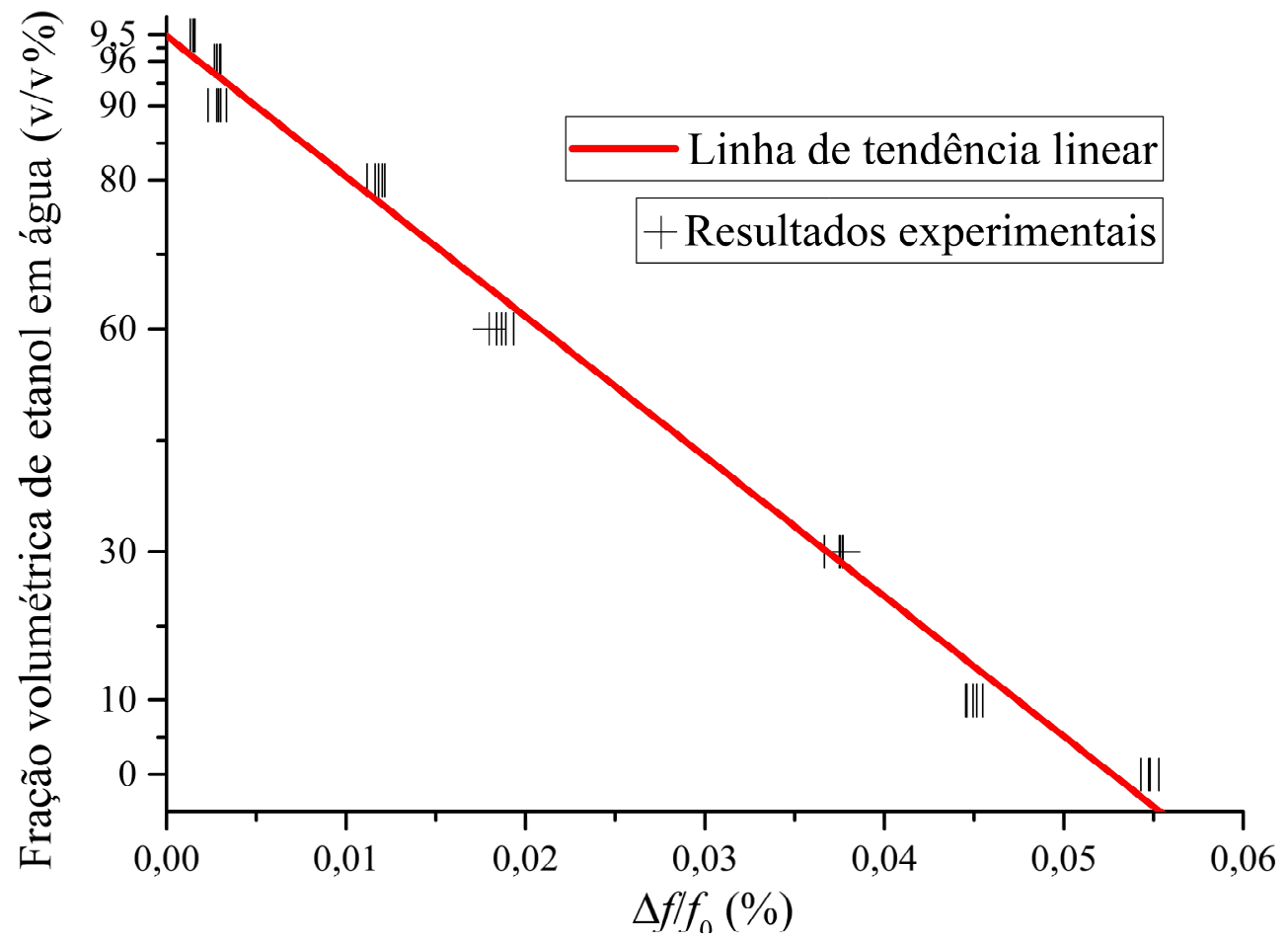

Como é estabelecido na literatura acerca da teoria da perturbação da cavidade ressonante (ver APÊNDICE B), a variação da frequência de ressonância está correlacionada com a parte real da permissividade complexa. Além disso, a sensibilidade do índice de mérito tem relação direta com as perdas no material e, por sua vez, com a parte imaginária da permissividade elétrica complexa ${ }^{4243}$.

42 Para a parte real, $\varepsilon_{r}^{\prime} \approx 1+A^{\prime} \frac{\Delta f}{f_{0}}$ e para parte imaginária $\varepsilon_{r}^{\prime \prime} \approx A^{\prime \prime}\left(\frac{1}{Q_{s}}-\frac{1}{Q_{0}}\right)=A^{\prime \prime} \frac{1}{Q_{s}}\left(\frac{\Delta Q}{Q_{0}}\right)$, no qual, $A^{\prime}$ e $A^{\prime \prime}$ representam constantes de ajustes relativos à geometria da cavidade ressonante.

${ }^{43}$ Como detalhado no Apêndice B, alguns autores, devido às aproximações que são realizadas, consideram que a relação entre a variação da frequência de ressonância e a parte real da permissividade elétrica complexa é dada pela equação $\varepsilon_{r}^{\prime} \approx 1+A^{\prime} \frac{\Delta f}{f_{s}}$. Neste trabalho, optou-se pela equação que normaliza a variação da frequência de ressonância, $\Delta f$, pela frequência de ressonância da cavidade sem o material perturbante, $f_{0}$. 
Dessa forma, é possível comparar os valores medidos de sensibilidade do sensor com os valores de permissividade elétrica complexa em $5,8 \mathrm{GHz}^{44}$, obtidos com os modelos das regras de mistura apresentadas no item 4.1.

A compilação dos resultados é descrita pela Tabela 4.3. Toma-se como referência, a média dos valores dos três picos a partir da segunda inserção da fase vapor dos materiais sob teste. Dessa forma cada fração de etanol e água corresponde a um valor de sensibilidade de frequência de ressonância e um valor de sensibilidade de índice de mérito.

Comparam-se os valores da permissividade elétrica complexa, obtidos através das regras de diluição, com os valores da sensibilidade da frequência de ressonância e índice de mérito da antena com SWCNT. Essa correlação é baseada no método da perturbação da cavidade ressonante. Os Gráficos 4.13 e 4.14 apresentam a correlação das sensibilidades com a permissividade elétrica complexa.

Tabela 4.3 - Valores de permissividade elétrica complexa com os parâmetros de sensibilidade obtidos na antena de microfita.

\begin{tabular}{cccccc}
\hline $\begin{array}{c}\text { Fração } \\
\text { volumétrica de } \\
\text { etanol (v/v \%) }\end{array}$ & $\begin{array}{c}\text { Fração } \\
\text { em massa } \\
\text { de etanol } \\
(\%)\end{array}$ & $\begin{array}{c}\Delta f / f_{0} \\
(\text { Medido) }\end{array}$ & $\begin{array}{c}\text { Parte real da } \\
\text { permissividade } \\
\text { elétrica }(\varepsilon r) \\
\text { (Regras de } \\
\text { diluição) }\end{array}$ & $\begin{array}{c}\text { Parte } \\
1 / Q_{s .}\left(\Delta Q / Q_{0}\right) \\
\text { (Medido) }\end{array}$ & $\begin{array}{c}\text { permissividade } \\
\text { imagíria da } \\
\text { elétrica }(\varepsilon r) \\
\text { (Regras de } \\
\text { diluição) }\end{array}$ \\
\hline 99,50 & 99,36 & 0,00158 & 6,06148 & $2,30 \times 10^{-5}$ & 4,33428 \\
96,00 & 94,96 & 0,00297 & 6,83668 & $3,18 \times 10^{-5}$ & 5,34917 \\
90,00 & 87,60 & 0,00334 & 7,87419 & $4,49 \times 10^{-5}$ & 8,21510 \\
80,00 & 75,84 & 0,01163 & 11,87095 & $9,11 \times 10^{-5}$ & 10,5160 \\
60,00 & 54,07 & 0,01868 & 20,64952 & $1,04 \times 10^{-4}$ & 17,37734 \\
30,00 & 25,17 & 0,03766 & 44,74362 & $2,43 \times 10^{-4}$ & 26,03145 \\
10,00 & 8,02 & 0,04460 & 65,32026 & $2,19 \times 10^{-4}$ & 23,92333 \\
0,00 & 0,00 & 0,05430 & 72,76004 & $1,94 \times 10^{-4}$ & 20,51856 \\
\hline
\end{tabular}

${ }^{44}$ Vale lembrar que a frequência de ressonância da antena com SWCNT era de 5,7875 GHz. Contudo os valores de permissividade elétrica complexa para essa frequência são próximos aos obtidos em $5,8 \mathrm{GHz}$. 
Gráfico 4.13 - Relação entre os picos da sensibilidade da frequência de ressonância e a parte real da permissividade elétrica para a antena de microfita com SWCNT.

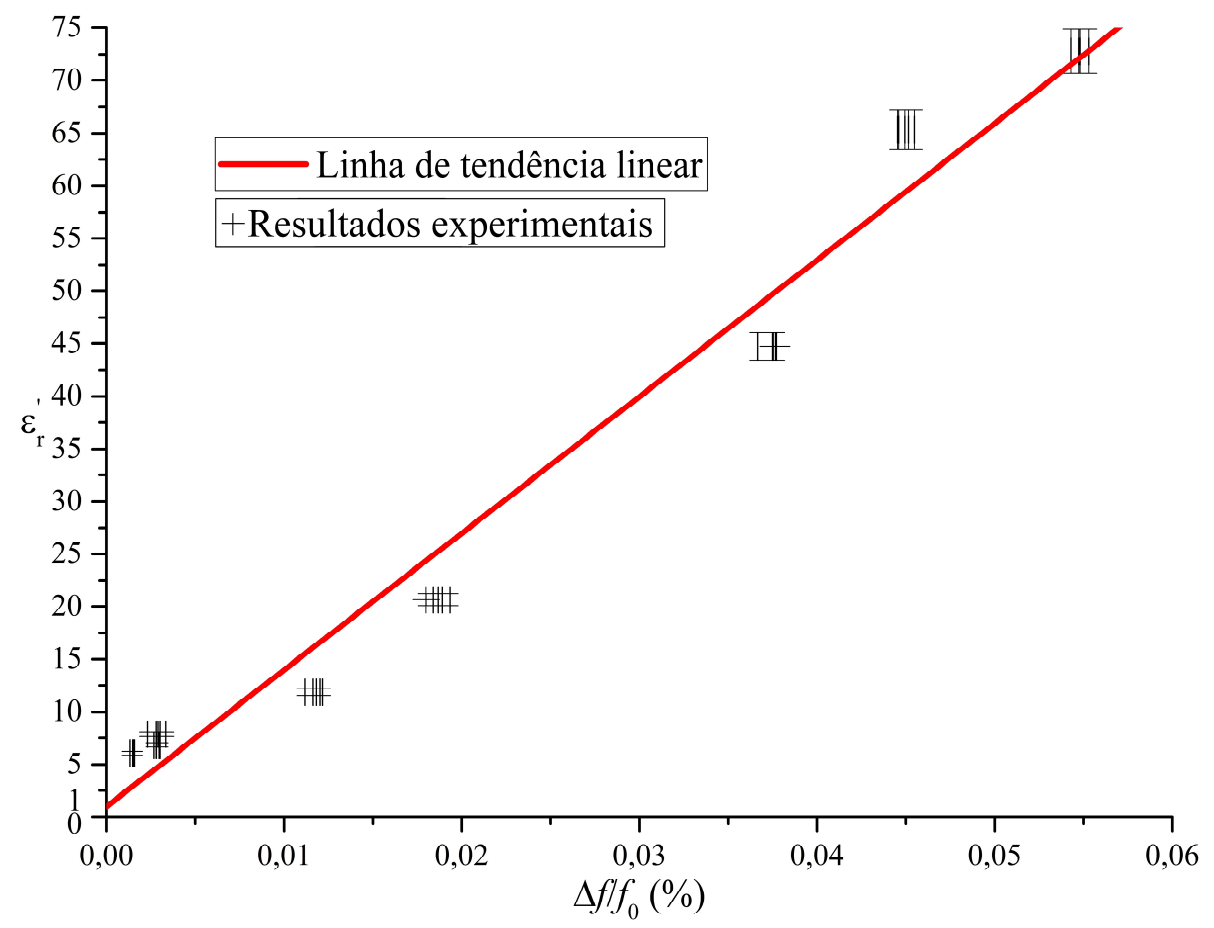

A caracterização da permissividade elétrica complexa do material é uma análise indireta em relação à adulteração de etanol combustível. Entretanto do ponto de vista de caracterização eletromagnética de materiais é mais importante, pois permite analisar os parâmetros constitutivos dos materiais sob teste.

Foi adotado um ajuste linear visando obter equações similares às utilizadas na teoria da perturbação da cavidade ressonante. Dessa forma, tanto a parte real como imaginária da permissividade elétrica das misturas de etanol em água possuem representação idênticas às obtidas pelas equações B.18 e B.19.

O Gráfico 4.13 apresenta a relação entre a sensibilidade da frequência de ressonância em função da parte real da permissividade elétrica complexa. Para um ajuste de primeira ordem dessa relação, de acordo com a equação 4.10, obteve-se $A^{\prime}=1298,75$. Do ajuste linear também é possível extrair o parâmetro de qualidade $R^{2}$ igual a 0,9940 . 


$$
\varepsilon_{r}^{\prime}=1+A^{\prime} \frac{\Delta f}{f_{0}}=1+1298,75 \frac{\Delta f}{f_{0}}(\%)
$$

Alguns pontos do gráfico ficam sensivelmente prejudicados para o ajuste linear, sendo que os valores próximos ao meio da faixa apresentam erros relativos superiores a $30 \%$. O Gráfico 4.14 apresenta a relação entre a sensibilidade do índice de mérito em função da parte imaginária da permissividade elétrica complexa.

Para um ajuste de primeira ordem, de acordo com a equação 4.11 , obteve-se $A^{\prime \prime}=$ 113.853,67. Do ajuste linear também é possível extrair o parâmetro de qualidade $R^{2}$ igual a 0,9752 , indicando bom ajuste da curva analítica obtida na regressão.

$$
\varepsilon_{r}^{\prime \prime}=A^{\prime \prime} \frac{1}{Q_{s}} \cdot \frac{\Delta Q}{Q_{0}}=113853,67 \frac{1}{Q_{s}} \cdot \frac{\Delta Q}{Q_{0}}
$$

Gráfico 4.14 - Relação entre os picos da variação do índice de mérito e a parte imaginária da permissividade elétrica para a antena de microfita com SWCNT.

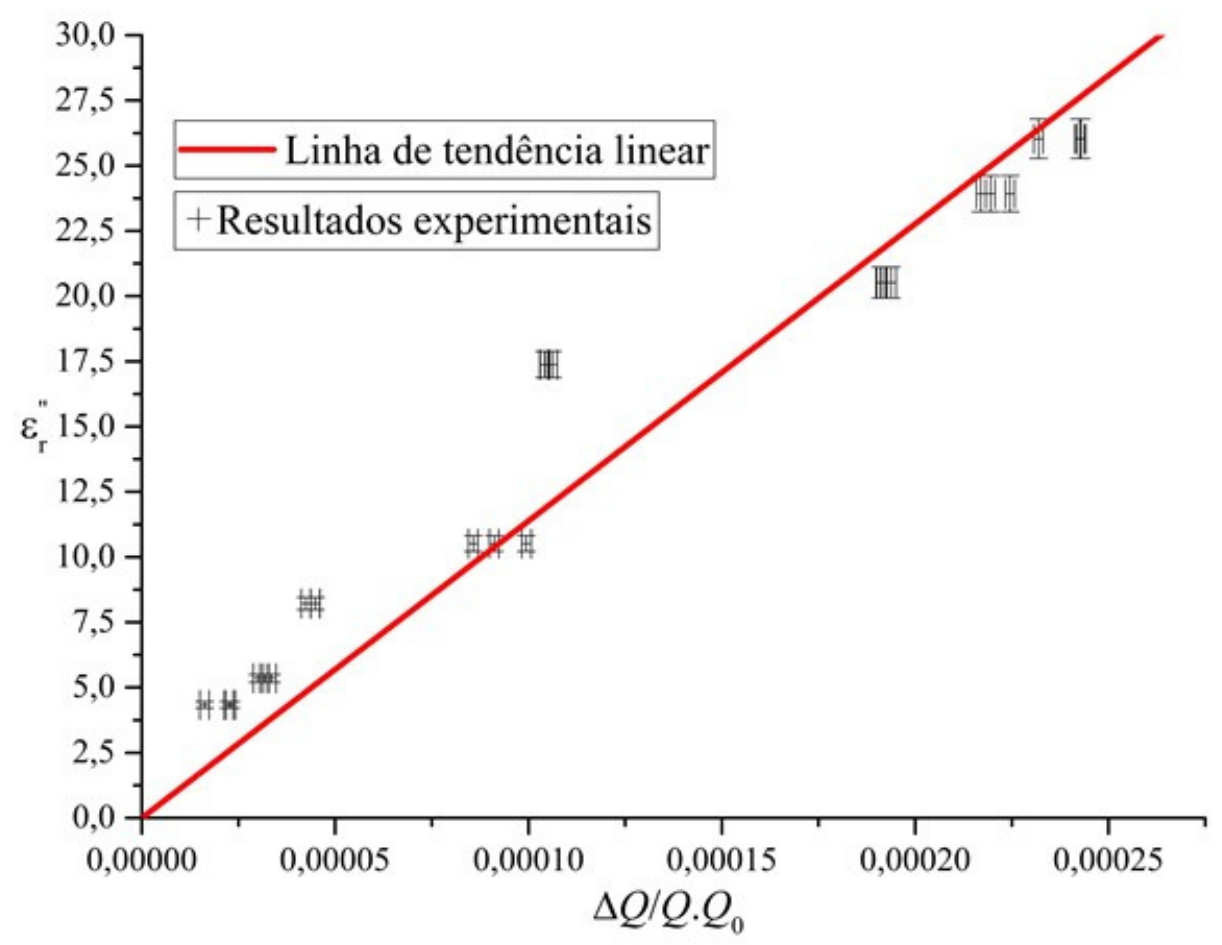


Nota-se correlação entre os dados obtidos nesse trabalho, com aqueles esperados a partir da literatura acerca dos métodos de caracterização eletromagnéticos de materiais através de técnicas ressonantes.

Os resultados de permissividade elétrica obtidos experimentalmente com o sensor usando antena de microfita recoberta por SWCNT possuem boa concordância com os valores relatados na literatura (BAO et al., 1996). Dessa forma, esses resultados serviram como prova de conceito, indicando sua potencialidade para caracterização de etanol combustível. Na sequência da pesquisa foi proposto um sensor empregando uma antena SIW com o mesmo conceito, contudo com maior sensibilidade.

\subsubsection{Antena com cavidade ressonante em SIW e fenda traseira}

Para o sensoriamento da fase vapor de etanol combustível foi desenvolvida uma antena com cavidade ressonante em SIW com fenda retangular traseira. A partir das características da estrutura SIW, em especial a distribuição do campo elétrico nas regiões centrais, obtém-se valores mais acentuados de sensibilidade da frequência de ressonância e de índice de mérito comparado com a antena de microfita com CNT. Dessa forma, foi possível melhorar a resposta dos sensores de fase vapor com CNT.

Utilizando as equações descritas em 3.5 foi projetada e simulada uma antena com cavidade ressonante em SIW na frequência de ressonância em 5,8 GHz. Utilizou-se o modo ressonante $\mathrm{TE}_{101}$, de forma que comprimento e a largura efetiva da seção transversal têm o mesmo valor, sendo igual a 26,5 mm (APÊNDICE N). Os valores das seções transversais $a$ e $b$ de 27,46 mm foram obtidos após otimização utilizando o simulador eletromagnético CST Studio. Esse fato é esperado, pois o valor da seção da seção transversal é maior do que seu valor efetivo.

Os valores apresentados na Tabela 4.4 descrevem os parâmetros geométricos da antena com cavidade e fenda obtidos após o projeto e a otimização computacional. A dimensão total da antena com cavidade foi de 39,46 × 39,46 mm. Ressalta-se o uso do mesmo substrato apresentado anteriormente. 
Tabela 4.4 - Dimensões otimizadas da antena com cavidade ressonante SIW com fenda traseira.

\begin{tabular}{lc}
\hline \multicolumn{1}{c}{ Parâmetro de projeto } & Especificação após otimização \\
\hline Frequência de operação $\left(f_{r}\right)$ & $5,8 \mathrm{GHz}$ \\
$\begin{array}{l}\text { Distância entre fileiras de furos } \\
\text { metalizados - largura e comprimento da } \\
\text { seção transversal }(a)(b)\end{array}$ & $27,46 \mathrm{~mm}$ \\
Largura e comprimento da antena com & \\
cavidade & $39,46 \mathrm{~mm}$ \\
Comprimento da reentrância $\left(y_{0}\right)$ & $25,49 \mathrm{~mm}$ \\
Largura da fenda da reentrância $\left(x_{0}\right)$ & $0,20 \mathrm{~mm}$ \\
Diâmetro do furo metalizado $(d)$ & $2 \mathrm{~mm}$ \\
Distância entre furos $(p)$ & $3,70 \mathrm{~mm}$ \\
Largura da fenda & $10,56 \mathrm{~mm}$ \\
Comprimento da fenda & $1,75 \mathrm{~mm}$ \\
Largura da linha de microfita $\left(W_{f}\right)$ & $1,52 \mathrm{~mm}$ \\
Comprimento da linha de microfita $\left(L_{f}\right)$ & $10 \mathrm{~mm}$ \\
\hline
\end{tabular}

A Figura 4.4 (a) apresenta o modelo de simulação utilizado no CST Studio Suite, enquanto que a Figura 4.4 (b) apresenta o protótipo desenvolvido.

A Figura 4.5 apresenta a distribuição do campo elétrico da antena com cavidade ressonante SIW com fenda. Como é esperado no modo TE101, a máxima distribuição de campo elétrico é obtida na região central da antena, onde está posicionada a linha de alimentação e a fenda radiante.

Foram depositados SWCNT funcionalizados na traseira da antena, em específico, na região com máximo campo elétrico que engloba a fenda radiante e suas proximidades. 
Figura 4.4 - (a) modelo de simulação da antena SIW com alimentação indentada e fenda traseira para projeto e simulação; (b) protótipo desenvolvido.
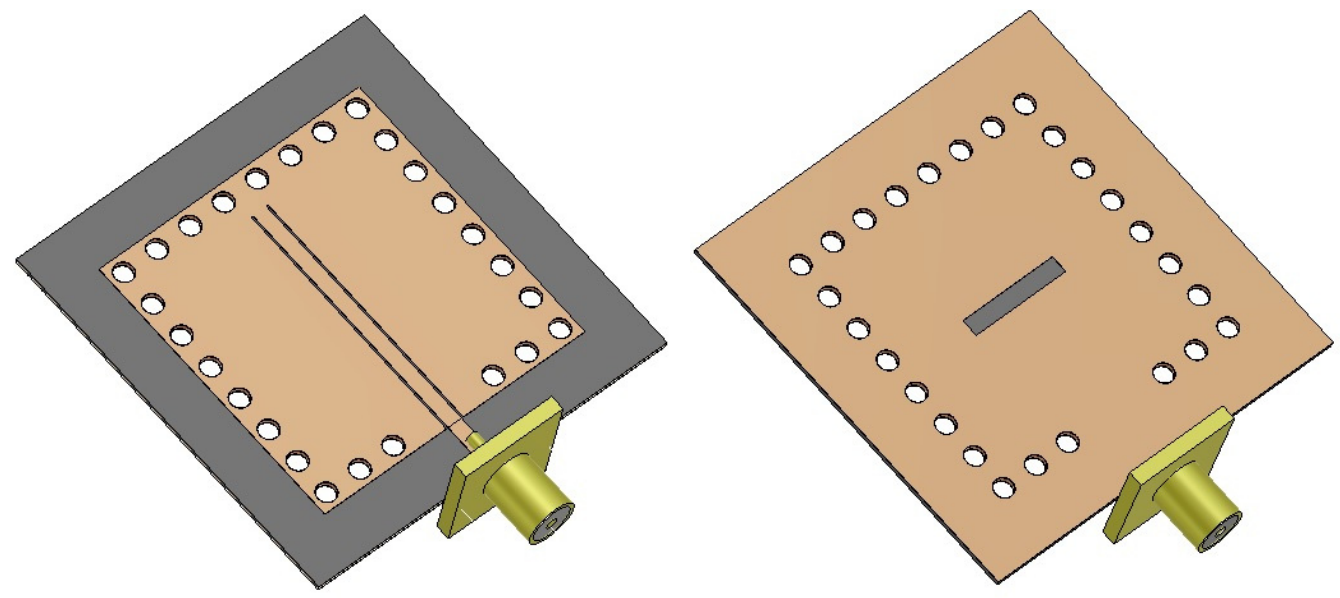

(a)
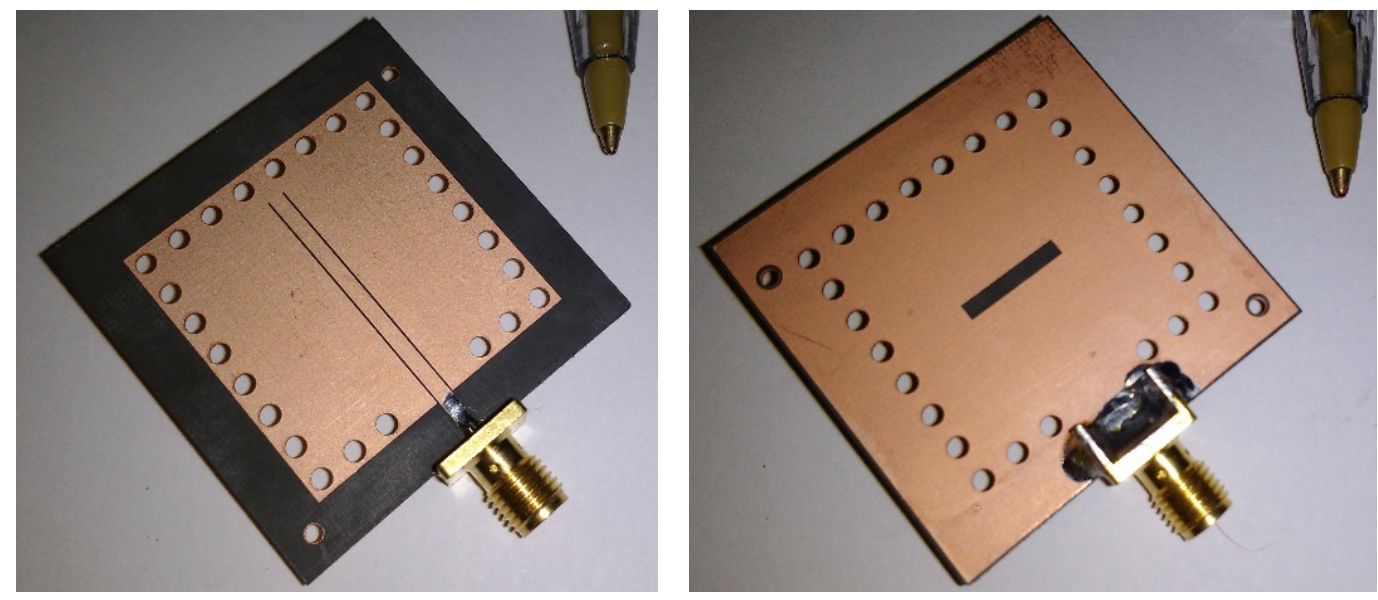

(b)

Figura 4.5 - Distribuição do campo elétrico [V/m] na antena com cavidade ressonante SIW com alimentação indentada e fenda traseira.
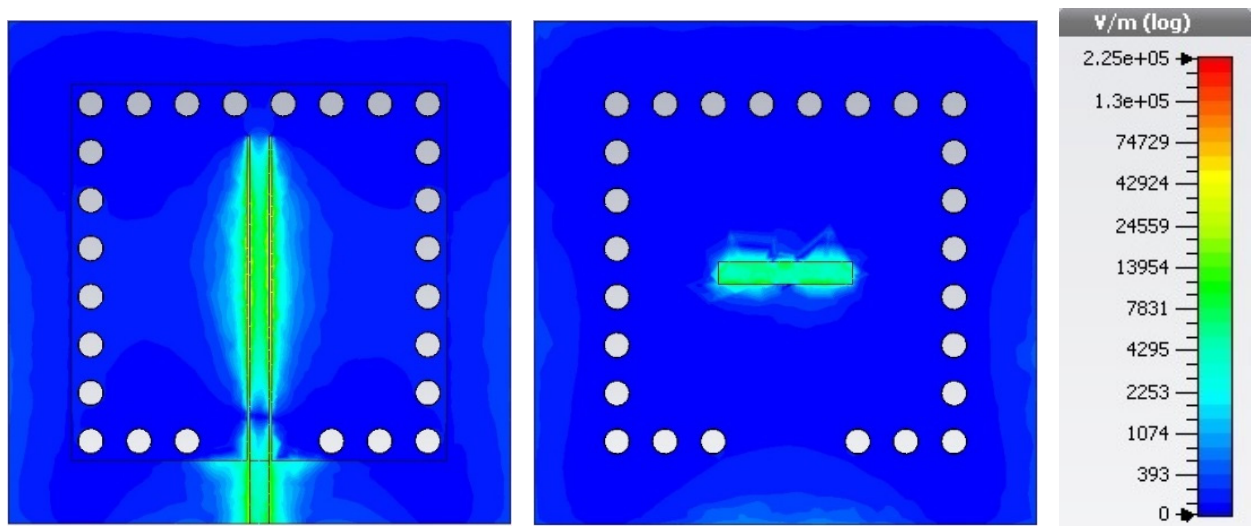
A mesma metodologia, descrita no capítulo 3, para deposição dos nanotubos na antena de microfita foi utilizada para a antena SIW com fenda traseira. A Figura 4.6 apresenta a antena SIW com SWCNT.

Figura 4.6 - Antena com cavidade ressonante em SIW e fenda traseira com depósito de nanotubos de carbono: SWCNT diluído em água.

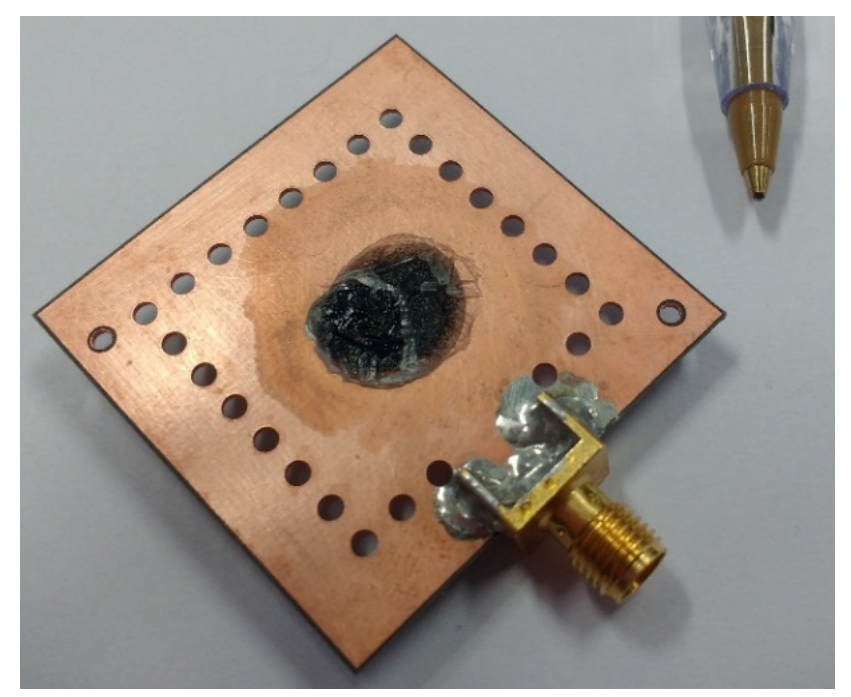

O Gráfico 4.15 apresenta os coeficientes de reflexão resultantes da simulação e da medida do protótipo da antena SIW com fenda traseira, bem como da antena SIW com fenda traseira recoberta por SWCNT. Ambas as medidas da antena SIW foram realizadas em ambiente com $\mathrm{N}_{2}$ seco. Para realizar a medida do coeficiente de reflexão, o analisador de redes foi calibrado na faixa de frequências entre 5 e $6 \mathrm{GHz}$. Uma primeira medida foi realizada com 401 pontos. Como a antena possui elevado índice de mérito, foi realizada uma nova calibração na faixa de 5,7 a 5,9 GHz com os mesmos 401 pontos. Ambas as curvas foram armazenadas e sua combinação está apresentada na Gráfico 4.15.

Obteve-se para a antena simulada o valor do coeficiente de reflexão mínimo de, aproximadamente, $-51,33 \mathrm{~dB}$ na frequência de ressonância de $5,8 \mathrm{GHz}$ e índice de mérito de, aproximadamente, 156,75. 
Gráfico 4.15 - Comparação entre os coeficientes de reflexão simulado e medido da antena com cavidade ressonante com alimentação indentada e fenda traseira em função da frequência.

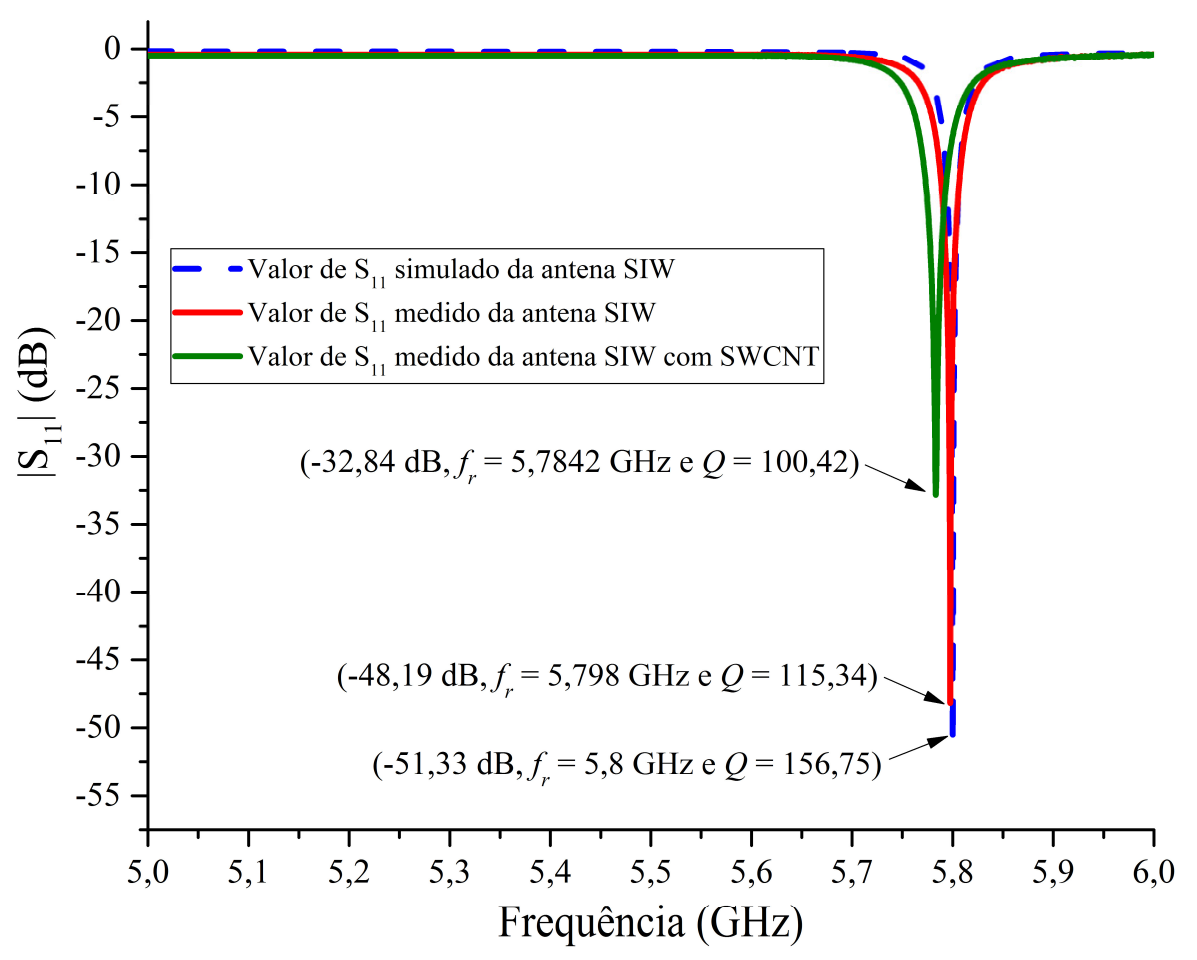

A medida do protótipo da antena SIW indicou coeficiente de reflexão mínimo de $-48,19 \mathrm{~dB}$ na frequência de $5,798 \mathrm{GHz}$. A pequena diferença observada em relação aos resultados de simulação é devida, principalmente, a variações nas dimensões da linha de alimentação e da posição da linha indentada. $O$ índice de mérito medido do protótipo da antena SIW foi de 115,34.

Para o protótipo com nanotubos de carbono foi medido o coeficiente de reflexão mínimo de $-32,84 \mathrm{~dB}$ na frequência de 5,7842 GHz. Essa medida foi realizada após os nanotubos estarem totalmente secos e com a injeção de fluxo de $\mathrm{N}_{2}$. Tanto para a antena de microfita como para a antena SIW, os nanotubos modificam as condições de permissividade elétrica efetiva, afetando, dessa forma, a frequência de ressonância e o índice de mérito.

Da estrutura da antena SIW desenvolvida, ressalta-se o elevado índice de mérito e a concentração do campo elétrico nas regiões centrais. Tal fato, como já mencionado, 
permitiu considerável melhoria na sensibilidade da frequência de ressonância e do índice de mérito do sensor para a medidas da fase vapor.

Após a caracterização inicial da antena SIW, foram realizados os ensaios de análise e qualificação desse sensor em relação à sensibilidade e repetitividade utilizando a fase vapor de amostras de água DI. Posteriormente, a antena SIW com SWCNT foi utilizada para caracterizar a fase vapor das amostras de etanol em água.

\subsubsection{Sensibilidade da antena SIW com SWCNT}

De maneira equivalente ao realizado para a antena de microfita com plaqueta retangular, caracterizou-se a antena SIW com SWCNT para diferentes ponderações de fluxo de $\mathrm{N}_{2}$ seco e $\mathrm{N}_{2}$ borbulhado em água deionizada. Essa medida, equivalente a testes de umidade relativa (\%), é apresentada no Gráfico 4.16.

Gráfico 4.16 - Sensibilidade da frequência de ressonância da antena SIW com SWCNT para diferentes proporções de umidade relativa (\%).

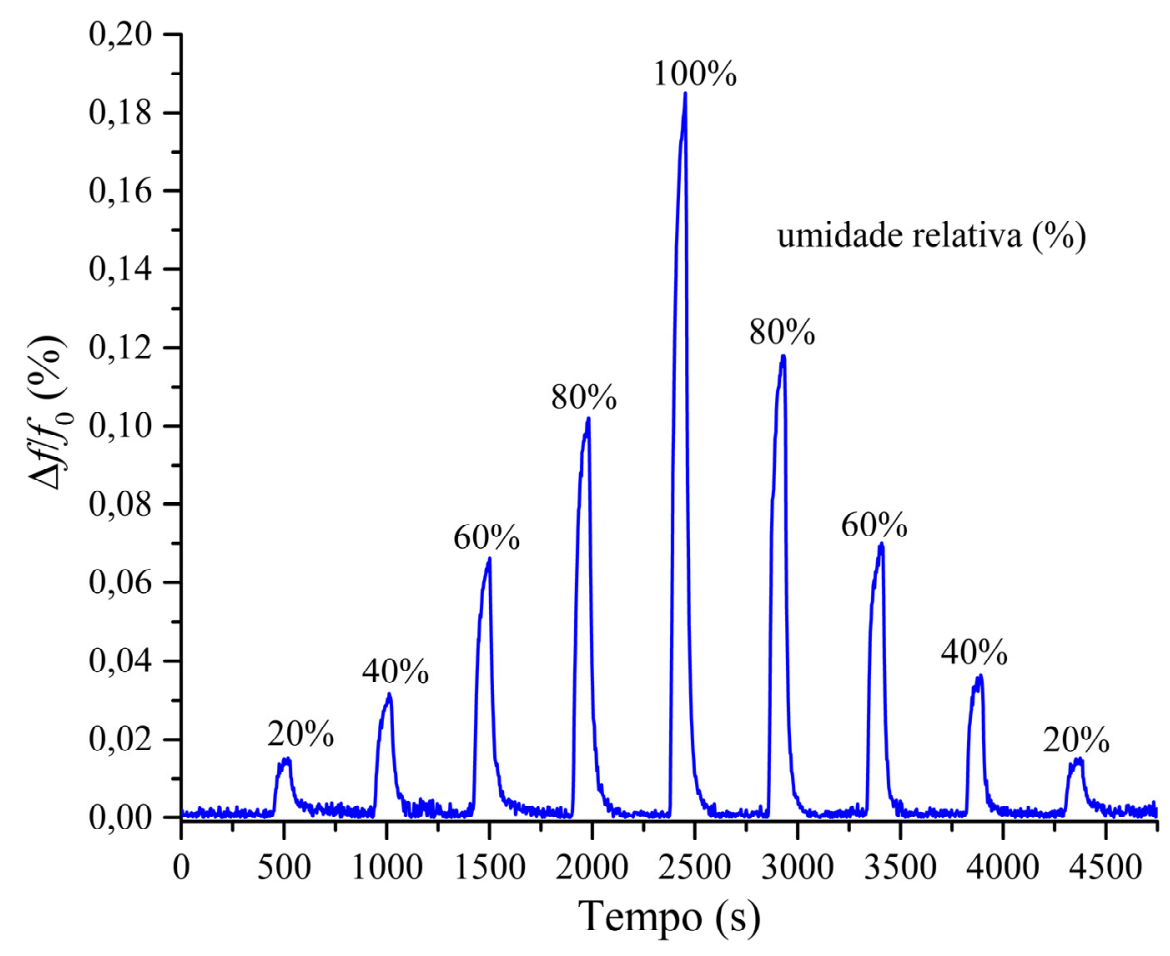


Do gráfico, nota-se que a sensibilidade da frequência de ressonância da antena SIW cresce gradativamente com o aumento da umidade relativa. Além disso, a sensibilidade da frequência de ressonância da antena SIW com SWCNT determinada experimentalmente é maior que a da antena de microfita com SWCNT.

Em comparação com o Gráfico 4.5, verifica-se que as respostas da variação da frequência de ressonância da antena SIW com SWCNT à umidade são no mínimo 3 vezes maiores comparadas com a antena de microfita com SWCNT. Esse resultado, além de demonstrar a viabilidade do uso da antena SIW com SWCNT como sensor de umidade relativa, também confirma a hipótese de que o material nanoestruturado depositado nas regiões de máximo campo elétrico resulta em sensores com alta sensibilidade.

Tal como apresentado no Gráfico 4.5, houve pequena variação no valor da sensibilidade da frequência de ressonância para o valor de umidade relativa de $80 \%$. Tal fato sugere que o sensor possui uma pequena deriva de seu comportamento.

A partir dos valores de pico obtidos no Gráfico 4.16, foi possível levantar o Gráfico 4.17, e ajustar duas curvas que descrevem o comportamento da umidade relativa do ar em função da sensibilidade $\Delta f / f_{0}$.

As equações 4.12 e 4.13 apresentam o ajuste linear e polinomial de $2^{\mathrm{a}}$ ordem, respectivamente. Para ajuste linear obteve-se $B=673,89$, sendo que o parâmetro de qualidade $R^{2}$ calculado foi de 0,9378 . Para o ajuste polinomial de $2^{\text {a }}$ ordem, foram obtidos os coeficientes $C=1112,70$ e $D=-3777,51$, sendo que o parâmetro de qualidade obtido de $R^{2}$ foi igual a 0,9939 .

$$
\text { Umidade relativa }(\%)=B \frac{\Delta f}{f_{0}}=673,89 \frac{\Delta f}{f_{0}}(\%)
$$

$$
\text { Umidade relativa }(\%)=C \frac{\Delta f}{f_{0}}+D\left(\frac{\Delta f}{f_{0}}\right)^{2}=1112,70 \frac{\Delta f}{f_{0}}-3177,51\left(\frac{\Delta f}{f_{0}}\right)^{2}(\%)
$$


Gráfico 4.17 - Relação entre a sensibilidade da frequência de ressonância da antena SIW com SWCNT em função da umidade relativa (\%).

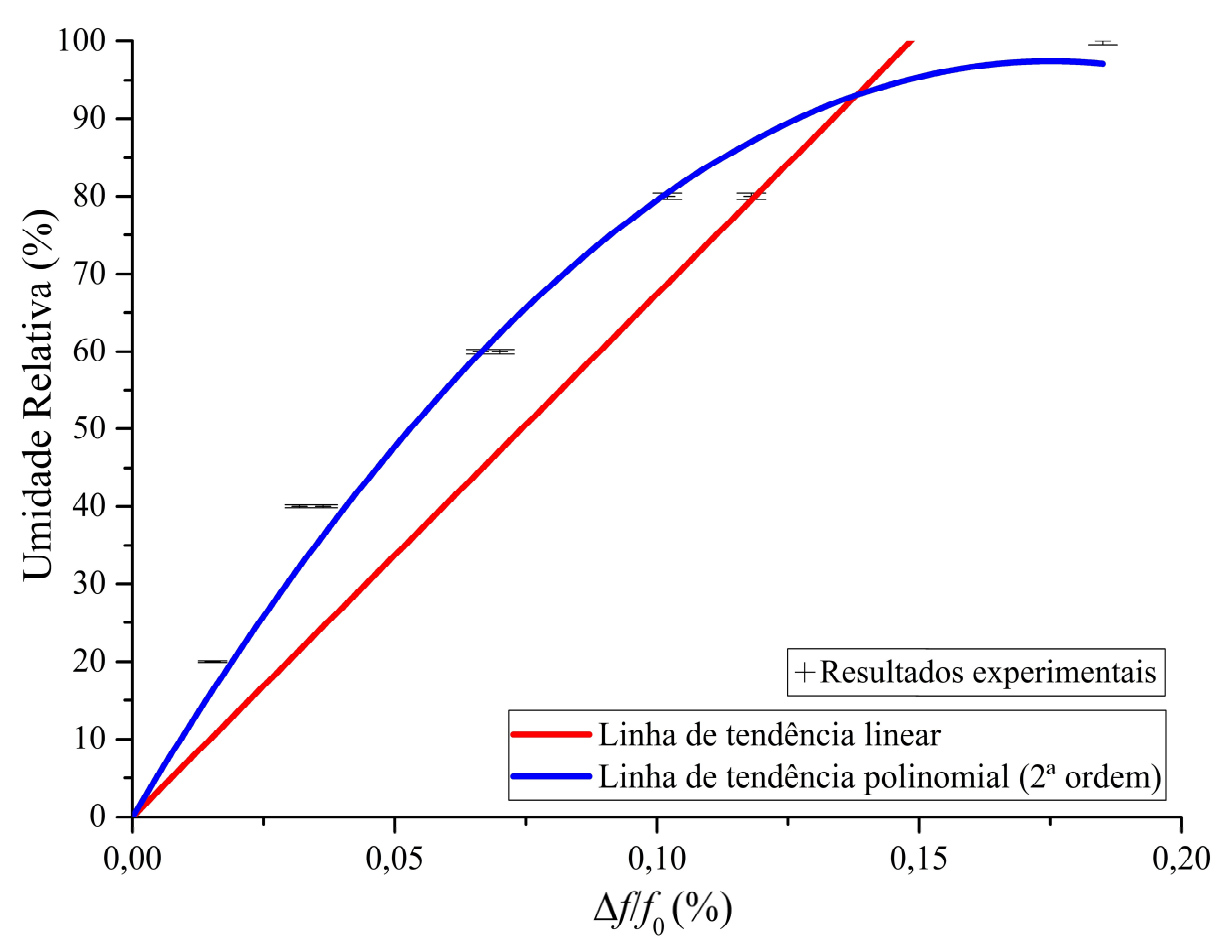

4.2.2.2. Ensaios para teste da repetitividade e dinâmica da resposta da antena SIW com SWCNT

O teste de repetitividade seguiu a metodologia utilizada no ensaio da antena de microfita. Como anteriormente, foram realizadas seis injeções consecutivas de $\mathrm{N}_{2}$ $100 \%$ saturado com água, contudo com duas diferenças. Primeiro, na montagem do aparato o borbulhador foi mergulhado numa cuba com água. O objetivo foi aumentar a inércia térmica da amostra de material no interior do borbulhador. A outra modificação foi nos tempos de injeção e secagem adotados durante os ensaios, de 120 s e 400 s, respectivamente. O Gráfico 4.18 apresenta a caracterização de repetitividade. A escolha do tempo de injeção foi feita após testes preliminares indicarem que a partir de 120 s não há variações significativas da frequência de ressonância do sensor. Além disso, o tempo de 120 s é uma solução de compromisso entre o tempo para estabilizar a injeção e o tempo para o sensor realizar a total dessorção do material sob teste. 
Nota-se que a resposta do sensor à primeira injeção de $\mathrm{N}_{2}$ saturado com água DI não difere das respostas às injeções subsequentes, diferentemente do ocorrido com a antena de microfita, tal como apresentado no Gráfico 4.7. Esse fato se deve, principalmente, ao uso do banho maria.

Gráfico 4.18 - Caracterização da repetitividade da sensibilidade da frequência de ressonância da antena SIW com N2 saturado com água DI.

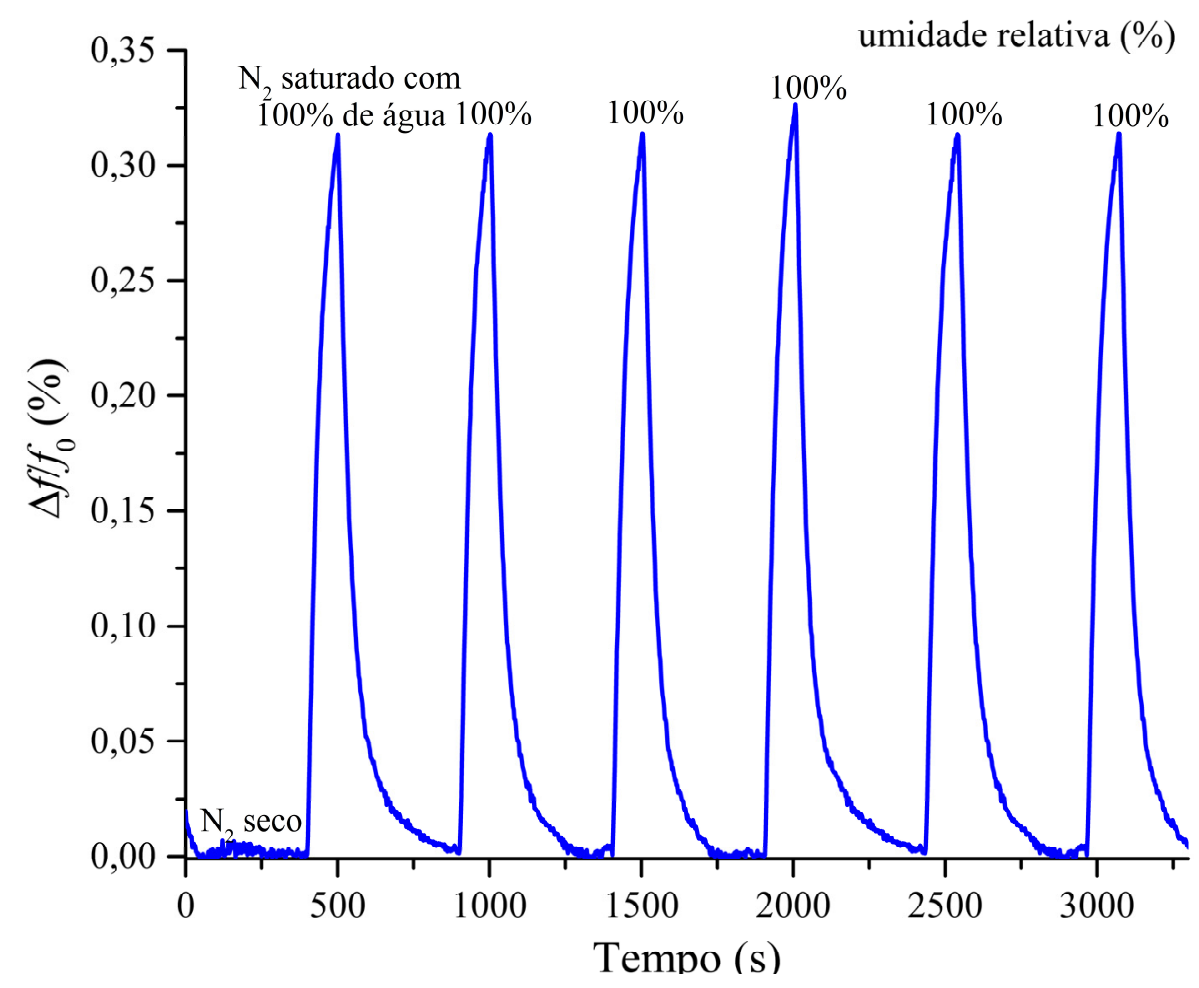

O uso da cuba com banho maria foi um aprimoramento do aparato de medida, pois verificou-se que o borbulhamento de $\mathrm{N}_{2}$ reduzia a temperatura do material sob teste em aproximadamente $5^{\circ} \mathrm{C}$ para medidas sem cuba. Dessa forma, a injeção de $\mathrm{N}_{2}$ resfriava o material sob teste, fazendo com que uma menor quantidade da amostra fosse arrastada, sendo que a após a primeira injeção a temperatura da amostra no borbulhador mantinha certa estabilidade térmica. Com o uso do banho maria, pôde-se manter a temperatura do material no borbulhador constante, com variação menor do $1^{\circ} \mathrm{C}$, durante todo o processo de injeção de $\mathrm{N}_{2}$. 
Do Gráfico 4.18, nota-se que não há evidência de degradação dos sensores, nem mesmo oxidação do cobre. As injeções apresentaram pequena dispersão dos valores máximos de sensibilidade (desvio padrão de 0,0052). O Gráfico 4.19 apresenta a resposta dinâmica do sensor.

Gráfico 4.19 - Resposta dinâmica da sensibilidade da frequência de ressonância da antena SIW com $\mathrm{N}_{2}$ saturado com água DI.

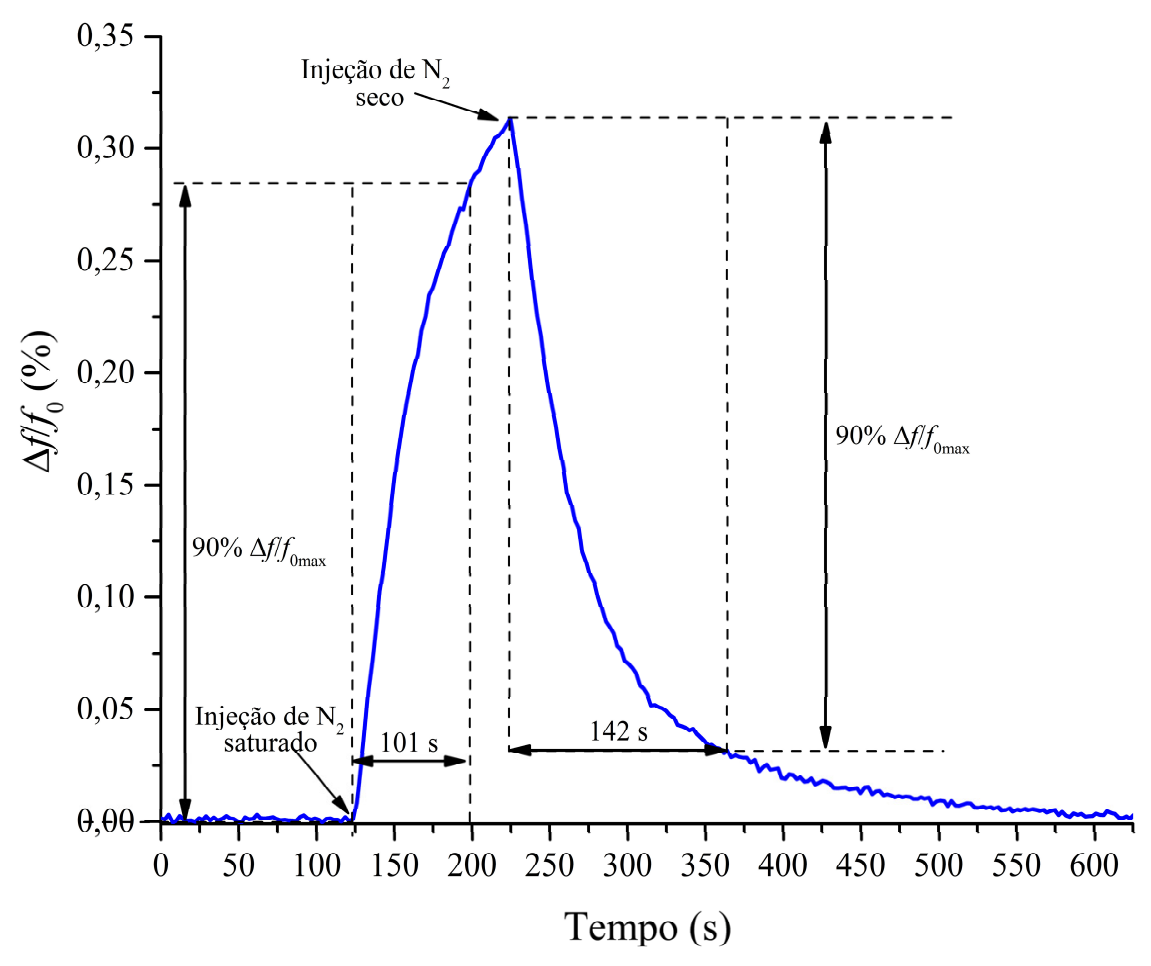

O tempo de resposta, a partir da injeção de $\mathrm{N}_{2}$ saturado com água, foi de 101 s. $\mathrm{O}$ tempo de restabelecimento foi calculado em 142 s. Esse resultado demonstra novamente que a interação entre o vapor de água e o CNT ocorre devido a processos de fisissorção com ligações fracas. Assim, as considerações realizadas para a antena de microfita com SWCNT servem para a antena SIW com SWCNT. 
4.2.2.3. Ensaios de qualificação de misturas de etanol combustível

A partir da caracterização da antena SIW com SWCNT como elemento sensor, diferentes amostras de etanol com água foram caracterizadas. Inicialmente, tomou-se as medidas do coeficiente de reflexão da antena SIW com SWCNT para as situações extremas: injeção de água DI e etanol 99,5\%.

O Gráfico 4.20 apresenta curvas de coeficiente de reflexão da antena SIW de referência (sem o depósito de SWCNT) em ambiente de $\mathrm{N}_{2}$ seco e da antena SIW com SWCNT, na presença de $\mathrm{N}_{2}$ seco, vapor de etanol 99,5\% e vapor saturado com água DI.

Gráfico 4.20 - Coeficiente de reflexão medido da antena SIW com SWCNT para as amostras de água DI e etanol 99,5\% em comparação com as curvas de referência.

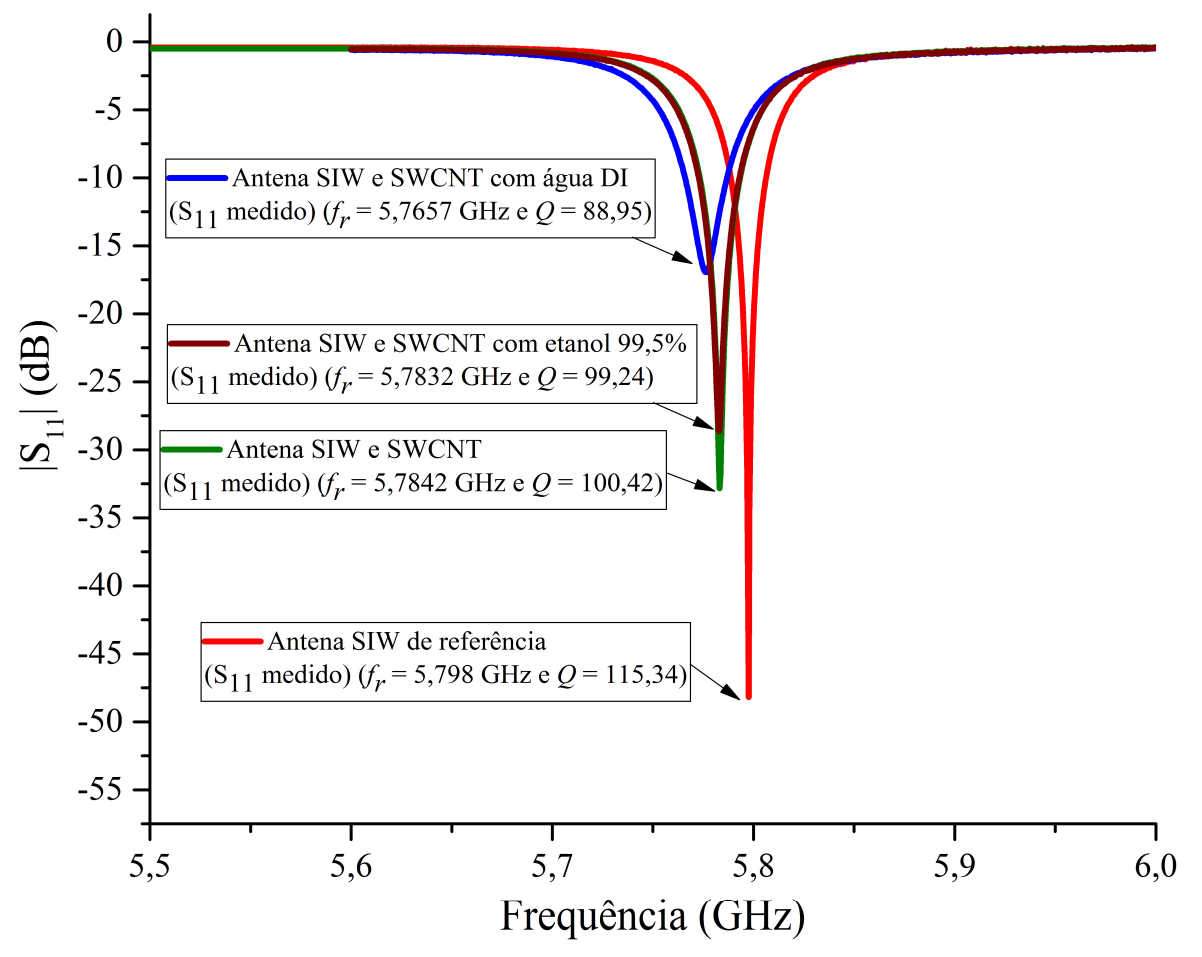

Nota-se, em comparação com o Gráfico 4.9, uma considerável diferença entre a resposta em frequência da antena SIW com SWCNT exposta à água pura e ao etanol 
99,5\%, indicando uma faixa dinâmica ${ }^{45} 3$ vezes maior para a resposta do sensor comparado com a resposta em do deslocamento da frequência de ressonância da antena de microfita com SWCNT.

Os mecanismos de transferência de cargas e polarização do SWCNT, que explicam o comportamento dos materiais adsorvidos apresentados no Gráfico 4.20, podem ser descritos tal como detalhado no subitem 4.2.1.3.

O Gráfico 4.21, obtido com a interface de aquisição automática (APÊNDICE G), apresenta a sensibilidade da frequência de ressonância para as diferentes frações de etanol em água.

Gráfico 4.21 - Sensibilidade da frequência de ressonância da antena SIW com SWCNT para caraterização de etanol combustível.

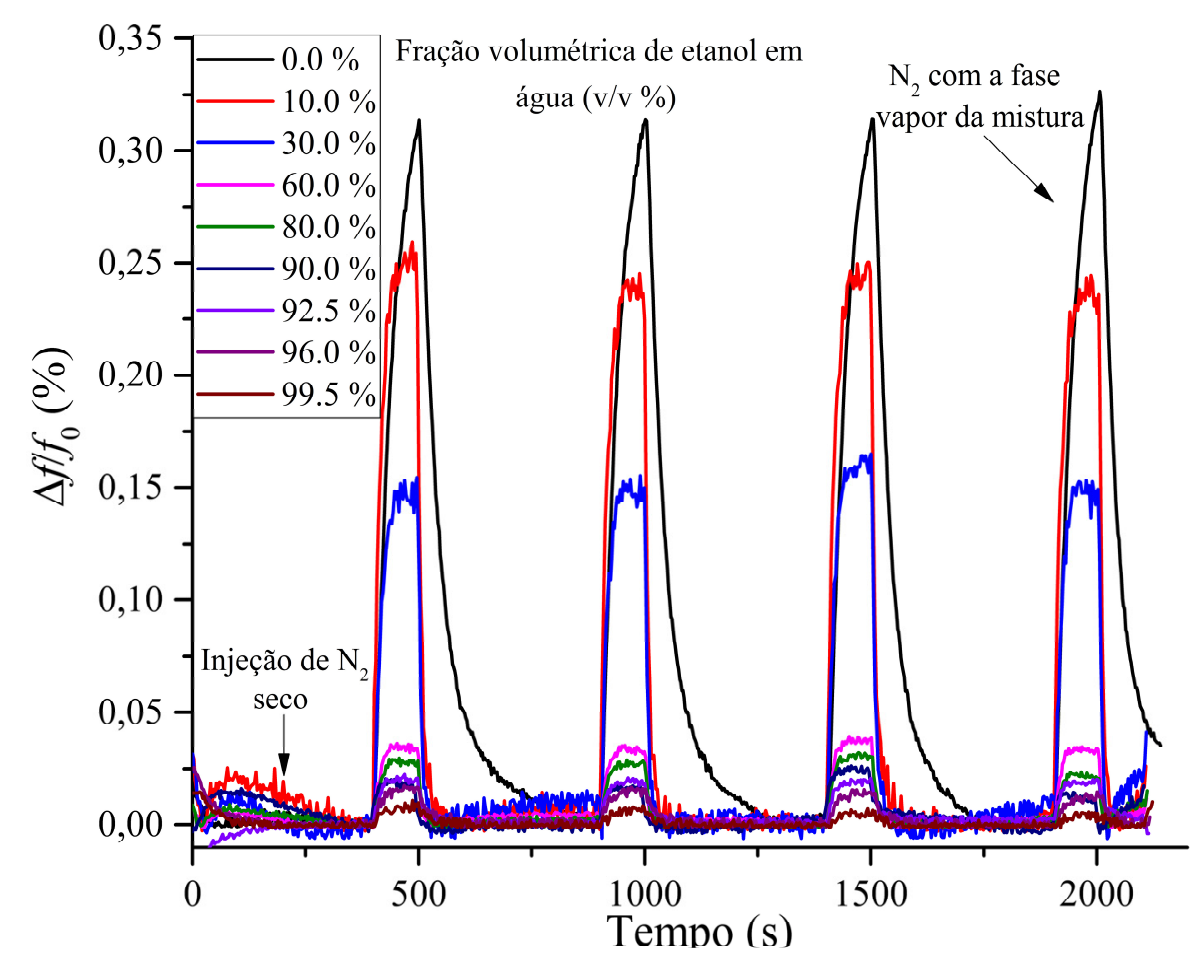

\footnotetext{
${ }^{45}$ Define-se faixa dinâmica como o valor total de operação do sensor, desde seu mínimo até o máximo valor de entrada.
} 
Diferente da antena de microfita, não houve a necessidade de tratar a resposta utilizando média móvel, posto que a amplitude de variação foi praticamente 3 vezes maior, tornando as flutuações de medição inexpressivas. Novamente, as medidas foram realizadas mantendo a temperatura do material sob teste constante com o uso do banho maria.

Do mesmo modo, foi obtido o Gráfico 4.22 que apresenta a variação o índice de mérito medido durante os ensaios com diferentes frações de etanol em água. Em ambos os gráficos, nota-se que o tempo de dessorção da água DI foi superior ao das frações de etanol em água. Esse fato indica, como já esperado, que os nanotubos possuem maior capacidade de aprisionar as moléculas de água, devido a sua maior eletronegatividade, sendo assim elemento sensor especialmente apto para verificar presença de água em diferentes misturas.

Gráfico 4.22 - Variação do índice de mérito da antena SIW com SWCNT para caracterização de etanol combustível.

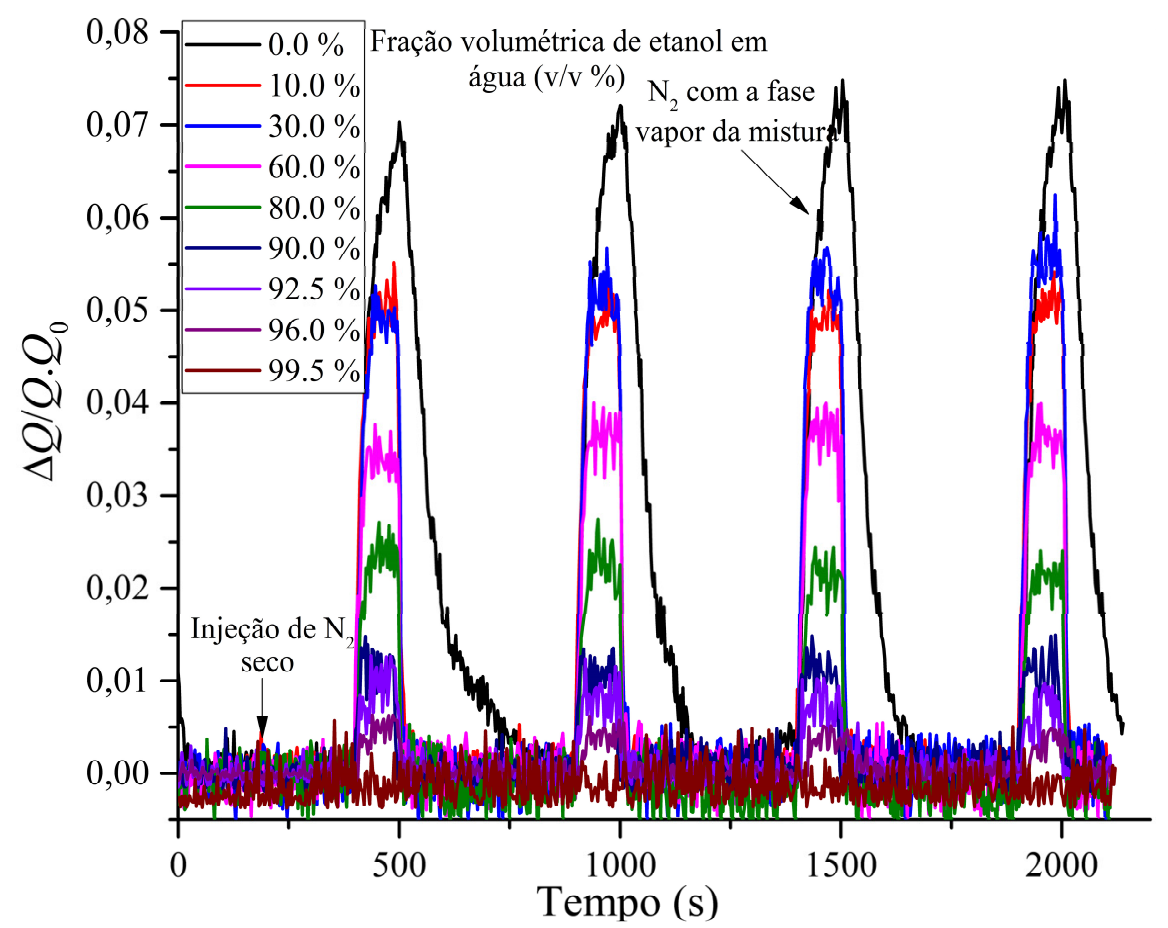

Correlacionando diretamente os picos da sensibilidade da frequência de ressonância com a fração volumétrica de álcool, obteve-se o Gráfico 4.23. A incerteza máxima da 
medida da sensibilidade de 1,2\% foi calculada através da propagação de erros. Através dos pontos, ajustou-se uma linha de tendência linear que permite descrever o comportamento da mistura etanol e água diretamente da variação da frequência de ressonância.

Gráfico 4.23 - Relação entre a sensibilidade da frequência de ressonância da antena SIW com SWCNT e a fração volumétrica de etanol e água.

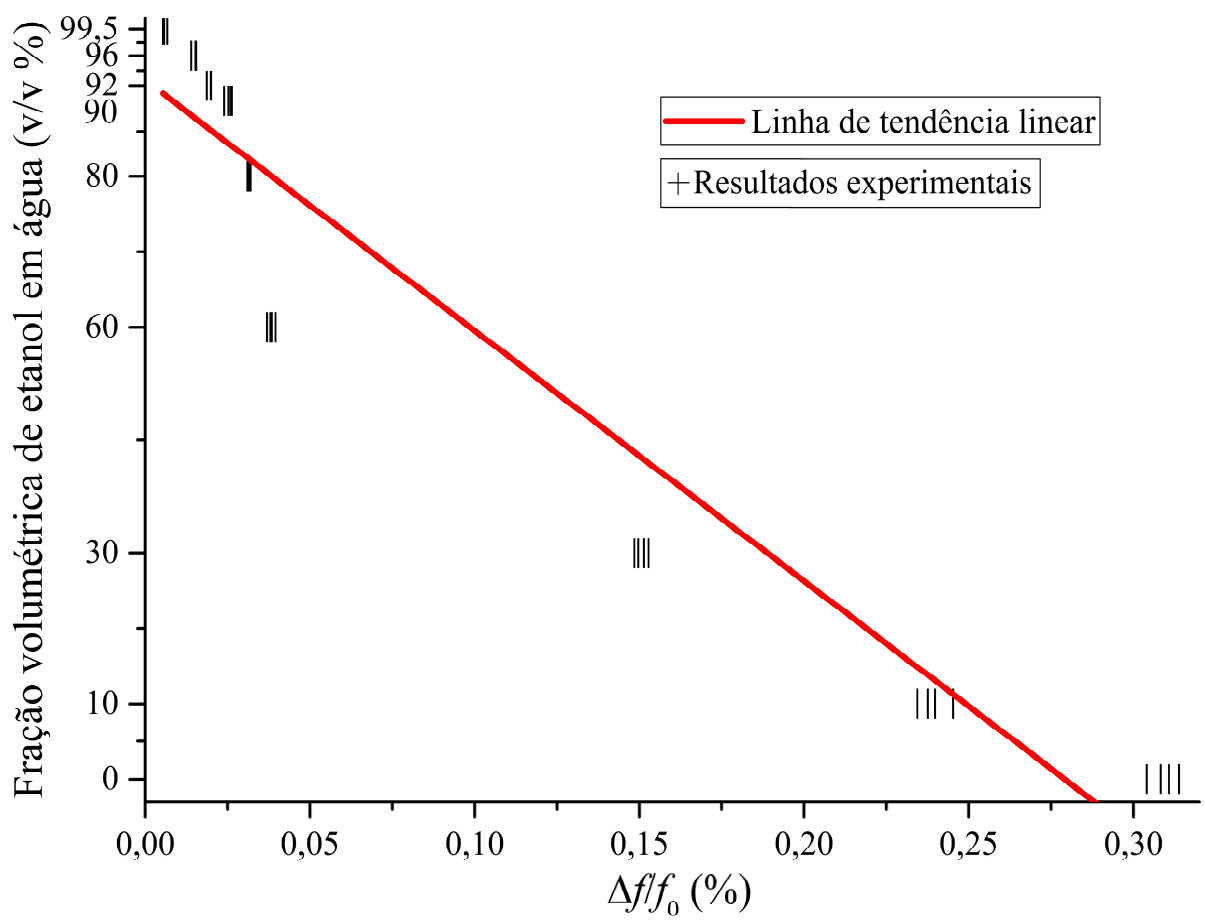

Para o ajuste de primeira ordem foram calculados $A=92,76$ e $B=-332,31$ presentes na equação 4.14. Do ajuste linear, foi extraído o parâmetro de qualidade $R^{2}$ de 0,9244 . Embora a antena SIW tenha apresentado maior sensibilidade, a antena de microfita demonstrou melhores resultados em termos de ajuste linear. Em específico, as frações intermediárias de $60 \%$ e $30 \%$ sofreram considerável desvio em relação à tendência linear. 
Fração em volume de etanol $\left({ }^{\circ} \mathrm{GL}\right)=A+B \frac{\Delta f}{f_{0}}=92,76-332,31 \frac{\Delta f}{f_{0}}(\%)$

Repetindo o modelamento realizado na antena de microfita, compilaram-se os resultados dos picos das sensibilidades na Tabela 4.5. Através da teoria da perturbação da cavidade ressonante (ver APÊNDICE B), pode-se correlacionar a variação da frequência de ressonância com a parte real da permissividade elétrica complexa, e a variação do índice de mérito com a parte imaginária da permissividade elétrica complexa.

Tabela 4.5 - Valores de permissividade elétrica complexa e parâmetros de sensibilidade experimentais obtidos na antena SIW com SWCNT.

\begin{tabular}{|c|c|c|c|c|c|}
\hline $\begin{array}{c}\text { Fração } \\
\text { volumétrica de } \\
\text { etanol (v/v \%) }\end{array}$ & $\begin{array}{c}\text { Fração } \\
\text { em massa } \\
\text { de etanol } \\
(\%)\end{array}$ & $\begin{array}{c}\Delta f / f_{0} \\
\text { (Medido) }\end{array}$ & $\begin{array}{l}\text { Parte real da } \\
\text { permissividade } \\
\text { elétrica }(\varepsilon r) \\
\text { (Regras de } \\
\text { diluição) }\end{array}$ & $\begin{array}{c}1 / Q_{s .}\left(\Delta Q / Q_{0}\right) \\
\text { (Medido) }\end{array}$ & $\begin{array}{c}\text { Parte } \\
\text { imaginária da } \\
\text { permissividade } \\
\text { elétrica }\left(\varepsilon r r^{\prime)}\right. \\
\text { (Regras de } \\
\text { diluição) } \\
\end{array}$ \\
\hline 99,50 & 99,36 & 0,00543 & 6,06148 & $3,29 \times 10^{-4}$ & 4,33428 \\
\hline 96,00 & 94,96 & 0,01398 & 6,83668 & $3,88 \times 10^{-3}$ & 5,34917 \\
\hline 92,50 & 90,64 & 0,01872 & 7,80644 & $8,91 \times 10^{-3}$ & 6,74690 \\
\hline 90,00 & 87,60 & 0,01989 & 7,87419 & $1,48 \times 10^{-2}$ & 8,21510 \\
\hline 80,00 & 75,84 & 0,03099 & 11,87095 & $2,26 \times 10^{-3}$ & 10,5160 \\
\hline 60,00 & 54,07 & 0,03701 & 20,64952 & $3,65 \times 10^{-3}$ & 17,37734 \\
\hline 30,00 & 25,17 & 0,01514 & 44,74362 & $5,70 \times 10^{-3}$ & 26,03145 \\
\hline 10,00 & 8,02 & 0,23978 & 65,32026 & $5,48 \times 10^{-3}$ & 23,92333 \\
\hline 0,00 & 0,00 & 0,31382 & 72,76004 & $4,86 \times 10^{-3}$ & 20,51856 \\
\hline
\end{tabular}

Os Gráficos 4.24 e 4.25 apresentam a correlação das sensibilidades da frequência de ressonância e do índice de mérito do sensor com a permissividade elétrica complexa. Ressalta-se, novamente, que essa é uma análise indireta para qualificação de etanol combustível, pois decorre do fato que é possível discriminar diferentes frações da mistura de etanol com água através da permissividade elétrica desses materiais. 
Gráfico 4.24 - Relação entre a sensibilidade da frequência de ressonância e a parte real da permissividade elétrica para a antena SIW com SWCNT.

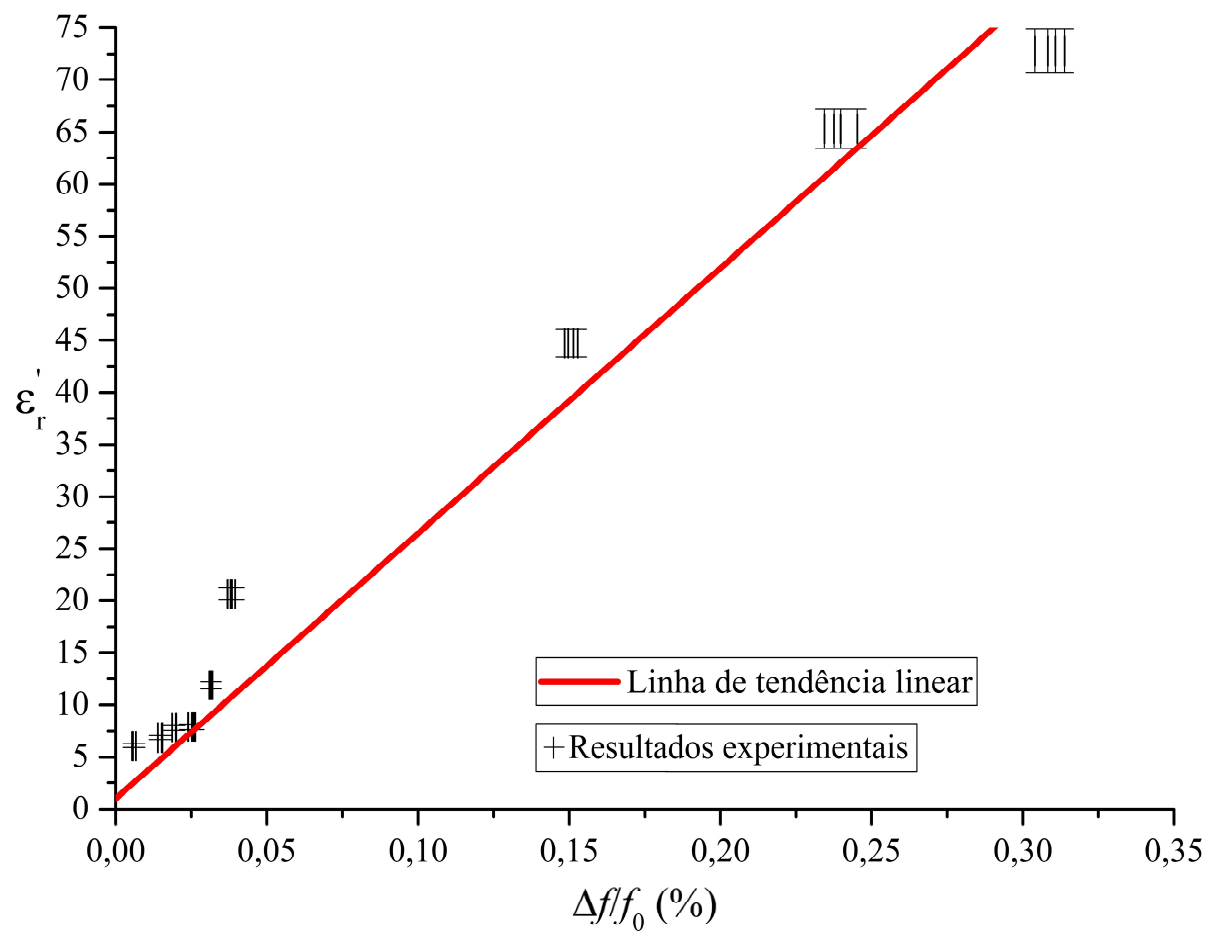

A equação 4.15 resulta da regressão linear, relacionando a parte real da permissividade elétrica com a sensibilidade da frequência de ressonância da antena SIW com SWCNT. Do ajuste de primeira ordem, foi obtido o coeficiente $A^{\prime}$ igual a 254,76 , conforme equação 4.15. O parâmetro de qualidade do ajuste foi calculado como $R^{2}$ igual a 0,9818. Novamente, os pontos intermediários apresentam erros relativos superiores a 65\%. Contudo a antena SIW apresentou melhor comportamento para análise dos valores próximos às frações de etanol em água permitidas na legislação para o álcool combustível.

$$
\varepsilon_{r}^{\prime}=1+A^{\prime} \frac{\Delta f}{f_{0}}=1+254,76 \frac{\Delta f}{f_{0}}(\%)
$$

Do Gráfico 4.25, obteve-se o coeficiente $A$ " igual a 459,29, equação 4.16, que expressa a linha de tendência linear da parte imaginária da permissividade elétrica com a 
sensibilidade normalizada do índice de mérito. O parâmetro de qualidade do ajuste foi calculado como $R^{2}$ igual a 0,9792 . Nota-se que as aproximações de primeira ordem realizadas com antena SIW apresentaram bom ajuste da curva analítica. Os resultados, além de serem maiores em amplitude, foram melhor ajustados no modelo da teoria da perturbação da cavidade ressonante. Esse fato indica a viabilidade do uso da tecnologia SIW para aplicações em sensoriamento e qualificação de materiais.

$$
\varepsilon_{r}^{\prime \prime}=A^{\prime \prime} \frac{1}{Q_{s}} \cdot \frac{\Delta Q}{Q_{0}}=459,28 \frac{1}{Q_{s}} \cdot \frac{\Delta Q}{Q_{0}}
$$

Gráfico 4.25 - Relação entre a sensibilidade normalizada do índice de mérito e a parte imaginária da permissividade elétrica para a antena SIW com SWCNT.

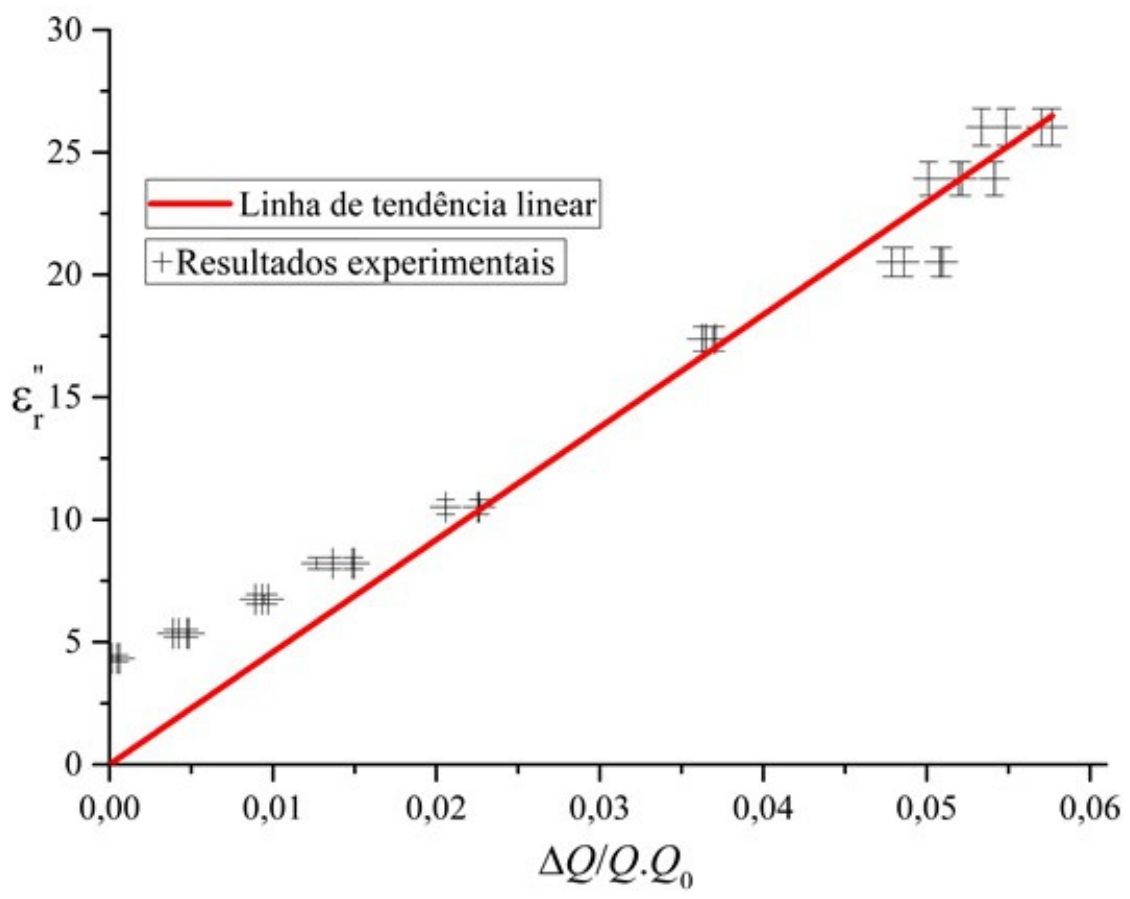

\subsubsection{Análise morfológica dos materiais nanoestruturados}

Para analisar a superfície da antena e verificar a morfologia dos CNTs depositados, utilizou-se um microscópio eletrônico de varredura convencional (MEV) FEI Nova 
Nanosem $400^{46}$. Dessa forma, foi possível realizar um mapeamento das superfícies dos sensores, além de uma microanálise qualitativa dos CNTs através da avaliação do tamanho dos nanotubos depositados.

As Figuras 4.7 (a) e (b) apresentam as imagens do SWCNT, enquanto que as Figuras 4.8 (a) e (b) mostram imagens do MWCNT. As imagens obtidas através do microscópio eletrônico de varredura foram amostradas em diferentes magnificações.

Os resultados indicam a presença de CNTs em diversas regiões do dispositivo. Em especial, verificou-se bom espalhamento nas regiões de máximo campo elétrico. Para o MWCNT, tal como no SWCNT, notam-se aglomerados típicos de nanotubos sem alinhamento.

Figura 4.7 - (a) Visão geral da amostra de SWCNT com magnificação de 30.000 vezes; (b) detalhe da amostra de SWCNT com magnificação de 150.000 vezes.

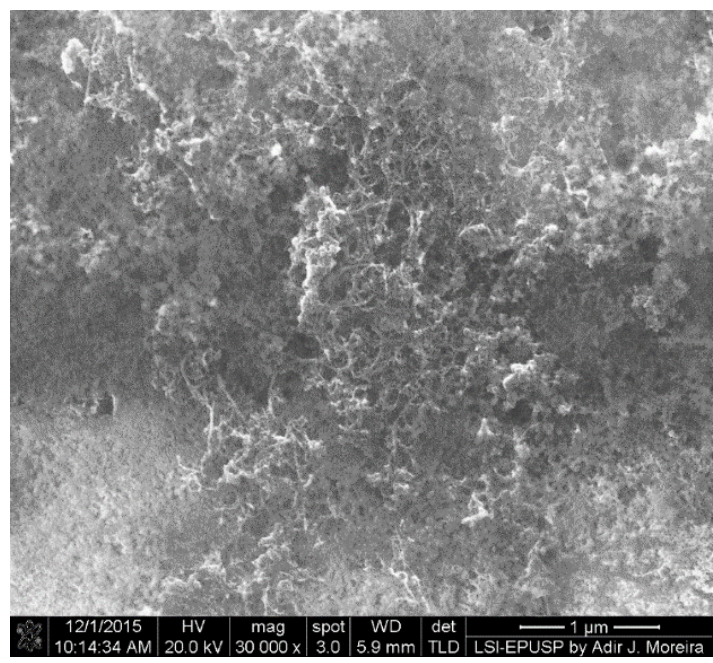

(a)

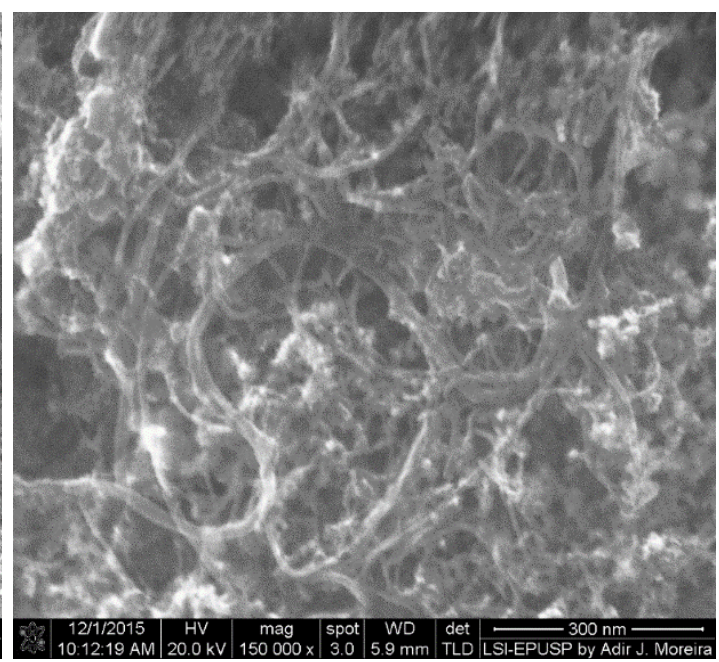

(b)

O aspecto de grande aglomeração obtido em ambos materiais demonstra a elevada área específica ativa para adsorção de espécies, aplicável para o projeto de sensores. Tanto para o SWCNT como para o MWCNT há integridade dos nanotubos, o que indica que

\footnotetext{
${ }^{46}$ Equipamento disponibilizado pelo Laboratório de Sistemas Integráveis da USP (LSI-EPUSP).
} 
o método de deposição não danificou nem alterou as propriedades químicas e físicas dos materiais nanoestruturados. Em geral, a deposição de material por gotejamento não foi homogênea, devido à tensão superficial das suspensões de CNT em água.

Figura 4.8 - (a) Visão geral da amostra de MWCNT com magnificação de 6.000 vezes; (b) detalhe da amostra de MWCNT com magnificação de 100.237 vezes.

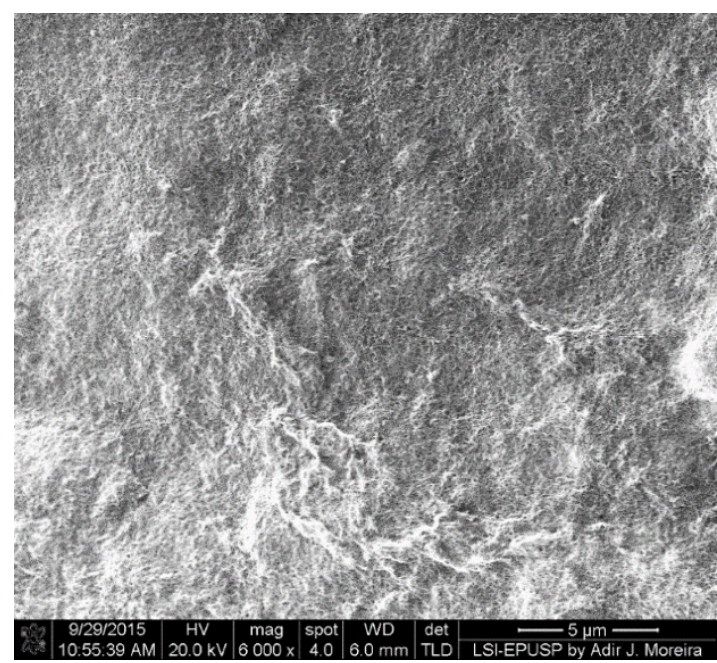

(a)

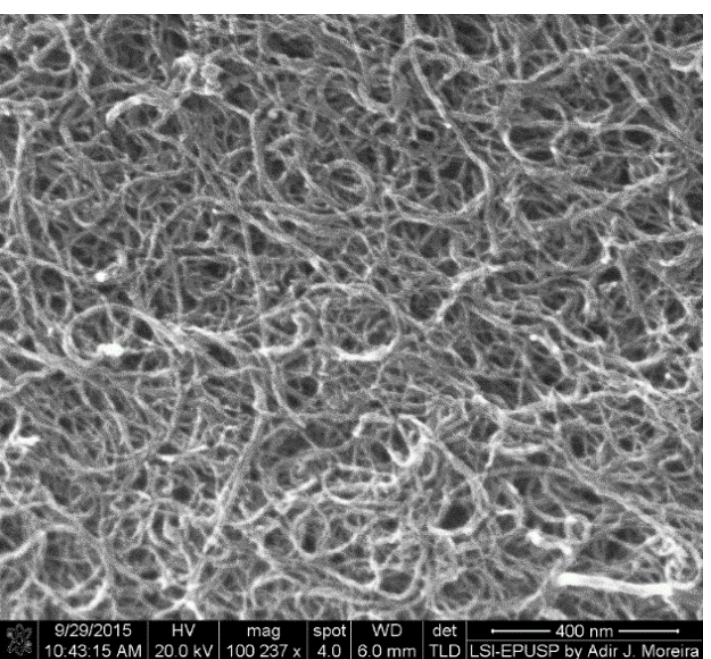

(b)

\subsection{Projeto, simulação e caracterização de sensores para análise da fase líquida de etanol combustível}

Foram propostos dois sensores para análise da fase líquida de etanol combustível. Uma antena SIW com fenda traseira e um guia de ondas com a mesma tecnologia.

\subsubsection{Antena SIW com fenda traseira para análise da fase líquida}

A antena SIW apresentada na Figura 4.4 foi utilizada para caracterização de amostras líquidas da mistura de etanol em água. Nesse caso, a fenda radiante da antena não foi recoberta com CNT, mas sim pelo líquido a ser caracterizado. Além das vantagens já citadas no item 3.9, a qualificação do etanol combustível através de uma pequena amostra diretamente alocada no sensor planar de micro-ondas possibilita obter 
resultados com maior rapidez e com maior nível de discriminação entre os materiais analisados. Além disso, o uso de um circuito planar possibilita o desenvolvimento de um sensor de baixo custo para qualificação de materiais em geral e, em específico, de amostras de etanol combustível.

A metodologia aqui adotada para ensaio de sensores de fase líquida foi apresentada no item 3.9. A Figura 4.9 apresenta em detalhe a antena SIW com uma pequena amostra do material depositado sobre a fenda traseira. Durante os ensaios, todas as medidas foram repetidas no mínimo 4 vezes para verificar sua repetitividade. Após o fim da medida, a amostra era removida da superfície da antena utilizando papel toalha e um jato de $\mathrm{N}_{2}$ seco durante aproximadamente $10 \mathrm{~s}$. Nessa condição, a antena SIW voltava a suas condições originais, o que demonstra a potencialidade no uso em aplicações de campo.

Figura 4.9 - Antena SIW com amostra do material sob teste aplicada sobre sua fenda traseira.

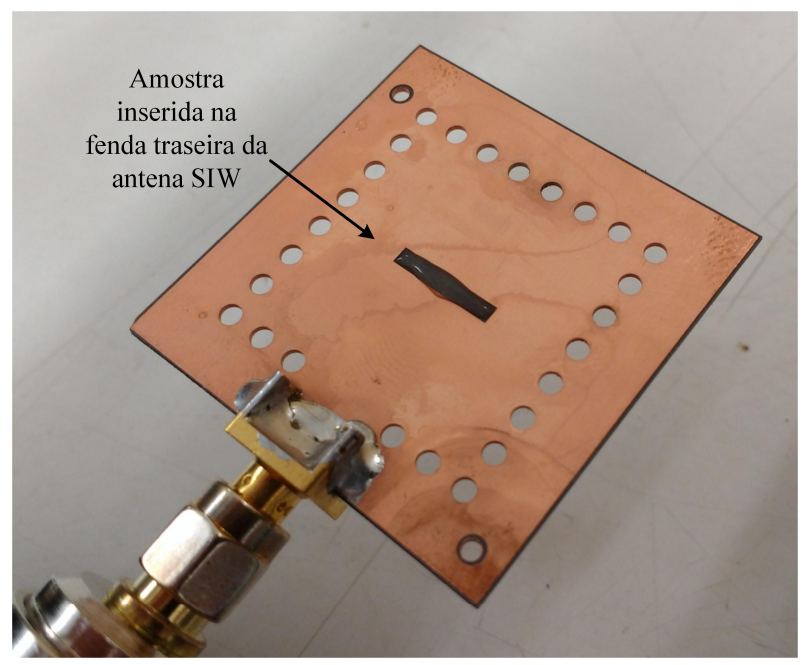

4.3.1.1. Ensaios de qualificação de misturas de etanol combustível

O Gráfico 4.26 apresenta a comparação entre os coeficientes de reflexão para a antena de referência (sem depósito de amostra sobre a fenda), da antena com amostras de água DI e etanol 99,5\% sobre a fenda. 
Inicialmente foram medidas as variações máxima e mínima da frequência de ressonância e do índice de mérito da antena para as amostras de água DI e etanol 99,5\%, respectivamente. Em comparação com os Gráficos 4.9 e 4.20 que apresentam os coeficientes de reflexão para a análise da fase vapor, a faixa dinâmica de variação da frequência de ressonância do sensor SIW é aproximadamente 30,9 vezes maior do que o da antena de microfita com SWCNT e 5,6 vezes maior do que a antena SIW com SWCNT. Em relação ao índice de mérito, a variação do sensor SIW foi de aproximadamente 105,1 vezes maior do que a antena de microfita com SWCNT e de, aproximadamente, 2,75 vezes maior do que a antena SIW com SWCNT.

Gráfico 4.26 - Coeficiente de Reflexão da antena SIW com fenda traseira para as amostras de água DI e etanol 99,5\% em comparação com as curvas de referência.

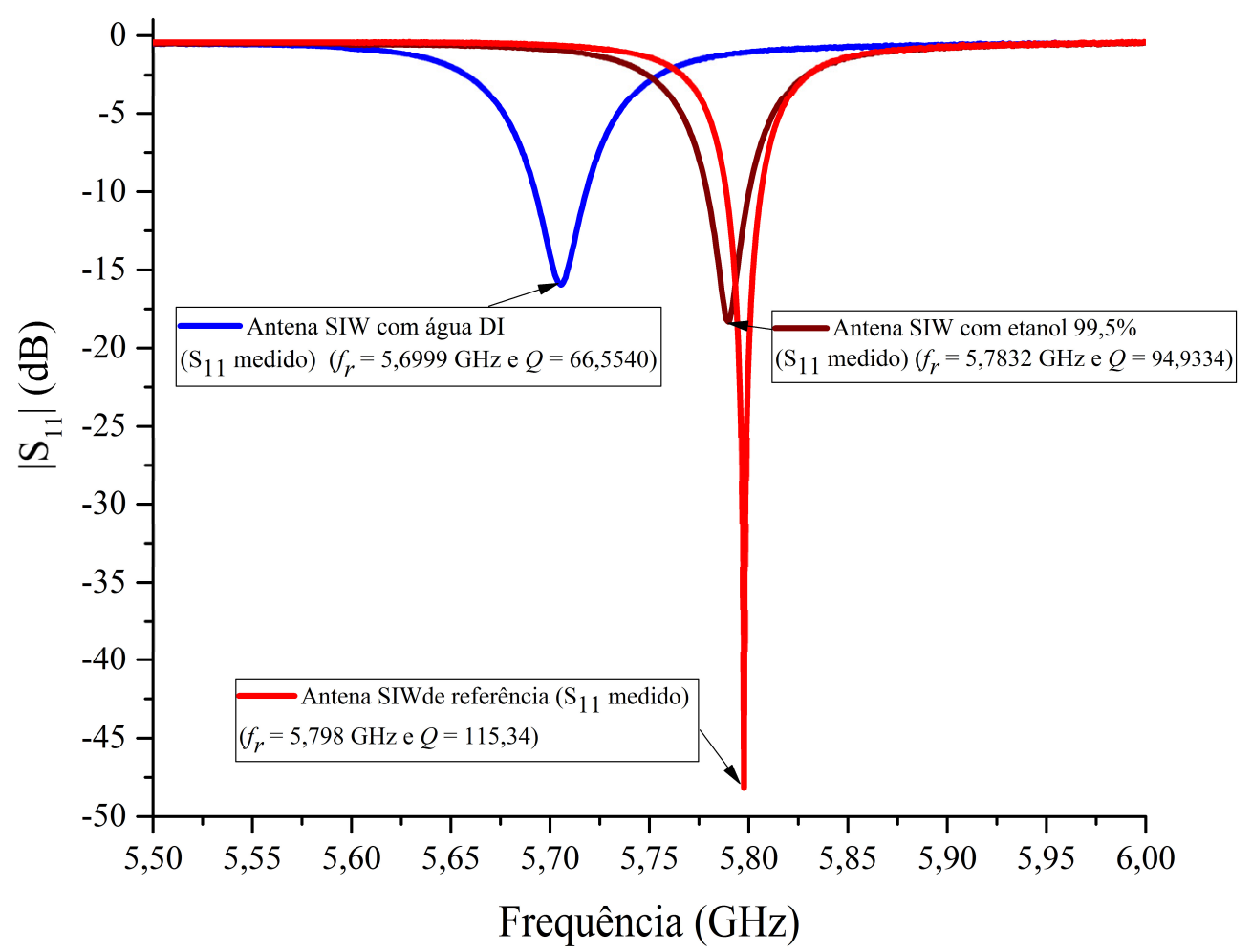

Utilizou-se a interface de aquisição (APÊNDICE G) para a tomada de medidas da frequência de ressonância e índice de mérito da antena SIW. Os Gráficos 4.27 e 4.28 apresentam a sensibilidade da frequência de ressonância e a variação do índice de mérito para as diferentes frações da mistura etanol em água, respectivamente. 
Gráfico 4.27 - Sensibilidade da frequência de ressonância da antena SIW para a

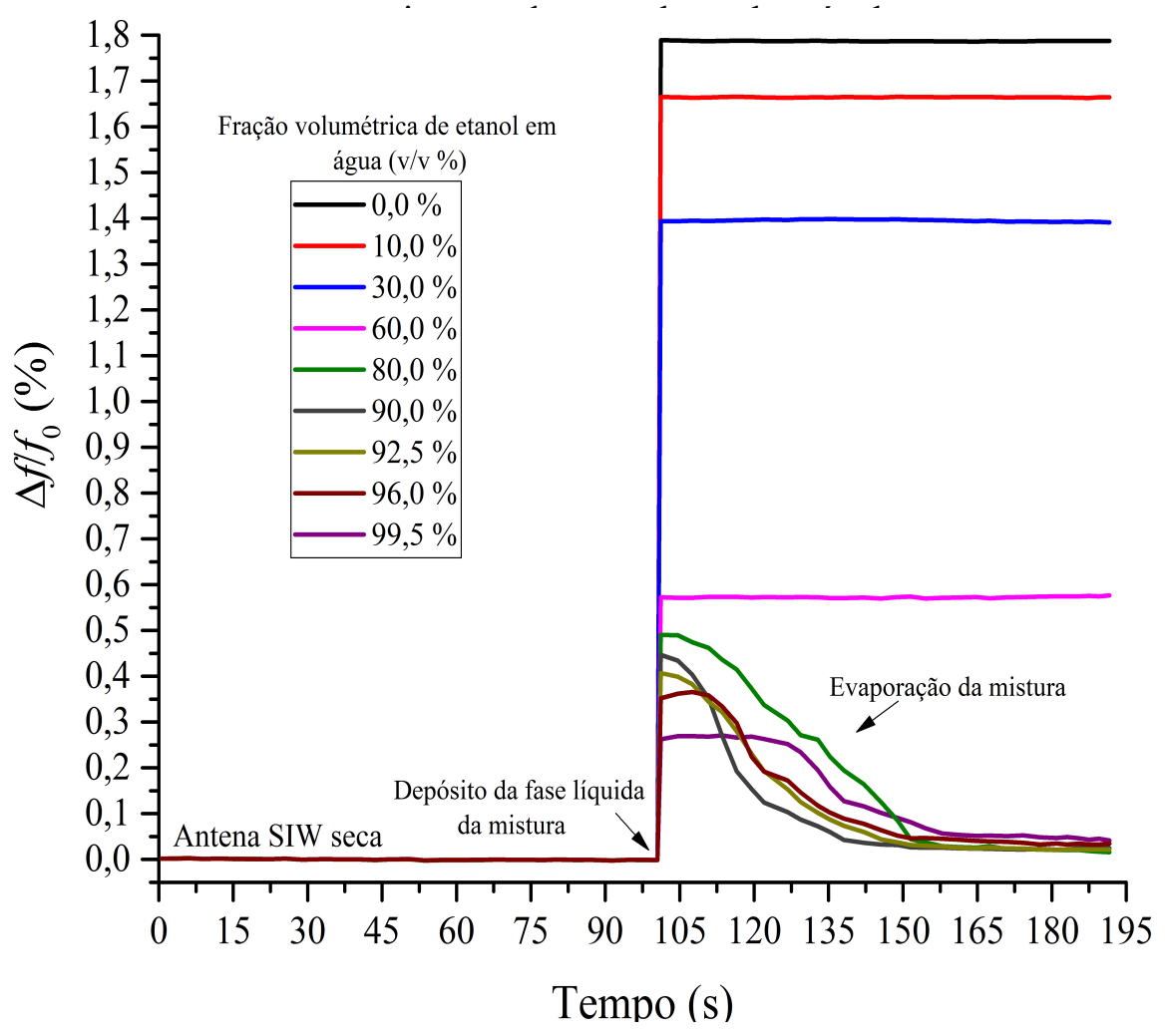

Gráfico 4.28 - Variação do índice de mérito normalizado da antena SIW para a caracterização de etanol combustível.

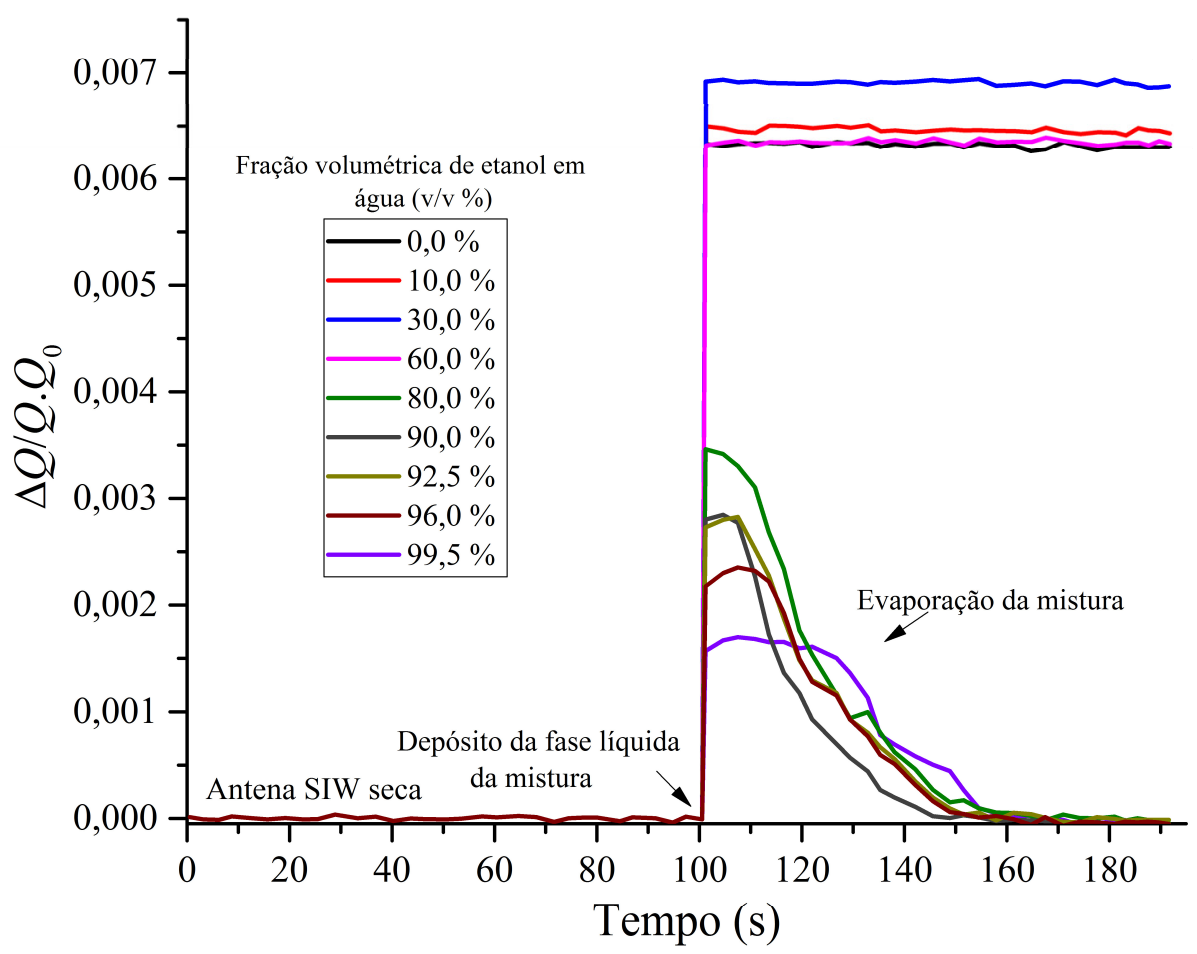


Em ambos os gráficos nota-se que para frações volumétricas maiores do que $80 \%$ de etanol em água há uma variação pronunciada dos parâmetros medidos devido à evaporação da mistura com o passar do tempo. Nesse sentido são utilizados somente os valores iniciais da faixa de transição, ou seja, logo após a deposição das amostras de etanol em água sobre a fenda da antena. Não são analisados, nesse trabalho, os efeitos termodinâmicos da evaporação da mistura, posto que o foco é medir a máxima variação dos parâmetros da antena e correlacionar esse comportamento com as características eletromagnéticas dos materiais sob teste.

Para uma análise direta, aos moldes do que foi proposto nas antenas com material nanoestruturado, o Gráfico 4.29 descreve a relação entre a sensibilidade da frequência de ressonância em função da fração volumétrica de álcool.

Gráfico 4.29 - Relação entre a sensibilidade da frequência de ressonância da antena SIW e a fração volumétrica de etanol e água.

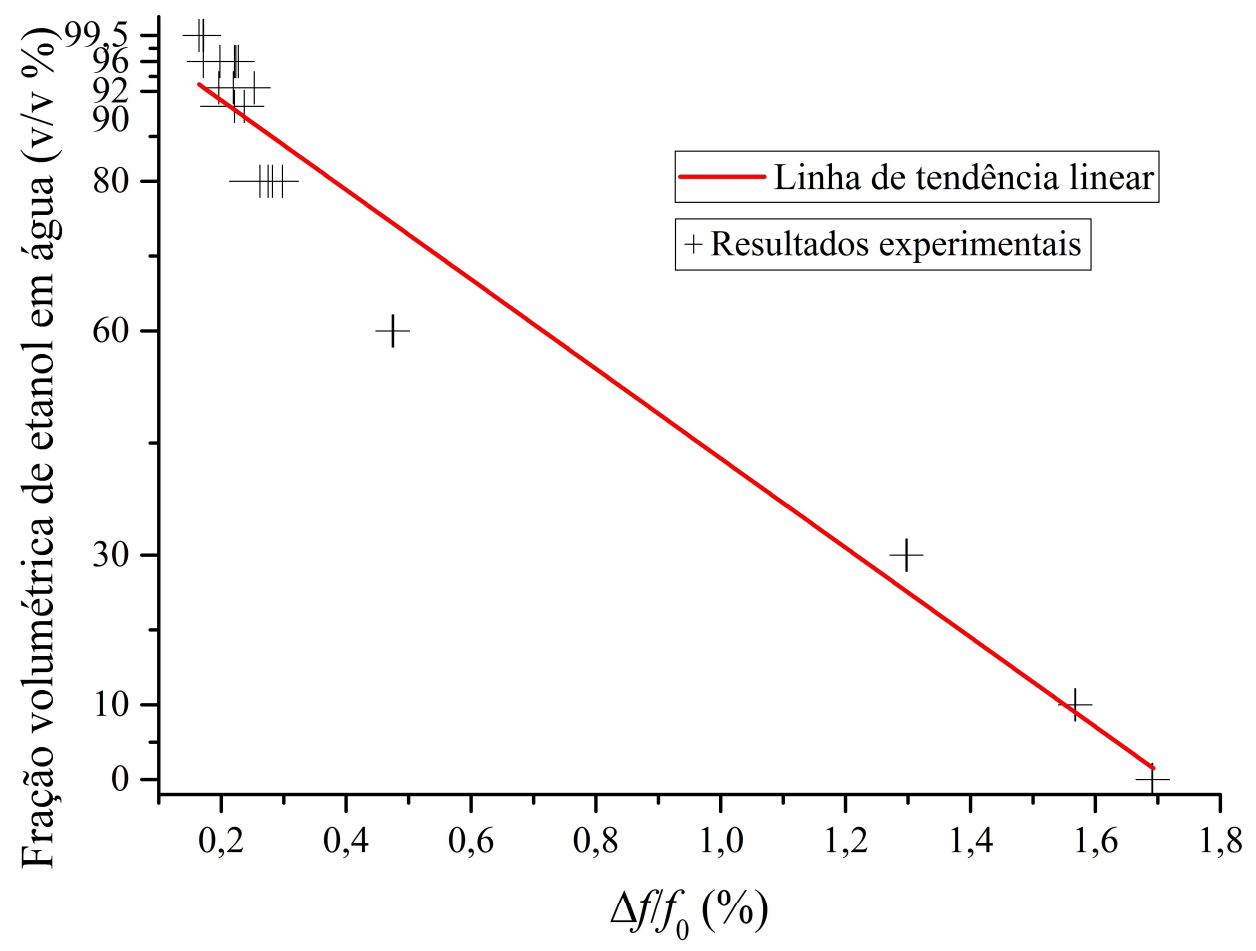

Para o ajuste de primeira ordem dos dados do Gráfico 4.29, foram calculados $A=$ 102,79 e $B=-59,83$ presentes na equação 4.17 . Do ajuste linear, foi extraído o 
parâmetro de qualidade $R^{2}$ de 0,9685. Novamente, as frações intermediárias de 30\%, $60 \%$ e $80 \%$ apresentaram os desvios mais significativos em relação à tendência linear.

Fração em volume de etanol $\left({ }^{\circ} \mathrm{GL}\right)=A+B \frac{\Delta f}{f_{0}}=102,79-59,83 \frac{\Delta f}{f_{0}}(\%)$

Repetindo o modelamento realizado nas antenas de microfita e SIW com SWCNT, compilaram-se os resultados dos picos das sensibilidades na Tabela 4.6. Através da teoria da perturbação da cavidade ressonante (ver APÊNDICE B), pôde-se correlacionar a variação da frequência de ressonância com a parte real da permissividade elétrica complexa, e a variação do índice de mérito com a parte imaginária da permissividade elétrica complexa. Os Gráficos 4.30 e 4.31 apresentam a correlação das sensibilidades das medidas com a permissividade elétrica complexa.

Tabela 4.6 - Valores de permissividade elétrica complexa e parâmetros de sensibilidade experimentais na antena SIW.

\begin{tabular}{cccccc}
\hline $\begin{array}{c}\text { Fração } \\
\text { volumétrica de } \\
\text { etanol (v/v \%) }\end{array}$ & $\begin{array}{c}\text { Fração } \\
\text { em massa } \\
\text { de etanol } \\
(\%)\end{array}$ & $\begin{array}{c}\Delta f / f_{0} \\
(\text { Medido) }\end{array}$ & $\begin{array}{c}\text { Parte real da } \\
\text { permissividade } \\
\text { elétrica }\left(\varepsilon_{r}^{\prime}\right) \\
\text { (Regras de } \\
\text { diluição) }\end{array}$ & $\begin{array}{c}\text { Parte } \\
1 / Q_{s .}\left(\Delta Q / Q_{0}\right) \\
\text { (Medido) }\end{array}$ & $\begin{array}{c}\text { imaginária da } \\
\text { permissividade } \\
\text { elétrica }\left(\varepsilon_{r}\right) \\
\text { (Regras de } \\
\text { diluição) }\end{array}$ \\
\hline 99,50 & 99,36 & 0,17022 & 6,06148 & 0,00157 & 4,33428 \\
96,00 & 94,96 & 0,17162 & 6,83668 & 0,00174 & 5,34917 \\
90,00 & 87,60 & 0,22776 & 7,87419 & 0,00244 & 8,21510 \\
80,00 & 75,84 & 0,23934 & 11,87095 & 0,00346 & 10,5160 \\
60,00 & 54,07 & 0,47469 & 20,64952 & 0,00656 & 17,37734 \\
30,00 & 25,17 & 1,29725 & 44,74362 & 0,00719 & 26,03145 \\
10,00 & 8,02 & 1,56854 & 65,32026 & 0,00673 & 23,92333 \\
0,00 & 0,00 & 1,69290 & 72,76004 & 0,00659 & 20,51856 \\
\hline
\end{tabular}

Do ajuste de primeira ordem dos dados do Gráfico 4.30, foi obtido o coeficiente $A^{\prime}$ igual a 39,63, conforme equação 4.18. O parâmetro de qualidade do ajuste foi calculado como $R^{2}$ igual a 0,9911 . O ponto referente à fração de $30 \%$ de etanol em 
água apresentou o maior desvio do ajuste linear, com erro relativo de aproximadamente $22 \%$. Os resultados foram mais coerentes e repetitivos do que aqueles analisados nas antenas de microfita e SIW com SWCNT.

$$
\varepsilon_{r}^{\prime}=1+A^{\prime} \frac{\Delta f}{f_{0}}=1+39,63 \frac{\Delta f}{f_{0}}(\%)
$$

Gráfico 4.30 - Relação entre a sensibilidade da frequência de ressonância e a parte real da permissividade elétrica para a antena SIW.

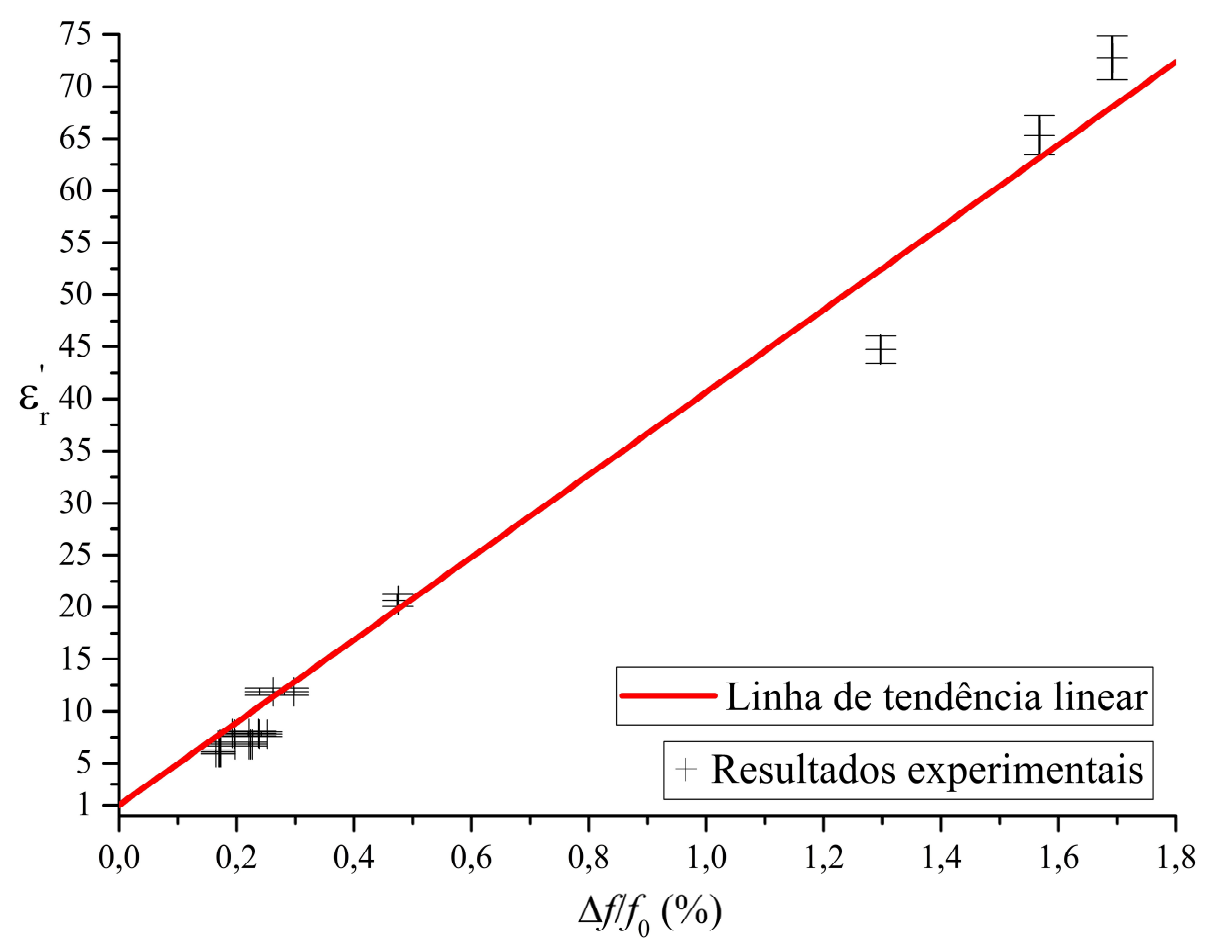

Para um ajuste linear realizado usando os dados pontos do Gráfico 4.31, obteve-se o coeficiente $A^{\prime \prime}$ igual a 3223,46 , conforme equação 4.19 . O parâmetro de qualidade do ajuste foi calculado como $R^{2}$ igual a 0,9857 . A fração de $60 \%$ etanol em água apresentou o maior erro relativo com, aproximadamente, $20 \%$ entre o valor medido.

As sensibilidades da frequência de ressonância e do índice de mérito da antena SIW, tal como em todos os casos apresentados neste trabalho, possuem variação crescente com a parte real e imaginária da permissividade elétrica, respectivamente. Ou seja, os 
pontos medidos sempre foram diretamente proporcionais à parte real e imaginária da permissividade elétrica da mistura etanol em água. Desse modo, pode-se confirmar a viabilidade do modelamento da mistura etanol em água através da teoria da perturbação da cavidade ressonante.

$$
\varepsilon_{r}^{\prime \prime}=A^{\prime \prime} \frac{1}{Q_{s}} \cdot \frac{\Delta Q}{Q_{0}}=3223,46 \frac{1}{Q_{s}} \cdot \frac{\Delta Q}{Q_{0}}
$$

Gráfico 4.31 - Relação entre a variação do índice de mérito e a parte imaginária da permissividade elétrica para a antena SIW.

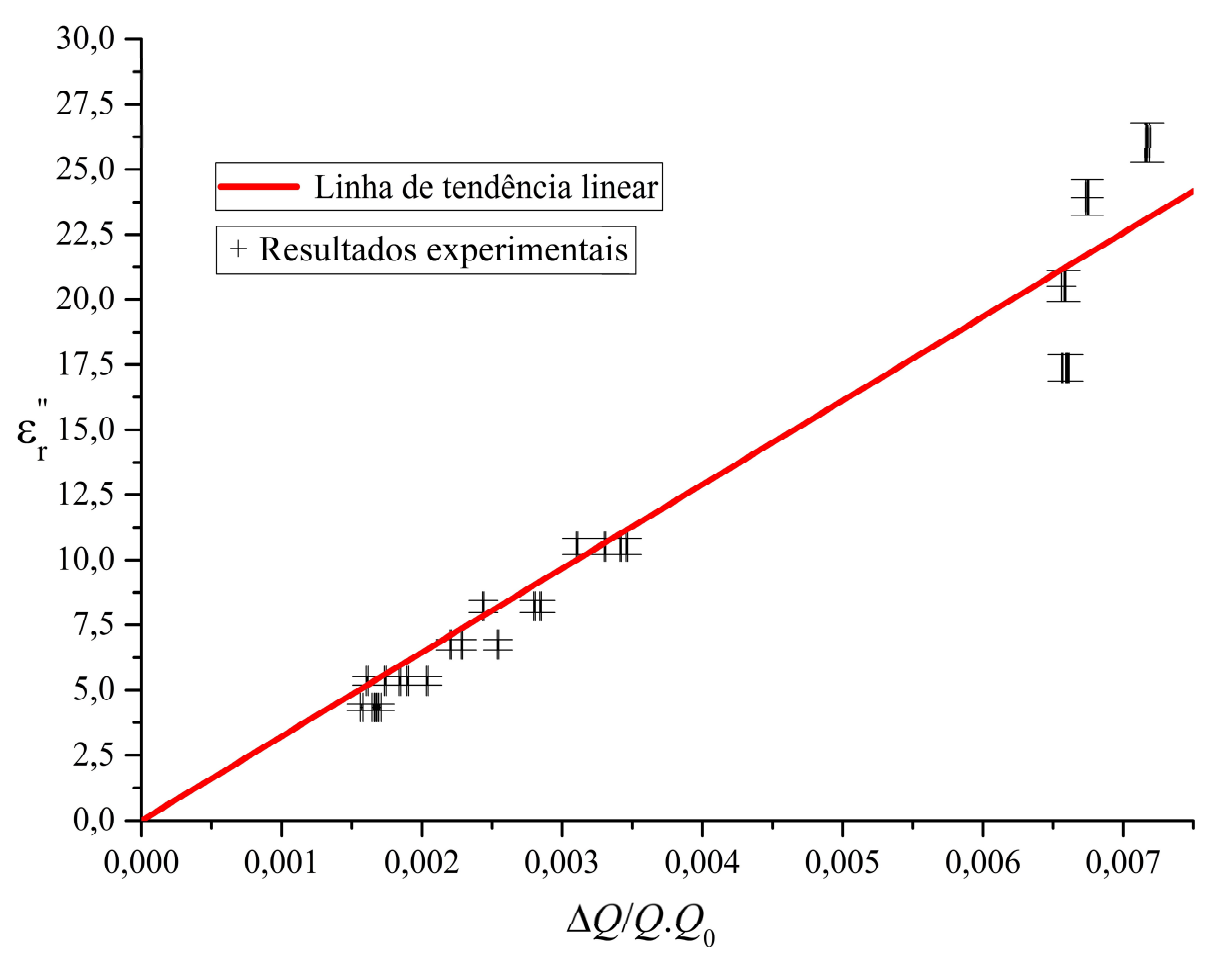

O sensor apresentou boa resposta para a caracterização das amostras de etanol em água. Contudo vale ressaltar que o aparato experimental ainda demanda um operador capaz de inserir corretamente uma quantidade limitada de material na posição correta. A antena com fenda traseira também foi utilizada para testar o comportamento da variação de temperatura na caracterização de materiais. $\mathrm{O}$ Apêndice $\mathrm{P}$ apresenta medidas de água DI para temperaturas entre $0,5^{\circ} \mathrm{C}$ e $35^{\circ} \mathrm{C}$. 


\subsubsection{Guia de ondas integrado em substrato}

Através das equações apresentadas no item 3.4, foi projetado um guia de ondas com tecnologia SIW com a banda de operação do guia padrão WR187 (ANEXO B), que atua nas frequências de 3,95 GHz a 5,85 GHz. O guia SIW projetado é apresentado na Figura 4.10. O substrato utilizado foi o RT Duroid® 5880 com espessura de $0,508 \mathrm{~mm}$. Primeiramente, calculou-se a largura da seção transversal efetiva, $a_{\text {eff }}$, valor da seção equivalente ao guia de ondas retangular para o modo TE10, utilizando $f_{c 10}$ igual a $3,16 \mathrm{GHz}$, equivalente à frequência de corte do guia de ondas no ar (APÊNDICE M). Considerando o diâmetro dos furos metalizados $d=2,4 \mathrm{~mm}$ e a distância entre os

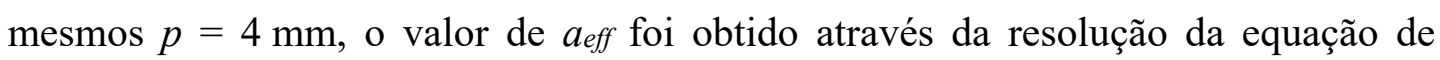
segundo grau apresentada pela equação 3.10, reescrita em 4.20.

$$
a_{e f f}=\frac{1}{2 f_{10} \sqrt{\varepsilon \cdot \mu}}=\frac{3 \times 10^{8}}{2 \times 3,16 \times 10^{9} \sqrt{2,2 \times 1}}=32,00 \mathrm{~mm}
$$

A partir da equação 3.12 foi possível obter a distância $a$ entre as fileiras dos furos metalizados igual a $32,36 \mathrm{~mm}$. Como já descrito, a largura da banda no modo

fundamental pode ser aproximada através da expressão: $1,25 f_{c_{T E_{10}}} \leq f \leq 0,95 f_{c_{T_{22} 0}}$. A frequência de corte do segundo modo de propagação, modo TE20, é descrita pela equação 4.21, resultando em 6,54 GHz. Dessa forma, a banda do guia é de 3,95 GHz a, aproximadamente, $6,21 \mathrm{GHz}$.

$$
\begin{aligned}
f_{20} & =\frac{1}{\sqrt{\varepsilon \cdot \mu}}\left(a-\frac{d^{2}}{1,1 p}-\frac{d^{3}}{6,6 p^{2}}\right)^{-1}= \\
& =\frac{3 \times 10^{8}}{\sqrt{2,2 \times 1}}\left[32,36 \times 10^{-3}-\frac{\left(2,4 \times 10^{-3}\right)^{2}}{1,1 \times 4 \times 10^{-3}}-\frac{\left(2,4 \times 10^{-3}\right)^{3}}{6,6 \times\left(4 \times 10^{-3}\right)^{2}}\right]^{-1}=6,54 \mathrm{GHz}
\end{aligned}
$$

Os valores calculados para o projeto do taper (APÊNDICE O), circuito de casamento de impedâncias entre a linha de transmissão e o guia, foram $W=7,39 \mathrm{~mm}$ e $L=17,4$ 
mm. Os valores apresentados na Tabela 4.7 descrevem os parâmetros geométricos do guia de ondas projetado e otimizado através de simulador eletromagnético CST Studio. A Figura 4.10 (a) ilustra o guia de ondas projetado, enquanto que a Figura 4.10 (b) demonstra o protótipo desenvolvido.

Figura 4.10 - Guia de ondas SIW: (a) modelo de simulação, (b) protótipo desenvolvido.

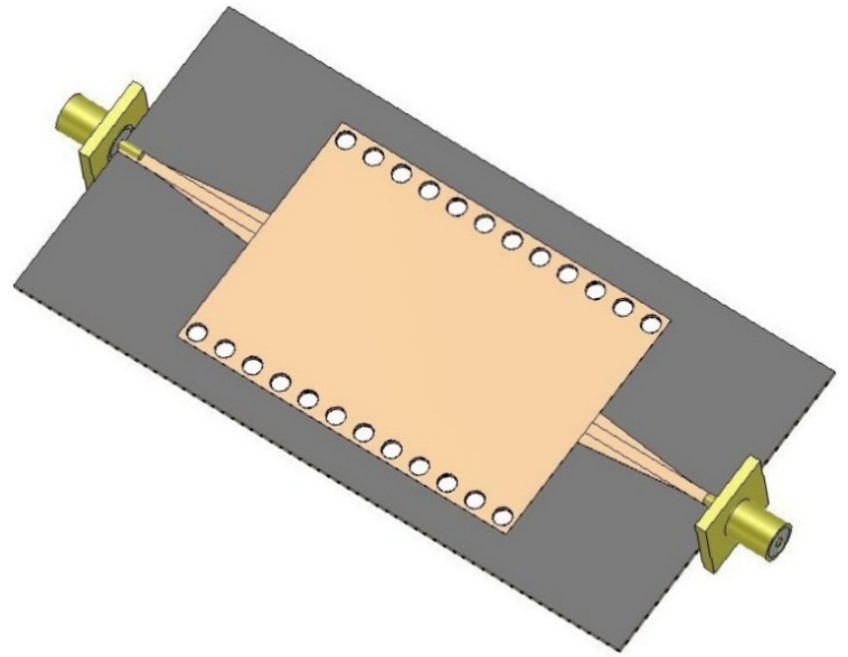

(a)

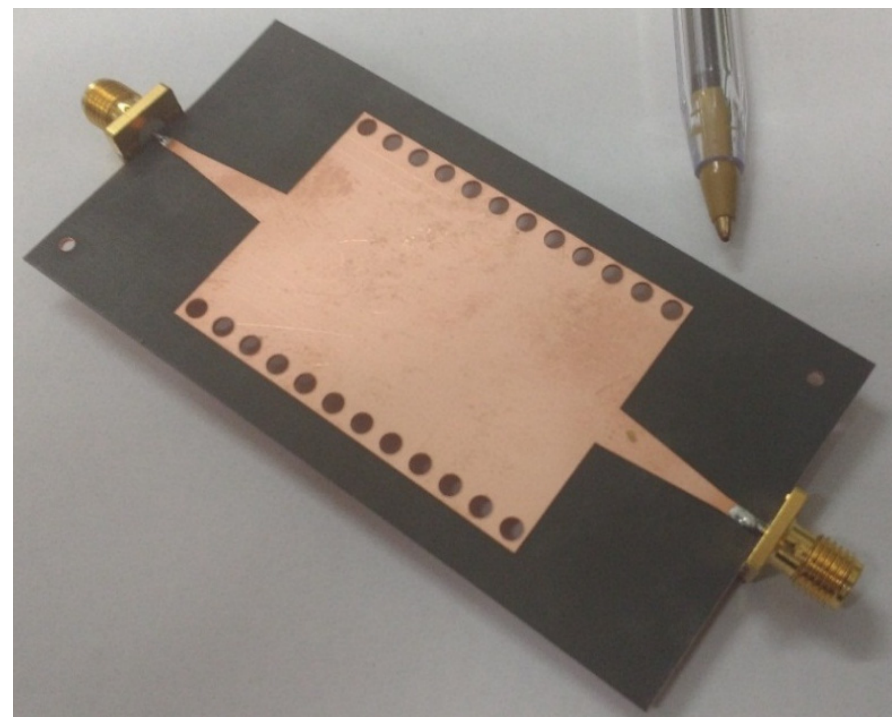

(b)

A Figura 4.11 apresenta a distribuição do campo elétrico no guia de ondas SIW para a frequência de 5,8 GHz, simulado no CST Studio Suite. Não há vazamento significativo 
de campo eletromagnético entre as vias metalizadas. Desse modo, o campo elétrico fica confinado no interior do substrato. Tal fato, serve como base para a proposta do sensor, cuja ideia é realizar um pequeno corte ao longo do guia e inserir diretamente o composto a ser analisado. Dessa maneira, utilizando a técnica da transmissão/reflexão e seus algoritmos (ver APÊNDICE D), propõe-se uma guia de ondas planar para caracterização eletromagnética de materiais.

Tabela 4.7 - Dimensões otimizadas do guia de ondas em SIW.

\begin{tabular}{lc}
\multicolumn{1}{c}{ Parâmetro de projeto } & Especificação após otimização \\
\hline $\begin{array}{l}\text { Banda de operação } \\
\text { Distância entre fileiras de furos } \\
\text { metalizados }(a)\end{array}$ & 3,95 a $6,00 \mathrm{GHz}$ \\
Comprimento do $\operatorname{taper}(L)$ & $33,26 \mathrm{~mm}$ \\
Largura do taper $(W)$ & $14,40 \mathrm{~mm}$ \\
Diâmetro do furo metalizado $(d)$ & $6,11 \mathrm{~mm}$ \\
Distância entre furos $(p)$ & $2,4 \mathrm{~mm}$ \\
Largura da linha de microfita $\left(W_{f}\right)$ & $4,10 \mathrm{~mm}$ \\
Comprimento da linha de microfita $\left(L_{f}\right)$ & $1,52 \mathrm{~mm}$ \\
\hline
\end{tabular}

Figura 4.11 - Distribuição do campo elétrico [V/m] no guia de ondas em SIW para a frequência de 5,8 GHz.

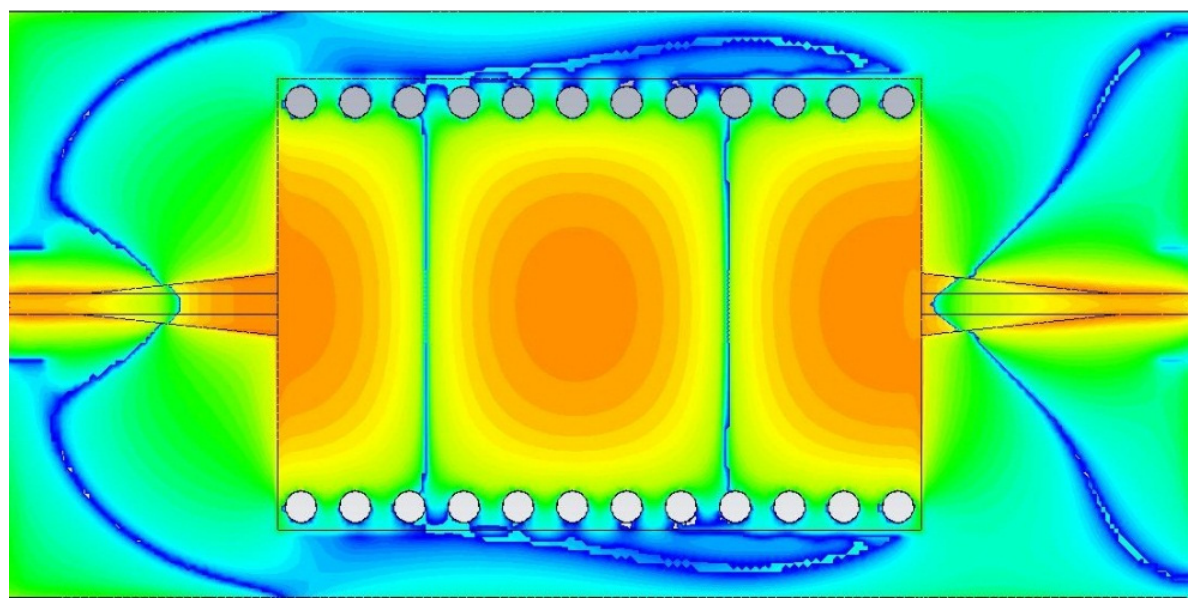


O Gráfico 4.32 apresenta os coeficientes de reflexão e transmissão simulados do guia de ondas em SIW. Para realizar as medidas de coeficiente de reflexão e transmissão, o analisador de redes foi calibrado na faixa de frequências entre 1 e $10 \mathrm{GHz}$ com 801 pontos. A perda de inserção na banda de operação ficou entre os valores de $-0,42 \mathrm{~dB}$ e $-0,94 \mathrm{~dB}$. A perda de retorno ficou abaixo de $-10 \mathrm{~dB}$ para a banda de operação. Esse parâmetro é diretamente relacionado ao casamento de impedância e foi ajustado através da sintonia do taper.

Gráfico 4.32 - Coeficientes de reflexão e transmissão do guia de ondas em SIW do modelo simulado e do protótipo medido.

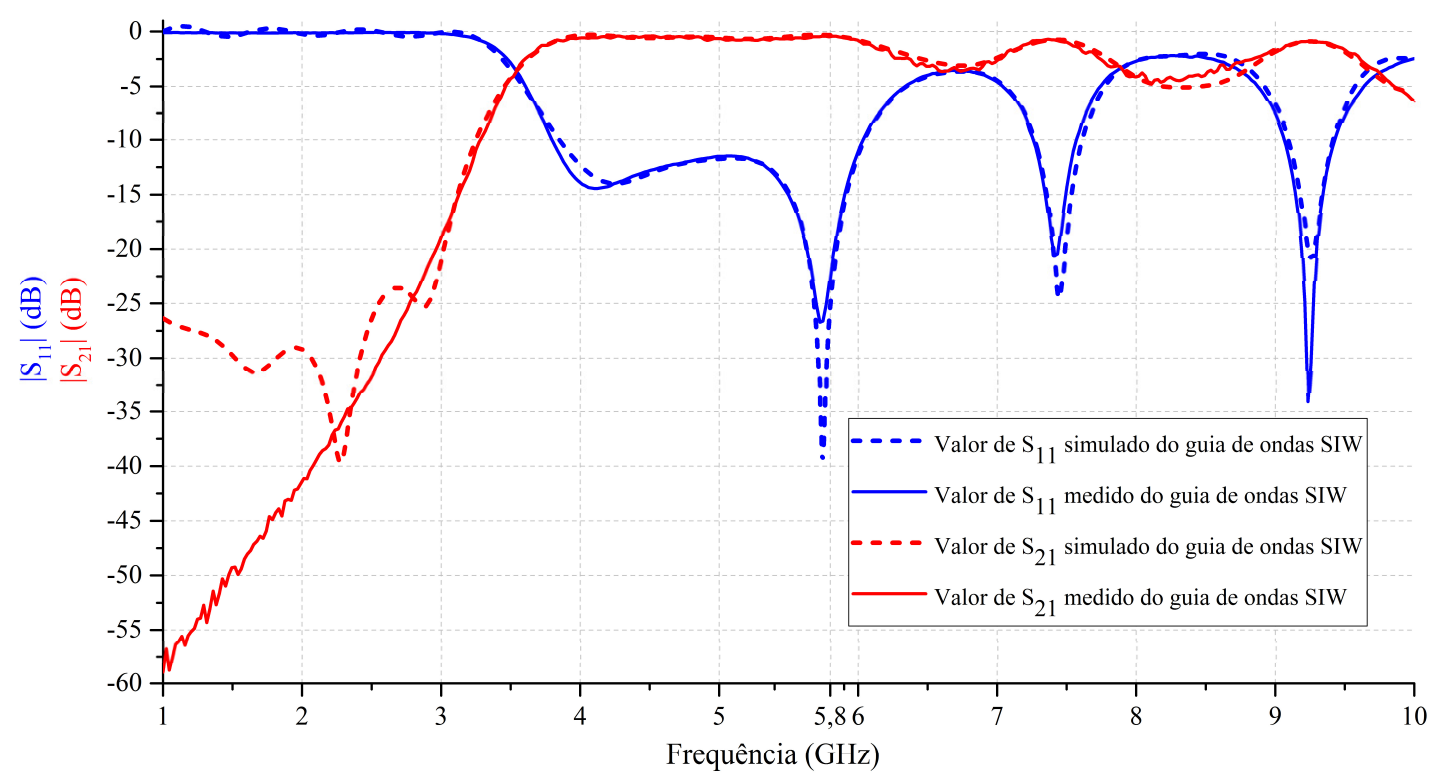

As curvas de coeficiente de reflexão e de transmissão do protótipo do guia SIW foram medidas com o analisador de redes vetorial HP 8722D, sendo apresentadas com as curvas simuladas. Nota-se boa concordância entre os resultados medidos e simulados. A banda especificada foi atendida, e os valores de coeficiente de reflexão ficaram abaixo de $-10 \mathrm{~dB}$ em toda a faixa de operação. A diferença entre os valores simulado e medido do coeficiente de transmissão do guia de ondas em SIW para as frequências entre 1 e $3 \mathrm{GHz}$ deve-se a ao procedimento de isolação durante a calibração e também devido à incerteza do analisador de redes na medida de sinais com baixa potência. 
No método da transmissão/reflexão a amostra faz parte da linha de transmissão e seus parâmetros de espalhamento são obtidos com um analisador de rede vetorial. Como a proposta é utilizar o guia para a caracterização de materiais tal como se faz em guias retangulares utilizando a técnica da transmissão/reflexão, foi realizado uma fenda de $1 \mathrm{~mm}$ transversal na posição central do guia SIW.

Figura 4.12 - Fabricação da fenda no guia SIW: (a) detalhe da fenda de $1 \mathrm{~mm}$ transversal ao guia; (b) guia com tampa e furação para inserção dos líquidos.

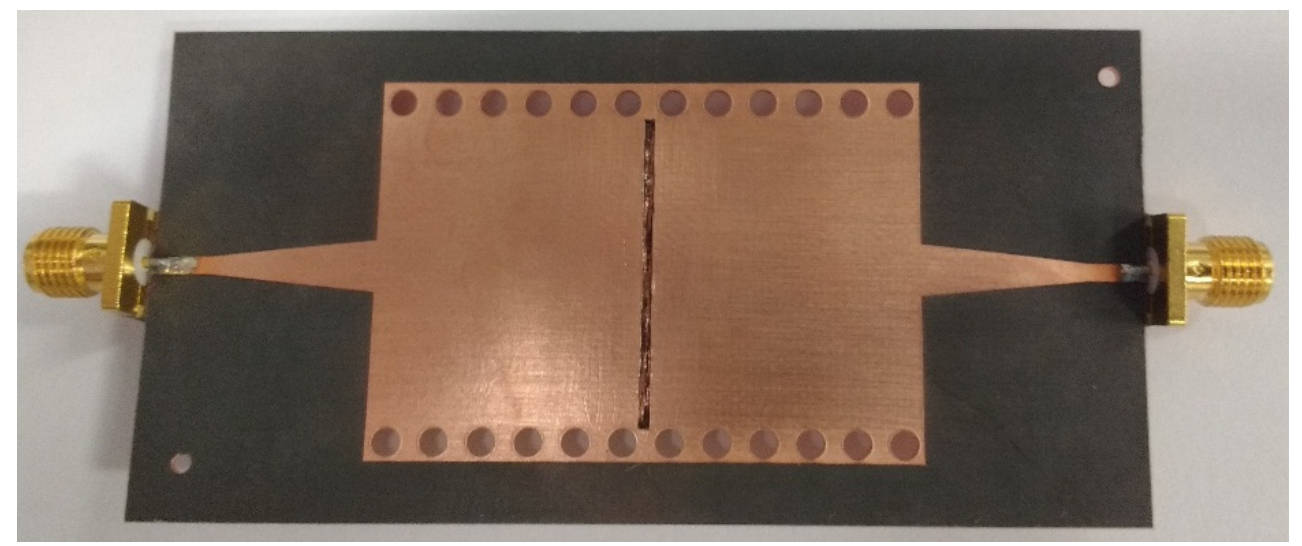

(a)

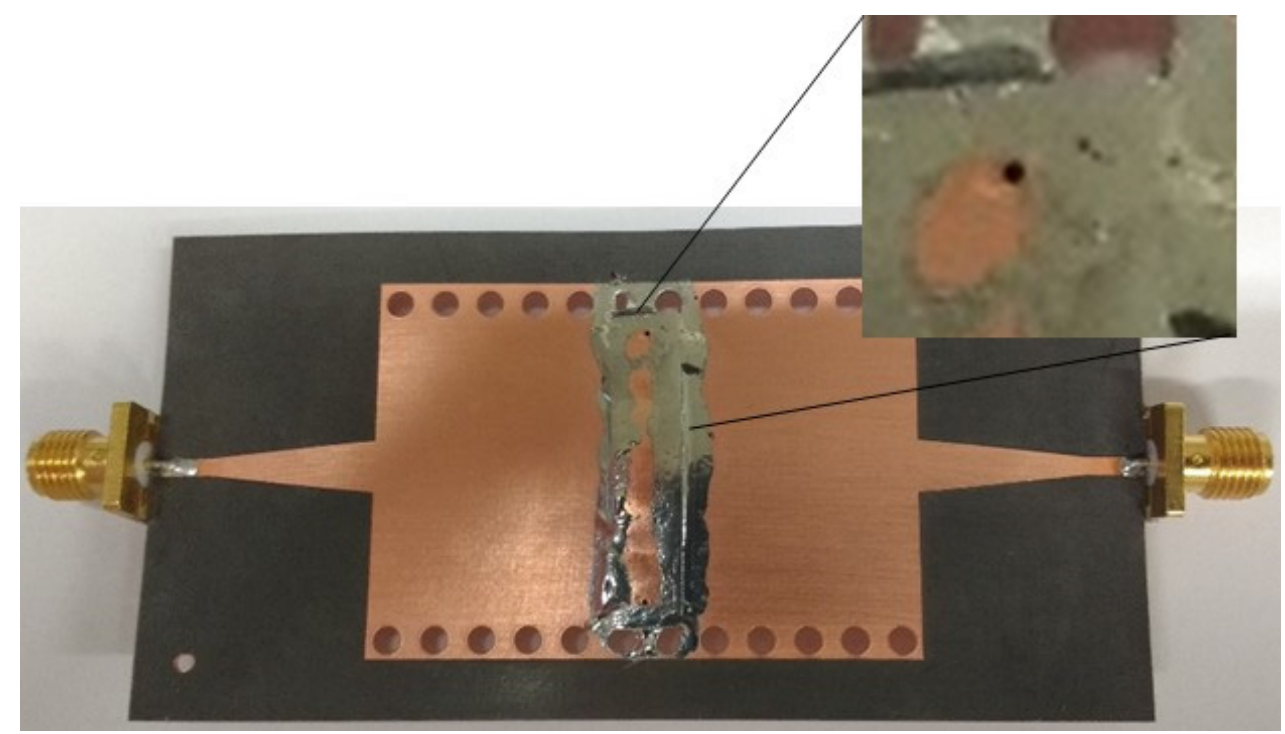

(b) 
A fenda transversal foi construída por meio de um bisturi, removendo completamente o dielétrico até alcançar o cobre do plano de terra. A fenda foi fechada por meio de uma tampa de cobre soldada no guia SIW. Dois pequenos furos permitem a injeção da amostra líquida e a saída do ar da fenda. A inserção é realizada por meio de uma seringa e a retirada é feita por jatos de $\mathrm{N}_{2}$. A Figura 4.12 (a) apresenta o detalhe da fenda e em (b) é apresentada a tampa e a furação realizada na mesma. No algoritmo NRW (NICOLSON et al., 1970), os planos de calibração estão localizados nas interfaces da amostra, no caso a região com o rasgo.

Para descontar o efeito dos conectores e das linhas de transmissão, bem como deslocar o plano de calibração para essa região, foi utilizado o procedimento de de-embedding. Inicialmente, foi realizada a medida dos parâmetros $\mathrm{S}$ para o guia sem amostras. Desse modo, a influência do guia e dos conectores são descontadas matematicamente das medidas realizadas com os materiais em teste.

Os resultados dos ensaios utilizando diferentes materiais estão descritos nos gráficos 4.33 e 4.34. O Gráfico 4.33 (a) apresenta a magnitude da perda de retorno e (b) a fase da perda de retorno. Já o Gráfico 4.34 (a) descreve a magnitude e (b) a fase da perda de inserção para os testes com diferentes frações de etanol e água.

As medidas foram realizadas 5 vezes para cada fração, sendo que houve repetitividade nas medidas, em diferentes horas do dia em diferentes dias.

Nota-se que é possível verificar um comportamento diferente para as distintas diluições. Para a amostra de água, verifica-se que há o maior valor de perda de retorno, como é esperado, devido a seu maior descasamento em relação à constante dielétrica do substrato RT Duroid ${ }^{\circledR} 5880$, que é de 2,2.

Os Gráficos 4.35 e 4.36 foram obtidos utilizando o algoritmo de Nicolson-Ross-Weir (NRW) programado utilizando a ferramenta matemática Matlab (APÊNDICE P). 
Gráfico 4.33 - Perda de retorno $\left(\mathrm{S}_{11}\right)$ do guia de ondas em SIW em função da frequência para as amostras de etanol em água, (a) magnitude (b) fase.

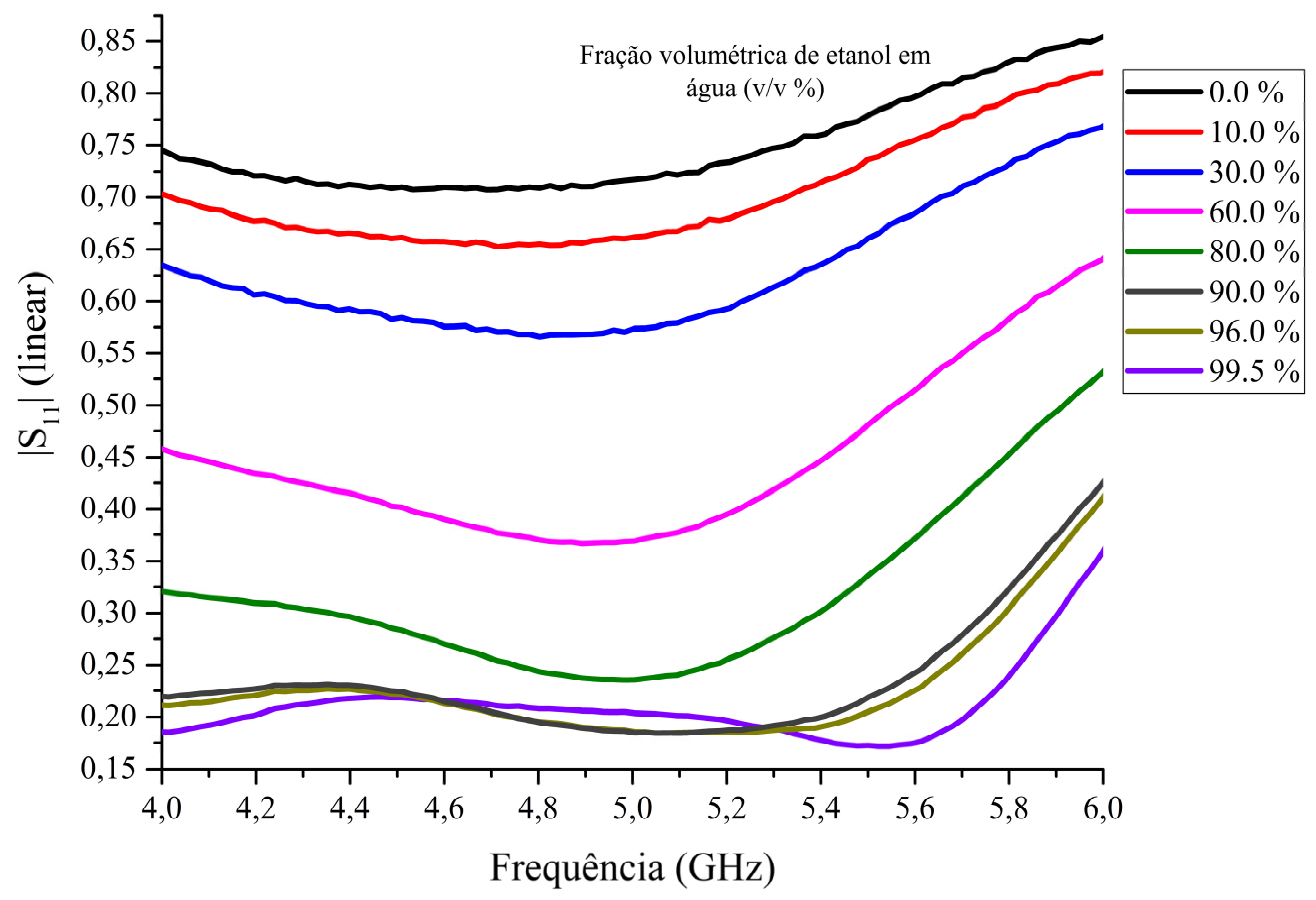

(a)

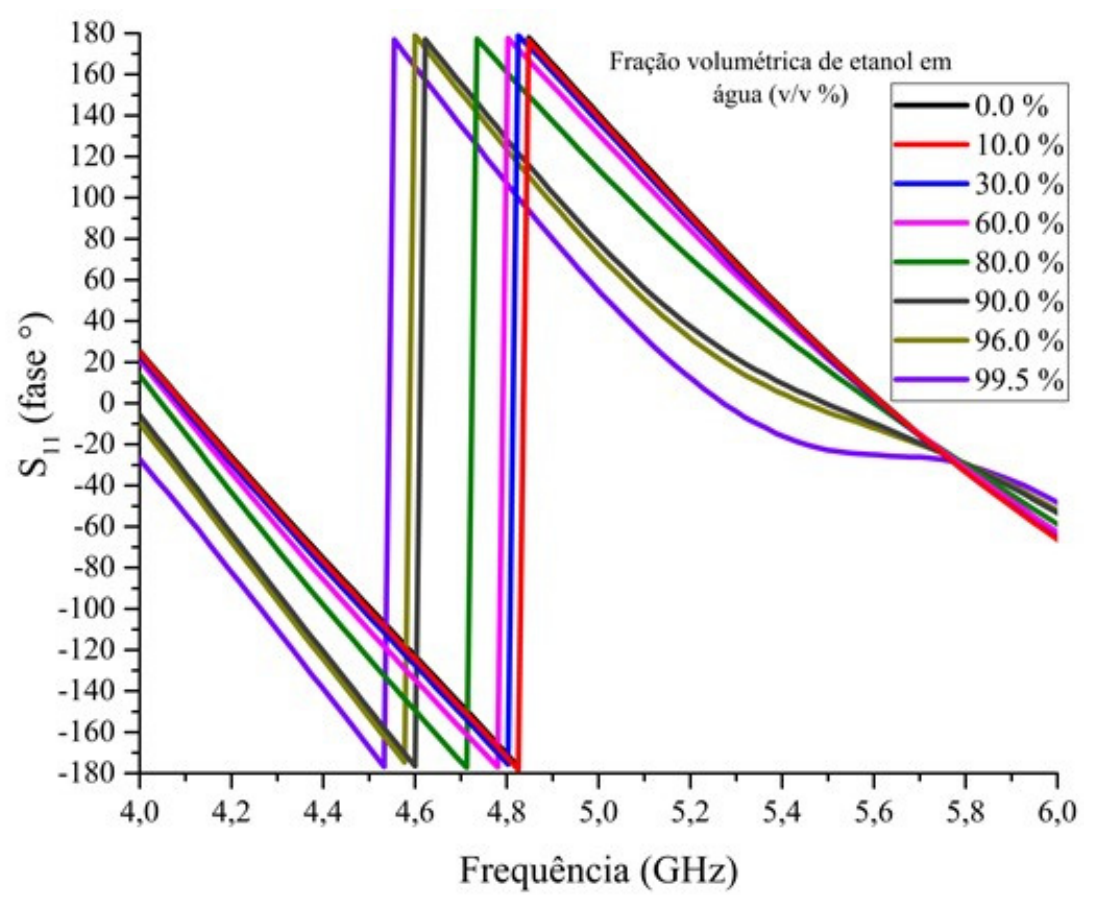

(b) 
Gráfico 4.34 - Perda de inserção $\left(\mathrm{S}_{21}\right)$ do guia de ondas em SIW em função da frequência para as amostras de etanol em água, (a) magnitude (b) fase.

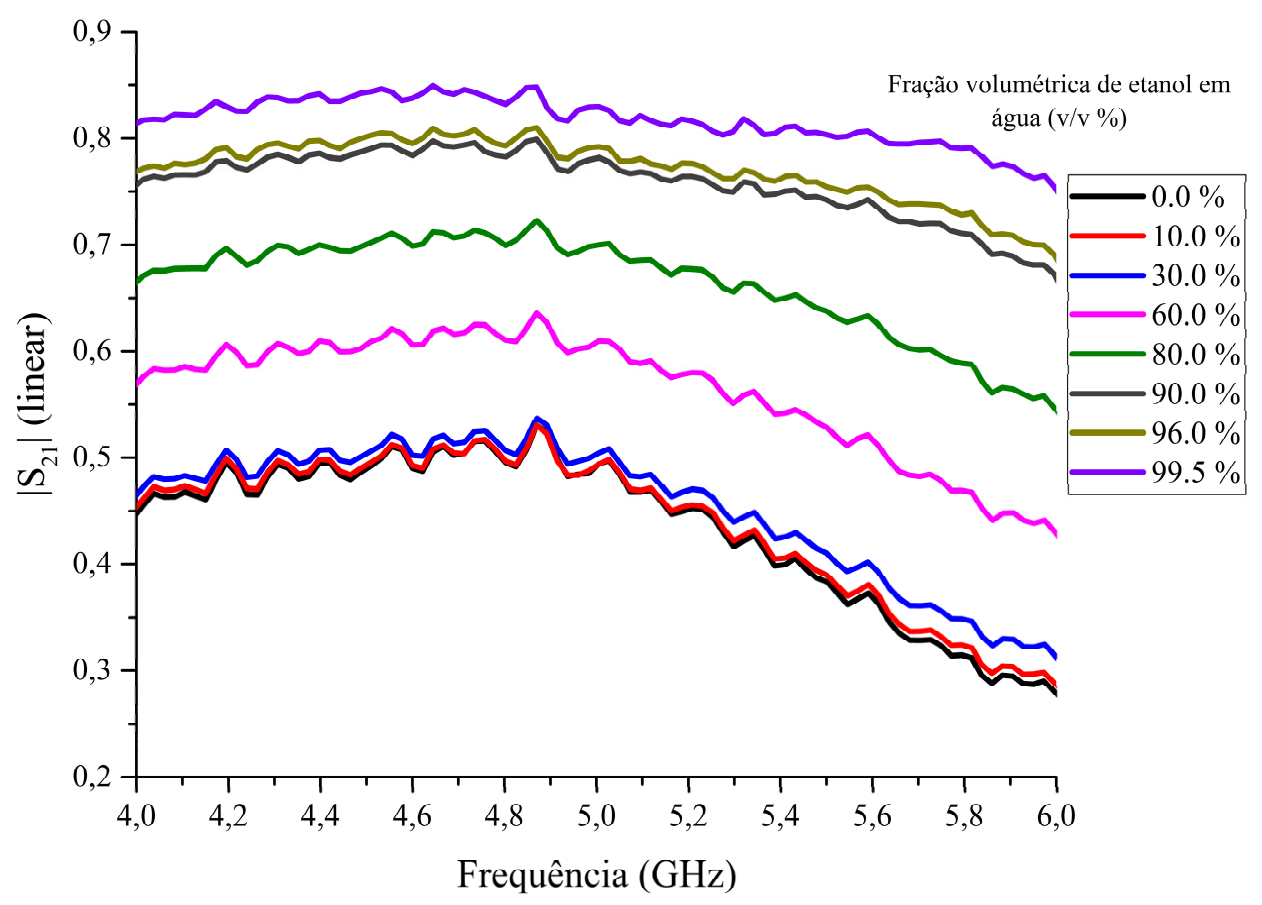

(a)

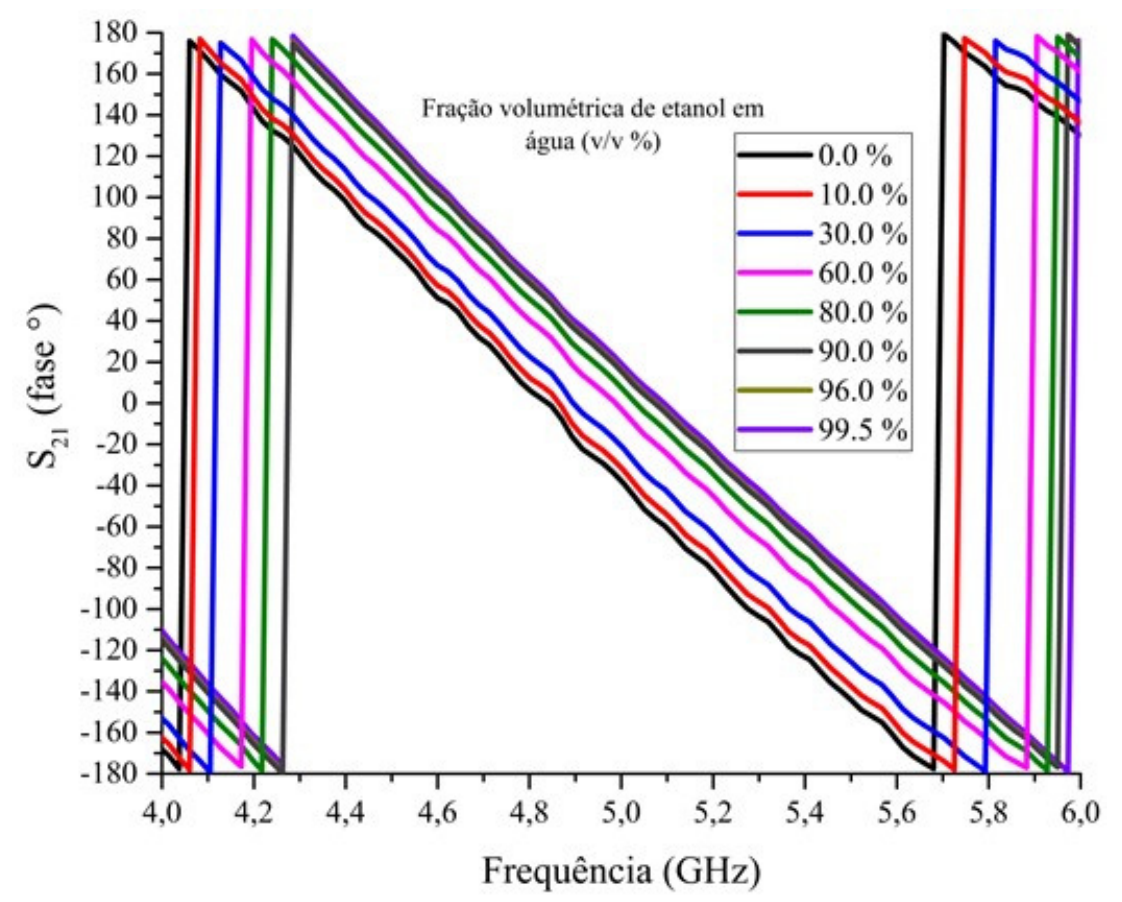

(b) 
Como o algoritmo NRW possui problemas de descontinuidade, Bartley e Begley (2010) propuseram um ajuste polinomial que tem como objetivo suavizar o comportamento das curvas de permissividade elétrica complexa e/ou permeabilidade magnética complexa em função da frequência. Neste trabalho optou-se por definir um ajuste polinomial fixo para as curvas de permissividade elétrica. Para a parte real desse parâmetro, realizou-se um ajuste de $2^{\circ}$ ordem, já para a parte imaginária um ajuste de $1^{\mathrm{o}}$ ordem modelou adequadamente a dispersão do material em função da frequência.

O Gráfico 4.35 apresenta a parte real da permissividade elétrica em função da frequência para diferentes frações de etanol em água. Verifica-se que as medidas obtidas pelo algoritmo NRW tratadas pelo ajuste polinomial estão coerentes com a referência (BAO et al., 1996). Somente para a fração de 30\% (v/v) de etanol e água, constatou-se um erro relativo maior do medido em relação à referência, com cerca de $11,11 \%$.

Gráfico 4.35 - Valores medidos da parte real da permissividade elétrica das amostras de etanol e água comparados com os valores de referência (BAO et al., 1996).

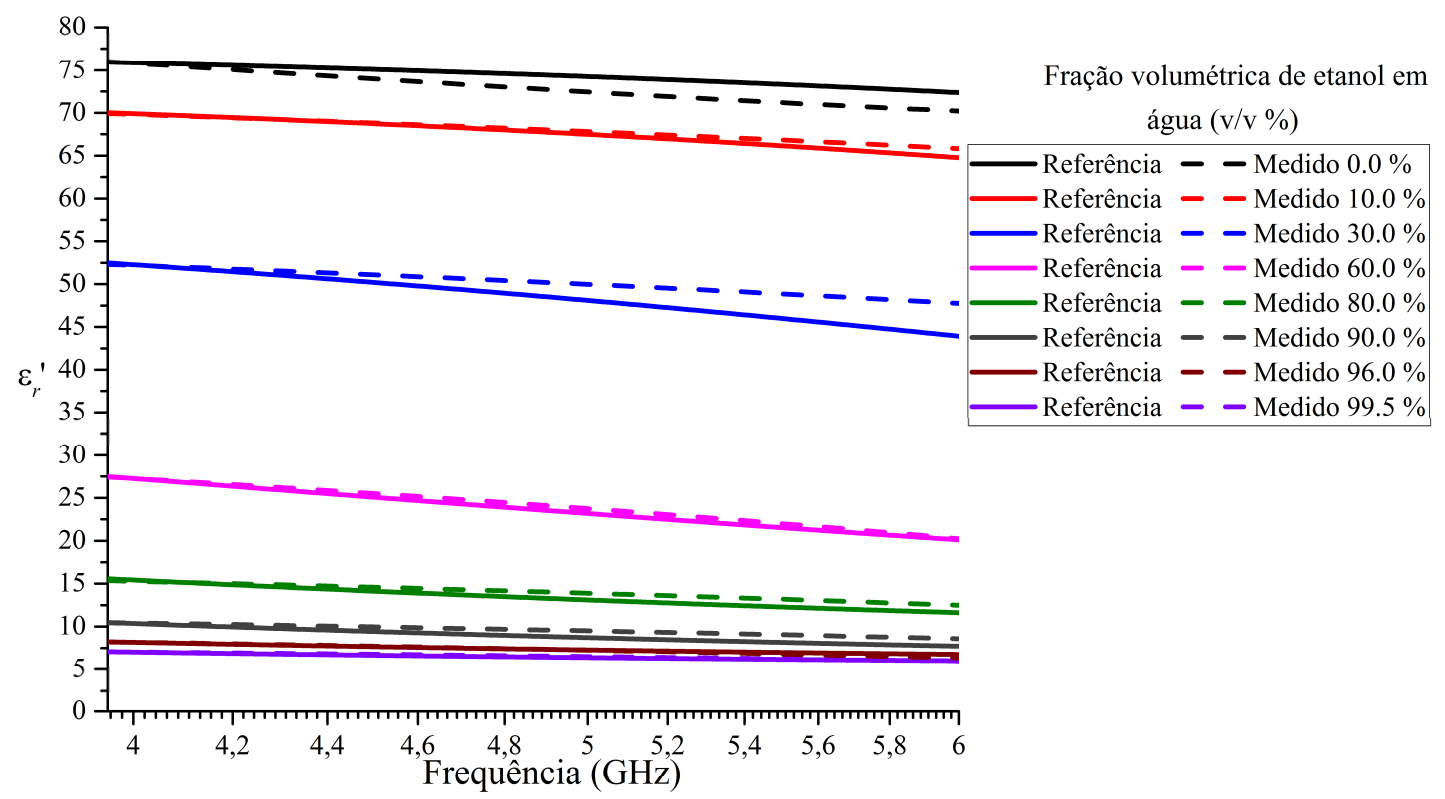

Para todas as curvas, nota-se que entre $4 \mathrm{GHz}$ e $5 \mathrm{GHz}$ o erro relativo máximo entre os valores medidos e os fornecidos pelo modelamento realizado a partir de Bao et al. 
(1996) foi de 3,4\%. A fração de 30\% (v/v) de etanol em água apresentou o maior erro para frequências acima de $5 \mathrm{GHz}$. Todas as outras amostras apresentaram coerência entre os valores modelados e medidos em toda a faixa de frequência do guia SIW.

O Gráfico 4.36 descreve a parte imaginária da permissividade elétrica das amostras de etanol em água. Novamente a fração de $30 \%(\mathrm{v} / \mathrm{v})$ de etanol em água apresentou o maior erro relativo, com $15 \%$ na frequência de $6 \mathrm{GHz}$. O comportamento de crescimento do valor da parte imaginária da permissividade elétrica para as amostras de $0 \%, 10 \%$ e $30 \%(\mathrm{v} / \mathrm{v})$ é verificado nas medidas. Contudo, nota-se que o erro relativo tende a aumentar com a frequência. Para as amostras de 90\%, 96\% e 99,5\% (v/v) de etanol em água verifica-se que o sensor é capaz de discriminar de maneira eficiente as misturas. Esse fato realça a potencialidade do uso da metodologia aqui proposta para a caracterização de etanol combustível, em especial, nos valores de fração em torno da faixa de EHC permitida pela ANP. Em média, obteve-se erro relativo máximo de $9 \%$.

Gráfico 4.36 - Valores medidos da parte imaginária da permissividade elétrica das amostras de etanol e água comparados com os valores de referência (BAO et al.,

1996).

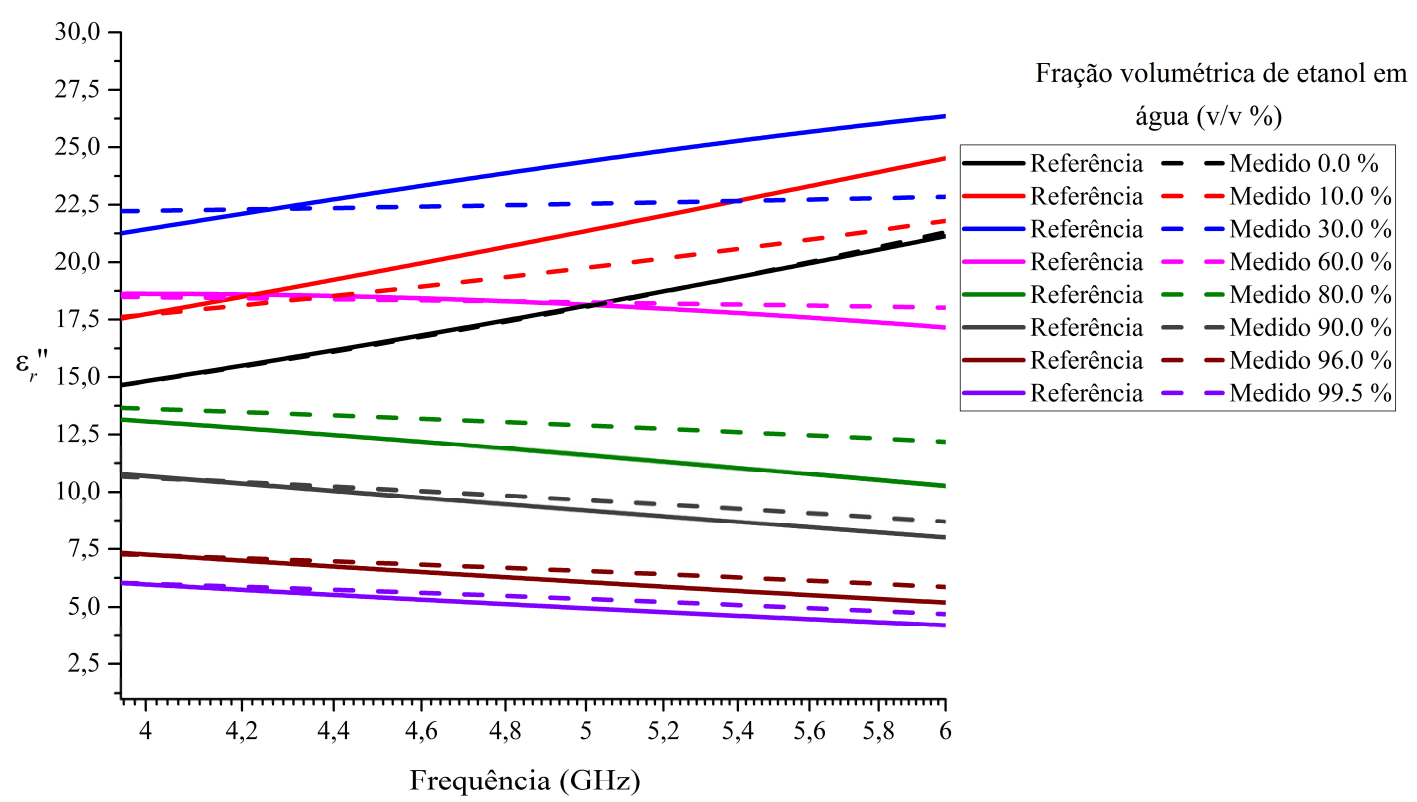

Dentre as vantagens do sensor proposto estão: facilidade da injeção do material, pois a própria fenda delimita a máxima quantidade de material a ser caracterizado; não 
dependência da habilidade do operador durante os ensaios; e rapidez na secagem e restauração do sensor para o valor inicial. Outro aspecto a ser destacado é que o sensor utilizando guia de ondas SIW não é ressonante, podendo cobrir diferentes faixas de frequência com largura de banda $\left(1,25 f_{c_{T E_{10}}} \leq f \leq 0,95 f_{c_{T E_{20}}}\right)$ maiores que $50 \%$. Dessa forma pode ser aplicado para caracterizar materiais em função da frequência. Contudo, esse sensor demanda uma instrumentação mais onerosa, pois utiliza um analisador de redes vetorial.

Foram apresentados o projeto, simulação e caracterização de quatro sensores para a caracterização de amostras de etanol em água, típica adulteração do etanol combustível. Duas técnicas de caracterização eletromagnética de materiais foram utilizadas: a teoria da perturbação da cavidade ressonante e a técnica da transmissão/reflexão. A discussão dos resultados e as conclusões são discutidas no próximo capítulo, que também apresenta uma comparação entre as metodologias aqui utilizadas e os possíveis trabalhos futuros. 


\section{CONCLUSÕES E SUGESTÕES DE TRABALHOS FUTUROS}

\subsection{Conclusões}

Foram projetados, simulados e caracterizados sensores de micro-ondas para a qualificação de etanol combustível adulterado com água, contribuindo de maneira original para o projeto de novos sensores, e para a caracterização de materiais em frequências de micro-ondas.

O texto apresentou uma revisão da literatura acerca dos métodos de caracterização eletromagnética de materiais, da adulteração de combustíveis, das estruturas de circuitos planares de micro-ondas e nanotubos de carbono - CNTs. Esses princípios teóricos apoiaram o desenvolvimento do trabalho.

Foram modelados, através das regras de diluição, os parâmetros de permissividade elétrica complexa das misturas típicas de adulteração de etanol por adição de água. Como apresentado no capítulo 4, essas misturas foram quantificadas através dos seus valores de permissividade elétrica complexa, correlacionando as mesmas com as variações da frequência de ressonância e índice de mérito medidos em antenas e cavidades ressonantes de micro-ondas.

Foram desenvolvidos dois grupos de sensores para a caracterização de etanol combustível: sensores para análise da fase vapor e da fase líquida.

Para o desenvolvimento de sensores da fase vapor, foram realizados testes preliminares que permitiram verificar a potencialidade do uso de materiais nanoestruturados para a caracterização de etanol combustível em frequências de micro-ondas. Posteriormente foi projetada, simulada e confeccionada uma antena de microfita em 5,8 GHz, sobre a qual foram depositados materiais nanoestruturados, em específico, SWCNT pela técnica do gotejamento. Com o uso de SWCNT, a área de adsorção de amostras em fase vapor foi incrementada, o que permitiu obter sensores com maior sensibilidade, potencializando a redução do tamanho dos dispositivos. Adicionalmente, o uso de SWCNT propiciou a utilização dos sensores de fase vapor em temperatura ambiente o que reduz custos de operações.

Após a execução de testes desse sensor exposto a diferentes frações de etanol e água, pôde-se observar diferenças mensuráveis na frequência de ressonância e no índice de 
mérito. Essas variações são relacionadas com as mudanças na permissividade elétrica relativa da amostra de material sob teste. Como a resposta em frequência das antenas dependem da constante dielétrica do substrato e da permissividade do meio em que as antenas estão submetidas, qualquer variação neste valor, afetará seus desempenhos. Dessa maneira foi possível modelar o comportamento da permissividade elétrica complexa de amostras de etanol combustível através das fórmulas derivadas da técnica da perturbação da cavidade ressonante.

Através dos mecanismos de adsorção pelo CNT e devido às trocas de cargas elétricas entre o CNT e as moléculas de água, foi possível variar a permissividade do meio em função da concentração das misturas de etanol adulterado. Os sensores projetados apresentaram repetitividade, boa sensibilidade e tempo de recuperação menor do que $45 \mathrm{~s}$ para o caso da antena de microfita com plaqueta retangular e $142 \mathrm{~s}$ para o caso da antena SIW com fenda traseira.

Para aumentar a sensibilidade da antena de microfita foi proposto o projeto e simulação das antenas de fenda em cavidades ressonantes SIW operando no modo TE101. Os resultados da simulação dessas estruturas indicaram maior concentração de campo elétrico no centro da cavidade, onde está localizada a fenda radiante. Dessa forma, de acordo com a técnica da perturbação da cavidade ressonante, o uso de SWCNT sobre a fenda tende a aumentar a sensibilidade desse sensor.

Para os sensores de fase líquida foram projetados e simulados dois sensores utilizando tecnologia SIW. O primeiro foi concebido a partir da própria antena de fenda com cavidade ressonante SIW sem uso de SWCNT, contudo com as amostras líquidas de etanol combustível diretamente depositadas sobre o sensor. Já o segundo, um guia de ondas com tecnologia SIW, operando na faixa de frequências entre $3,95 \mathrm{GHz}$ e $6,00 \mathrm{GHz}$, foi utilizado para caracterizar as amostras líquidas de etanol combustível alocadas diretamente em uma pequena fenda desse guia de ondas.

A Tabela 5.1 apresenta uma síntese comparativa dos sensores desenvolvidos. São comparados: o tempo de recuperação, a faixa de frequência para caracterização, sensibilidade e custo. Os três primeiros sensores utilizaram o método da perturbação da cavidade ressonante, com isso possuem faixa de operação limitada, que somente garante a análise dos dados em frequências discretas. Já o guia SIW foi projetado e 
caracterizado com base no método da transmissão/reflexão, possibilitando a medida em toda a faixa de frequências de operação do guia.

Ressalta-se que os sensores que analisam líquidos possuem rápido tempo de recuperação, sendo facilmente reutilizáveis após realizarem uma medida. Como é de se esperar, os sensores da fase vapor são mais lentos, pois necessitam de uma etapa de dessorção controlada para que os sensores voltem às suas condições iniciais.

Tabela 5.1 - Comparativo entre métodos de medida e sensibilidade para a caracterização e qualificação de etanol combustível.

\begin{tabular}{cccccc}
\hline Sensor & Fase & $\begin{array}{c}\text { Tempo de } \\
\text { recuperação } \\
\text { (valor } \\
\text { estimado) }\end{array}$ & $\begin{array}{c}\text { Faixa de } \\
\text { frequências para } \\
\text { caracterização } \\
\text { eletromagnética }\end{array}$ & $\begin{array}{c}\text { Sensibilidade } \\
\text { do sensor }\end{array}$ & $\begin{array}{c}\text { Custo para } \\
\text { implementação } \\
\text { de um sistema } \\
\text { dedicado }\end{array}$ \\
\hline $\begin{array}{c}\text { Antena de } \\
\text { microfita } \\
\text { com }\end{array}$ & Vapor & $\begin{array}{c}\text { Médio } \\
(\approx 100 \mathrm{~s})\end{array}$ & $\begin{array}{c}\text { Frequências } \\
\text { discretas }\end{array}$ & Baixíssima & Alto \\
$\begin{array}{c}\text { SWCNT } \\
\text { Antena SIW } \\
\text { com } \\
\text { SWCNT }\end{array}$ & Vapor & $\begin{array}{c}\text { Médio } \\
(\approx 100 \mathrm{~s})\end{array}$ & $\begin{array}{c}\text { Frequências } \\
\text { discretas }\end{array}$ & Baixa & Alto \\
$\begin{array}{c}\text { Antena SIW } \\
\text { Líquida }\end{array}$ & $\begin{array}{c}\text { Baixo } \\
(\approx 10 \mathrm{~s})\end{array}$ & $\begin{array}{c}\text { Frequências } \\
\text { discretas }\end{array}$ & Alta & Baixo \\
Guia SIW & Líquida & $\begin{array}{c}\text { Baixo } \\
(\approx 10 \mathrm{~s})\end{array}$ & Banda larga & Alta & Alto \\
\hline
\end{tabular}

Todos os sensores propostos demonstraram capacidade de discriminação de frações volumétricas de etanol em água de $2 \%$ (v/v) na faixa especificada pela legislação.

Para os sensores ressonantes, notou-se que o mais sensível, exato e preciso foi a antena SIW para análise de líquidos. Para os sensores de fase vapor, a antena SIW com SWCNT apresentou uma faixa dinâmica de frequência de ressonância 5,1 vezes maior do que a antena de microfita com SWCNT.

O sensor de fase líquida usando a antena com fenda apresentou a maior sensibilidade entre os sensores ressonantes, com valor 30,9 vezes maior do que o obtido com a 
antena de microfita com SWCNT. O sensor com guia de ondas integrado ao substrato apresentou incerteza máxima de 3,4\% para medidas de frações de etanol em água nas regiões permitidas pela legislação.

Em relação ao custo, a aplicação dos sensores de fase vapor propostos demandam uma instrumentação para controle do fluxo, além do analisador de redes. Além disso, esses sensores necessitam de uma etapa adicional de fabricação, que consiste na deposição controlada de material nanoestruturado. Já os sensores de fase líquida propostos demandam basicamente o uso analisador de redes vetorial, sendo que sua fabricação é mais simples, dispensando a etapa de deposição de nanotubos de carbono.

A bancada desenvolvida para a caracterização de materiais em fase vapor possui custo da ordem de $\mathrm{R} \$ 50.000,00$, o que inclui os MFCs e o analisador de redes, equipamentos com maior valor. Esse é um valor intermediário, quando comparado ao de equipamentos de caracterização de combustíveis disponíveis no mercado.

No Brasil, existem empresas especializadas em equipamentos para caracterização de materiais e também de combustíveis. Os equipamentos da empresa Xerloq $q^{47}$ permitem análise combustíveis através de diferentes métodos, como condutividade e fotometria, e custam na ordem de $\mathrm{R} \$ 5.000,00$.

A empresa multinacional Agilent Technologies ${ }^{48}$ fabrica espectrômetros de infravermelho para qualificação com alta sensibilidade de etanol combustível, sendo que os modelos mais simples desses equipamentos custam em torno de US\$ $100.000,00^{49}$.

A sensibilidade dos sensores aqui propostos é comparável com a obtida pelos analisados de combustíveis de mais baixo custo. No entanto, o custo de sistema de medidas usando sensores de micro-ondas pode ser reduzido, no caso de medida em banda estreita de frequência, como as realizadas em sensores ressonantes. Nesse caso, pode-se utilizar reflectômetros de seis portas, ou circuitos dedicados com osciladores

\footnotetext{
${ }^{47}$ Xerloq - Analisador de Combustível: http://www.analisadordecombustivel.com.br/

${ }^{48}$ Agilent Technologies: www.agilent.com/

${ }^{49}$ Valores estimados para o ano de 2016.
} 
controlados por tensão, acopladores e detectores de micro-ondas para substituir o uso do analisador de rede. Na literatura, são encontrados trabalhos que implementam analisadores de rede de baixo custo (WANGSANATA, 2002) (CHOI et al., 2005) (FALLAHPOUR et al., 2012). Ressalta-se que para os sensores ressonantes, podemse ser utilizados analisadores de rede escalar. Somente para o guia em SIW utilizando o algoritmo NRW é necessário o analisador de redes vetorial. Nesse caso, devido às medidas em banda larga, é necessário o uso de analisadores de rede vetoriais comerciais, que têm custo elevado.

Em resumo, foi possível contribuir para a área de caracterização eletromagnética de materiais através do desenvolvimento de estruturas planares de micro-ondas. Dentre os resultados: foi modelado o comportamento da permissividade elétrica complexa das frações de etanol e água através das regras de mistura; foi estabelecida uma técnica para caracterizar a fase vapor de materiais utilizando nanotubos depositados sobre uma antena de microfita e sobre uma cavidade ressonante SIW; e foram desenvolvidas topologias originais utilizando tecnologia SIW para caracterização da fase líquida de materiais. Todas as estruturas em micro-ondas foram projetadas, simuladas computacionalmente e validadas experimentalmente. Os resultados permitiram a elaboração de artigos científicos, descritos no item 5.3. Além disso, foi possível propor o uso da permissividade elétrica complexa como parâmetro de qualificação de etanol combustível. Por fim, espera-se, com o presente trabalho, colaborar no desenvolvimento de sensores capazes de auxiliar a sociedade no avanço técnico e científico nessa área.

\subsection{Trabalhos Futuros}

Os resultados apresentados permitem propor várias frentes de trabalho futuros: análise e caracterização de novos materiais para sensoriamento; desenvolvimento de novas estruturas e topologias que aumentem a sensibilidade para diferentes materiais; proposta de novos algoritmos para extração de características eletromagnéticas a partir das respostas dos sensores; o desenvolvimento de uma eletrônica embarcada com circuitos de micro-ondas para substituir o uso do analisador de redes vetorial; entre outros. 
Para o desenvolvimento de sensores de fase vapor, há três alternativas de otimização. A primeira consiste na seleção de materiais mais sensíveis para cada tipo de aplicação. Nesse caso, há diferentes possibilidades de projetos com materiais sensíveis, como óxidos em geral e mais recentemente o grafeno. Além disso, pode-se melhorar a técnica de deposição dos nanomateriais sobre o sensor utilizando CVD, spray, dieletroforese ou eletroforese. A segunda estratégia é a otimização da extração de atributos das curvas de caracterização dos materiais. Por último, a utilização de diferentes métodos de classificação e inteligência computacional.

Em relação ao desenvolvimento de novas estruturas, ressalta-se a possibilidade de estudar diferentes topologias de ressoadores de micro-ondas. Entre elas as estruturas de micro-ondas planares em anel. Além disso, a tecnologia SIW possibilita muitas possibilidades de topologias, que se analisadas comparativamente, podem render bons resultados na caracterização tanto da fase vapor, como líquida de materiais.

Em termos dos algoritmos de caracterização de materiais em frequência de microondas, indica-se um campo próspero para novos modelamentos que permitam extrair os parâmetros de permissividade elétrica complexa e permeabilidade magnética complexa com maior precisão. Nesse trabalho foram utilizados dois modelamentos já estabelecidos na literatura: teoria da perturbação da cavidade ressonante e o método da transmissão/reflexão.

Por último, uma consequência da proposta de um sensor é o desenvolvimento de uma eletrônica embarcada e portátil com a finalidade do desenvolvimento de um equipamento, que permita entre outras coisas, o uso final. Para tanto, pode-se propor um sistema embarcado de baixo custo, integrado a circuitos de micro-ondas, tais como reflectômetros de seis portas, ou circuitos dedicados com osciladores controlados por tensão, acopladores e detectores de micro-ondas.

\subsection{Trabalhos Apresentados}

Abaixo são detalhados os trabalhos divulgados durante o desenvolvimento desse doutorado ou que estão relacionados diretamente com a qualificação de combustíveis. 


\subsubsection{Artigos submetidos em jornais e periódicos}

BECARI, W; RODRIGUES, D. B. R.; PERES, H. E. M.; CORRERA, F. S. Microwave Sensor for Ethanol Fuel Qualification Based on Single Walled Carbon Nanotubes. Current Nanoscience, $2016 . \quad$ DOI: $10.2174 / 1573413713666161228142437$

BECARI, W; OLIVEIRA, M. A.; PERES, H. E. M.; CORRERA, F. S. MicrowaveBased System for Non-Destructive Monitoring Water Pipe Networks Using Support Vector Machine. IET Science, Measurement \& Technology, vol. 10, p. 910-915, 2016. DOI: 10.1049/iet-smt.2016.0131.

BECARI, W; PERES, H. E. M.; FALLA, M. P.; CORRERA, F. S. Development of Microstrip Patch Antenna Humidity Sensor Based on Single Walled Carbon Nanotubes. Sensors Letters, vol. 14, p. 1123-1128, 2016. DOI: 10.1166/s1.2016.3756. RODRIGUES, D.; BECARI W.; PERES, H. E. M.; CORRERA, F. S. Analysis of Different Probe Geometries for Ethanol Fuel Qualification Using Time-Domain Reflectometry. Progress In Electromagnetics Research Letters, vol. 61, p. 105-109, 2016. DOI:10.2528/PIERL16051909

\subsubsection{Trabalhos em simpósios e congressos internacionais}

BECARI, W; PERES, H. E. M.; CORRERA, F. S.; ARAUJO, L. C.; FALlA, M. P. Microwave-based gas sensor using carbon nanotubes: an approach to ethanol fuel adulteration analysis. XIV Brazil MRS Meeting, XIV Encontro da SBPMat, Rio de Janeiro, 2015.

RODRIGUES, D.; BECARI W.; PERES, H. E. M. Ethanol Fuel Analysis Using Artificial Neural Networks. EBICC - 10th International Brazilian Meeting on Cognitive Science, 2015.

RODRIGUES, D. B. R.; BECARI, W.; PERES, H. E. M. Ethanol Fuel Analysis by Time-Domain Reflectometry. International Microwave and Optoelectronics Conference, 2013. DOI: 10.1109/IMOC.2013.6646441 


\subsubsection{Trabalhos em simpósios e congressos nacionais}

RODRIGUES, D.; BECARI, W.; PERES, H. E. M.; CORRERA, F. Análise e Simulação pelo Método FDTD de Sondas para Qualificação de Etanol Combustível Utilizando Reflectometria no Domínio do Tempo, $\mathbf{1 7}^{\circ}$ SBMO - Simpósio Brasileiro de Micro-ondas e Optoeletrônica, MOMAG, 2016.

OLIVEIRA, A. M. de; PERES, H. E. M.; BECARI, W; - Desenvolvimento de sensor de umidade relativa em frequências de micro-ondas utilizando nanotubos de carbono. $17^{\circ}$ SICT - Simpósio de Iniciação Científica e Tecnológica, Fatec - São Paulo, 2015. OLIVEIRA, A. M. de; MAGALHÃES, C. F.; VELLOZO, B. R.; SOUZA, R. M. de; DALPINO, R. P.; CORRERA, F. S.; BECARI, W. Sistema de detecção de tubulação de PVC utilizando antena patch de microfita. $23^{\circ}$ SIICUSP - Simpósio Internacional de Iniciação Científica da USP, Universidade de São Paulo, 2015. 


\section{REFERÊNCIAS BIBLIOGRÁFICAS}

ABBAS, Z.; POLLARD, R. D; KELSALL, R. W. Complex permittivity measurements at Ka-Band using rectangular dielectric waveguide. IEEE Transactions on Instrument and Measurement, v. 50, n. 5, p. 1334-1342, Oct. 2001. AGÊNCIA NACIONAL DO PETRÓLEO, GÁS NATURAL E BIOCOMBUSÍVEIS - ANP. Resolução ANP n⿳36 de 06/12/2005: Especificações do Álcool Etílico Anidro Combustível (AEAC) e do Álcool Etílico Hidratado Combustível (AEHC).

AGILENT, Basics of Measuring the Dielectric Properties of Materials. Application Note. Agilent Technologies, Apr. 2005.

AGILENT. Basics of measuring the dielectric properties of materials. USA: Agilent Technologies, 26 June 2006, p. 1-32. Application Note. Disponível em: <http://cp.literature.agilent.com/litweb/pdf/5989-2589EN.pdf $>$. Acesso em: 15 janeiro de 2015.

AGILENT. Understanding the Fundamental Principles of Vector Network Analysis. Application Note, AN 1287-1. Agilent Technologies, 2000.

AGMON, N. "Tetrahedral displacement: the molecular mechanism behind the Debye relaxation in water". Journal Physics Chemistry, v. 100, p. 1072-1080, 1996.

AMERICAN SOCIETY FOR TESTING AND MATERIALS. ASTM D5568-1: Standard test method for measuring relative complex permittivity and relative magnetic permeability of solid materials at microwave frequencies. West Conshohoken, PA: ASTM, 2001.

AMORIM, R. G. Estudo da Influência de Defeitos Estruturais nas Propriedades de Nanotubos de Carbono. Tese de Doutorado. Universidade de São Paulo. Instituto de Física, 2009.

AN, K. H.; KIM, W. S.; PARK, Y. S.; CHOI, Y. C.; LEE, S. M.; CHUNG, D. C.; BAE, D. J.; LIM, S. C.; LEE, Y. H. Supercapacitors Using Single-Walled Carbon Nanotube Electrodes. Adv. Mater., vol.13, p. 497-500, 2001. 
ANDERSON, L. S.; GAJDA G. B.; STUCHLY, S. S. Dielectric measurements using a rational functional model. IEEE Transactions on Microwave Theory and Technique, v. 42, n. 2, p. 199-204, Feb. 1994.

ANDREUCCETTI, D.; FOSSI, R.; PETRUCCI, C. An internet resource for the calculation of the dielectric properties of body tissues in the frequency range $\mathbf{1 0}$ Hz - 100 GHz. Produced by Italian National Research Council, Institute for applied Physics 'Nello Carrara' (IFAC). Florence, Italy, 1997. Disponível em: <http://niremf.ifac.cnr.it/tissprop/>. Acesso em: 20 Jan. 2015.

ANSARI, M.A.H.; JHA, A.K.; AKHTAR, M.J. Design and Application of the CSRRBased Planar Sensor for Noninvasive Measurement of Complex Permittivity. IEEE Sensors. v.15, 12, p. 7181-7189, Dec. 2015.

ASSOCIAÇÃO BRASILEIRA DE NORMAS TÉCNICAS - ABNT. NBR 10547: Etanol combustível - Determinação da condutividade elétrica. Rio de Janeiro: ABNT, 2012.3p.

ASSOCIAÇÃO BRASILEIRA DE NORMAS TÉCNICAS - ABNT. NBR 10891: Etanol hidratado combustível - Determinação do pH - Método potenciométrico. Rio de Janeiro: ABNT, 2013. 3p.

ASSOCIAÇÃO BRASILEIRA DE NORMAS TÉCNICAS - ABNT. NBR 16041: Etanol combustível - Determinação dos teores de metanol e etanol por cromatografia gasosa. Rio de Janeiro: ABNT, 2012. 7p.

ASSOCIAÇÃO BRASILEIRA DE NORMAS TÉCNICAS - ABNT. NBR 5992: Álcool etílico e suas misturas com água - Determinação da massa específica e do teor alcoólico - Método do densímetro de vidro. Rio de Janeiro: ABNT, 2008. 5p.

BAKER-JARVIS, J. et al. Measuring the Permittivity and Permeability of Loss Materials: Solids, Liquids, Metals, Building Materials, and Negative-Index Materials. National Institute of Standards and Technology - NIST: Technical Note 1536. U.S. Department of Commerce, 2005.

BAKER-JARVIS, J. Transmission/Reflection and Short-Circuit Line Permittivity Measurements. National Institute of Standards and Technology - NIST: Technical Note 1341. U.S. Department of Commerce, 1990. 
BAKER-JARVIS, J.; JANEZIC, M. D.; GRASVENOR JR. J. H.; GEYER, R. G. Transmission/reflection and short-circuit line of methods for measuring permittivity and permeability. National Institute of Standards and Technology - NIST: Technical Note 1355-R. U.S. Department of Commerce, Colorado, 1993.

BAKER-JARVIS, J.; VANZURA, E.; KISSICK, W. Improved Technique for Determining Complex Permittivity with the Transmission/Reflection Method. IEEE Transactions on Microwave Theory and Techniques, v. 38, n.8, p. 1096-1103, Aug, 1990.

BALANIS, C. A. Antenna Theory-Analysis and Design. 2a ed. New York: John Wiley and Sons, Inc., 1997.

BANDARU, P. R. Electrical Properties and Applications of Carbon Nanotube Structures. Journal of Nanoscience and Nanotechnology, vol. 7, p. 1-29, 2007.

BAO, J. Z.; SWICORD, M. L.; DAVIS, C. Microwave dielectric characterization of binary mixtures of water, methanol and ethanol. Journal of Chemical Physics, v. 104, n. 12, p. 4441-4450, Mar. 1996.

BAUGHMAN, R. H.; ZAKHIDOV, A. A.; DE HEER, W. A. Carbon nanotubes - the route toward applications. Science, v.297, p.787-792, 2002.

BARTLEY, P. G, BEGLEY, S. B. Improved free-space S-parameter calibration. IMTC 2005 - Instrumentation and Measurement Technology Conference. Proceedings of the IEEE, v. 1, p. 372-375, Ottawa, Canada, May. 2005.

BARTLEY, P. G.; BEGLEY, S. B. "A New Technique for the Determination of the Complex Permittivity and Permeability of Materials". Proc. IEEE Instrument Meas. Technol. Conf., p. 54-57, 2010.

BEGLEY, S. Electromagnetic Properties of Materials: Characterization at Microwave Frequencies and Beyond. Application Development Engineer, Agilent Technologies, 2009. Disponível em: www.keysight.com. Acesso em: Julho de 2016. BERDEL, K.; RIVAS, J. G.; BOLIVAR, P. H.; MAAGT, P.; KURZ, H. Temperature dependence of the permittivity and loss tangent of high-permittivity materials at terahertz frequencies" IEEE Transactions on Microwave Theory and Techniques, v. 53, n. 4, p. 1266-1271, 2005. 
BERTOLINI, D.; CASSETARI, M., SALVETTI, G.; TOMBARI, E.; VERONESI, S. The Dielectric relaxation of water - alcohol and alcohol - alcohol solutions. Journal of Non-Crystalline Solids, v. 131 - 133, part 2, p. 1169 - 1173, Jun. 1991.

BERUBE, D.; GHANNOUCHI, F. M.; SAVARD, P. A comparative study of four open-ended coaxial probe models for permittivity measurements of lossy dielectric/biological materials at microwave frequencies. IEEE Transactions on Microwave Theory and Techniques, v. 44, n. 10, p. 1928-1934, Oct. 1996.

BOHORQUEZ, J. C.; FORERO Pedraza, H. A.; PINZON, I. C.; CASTIBLANCO, H. J. A.; PENA, N.; GUARNIZO, H. F. "Planar Substrate Integrated Waveguide CavityBacked Antenna", IEEE Antennas and Wireless Propagation Letters, vol. 8, p. 1139-1142, 2009.

BOUGHRIET, A. H.; Legrand, C.; Chapoton, A. Noniterative stable transmission/reflection method for low-loss material complex permittivity determination. IEEE Transactions on Microwave Theory and Techniques, v. 45, n. 1, p. 52-57, Jan. 1997.

BONARD, J. M.; KIND, H.; STOCKLI, T.; NILSSON, L. O. Field emission from carbon nanotubes: the first five years. Solid-State Electronics, v.45, p.893-914, 2001.

BOZZI, M.; XU, F.; DESLANDES, D.; WU, K. Modeling and Design Considerations for Substrate Integrated Waveguide Circuits and Components, 8th International Conference on Telecommunications in Modern Satellite, Cable and Broadcasting Services, Nis, 2007.

BOCCACCINI, A. R.; CHO, J.; ROETHER, J. A.; THOMAS, B. J. C.; MINAY, E. J.; SHAFFER, M. S. P. Electrophoretic deposition of carbon nanotubes. Carbon, vol. 44, p. 3149-3160, 2006.

BOZZI, M.; GEORGIADIS, A.; WU, Ke. Review of substrate-integrated waveguide circuits and antennas. Institution of Engineering and Technology Microwaves, Antennas \& Propagation, v. 5, n. 8, p. 909- 920, 2011.

BO-HIGAS, X.; TEJADA, J. Dielectric Characterization of Alcoholic Beverages and Solutions of Ethanol in Water under Microwave Radiation in the $1-20 \mathrm{GHz}$ Range, Food Research International, vol. 43, nº 6, 2010. 
BRADY, M. M.; SYMONS, S. A.; STUCHLY, S. S. Dielectric behavior of selected animal tissues in vitro at frequencies from 2 to $4 \mathrm{GHz}$. IEEE Transactions on Biomedical Engineering, v. BME-28, n. 3, p. 305-307, Mar. 1981.

BUCHNER, R.; BARTHEL, J.; STAUBER, J. The dielectric relaxation of water between $0^{\circ} \mathrm{C}$ and $35^{\circ} \mathrm{C}$. Chemical Physics Letters, v. 306, n. 1-2, p. 57-63, Jun. 1999. BUCKLEY, F.; MARYOTT, A. A. Tables of Dielectric Dispersion Data for Pure Liquids and Dilute Solutions. National Bureau of Standards Circular, v. 589. U.S. Department of Commerce, Nov. 1958.

BURDETTE, E. C.; CAIN, F. L; SEALS, J. In Vivo Probe Measurement Technique for Determining Dielectric Properties at VHF through Microwave Frequencies, IEEE Transactions on Microwave Theory and Techniques, MIT-28, nº 4, 1980.

CALEFFO, R. C. Estudo e aplicação de guias de ondas integrados ao substrato em frequências de micro-ondas. 2016. Dissertação (Mestrado em Microeletrônica) Escola Politécnica, Universidade de São Paulo, São Paulo, 2016. Acesso em: Novembro de 2016.

CASSIVI, Y.; PERREGRINI, L.; P. ARCIONI; BRESSAN, M.; WU, K.; CONCIAURO, G. Dispersion Characteristics of Substrate Integrated Rectangular Waveguide. IEEE Microwave and Wireless Component Letters, vol. 12, n. 9, p. 333-335, 2002.

CATENACCIO, A.; DARUICH, Y.; MAGALlANES, C. Temperature dependence of the permittivity of water. Chemical Physics Letters, vol. 367, p. 669-671, 2003.

CHEN, L.; ONG, C. K.; TAN, B. T. G. Amendment of cavity perturbation method for permittivity measurement of extremely low-loss dielectrics. IEEE Transactions on Instrumentation and Measurement, vol. 48, n. 6, p. 1031-1037, Dec 1999.

CHEN, L. F.; ONG, C. K. ONG; NEO C. P.; VARADAN, V. V., VARADAN, V. K. Microwave electronics: measurement and materials characterization. 552 p., 1 ed. Wiley. Apr. 2004.

CHEN, X. P.; WU, K. Substrate Integrated Waveguide Filter. IEEE Microwave Magazine, IEEE Microwave Magazine, vol. 15, n. 5, p. 108-116, July-Aug. 2014. 
CHOI, M. K.; ZHAO, M.; HAGNESS, S. C.; van der WEIDE, D. W. Compact MixerBased 1-12 GHz Reflectometer. IEEE Microwave and Wireless Components Letters, vol. 15, n. 11, 2005.

CLARKE, R. N.; GREGORY, A. P.; CANNELl, D.; PATRICK, M.; WYLIE, S.; YOUNGS, I.; HILL, G. A guide to the characterization of dielectric materials at RF and microwave frequencies. Institute of Measurement and Control. National Physical Laboratory Guide. 179 p., London, 2003.

COLE, K. S.; COLE, R. H. Dispersion and absorption in dielectrics: I. Alternating current characteristics. The Journal of Chemical Physics, v. 9, p. 341-351, Apr. 1941.

COLE, R. H.; DAVIDSON, D. W. High frequency dispersion in n-propanol. The Journal of Chemical Physics, v. 20, n. 9, p. 1389-1391, Sep. 1952.

COLlinS, P. G.; BRADLEY, K.; ISHIGAMI, M.; ZETTL, A. Extreme oxygen sensitivity of electronic properties of carbon nanotubes. Science, vol. 287, p. 18011804, 2000.

DE HEER, W. A.; CHATELAIN, A.; UGARTE, D. A carbon nanotube field-emission electron source. Science, vol. 270(5239), p. 1179-1180, 1995.

DEBYE, P. Polar Molecules. $1^{\text {a }}$ ed. The Chemical Catalog Company, New York, 1929.

DELGADO, R.; ARAUJO, A.; FERNANDES, V. Properties of Brazilian gasoline mixed with hydrated ethanol for flex-fuel technology. Fuel processing technology. v. 88, p. 365-368, 2007.

DERNERYD, A. G. A theoretical investigation of the rectangular microstrip patch antenna element. IEEE Trans. Antennas and Propagation, vol. AP-26, n. 4, p. 532535, July, 1978.

DESCHAMP, G. A. Microstrip Microwave Antennas. In: III USAF Symposium on Antennas, 1953.

DESCHAMPS, G., A. Impedance of an antenna in a conducting medium. IRE Transactions on Antennas and Propagation, p. 648-650, Sep. 1962. 
DESLANDES, D.; WU, K. Integrated Microstrip and Rectangular Waveguide in Planar Form. IEEE Microwave and Wireless Components Letters, v. 11, n. 2, p. 6870, Feb. 2001.

DIAMOND, D. Principles of Chemical and Biological Sensors, John Wiley, New York, 1998.

DIAS, A. J.; MACHADO, P. A. O.; MACHADO E. H.; DIANA R. A. D. Entendendo a Adulteração de Combustíveis. Grupo de Combate à Adulteração de Combustíveis do Ministério Público Federal no Estado de São Paulo, 3 ${ }^{a}$ ed., May. 2010. Disponível em: <www.prsp.mpf.gov.br>. Acesso em Março de 2015.

DIAS, J. A. et al. Entendendo a adulteração. Ministério Público Federal, $3^{\text {a }}$ ed., São Paulo, 2007.

DISSADO, L. A.; HILL, R. M. Anomalous low-frequency dispersion. Near direct current conductivity in disordered low-dimensional materials. Journal of Chemical Society. Faraday Transactions, v. 2, n. 80, p. 291-319, 1984.

DURNEY, C.H; MASSOUDI, H.; ISKANDER, M. F. Radiofrequency radiation dosimetry handbook. USASFSAM-TR-85-73. Air Base Force. Electrical Engineering Department. The University of Utah. Salt Lake City, UT 84112. 505 p. Oct. 1986.

ELLISON, W. J. Permittivity of pure water, at standard atmospheric pressure, over the frequency range $0-25 \mathrm{THz}$, and the temperature range $0-100^{\circ} \mathrm{C}$. Journal of Physical and Chemical Reference Data, v. 36, n. 1, p. 1-18, Feb. 2007.

ESEN, G.; FUHRER, M. S.; ISHIGAMI, M.; WILLIAMS, E. D. Transmission Line Impedance of Carbon Nanotube Thin Films for Chemical Sensing, Applied Physics Letters, vol. 90, p. 123510- 123513, 2007.

FALLAHPOUR, M.; BAUMGARTNER, M.; KOTHARI, A.; GHASR, M.; POMMERENKE, D.; ZOUGHI, R. Compact Ka-Band One-Port Vector Reflectometer Using a Wideband Electronically Controlled Phase Shifter. IEEE Transactions on Instrumentation and Measurement, vol. 61, n. 10, p. 2807-2816, Oct. 2012. 
FOSTER, K. R. Herman P. Schwan: A scientist and pioneer in biomedical engineering. Annual Review of Biomedical Engineering, v. 4, p. 1-27, Aug. 2002.

FOSTER, K. R.; SCHWAN, H. P. Dielectric properties of tissues. In: POLK, C.; POSTOW, E. Handbook of biological effects of electromagnetic fields. 2 ed. CRC Press. Chap. 1, p. 25-102, 1996

FRADEN, J. Handbook of Modern Sensors: Physics, Designs, and Applications. 2 ed. San Diego, California, 1996.

FRANCIOSO, L.; TAURINO, A.M.; FORLEO, A.; SICILIANO, P. TiO 2 nanowires array fabrication and gas sensing properties. Sensors and Actuators B. vol. 130, p. 70-76, 2008.

FRICKE, H. A mathematical treatment of the electrical conductivity of colloids and cell suspensions. The Journal of General Physiology, v. 6, p. 375-384, Mar. 1924.

FUOSS, R. M.; KIRKWOOD, J. G. Electrical properties of solids. VIII. Dipole moments in polyvinyl chloride-diphenyl systems. Journal of American Chemical Society, v. 63, n. 2, p. 38-394, Feb. 1941.

GABRIEL, C.; GABRIEL, S; CORTHOUT, E. The dielectric properties of biological tissues: I. Literature survey. Phys. Med. Biol., UK, v. 41, p. 2231-2249, Apr. 1996.

GARG, R. et al. Microstrip Antenna Design Handbook. Norwood: Artech House, Inc., 2001.

GEYER, R.G. Dielectric Characterization and Reference Materials. National Institute of Standards and Technology - NIST: Technical Note 1338. U.S. Department of Commerce, Apr. 1990.

GHANNOUCHI, F. M.; BOSISIO, R. G. Measurement of microwave permittivity using six-port reflector with an open-ended coaxial line. IEEE Transactions on Instrumentation and Measurement, v. 38, n.2, p. 505-508, 1989.

GREFFE, J. L.; GROSSE, C. Static Permittivity of Emulsions. Progress In Electromagnetics Research, vol. 06, p. 41-100, 1992. 
GREGORY A. P.; CLARKE R. N. A review of RF and microwave techniques for dielectric measurements on polar liquids. IEEE Transactions on Dielectrics and Electrical Insulation, v. 13, n. 4, p. 727-743, Aug. 2006.

HASAR, U. C.; WESTGATE, C. R. A broadband and stable method for unique complex permittivity determination of low-loss materials. IEEE Transactions on Microwave Theory and Techniques, v. 57, n. 2, p. 471-477. Feb. 2009.

HASHIM, U. et al., Comparison of drop casting vs. spray pyrolysis MWCNTs technique for surface modification based interdigitated electrode, 2nd International Conference on Biomedical Engineering (ICoBE), Penang, p. 1-3, 2015.

HAVRILIAK, S.; NEGAMI, S. A complex plane analysis of dispersions in some polymer systems. Journal of Polymer Science Part C: Polymer Symposia, Wiley Subscription Services, Inc., Wiley Company, v. 14, n. 1, p. 99-117, 1966.

HAYT JR., W. H.; BUCK, J. A. Eletromagnetismo, $8^{\text {a }}$ ed. São Paulo, McGraw-Hill, 2012.

HELME, B. G. M. Measurement of the microwave properties of materials. Industrial Uses of Microwaves, p. 3/1-3/7. IEE Colloquium, Jun. 1990.

HEWLETT-PACKARD. S-Parameter Design. Hewlett-Packard Application Note 154, 1990.

HINES, D. R.; MEZHENNY, S.; BREBAN, M.; WILLIAMS, E. D.; BALLAROTTO, V. W.; ESEN, G.; SOUTHARD, A.; FUHRER, M. S. Nanotransfer printing of organic and carbon nanotube thin-film transistors on plastic substrates. Applied Physics Letters, vol. 86, p. 163101-163104, 2005.

IIJIMA, S. Helical microtubules of graphitic carbon. Nature, v.354, 1991.

IIJIMA, S.; ICHIHASHI, T. Single-shell carbon nanotubes of 1-nm diamenter. Nature, v.363, p.603-605, 1993.

JACOB, M. V.; KRUPKA, J.; MAZIERSKA, J.; BIALKOWSKI, M. "Temperature dependence of complex permittivity of planar microwave materials" Asia-Pacific Microwave Conference, Yokohama, p. 1453-1456, 2006. 
JAMES, J. R.; HALL, P. S. Handbook of Microstrip Antennas. London, UK. Peter Peregrinus Ltd., 1989.

JANATA, J. Principles of Chemical Sensors, Plenum Press, New York, $2^{\text {a }}$ ed., 2009 JOURNET, C.; MASER, W. K.; BERNIER, P.; LOISEAU, A.; CHAPELL, M. L.; LEFRANT, S.; DENIARD, P.; LEE, R. FISCHER, J. E. Large-scale production of single-walled carbon nanotubes by the electric-arc technique. Nature, v.388, p. 756758, 1997.

LI, C.-L.; CHEN, K.-M. Determination of electromagnetic properties of materials using flanged open-ended coaxial probe-full-wave analysis. IEEE Transactions on Instrumentation and Measurement, vol. 44, n. 1, p. 19-27, Feb 1995.

LIN, M.; DUANE, M. H.; AFSAR, M. N. Cavity-Perturbation Measurement of Complex Permittivity and Permeability of Common Ferrimagnetics in MicrowaveFrequency Range. IEEE Transactions on Magnetics, vol. 42, n. 10, p. 2885-2887, Oct. 2006.

KEYES, D.B. Process of obtaining absolute alcohol. Pat. US 1676735 A, Jul. 1928. KIM, J. M. et al. Permittivity measurements up to $30 \mathrm{GHz}$ using micromachined probe. Journal of Micromechanics and Microengineering, v. 15, p. 543-550, 2005.

KINDT, J. T.; SCHMUTTENMAER, C. A. Far-Infrared dielectric properties of polar liquids probed by femtosecond terahertz pulse spectroscopy. Journal Physical Chemistry, p. 10373-10379, 1996.

KISTER, H. Z. Distillation design, McGraw-Hill. 710 p., New York, 1992.

KOBAYASHI, Y.; TANAKA, S. Resonant Modes of a Dielectric Rod Resonator Short-Circuited at Both Ends by Parallel Conducting Plates. IEEE Transactions on Microwave Theory and Techniques, vol. 28, n. 10, p. 1077-1085, Oct 1980.

KOMAROV, V.; WANG, S.; TANG, J. Permittivity and measurements. Encyclopedia of RF and Microwave Engineering; Chang, K., Ed.; John Wiley and Sons, Inc.: New York, NY, USA, p. 3693-3711, 2005. 
KONG, J.; FRANKLIN, N. R.; ZHOU, C.; CHAPLINE, M. G.; PENG, S.; CHO, K.; DAI, H. Nanotube molecular wires as chemical sensors. Science, vol. 87, p. 622-625, 2000.

KRASZEWSKI, A. W.; NELSON, S. O. Observation on resonant cavity perturbation by dielectric objects. IEEE Trans. Microwave Theory Tech., vol. 40, p. 151-155, 1992.

KRASZEWSKI, A. Microwave Aquametry: Electromagnetic Wave Interaction with Water-Containing Materials. IEEE. New York, May 1996.

KRATZENBERG, E.; AFSAR, M. N.; WANG, Y. Complex permittivity measurements of chicken blood. Microwave and Optical Technology Letters, v. 39, n. 1, p. 54-56, Oct. 2003.

KRUPKA, J. Precise measurements of the complex permittivity of dielectric materials at microwave frequencies. Materials Chemistry and Physics, v. 79, p. 195-198, 2003.

KRUPKA, J. Frequency domain complex permittivity measurements at microwave frequencies. Measurement and Science Technology, vol. 17, 2006.

KUMAR, G.; RAY, K. P. Broadband Microstrip Antennas. Artech House. USA, 2003.

KUMAR, M.; ANDO, Y. Chemical Vapor Deposition of Carbon Nanotubes: A Review on Growth Mechanism and Mass Production, Journal of Nanoscience and Nanotechnology, vol. 10(6), p. 3739-3758, 2010.

KUROKAWA, K. Power Waves and the Scattering Matrix, IEEE Transactions on Microwave Theory and Techniques, vol. MTT-13, nº 2, 1965.

LANDAU, L. D.; LIFSCHITZ, E. M.; PITAEVSKI, L.P. Electrodynamics of Continuous Media. Landau and Lifshitz Course of Theoretical Physics - Volume 8. Pergamon Press. 2 ed., 1984.

LOBATO-MORALES, H.; CHÁVES, A. C.; MURTHY, D. V. B.; CERVANTES, J. L. O. Complex permittivity measurements using cavity perturbation technique with substrate integrated waveguide cavities. Review of Scientific Instruments, 2010. 
LOU, J.; PARAVASTU, A. K., LAIBINIS, P. E.; HATTON T. A. Effect of Temperature on the Dielectric Relaxation in Solvent Mixtures at Microwave Frequencies, The Journal of Physical Chemistry A, v. 101(51), p. 9892-9899, 1997. MARLIERE, C.; PONCHARAL, P.; VACCARINI, L.; ZAHAB, A. Effect of gas adsorption on the electrical properties of Single-Walled carbon nanotubes mats. Proceedings of MRS Amorphous and nanostructured carbon: symposium, Massachusetts, U.S.A.; p.173-177, 1999.

MATHEW, K.T.; RAVEENDRANATH, U. Cavity Perturbation Techniques for Measuring Dielectric Parameters of Water and Other Allied Liquids. Sensors Update, v. 7, p. 185-210, Jan. 2000.

McCLENDON, J. F. Colloidal properties of the surface of the living cell: II. Electric conductivity and capacity of blood to alternating currents of long duration and varying in frequency from 266 to 2,000,000 cycles per second. Journal of Biological Chemistry, v. 69, p. 733-754, Jun. 1926.

MEGRICHE, A.; BELHADJ, A.; MGAIDI, A. Microwave dielectric properties of binary solvent water - alcohol, alcohol - alcohol mixtures at temperatures between $35^{\circ} \mathrm{C}$ and $+35^{\circ} \mathrm{C}$ and dielectric relaxation studies. Mediterranean Journal of Chemistry, p. $200-209,2012$.

MINTEER, S. Alcoholic fuels. CRC Press. Taylor and Francis Group. Boca Raton. 296 p., 2006.

MILANEZ, Artur Y; FILHO, Paulo de Sá Campelo F. e ROSA, Sergio Eduardo S. Perspectivas para o Etanol Brasileiro. Estudo Setorial - BNDES, 2008.

MORO, R.; AGNEESSENS, S.; ROGIER, H.; BOZZI, M. Wearable textile antenna in substrate integrated waveguide technology. Electronics letters, vol. 48, n. 16, August, 2012.

MORRIS, J. E.; INIEWSKI, K. Nanoelectronic Device Applications Handbook. CRC Press, 2013.

MUQAIBEL, A.; SAFAAI-JAZI, A. "New formulation for evaluating complex permittivity of low-loss materials". Antennas and Propagation Society International Symposium, 2003, v.4, p. 631-634, 2003. 
NATIONAL PHYSICAL LABORATORY Guide. A guide to the characterization of dielectric materials at RF and microwave frequencies. Institute of Measurement and Control, p. 145, 2003.

NAWAZ, M. I.; HUILING, Z. Substrate Integrated Waveguide (SIW) to Microstrip Transition at X-Band. Proceedings of the 2014 International Conference on Circuits, Systems and Control, 2014.

NELSON, S. O. Dielectric properties measurement techniques and applications. National Agricultural Library. Transactions of the ASAE, v. 42, n. 2, p. 523-529, Apr. 1999.

NICOLSON, A. M.; ROSS, G. F. Measurement of the intrinsic properties of materials by time domain techniques. IEEE Transactions on Instrument and Measurement, v. IM19, n. 4, p. 377-382, Nov. 1970.

OLMI, R.; MERIAKRI, V. V.; IGNESTI, A.; PRIORI, S.; RIMINESI, C. Monitoring Alcoholic Fermentation by Microwave Dielectric Spectroscopy. Journal of Microwave Power \& Electromagnetic Energy, v. 41, n. 3, p. 38-50, Nov. 2007.

POURNAROPOULOS, C. L.; MISRA, D. K. The co-axial aperture electromagnetic sensor and its application in material characterization. Measurement Science and Technology, v. 8, p.1191-1202, Jul. 1997.

PONGSUWAN, K.; PAMORNNAK, B.; CHONGCHEAWCHAMNAN, M.; TONGURAI, C. "Complex permittivity of fully ripe palm fruit and its application for microwave heating," IEEE Transactions on Dielectrics and Electrical Insulation, v. 21, n. 3, p. 1415-1423, 2014.

POZAR, D. M. Microwave Engineering. 3ed, New York: John Wiley, 2005.

PURANIK, S. M.; KUMBHARKHANE, A. C.; MEHROTRA, S. C. The static permittivity of binary mixtures using an improved Bruggeman model, Journal of Molecular Liquids, vol. 59, p.173-177, March, 1994.

RAMESH, M.; KB, Y. Design Formula for Inset Fed Microstrip Patch Antenna. Journal of Microwaves and Optoelectronics. v. 3, n. 3, p. 5-10, Dec. 2003. 
RAMO, S.; WHINNERY, J. R.; VAN DUZER, T. Field and Waves in Communication Electronics, $3^{\text {a }}$ ed, John Wiley \& Sons, Inc. New York, 1994.

RODHE \& SCHWARTZ. Measurement of Dielectric Material Properties. Application Note, 2008.

SADIKU, M. O. Elementos de eletromagnetismo, $5^{\text {a }}$ ed. Porto Alegre, Bookman, 2012.

SAEED, K.; POLLARD, D. P.; HUNTER, I. C. Substrate Integrated Waveguide Cavity Resonators for Complex Permittivity Characterization of Materials. IEEE Transactions on Microwave Theory and Techniques. v.56, 10, p. 2340-2347, Oct. 2008.

SAEED, K.; SHAFIQUE, M. F.; BYRNE, M. B.; HUNTER, I. C. Planar Microwave Sensors for Complex Permittivity Characterization of Materials and Their Applications. In: HAQ, Z. Applied Measurement Systems. In Tech, p. 319-350, Feb. 2012.

SEEWATTANAPON, S.; AKKARAEKTHALIN, P. A Broadband Complex Permittivity Probe Using Stepped Coaxial Line, Journal of Electromagnetic Analysis and Applications, vol. 3 n $8,2011$.

SEKO, M. H. Antenas planares de micro-ondas multibandas para terminais móveis de sistemas de comunicação sem fio. 2013. Dissertação (Mestrado em Microeletrônica) - Escola Politécnica, Universidade de São Paulo, São Paulo, 2013. Acesso em: Novembro de 2016.

SILLARS, R.W. The properties of dielectric containing semi-conducting particles of various shapes. IEEE - Wireless Section, v. 12, n. 35, p. 139-155, Jun. 1937.

SNOW, E. S.; PERKINS, F. K.; HOUSER, E.H. Chemical detection with a SingleWalled carbon nanotube capacitor. Science, vol. 307, p.1942-1945, 2005.

SNOW, E. S.; PERKINS, F. K. Capacitance and conductance of Single-Walled carbon nanotubes in the presence of chemical vapors. Nano Letters, vol. 5(12), p. 2414-2417, 2005. 
SNOW, E. S.; PERKINS, F. K.; ROBINSON, J. A. Chemical vapor detection using Single-Walled carbon nanotubes. Chem. Soc. Rev. vol. 35(9), p. 790-798, 2006.

SOTODEH, S. Effective Broadband Measurements of the Permittivity of Geological Materials. Graduate Program in Earth and Space Science, York University, Toronto, Ontario, 2014.

SPICHIGER-KELLER, U. E.; Chemical Sensors and Biosensors for Medical and Biological Applications, Wiley-VCH, Weinheim, 1998.

STUCHLY, M. A.; STUCHLY, S. S. Dielectric properties of biological substances tabulated. Journal of Microwave Power \& Electromagnetic Energy, v. 15, n.1, p. 19-26, 1980.

STUCHLY, M. A.; STUCHLY, S. S. Electrical properties of biological substances. In: GANDHI, O. P. Biological effects and medical applications of electromagnetic energy. Englewood Cliffs, New Jersey: Prentice Hall, Chap. 5, p. 75-112, 1990.

TAKAHASHI, T.; IIJIMA, Y.; MIURA, T. Measurement of temperature dependence of relative permittivity by the cavity perturbation method. Microwave Symposium Digest, IEEE MTT-S International, v. 3, p. 1683-1686, 1997.

TANG, Z. K.; ZHANG, L.; WANG, N.; ZHANG, X. X.; WEN, G. H.; WEN, G. H.; LI, G. D.; WANG, J. N.; CHAN, C. T.; SHENG, P. Superconductivity in 4 angstrom single-walled carbon nanotubes. Science. Jun 29, vol. 292(5526), p. 2462-2465, 2001. TANS, S. J.; DEVORET, M. H.; GROENEVELD, R. J. A.; DEKKER, C. Electronelectron correlations in carbon nanotubes. Nature, vol. 394-398, p. 761, 1998.

TANS, S. J.; VERSCHUEREN, R. M.; DEKKER, C. Room temperature transistor based on a single carbon nanotube. Nature, vol. 393, p. 49-53, 1998.

TINGA, W. R. Mixture Laws and Microwave-Material Interactions. Progress In Electromagnetics Research, Vol. 06, 1-40, 1992.

TOPP. C.; DAVIS, J. L.; ANNAN, A. P. Electromagnetic determination of soil water content: measurements in coaxial transmission lines. Water Resources Research, p. 574-582, 1980. 
TOSTENSON, E. T.; CHOU, T. W. Microwave processing: fundamentals and applications. Composites: Part A: Applied Science and Manufacturing, v. 30, n. 9, p. 1055-1071, Feb. 1999.

UNICA. Produção e uso do etanol combustível no Brasil. União da Agroindústria Canavieira de São Paulo. Disponível em: http://www.ambiente.sp.gov.br/. Acesso em: dezembro de 2015.

VEnKatesh, M. S. Cavity Perturbation Technique for Measurement of Dielectric Properties of Some Agri-food Materials. 1996. Tese (Mestrado) Department of Agricultural \& Biosystems Engineering McGill University, Montreal, Canadá, 1996. Acesso em: Janeiro, 2017.

von HIPPEL, A. R. Dielectric Materials and Applications. New York: The Technology Press of M.I.T. and John Wiley \& Sons, 1954.

von HIPPEL, A. R. Dielectrics and Waves. New York: John Wiley \& Sons, 1954.

VYAS, A. D.; RANA, V. A.; GADANI, D. H.; PRAJAPATI, A. N. Cavity perturbation technique for complex permittivity measurement of dielectric materials at X-band microwave frequency. International Conference on Recent Advances in Microwave Theory and Applications, Jaipur, p. 836-838, 2008.

WALDRON, R.A. Perturbation theory of resonant cavities, Proceedings of the IEEE, v. 107C, p. 272-274, Sept. 1960.

WAN, Q.; LI, Q. H.; CHEN, Y. J.; WANG, T. H.; HE, X. L.; LI, J. P.; LIN, C. L. Fabrication and ethanol sensing characteristics of $\mathrm{ZnO}$ nanowire gas sensors. Applied Physical Letters, vol. 84, p. 3654-3657, 2004.

WANG, F. X. The Effect of $\mathrm{HNO}_{3}$ on Functionalization of CNTs. Applied Mechanics and Materials, vol. 457-458, p. 280-283, 2014.

WANGSANATA, A. A planar vector network analyzer. Tese de Mestrado - Univ. of Wisconsin, Madison, 2002. Acesso em Abril de 2017.

WEI, Y.; SRIDHAR, S. Biological applications of a technique for broadband complex permittivity measurements. IEEE Microwave Theory and Techniques Society International. Microwave Symposium Digest, v. 3, p. 1271-1274, 1-5 Jun. 1992. 
WEIR, W. B. Automatic measurement of complex dielectric constant and permeability at microwave frequencies. Proceedings of the IEEE, v. 62, n. 1, p. 33-36, Jan. 1974. WENTWORTH, S. M. Fundamentos de eletromagnetismo com aplicações em engenharia. Rio de Janeiro: LTC, 2006.

WILLIAMS, G.; WATTS, D. C. Non-symmetrical dielectric relaxation behavior arising from a simple empirical decay function. Transactions of the Faraday Society, v. 66, p. $80-85,1970$.

WU, X. H; KISHK, A. A. Analysis and Design of Substrate Integrated Waveguide Using Efficient 2D Hybrid Method. San Rafael, Calif.: Morgan and Claypool Publishers, 2010.

XU, F.; WU, K. Guided-Wave and Leakage Characteristics of Substrate Integrated Waveguide. IEEE Transactions on Microwave Theory and Techniques, v. 53, n. 1, p. 66-73, Jan. 2005.

XU, Y.; GHANNOUCHI, F. M.; BOSISIO, R. G. Theoretical and experimental study of measurement of microwave permittivity using open ended elliptical coaxial probes. IEEE Transactions on Microwave Theory and Techniques, v. 40, n.1, p. 143-150, Jan. 1992.

YANG, L. J.; YANG, X. Q.; HUANG, K. M.; SHANG, H.; JIA, G. Z. Experimental and theoretic study of the dielectric properties of ethanol plus methanol mixtures, Journal of Solution Chemistry, v. 39, n. 4, p. 473-481, Apr. 2010.

YU, K. B. et al. Accurate microwave resonant method for complex permittivity measurements of liquids. IEEE Transactions on Microwave Theory and Techniques, v.48, n. 11, p. 2159-2164, Nov. 2000.

ZAJÍCEK, R.; OPPL L.; VRBA J. Broadband Measurement of Complex Permittivity Using Reflection Method and Coaxial Probes. Radio Engineering Journal, v. 17, n. 1, p. 14-19, Apr. 2008.

ZAJICEK, R.; VRBA, J. Broadband Complex Permittivity Determination for Biomedical Applications. Advanced Microwave Circuits and Systems. In: ZHURBENKO, V. InTech, p. 365-386, Apr. 2010. 
ZARBIN, A. J. Química de (nano)materiais, Quimica Nova, vol. 30, p. 1469-1479, 2007.

ZHANG, Y.; HE, X.L.; LI, J.P.; MIAO, Z.J.; HUANG, F. Fabrication and ethanolsensing properties of micro gas sensor based on electrospun $\mathrm{SnO}_{2}$ nanofibers. Sensors and Actuators B., vol. 132, p. 67-73, 2008. 


\section{APÊNDICE A - TEORIA DE REDES E PARÂMETROS DE ESPALHAMENTO}

Os parâmetros de espalhamento ou parâmetros S (Scattering Parameters) são empregados na análise e projeto de dispositivos de micro-ondas. Diferentemente do que ocorre com os parâmetros Z, H e Y, que utilizam terminação em curto-circuito e aberto, os parâmetros $\mathrm{S}$ assumem que os acessos são terminados por uma impedância de referência real, $Z_{0}$, igual a $50 \Omega$ em frequências de micro-ondas.

Os parâmetros S foram propostos formalmente por Kurokawa (1965), que descrevia as relações entre um conjunto das variáveis $a_{i}$ e $b_{i}$, ondas, que representam as tensões complexas normalizadas definidas em termos de uma tensão $V_{i}$, uma corrente $I_{i}$ e uma impedância arbitrária $Z_{i}$ na $i$-ésima porta do circuito analisado.

As equações A.1 e A.2 representam as ondas incidente e refletida no acesso $i$, respectivamente.

$$
\begin{aligned}
& a_{i}=\frac{V_{i}+Z_{i} I_{i}}{2 \sqrt{\left|\operatorname{Re}\left(Z_{i}\right)\right|}} \\
& b_{i}=\frac{V_{i}-Z_{i}^{*} I_{i}}{2 \sqrt{\left|\operatorname{Re}\left(Z_{i}\right)\right|}}
\end{aligned}
$$

no qual $V_{i}$ e $I_{i}$ são a tensão e a corrente na porta $i$, respectivamente, e $Z_{i}$ é a impedância de referência.

É usual realizar medidas em rede de duas portas, tal como representado na Figura A.1. Nesse caso, as variáveis independentes $a_{1}$ e $a_{2}$, ondas incidentes, são normalizadas em função das tensões nos acessos da rede e da impedância de referência $Z_{0}$, de acordo com as equações A.3 e A.4. 
Figura A.1 - Rede de duas portas caracterizada pelos parâmetros S.

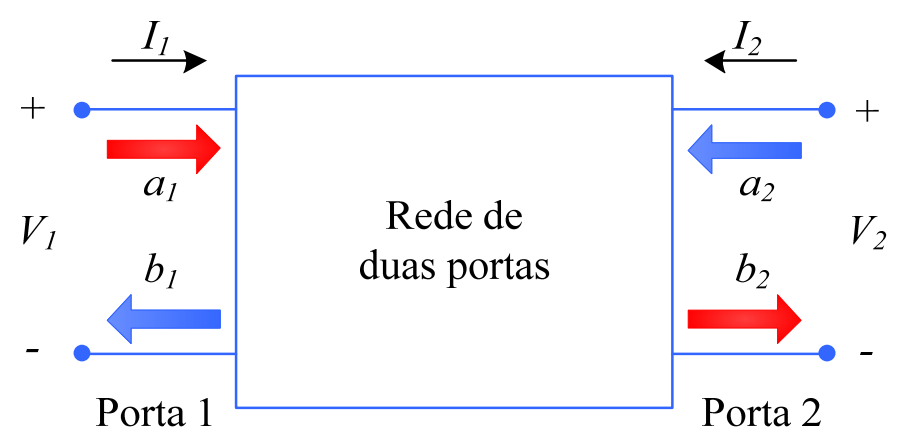

$$
\begin{aligned}
& a_{1}=\frac{V_{1}+Z_{0} I_{1}}{2 \sqrt{Z_{0}}}=\frac{\text { onda incidente em } 1}{\sqrt{Z_{0}}} \\
& a_{2}=\frac{V_{2}+Z_{0} I_{2}}{2 \sqrt{Z_{0}}}=\frac{\text { onda incidente em } 2}{\sqrt{Z_{0}}}
\end{aligned}
$$

Já as variáveis independentes $b_{1} \mathrm{e} b_{2}$, ondas refletidas, são normalizadas com relação às mesmas tensões incidentes $V_{1}$ e $V_{2}$ e a impedância de referência $Z_{0}$ de acordo com as equações A.5 e A.6.

$$
\begin{aligned}
& b_{1}=\frac{V_{1}-Z_{0} I_{1}}{2 \sqrt{Z_{0}}}=\frac{\text { onda refletida em } 1}{\sqrt{Z_{0}}} \\
& b_{2}=\frac{V_{2}-Z_{0} I_{2}}{2 \sqrt{Z_{0}}}=\frac{\text { onda refletida em } 2}{\sqrt{Z_{0}}}
\end{aligned}
$$

Para um quadripolo de duas portas é possível definir seus parâmetros $\mathrm{S}$ através das equações A.7 a A.10, considerando que os dois acessos do quadripolo estão terminados pela impedância de referência $Z_{0}$. 


$$
\begin{aligned}
& S_{11}=\left.\frac{b_{1}}{a_{1}}\right|_{a_{2}=0} \Rightarrow\{\text { coeficiente de reflexão de tensão no acesso } 1\} \\
& S_{21}=\left.\frac{b_{2}}{a_{1}}\right|_{a_{2}=0} \Rightarrow\{\text { coeficiente de transmissão direta }\} \\
& S_{12}=\left.\frac{b_{1}}{a_{2}}\right|_{a_{1}=0} \Rightarrow\{\text { coeficiente de transmissão reversa }\} \\
& S_{22}=\left.\frac{b_{2}}{a_{2}}\right|_{a_{1}=0} \Rightarrow\{\text { coeficiente de reflexão de tensão no acesso } 2\}
\end{aligned}
$$

A relação entre ondas incidentes e refletidas nos acessos do quadripolo pode ser expressa pelo conjunto de equações lineares A.11 ou na forma matricial por A.12 (KUROKAWA, 1965).

$$
\begin{aligned}
& b_{1}=S_{11} a_{1}+S_{12} a_{2} \\
& b_{2}=S_{21} a_{1}+S_{22} a_{2} \\
& {\left[\begin{array}{l}
b_{1} \\
b_{2}
\end{array}\right]=\left[\begin{array}{ll}
S_{11} & S_{12} \\
S_{21} & S_{22}
\end{array}\right]\left[\begin{array}{l}
a_{1} \\
a_{2}
\end{array}\right]}
\end{aligned}
$$

A representação dos parâmetros $\mathrm{S}$ é feita através dos seus subíndices $\mathrm{S}_{i j}$, no qual o subíndice $i$ representa a porta na qual o sinal foi medido e o subíndice $j$ descreve a porta por onde o sinal foi injetado na rede.

$\mathrm{Na}$ prática, os parâmetros $\mathrm{S}$ de redes formadas por componentes ou dispositivos passivos ou ativos são caracterizados por analisadores de rede, VNA (Vector Network Analyser). Esses instrumentos possuem um gerador e receptor de micro-ondas com dois ou quatro canais que processam e medem amplitude e fase das ondas incidentes e refletidas. Vale ressaltar que um analisador de redes escalar, usual em bancadas de teste de radiofrequência (RF), mede somente as amplitudes dos parâmetros $\mathrm{S}$ (AGILENT, 2000). 


\section{APÊNDICE B - TEORIA DA PERTURBAÇÃO RESSONANTE}

A teoria da perturbação ressonante é descrita por diferentes autores, principalmente, por Waldron (1960). Em todos os modelamentos, supõem-se campos eletromagnéticos em uma cavidade ressonante na sua condição inicial e, posteriormente, com um pequeno objeto perturbante. $\mathrm{Na}$ primeira condição, os campos são descritos por: $E_{0} e^{j \omega_{0} t}$ e $H_{0} e^{j \omega_{0} t}$, no qual $E_{0}$ e $H_{0}$ correspondem ao campo elétrico e magnético da cavidade de ressonância, respectivamente. Já com o elemento perturbante os campos são: $E_{s} e^{j \omega_{s} t}$ e $H_{s} e^{j \omega_{s} t}$, no qual $E_{s}$ e $H_{s}$ correspondem, respectivamente, ao campo elétrico e magnético da cavidade de ressonância com o elemento perturbante.

A partir das equações de onda aplicadas a $E_{0}$ e $H_{s}$ obtém-se as equações B.1 e B.2, sendo possível deduzir a teoria da perturbação ressonante.

$$
\begin{aligned}
& \nabla \times \vec{E}_{0}=-j \omega_{0} \vec{B}_{0} \\
& \nabla \times \vec{H}_{s}=j \omega_{s} \vec{D}_{s}
\end{aligned}
$$

Tomando a subtração entre o produto escalar de $H_{s}$ com a equação B.1 e o produto escalar de $E_{0}$ com B.2, obtêm-se B.3.

$$
H_{s} \cdot\left(\nabla \times \vec{E}_{0}\right)-E_{0}\left(\nabla \times \vec{H}_{s}\right)=-j \omega_{0} H_{s} \cdot B_{0}-j \omega_{s} E_{0} \cdot D_{s}
$$

Sabe-se que,

$$
\begin{aligned}
& \nabla \cdot\left(E_{0} \times H_{s}\right)=H_{s} \cdot\left(\nabla \times E_{0}\right)-E_{0} \cdot\left(\nabla \times H_{s}\right), \\
& \nabla \cdot\left(E_{0} \times H_{s}\right)=-j \omega_{0} H_{s} \cdot B_{0}-j \omega_{s} E_{0} \cdot D_{s}
\end{aligned}
$$


Integrando B.5 no volume da cavidade ressonante, $V_{c}$ e na superfície $S_{c}$ da cavidade, utilizando o teorema de Gauss, descrito em B.6, obtém-se B.7.

$$
\begin{gathered}
\iiint \nabla A \cdot d v=\iint A \cdot d S \\
\iint_{S_{c}}\left(E_{0} \times H_{s}\right) \cdot d S=\iiint_{V_{c}}\left(-j \omega_{0} H_{s} \cdot B_{0}-j \omega_{s} E_{0} \cdot D_{s}\right) \cdot d v
\end{gathered}
$$

De maneira análoga, pode-se reescrever B.7 conforme B.8:

$$
\iint_{S_{c}}\left(E_{s} \times H_{0}\right) \cdot d S=\iiint_{V_{c}}\left(-j \omega_{s} H_{0} \cdot B_{s}-j \omega_{0} E_{s} \cdot D_{0}\right) \cdot d v
$$

Em uma cavidade, cujas bordas podem ser consideradas um condutor perfeito, têm-se $E$ normal à borda e $H$ tangencial. Dessa maneira o produto vetorial de B.7 e B.8 é igual a zero. Igualando B.7 e B.8 e rearranjando as equações:

$$
j \omega_{0} \iiint_{V_{c}}\left(E_{s} \cdot D_{0}-H_{s} B_{0}\right) \cdot d v=j \omega_{s} \iiint_{V_{c}}\left(-E_{0} \cdot D_{s}-H_{0} \cdot B_{s}\right) \cdot d v
$$

Assumindo que $\omega_{s}=\omega_{0}+\Delta \omega$, pode-se rearranjar a equação B.9, obtendo-se B.10.

$$
\frac{\Delta \omega}{\omega_{0}}=\frac{\omega_{s}-\omega_{0}}{\omega_{0}}=\frac{\iiint_{V_{c}}\left[\left(E_{s} \cdot D_{0}-E_{0} \cdot D_{s}\right)-\left(H_{s} \cdot B_{0}-H_{0} \cdot B_{s}\right)\right] d V}{\iiint_{V_{c}}\left(E_{0} \cdot D_{s}-H_{0} \cdot B_{s}\right) d V}
$$


Vale ressaltar que o valor da integral do numerador somente terá valor não nulo no volume relativo ao objeto perturbante, $V_{s}$. Dessa maneira, pode-se restringir o volume de integração ao volume do material sob teste, conforme a equação B.11.

$$
\frac{\Delta \omega}{\omega_{0}}=\frac{\omega_{s}-\omega_{0}}{\omega_{0}}=\frac{\iiint_{V_{s}}\left[\left(E_{s} \cdot D_{0}-E_{0} \cdot D_{s}\right)-\left(H_{s} \cdot B_{0}-H_{0} \cdot B_{s}\right)\right] d V}{\iiint_{V_{c}}\left(E_{0} \cdot D_{s}-H_{0} \cdot B_{s}\right) d V}
$$

Para materiais dielétricos, a variação da permeabilidade magnética complexa pode ser assumida como zero. Nessas condições, a equação B.11 pode ser simplificada por B.12.

$$
\frac{\Delta \omega}{\omega_{0}}=\frac{\iiint_{V_{s}}\left(E_{s} \cdot D_{0}-E_{0} \cdot D_{s}\right) d V}{\iiint_{V_{c}}\left(E_{0} \cdot D_{s}\right) d V}
$$

Para materiais homogêneos e isotrópicos é possível descrever $D$ em termos de $E$.

$$
\frac{\Delta \omega}{\omega_{0}}=\frac{\iiint_{V_{s}}\left(\varepsilon_{0}-\varepsilon_{s}\right) E_{0} \cdot E_{s} d V}{\iiint_{V_{c}} \varepsilon_{0} E_{0} \cdot E_{s} d V}
$$

Considerando a amostra pequena em relação ao volume da cavidade, pode-se aproximar $E_{s}=E_{0}$. Além disso, $\varepsilon_{0}$ é a própria constante dielétrica do ar e $\varepsilon_{s}$ pode ser descrita como $\varepsilon_{s}=\varepsilon_{r} \varepsilon_{0}$. 


$$
\frac{\Delta \omega}{\omega_{0}}=\frac{-\left(\varepsilon_{r}-1\right) \iiint_{V_{s}} E_{0} \cdot E_{s} d V}{2 \iiint_{V_{c}}\left|E_{0}\right|^{2} d V}
$$

A perturbação irá afetar a frequência de ressonância e o índice de mérito da cavidade. Como o material sob teste possui perdas, a frequência angular associada a esse sistema dissipativo é representada por um valor complexo. Assumindo que $E_{S}=E_{0}$, é possível, novamente, simplificar a equação B.14 e separar as partes real e imaginária nas equações B.15 e B.16 (VYAS et al., 2008) (VENKATESH, 1996) (KRASZEWSKI; NELSON, 1992) (KOMAROV et al., 2005).

$$
\begin{aligned}
& \varepsilon_{r}^{\prime}=1+\frac{\left(f_{s}-f_{0}\right)}{f_{0}} \frac{V_{c}}{2 V_{s}} \approx 1+A^{\prime} \frac{f_{s}-f_{0}}{f_{0}} \\
& \varepsilon_{r}^{\prime \prime}=\frac{V_{c}}{4 V_{s}}\left(\frac{1}{Q_{s}}-\frac{1}{Q_{0}}\right) \approx A^{\prime \prime} \frac{1}{Q_{s}} \cdot \frac{\Delta Q}{Q_{0}}
\end{aligned}
$$

As equações B.15 e B.16 são fundamentais, pois relacionam os valores da frequência de ressonância e índice de mérito, em uma determinada frequência, com o valor da permissividade elétrica complexa. Ou seja, $\varepsilon r$ depende da variação da frequência de ressonância e $\varepsilon r$ " depende da variação do índice de mérito da cavidade ressonante. Como os volumes podem ser considerados constantes, a expressão final pode ser obtida através de uma aproximação linear de $1^{\mathrm{a}}$ ordem. As constantes $A^{\prime}$ e $A^{\prime \prime}$ estão relacionadas com a configuração da cavidade, com o modo de operação, formato do dispositivo e posição da amostra dentro da cavidade. Esses parâmetros podem ser obtidos, experimentalmente, utilizando amostras padronizadas ou através de regressão linear. Essas equações servem de base para o modelamento feito dos resultados obtidos a partir dos sensores propostos nos subitens 4.2.1, 4.2.2 e 4.3.1. Os trabalhos encontrados na literatura (SAEED et al., 2008) (ANSARI et al., 2015), lançam mão dessa teoria em circuitos planares e baseiam-se na relação linear entre a sensibilidade 
da frequência de ressonância e do índice de mérito e os parâmetros da permissividade elétrica complexa.

Vale ressaltar que, alguns trabalhos (LOBATO-MORALES et al., 2010) (LIN et al., 2006) (CHEN et al., 1999) consideram que na equação B.18 o denominador não é a frequência de ressonância da cavidade sem o material perturbante, $f_{0}$, e sim o valor da frequência de ressonância com o material perturbante, $f_{s}$, tal como apresentado na equação B.17.

$$
\varepsilon_{r}^{\prime}=1+\frac{\left(f_{s}-f_{0}\right)}{f_{s}} \frac{V_{c}}{2 V_{s}} \approx 1+A^{\prime} \frac{f_{s}-f_{0}}{f_{s}}
$$

Esse fato se deve as inúmeras aproximações que são feitas para chegar até as equações B.15 e B.16. Dentre essas aproximações é considerado que $\omega_{0} \approx \omega_{\mathrm{s}}$. De fato, isso é esperado, pois tanto o valor de $\omega_{0}$ como de $\omega_{\mathrm{s}}$ são muito maiores do que $\Delta \omega$.

Neste trabalho, verificou-se que o melhor ajuste para as curvas era obtido normalizando a variação da frequência de ressonância, $\Delta f$, pela frequência de ressonância da cavidade sem o material perturbante, $f_{0}$. 


\section{APÊNDICE C - ONDAS GUIADAS E MODOS DE PROPAGAÇÃO}

Este apêndice tem como objetivo apresentar os princípios teóricos sobre ondas guiadas e seus modos de propagação. Além disso, faz-se uma revisão da propagação de ondas de modo TE em guias de ondas retangulares, de maneira a compreender o funcionamento dos guias de ondas integrados ao substrato.

Guias de ondas são estruturas guiantes, longitudinais e de seção uniforme, capazes de propagar ondas eletromagnéticas de alta frequência, usualmente, na faixa de RF e micro-ondas ${ }^{50}$. Essas estruturas apresentam baixas perdas, e por isso são utilizadas em aplicações que demandam alta potência. Nesses casos, opta-se por estruturas metálicas como o guia de ondas retangular e o guia de ondas circular. Contudo, os guias possuem a desvantagem de serem grandes e de alto custo.

Supõe-se que a estrutura de um guia de ondas é realizada através de paredes metálicas condutoras paralelas ao eixo longitudinal, usualmente eixo $z$, como apresentado na Figura C.1. Em guias de ondas metálicos somente são possíveis dois tipos de modos fundamentais de propagação: os modos TE (tipo H) e os modos TM (tipo E). Para os modos TE, a única componente longitudinal é a do campo magnético. Todo o campo elétrico está no plano transversal à propagação. Para a propagação na direção $z$, então, $H_{z} \neq 0$ e $E_{z}=0$. Para os modos TM, ocorre o inverso, $H_{z}=0$ e $E_{z} \neq 0$. O modo TEM de propagação não ocorre em guias metálicos, pois nesse modo os campos elétricos e magnéticos são transversais à direção de propagação, uma vez que $H_{z}=0$ e $E_{z}=0$, condição em que não seriam obedecidas as leis de Maxwell.

Nesse sentido, para guias de ondas retangulares, as soluções dos modos TE e TM são obtidas pela equação de onda para os componentes de campo em $z$. Através das equações de Maxwell todos os componentes de campos transversais são obtidos diretamente (SADIKU, 2012).

\footnotetext{
${ }^{50}$ Para a região de espectro ópticas, podem ser utilizadas fibras ópticas, que são guias de ondas feitos de material totalmente dielétrico, tal como o vidro.
} 
Figura C.1 - Primeiros modos de propagação TE em um guia de onda retangular.

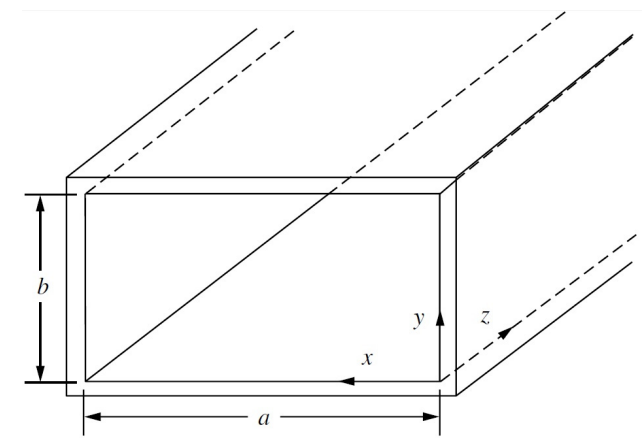

Fonte: Adaptado de (RAMO et al., 1994).

As equações C.1 e C.2 apresentam os fasores de campos elétrico e magnético em função da propagação em $z$, pela sua variação espacial no plano $x y$.

$$
\begin{aligned}
& \vec{E}(x, y, z)=\vec{E}(x, y, 0) e^{-j \beta z} \\
& \vec{H}(x, y, z)=\vec{H}(x, y, 0) e^{-j \beta z}
\end{aligned}
$$

Os componentes transversos dos fasores de campo a partir dos componentes $x$ e $y$ das equações rotacionais de Maxwell em um meio sem fontes são descritos pelas equações C.3 a C.4.

$$
\begin{gathered}
\nabla \times \vec{E}=-j \omega \mu \vec{H} \rightarrow\left\{\begin{array}{l}
\partial E_{z} / \partial y+j \beta E_{y}=-j \omega \mu H_{x}(\text { componente em } x) \\
j \beta E_{x}+\partial E_{z} / \partial x=j \omega \mu H_{y}(\text { componente em } y)
\end{array}\right. \\
\vec{\nabla} \times \vec{H}=j \omega \varepsilon \vec{E} \rightarrow\left\{\begin{array}{l}
\partial H_{z} / \partial y+j \beta H_{y}=j \omega \varepsilon E_{x}(\text { componente em } x) \\
j \beta H_{x}+\partial H_{z} / \partial x=-j \omega \varepsilon E_{y}(\text { componente em } y)
\end{array}\right.
\end{gathered}
$$

As equações podem ser combinadas, expressando os componentes individuais de campo transverso pelas derivadas dos componentes em $z$ de $\vec{E}$ e $\vec{H}$. Dessa forma, obtêm-se as equações C.5 a C.6 para os componentes dos campos magnéticos. 


$$
\begin{aligned}
& H_{x}=\frac{-j}{k_{c}^{2}}\left[\beta \frac{\partial H_{z}}{\partial x}-\omega \varepsilon \frac{\partial E_{z}}{\partial y}\right] \\
& H_{y}=\frac{-j}{k_{c}^{2}}\left[\beta \frac{\partial H_{z}}{\partial y}+\omega \varepsilon \frac{\partial E_{z}}{\partial x}\right]
\end{aligned}
$$

Os componentes transversos de campo elétrico são descritos nas equações C.7 e C.8.

$$
\begin{aligned}
& E_{x}=\frac{-j}{k_{c}^{2}}\left[\beta \frac{\partial E_{z}}{\partial x}+\omega \mu \frac{\partial H_{z}}{\partial y}\right] \\
& E_{y}=\frac{-j}{k_{c}^{2}}\left[\beta \frac{\partial E_{z}}{\partial y}-\omega \mu \frac{\partial H_{z}}{\partial x}\right]
\end{aligned}
$$

no qual $k_{c}^{2}=k^{2}-\beta^{2}$ e $k=\omega \sqrt{\mu \varepsilon}$. Para se obter os campos dos modos TE e TM é necessário resolver a equação de onda para os componentes em $z$. Para o modo TE, as ondas transversais elétricas são caracterizadas por $E_{z}=0$ e $H_{z} \neq 0$. Dessa forma as equações C.5 a C.8 são reescritas como:

$$
\begin{gathered}
H_{x}=\frac{-j \beta}{k_{c}^{2}} \frac{\partial H_{z}}{\partial x} \\
H_{y}=\frac{-j \beta}{k_{c}^{2}} \frac{\partial H_{z}}{\partial y} \\
E_{x}=\frac{-j \omega \mu}{k_{c}^{2}} \frac{\partial H_{z}}{\partial y} \\
E_{y}=\frac{j \omega \mu}{k_{c}^{2}} \frac{\partial H_{z}}{\partial x}
\end{gathered}
$$

Como $k_{c}$ é diferente de zero, a constante de fase é dada por $\beta=\sqrt{k^{2}-k_{c}^{2}}$. 
Em guias de ondas retangulares com estruturas metálicas preenchidas com dielétrico, os modos de propagação TE são descritos pela equação C.13.

$$
\left(\frac{\partial^{2}}{\partial x^{2}}+\frac{\partial^{2}}{\partial y^{2}}+k_{c}^{2}\right) h_{z}(x, y)=0
$$

no qual $H_{z}(x, y, z)=h_{z}(x, y) e^{-j \beta z}$. Resolvendo essa equação pelo método da separação de variáveis (BUCK; HAYT, 2012), obtém-se C.14.

$$
h_{z}(x, y)=\left(A \cos k_{x} x+B \operatorname{sen} k_{x} x\right)\left(\mathrm{C} \cos k_{y} y+D \operatorname{sen} k_{y} y\right)
$$

As constantes $A, B, C$ e $D$ são determinadas aplicando-se as condições de contorno para as componentes tangenciais de campo elétrico, no qual: $e_{x}(x, y)=0$ em $y=0, b$; $e_{y}(x, y)=0$ em $x=0, a$. A solução para o campo longitudinal, $H_{z}$, é obtida através da equação C.15, a qual $a$ e $b$ são, respectivamente, a maior e a menor dimensões da seção transversal retangular, tal como descrito na Figura C.1.

$$
H_{z}(x, y, z)=A_{m n} \cos \left(\frac{m \pi x}{a}\right) \cos \left(\frac{n \pi y}{b}\right) e^{-j \beta z}
$$

sendo $A_{m n}$ a amplitude arbitrária, $m$ e $n=0,1,2, \ldots$ e $m+n \neq 0$. Dessa forma, os modos de TE que dependem dos coeficientes $m$ e $n$. Os componentes de campo para os modos TEmn são dados pelas equações C.16 a C.19.

$$
E_{x}=\frac{j \omega \mu}{k_{c}^{2}} \frac{n \pi}{b} A_{m n} \cos \left(\frac{m \pi x}{a}\right) \operatorname{sen}\left(\frac{n \pi y}{b}\right) e^{-j \beta z}
$$




$$
\begin{aligned}
& E_{y}=\frac{-j \omega \mu}{k_{c}^{2}} \frac{m \pi}{a} A_{m n} \operatorname{sen}\left(\frac{m \pi x}{a}\right) \cos \left(\frac{n \pi y}{b}\right) e^{-j \beta z} \\
& H_{x}=\frac{j \beta}{k_{c}^{2}} \frac{m \pi}{a} A_{m n} \operatorname{sen}\left(\frac{m \pi x}{a}\right) \cos \left(\frac{n \pi y}{b}\right) e^{-j \beta z} \\
& H_{y}=\frac{j \beta}{k_{c}^{2}} \frac{n \pi}{b} A_{m n} \cos \left(\frac{m \pi x}{a}\right) \operatorname{sen}\left(\frac{n \pi y}{b}\right) e^{-j \beta z}
\end{aligned}
$$

O número de onda de corte pode ser reescrito por:

$$
\begin{aligned}
k_{c}^{2} & =\sqrt{k_{x}^{2}+k_{y}^{2}} \\
& =\sqrt{\left(\frac{m \pi}{a}\right)^{2}+\left(\frac{n \pi}{b}\right)^{2}}
\end{aligned}
$$

A Figura C.2 apresenta a distribuição dos modos $\mathrm{TE}_{10}$ e $\mathrm{TE}_{20}$ em um guia de onda retangular.

Figura C.2 - Distribuição de campo elétrico dos modos TE 10 e TE20 em um guia de onda retangular.

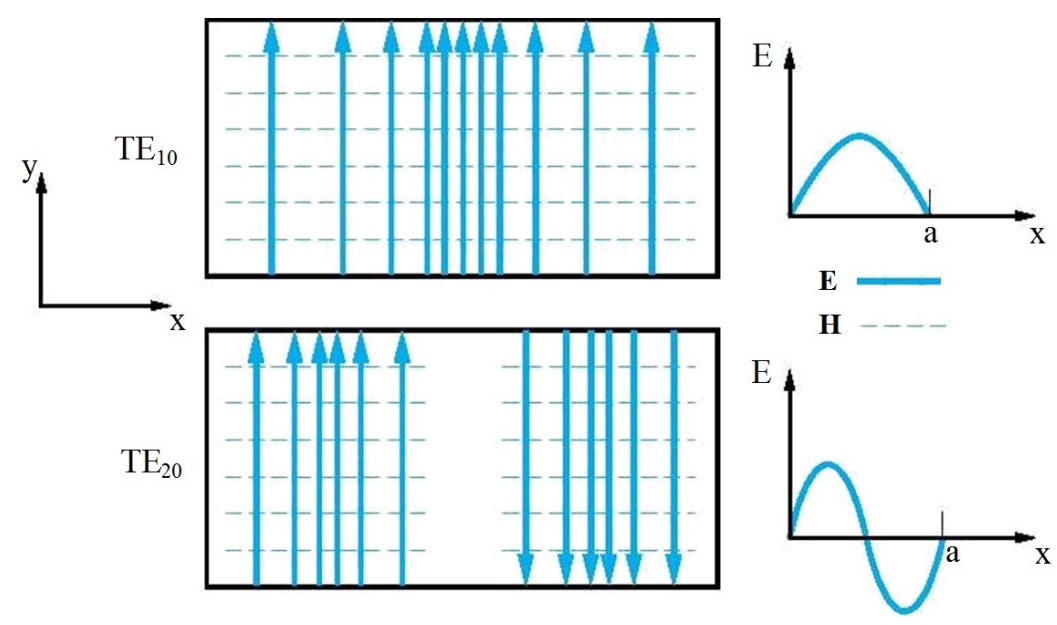

Fonte: Adaptado de (RAMO et al., 1994). 
A constante de fase, $\beta$, dada pela equação C.21, deve ser real para que a onda eletromagnética se propague no guia. Isso só será possível se $k>k_{c}$, portanto cada modo de propagação possuirá frequência de corte $f_{c_{m n}}$ dado pela equação C.22.

Essa solução indica que ondas eletromagnéticas com frequências menores do que a de corte não se propagam no guia de ondas. Já para frequências menores do que a de corte, a intensidade dos campos decai exponencialmente ao longo da direção de propagação, havendo desvanecimento do sinal.

$$
\begin{aligned}
& \beta=\sqrt{k^{2}-k_{c}^{2}}=\sqrt{k^{2}-\left(\frac{m \pi}{a}\right)^{2}-\left(\frac{n \pi}{b}\right)^{2}} \\
& f_{c_{m n}}=\frac{k_{c}}{2 \pi \sqrt{\mu \varepsilon}}=\frac{1}{2 \pi \sqrt{\mu \varepsilon}} \sqrt{\left(\frac{m \pi}{a}\right)^{2}+\left(\frac{n \pi}{b}\right)^{2}}
\end{aligned}
$$

A menor frequência de corte de um tipo de modo é conhecida como modo dominante ou fundamental. Para os modos TE em guias de ondas retangulares, o modo fundamental é o TE10, cuja frequência de corte pode ser obtida através da equação C.23:

$$
f_{c_{10}}=\frac{1}{2 a \sqrt{\mu \varepsilon}}
$$

$\mathrm{Na}$ prática, a frequência fundamental serve como requisito para o projeto das dimensões do guia. A faixa de frequência de operação de guias de ondas retangulares $\operatorname{com} a \approx 2 \times b$, na qual se propaga um único modo, é dada pela equação C.24. O limite inferior da faixa tem como objetivo garantir a operação no modo TE10 com pequenas perdas, e o limite superior evita a presença de modos de propagação de ordem superior. Também é usual indicar o limite superior da frequência como $0,95 f_{{ }_{T E_{22}}}$.

$$
1,25 f_{c_{T E_{10}}} \leq f \leq 1,9 f_{c_{T E_{10}}}
$$




\section{APÊNDICE D - TÉCNICA DA TRANSMISSÃO/REFLEXÃO}

A técnica da transmissão/reflexão foi descrita no item 2.6.1. A Figura D.1 descreve a topologia típica da caracterização eletromagnética de materiais utilizando essa técnica. A técnica apresentada neste apêndice foi aplicada no item 4.3.2 para caracterizar os materiais sob teste empregando o guia de ondas SIW.

Para a extração da permissividade elétrica complexa e da permeabilidade magnética complexão são utilizados algoritmos de extração das características eletromagnéticas dos materiais a partir dos parâmetros S. Os principais métodos de conversão são: método Nicolson-Ross-Weir (NRW) (NICOLSON et al., 1970) (WEIR, 1974), método dos parâmetros efetivos (CHEN et al., 2004), solução não linear dos mínimos quadrados efetivos (CHEN et al. 2004), método do espaço livre (BAKER-JARVIS et al., 2005), método de Hakki e Coleman efetivos (CHEN et al., 2004), método interativo elaborado pela NIST (NIST interative) (BAKER-JARVIS et al., 2005) (BAKER-JARVIS, 1990), entre outros.

Figura D.1 - Técnica da transmissão/reflexão: medida dos coeficientes de reflexão e transmissão nos planos do material em teste.

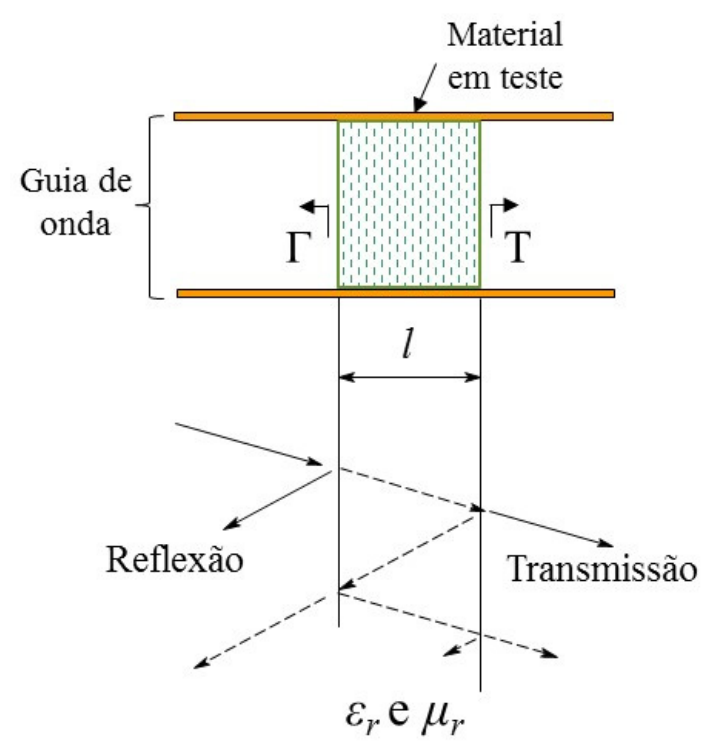

Fonte: Adaptado de (BEGLEY, 2009). 
O método Nicolson-Ross-Weir (NRW) baseia-se nos fenômenos da reflexão e transmissão em um determinado material cujas propriedades dielétricas se pretende determinar. Estes fenômenos ocorrem devido à diferença entre a permissividade elétrica complexa e/ou permeabilidade magnética complexa no ambiente interior e exterior do material. A partir do conhecimento dos efeitos desses fenômenos, é possível determinar os parâmetros que originaram estes efeitos (reflexão e transmissão) ao longo do material.

As equações propostas por Nicolson-Ross-Weir (NRW) consideram as múltiplas reflexões da onda incidente que ocorrem nas interfaces ar-amostra. Esse algoritmo possibilita a determinação direta tanto da permissividade como da permeabilidade a partir da medida dos parâmetros de espalhamento.

Para que sejam determinados os coeficientes de transmissão e reflexão, é necessário medir os valores dos parâmetros de espalhamento $\mathrm{S}_{11}, \mathrm{~S}_{21}, \mathrm{~S}_{12}, \mathrm{~S}_{22}$, ou devido à simetria, somente, $\mathrm{S}_{11}$ e $\mathrm{S}_{21}$. No caso em que são utilizados materiais com baixas perdas, o método NRW não converge nas frequências que correspondem a múltiplos inteiros de meio comprimento de onda na amostra. Nesses casos, o módulo de $\mathrm{S}_{11}$ tende a zero, levando a um aumento na incerteza da fase de $\mathrm{S}_{11}$, medida no VNA. Uma maneira de contornar esse problema é reduzir o tamanho da amostra, desta forma, o método fica limitado a materiais que não apresentem baixas perdas e com amostras de espessura máxima de $\lambda_{g} / 4$.

De um modo geral, o método pode ser expresso pelo seguinte conjunto de equações, deduzidas a partir das seguintes expressões apresentadas em D.1.

$$
S_{11}=\frac{\Gamma\left(1-\mathrm{T}^{2}\right)}{\left(1-\Gamma^{2} \mathrm{~T}^{2}\right)} e S_{21}=\frac{\mathrm{T}\left(1-\Gamma^{2}\right)}{\left(1-\Gamma^{2} \mathrm{~T}^{2}\right)},
$$

no qual $\Gamma$ corresponde ao coeficiente de reflexão e $T$ ao coeficiente de transmissão na interface do material em teste, tal como descrito na Figura D.1. O primeiro coeficiente pode ser deduzido através da equação D.2. 


$$
\Gamma=K \pm \sqrt{K^{2}-1}
$$

no qual $K$ é dado pela equação D.3.

$$
K=\frac{S_{11}^{2}-S_{21}^{2}+1}{2 S_{11}}
$$

O coeficiente de transmissão $T$ é determinado pela equação D.4.

$$
\mathrm{T}=\frac{\left(S_{11}+S_{21}\right)-\Gamma}{1-\left(S_{11}+S_{21}\right) \Gamma}
$$

Com o valor do coeficiente de reflexão obtido através da equação D.1, os parâmetros permeabilidade magnética complexa e permissividade elétrica complexa podem ser determinados pelas equações D.5 e D.6, respectivamente.

$$
\begin{aligned}
& \mu_{r}^{*}=\frac{1}{\Lambda}\left(\frac{1+\Gamma}{1-\Gamma}\right) \lambda_{g} \\
& \varepsilon_{r}^{*}=\frac{\lambda_{g}}{\Lambda}\left(\frac{1-\Gamma}{1+\Gamma}\right)
\end{aligned}
$$

sendo,

$$
\frac{1}{\Lambda}=-\left[\frac{1}{2 \pi l} \ln \left(\frac{1}{T}\right)\right]
$$

no qual $l$ é a espessura do material em teste, tal como apresentado na Figura D.1. 
O comprimento de onda guiado $\lambda_{g}$ de um guia de ondas é dado pelas equações D.8 e D.9, sendo que a equação D.9 é consequência da equação D.8.

$$
\begin{aligned}
& \lambda_{g}=\frac{2 \pi}{\beta} \\
& \lambda_{g}=\frac{1}{\sqrt{\frac{1}{\lambda_{0}^{2}}-\frac{1}{\lambda_{c}^{2}}}}
\end{aligned}
$$

no qual $\beta$ é a constante de fase, $\lambda_{o}$ e $\lambda_{c}$ correspondem ao comprimento de onda no espaço livre e ao comprimento de onda correspondente à frequência de corte, respectivamente.

Uma possível modificação do método NRW, é atribuir o valor unitário à permeabilidade magnética, pois para materiais não ferromagnéticos, tem-se valor $\mu_{r}$ igual a 1. Isso permite o uso de amostras de qualquer tamanho e espessura, não sendo necessária uma estimativa prévia do valor da permissividade como ocorre no método NIST interativo (ROHDE \& SCHWARZ, 2008).

Outro algoritmo também utilizado consiste no método interativo NIST, que utiliza o algoritmo de Newton-Raphson para calcular o valor de permissividade elétrica. Esse método garante o cálculo dos valores para qualquer tamanho e espessura de amostra, contudo necessita estimativa prévia do valor da permissividade. Além disso, esse método minimiza a instabilidade presente no método NRW. 


\section{APÊNDICE E - TÉCNICA DA LINHA COAXIAL EM ABERTO}

Os resultados experimentais obtidos com os sensores desenvolvidos foram comparados com os apresentados por Bao et al. (1996), utilizados como referência. Esses autores empregaram a técnica da linha coaxial em aberto, descrita neste apêndice. Adicionalmente, são fornecidos os resultados experimentais obtidos neste trabalho para confirmação dos valores que foram usados como referência, empregando-se uma variação do método aplicado por Bao et al. (1996), em outras palavras, uma linha coaxial em aberto realizada por meio de uma transição coaxialmicrofita.

O processo básico para a extração dos valores de permissividade complexa pode ser descrito através da Figura E.1. Nele fica evidenciado que os parâmetros são obtidos através da medida do coeficiente de reflexão $\Gamma^{*}$ no plano de abertura $\mathrm{AA}^{\prime}$ da linha coaxial. A partir dessa medida, a literatura apresenta diferentes modelos que descrevem a distribuição do campo elétrico na região de contato.

Tipicamente são quatros as formas de extração dos valores de permissividade complexas (BERUBE et al., 1996), seja pelo modelo capacitivo, pelo modelo de radiação (radiation model) (BRADY et al., 1981), pelo modelo de linha virtual (virtual line model) (GHANNOUCHI; BOSISIO, 1989), ou pelo modelo de função racional (rational function model) (ANDERSON et al., 1994). O presente trabalho opta por apresentar o modelo capacitivo e o modelo de radiação.

Figura E.1 - Circuito equivalente da linha de transmissão em aberto para o modelo capacitivo.

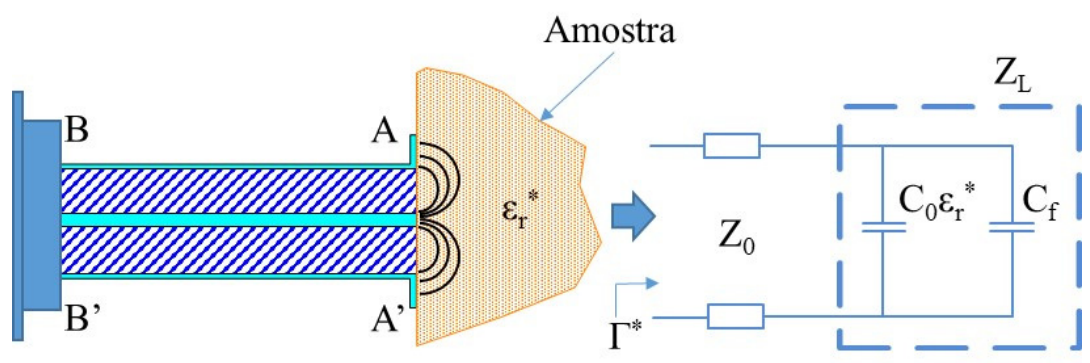

Fonte: Adaptado de (BEGLEY, 2009). 
O modelo capacitivo é descrito nas equações E.1 a E.8. O coeficiente de reflexão complexo pode ser expresso em função da impedância característica da linha coaxial, $Z_{0}$, e da impedância da carga $Z_{L}$, como descrito na equação E.1.

$$
\Gamma^{*}=\frac{Z_{L}-Z_{O}}{Z_{L}+Z_{O}}
$$

De acordo com o modelo capacitivo, a impedância que termina a linha de transmissão pode ser dada por duas capacitâncias em paralelo, $C_{0}$ e $C_{f}$, que representam as capacitâncias associadas à linha coaxial e ao material sob teste, respectivamente. A capacitância $C_{0}$ é alterada em função da permissividade elétrica do material sob teste. A impedância equivalente, $Z_{L}$, é dada pela equação E.2.

$$
Z_{L}=\frac{1}{j \omega\left(C_{0} \varepsilon_{r}^{*}+C_{f}\right)},
$$

Dessa forma, substituindo a equação E.2 em E.1, obtém a relação entre o coeficiente de reflexão e o valor da permissividade elétrica relativa do material. Tal como descrito na equação E.3 e, posteriormente, rearranjada na equação E.4.

$$
\begin{gathered}
\Gamma^{*}=|\Gamma| e^{j \varphi}=|\Gamma| \cos \varphi+j|\Gamma| \operatorname{sen} \varphi=\frac{1-j \omega Z_{O}\left(C_{O} \varepsilon_{r}^{*}+C_{f}\right)}{1+j \omega Z_{O}\left(C_{O} \varepsilon_{r}^{*}+C_{f}\right)} \\
\varepsilon_{r}^{*}=\varepsilon_{r}^{\prime}-j \varepsilon_{r}^{\prime \prime}=\frac{1-\Gamma^{*}}{j \omega Z_{O} C_{O}\left(1+\Gamma^{*}\right)}-\frac{C_{f}}{C_{O}}
\end{gathered}
$$

Substituindo os valores de $\varepsilon^{*}$ e $\Gamma^{*}$, bem como separando as partes reais e imaginárias, as expressões de $\varepsilon^{\prime}$ e $\varepsilon^{\prime \prime}$ podem ser descritas nas equações E.5 e E.6. 


$$
\begin{aligned}
& \varepsilon_{r}^{\prime}=\frac{-2|\Gamma| \operatorname{sen} \varphi}{\omega Z_{O} C_{O}\left(1+2|\Gamma| \cos \varphi+|\Gamma|^{2}\right)}-\frac{C_{f}}{C_{O}} \\
& \varepsilon_{r}^{\prime \prime}=\frac{1-|\Gamma|^{2}}{\omega Z_{O} C_{O}\left(1+2|\Gamma| \cos \varphi+|\Gamma|^{2}\right)}
\end{aligned}
$$

Para determinar as capacitâncias $C_{0}$ e $C_{f}$, pode-se medir um material com valor de permissividade elétrica relativa conhecida, a exemplo da água destilada. Dessa forma, obtêm-se os valores de coeficiente de reflexão que permitem, de forma interativa, aproximar os valores das capacitâncias em questão, como descrito nas equações E.7 e E.8.

$$
\begin{gathered}
C_{O}=\frac{1-\left|\Gamma_{r e f}^{*}\right|^{2}}{\omega Z_{O} \varepsilon_{r e f}^{\prime \prime}\left(1+2\left|\Gamma_{r e f}^{*}\right| \cos \left(\varphi_{r e f}\right)+\left|\Gamma_{r e f}^{*}\right|^{2}\right)} \\
C_{f}=\frac{-2\left|\Gamma_{r e f}^{*}\right| \operatorname{sen}\left(\varphi_{r e f}\right)}{\omega Z_{O}\left(1+2\left|\Gamma_{r e f}^{*}\right| \cos \varphi+\left|\Gamma_{r e f}^{*}\right|^{2}\right)}-\varepsilon_{r e f}^{\prime} C_{O}
\end{gathered}
$$

Vale ressaltar que o coeficiente de reflexão deve ser medido no plano de abertura da linha em aberto, $A-A$ '. Contudo, calibra-se o analisador de redes vetorial no plano $B$ $B$ '. Essa diferença de fases deve ser compensada diretamente no equipamento ou através da equação E.9.

$$
\Gamma^{*}=\Gamma_{A-A^{\prime}}^{*}=\Gamma_{B-B}^{*}, e^{j 2 \theta},
$$

sendo que a determinação do fator de fase $2 \theta$ pode ser estimada a partir das dimensões da linha a partir da equação E.10. 
no qual $L$ é o comprimento da linha e $k$ é dado pela equação E.11.

$$
k=\frac{2 \pi}{\lambda}
$$

Dessa maneira, basta realizar a correção considerando que a defasagem consiste em $2 \theta=\varphi_{B-B^{\prime}}-\varphi_{A-A^{\prime}}$, no qual $\varphi_{B-B^{\prime}}=\angle \Gamma_{B-B^{\prime}}^{*}$ e $\varphi_{A-A^{\prime}}=\angle \Gamma_{A-A^{\prime}}^{*}$. O Apêndice K apresenta em detalhe o desenvolvimento do algoritmo de caracterização.

Para o modelo de radiação, a linha coaxial terminada em aberto é modelada de acordo com a Figura E.2. A capacitância $C_{1}$ corresponde à estrutura da linha coaxial e é independente do material sob teste. A amostra é modelada através da capacitância $\varepsilon_{r} C_{2}$ e pela condutância $G$, conectada em paralelo.

Figura E.2 - Circuito equivalente da linha de transmissão em aberto para o modelo de radiação.

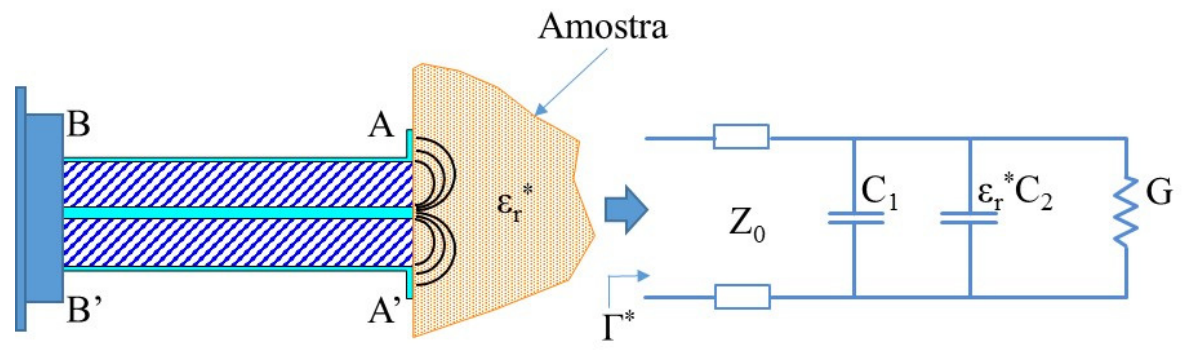

Fonte: Adaptado de (BEGLEY, 2009). 
A admitância normalizada é dada pela equação E.12, na qual $Z_{0}$ é a impedância característica da linha coaxial $\left(Y_{0}=1 / Z_{0}\right)$. A admitância do material sob teste é descrita pela equação E.13.

$$
\begin{gathered}
\frac{Y}{Y_{0}}=j \omega C_{1} Z_{0}+j \omega \varepsilon_{r} C_{2} Z_{0}+Z_{0} G\left(\omega, \varepsilon_{r}\right) \\
Y=Y_{0} \frac{1-\Gamma(\omega, \varepsilon)}{1+\Gamma(\omega, \varepsilon)}
\end{gathered}
$$

A condutância de radiação, $G\left(\omega, \varepsilon_{r}\right)$, modelada como a condutância de uma antena infinitesimal, é descrita pela equação E.14 (BURDETTE et al., 1980) (SEEWATTANAPON, AKKARAEKTHALIN; 2011) (BO-HIGAS, TEJADA; 2010).

$$
G\left(\omega, \varepsilon_{r}\right)=\varepsilon_{r}^{5 / 2} G\left(\omega, \varepsilon_{0}\right)
$$

Substituindo E.14 em E.13, pode-se obter a equação E.15 que correlaciona a permissividade complexa com a admitância normalizada.

$$
\frac{Y}{Y_{0}}=j \omega C_{1} Z_{0}+j \omega \varepsilon_{r} C_{2} Z_{0}+\varepsilon_{r}^{5 / 2} G\left(\omega, \varepsilon_{0}\right) Z_{0}
$$

A equação E.16, simplificação da E.15, modela os parâmetros $K_{1}, K_{2}$ e $K_{3}$ que são valores complexos e obtidos através de três amostras de calibração com valores de permissividade complexa conhecidos. Uma vez encontrado os coeficientes para cada frequência, as permissividades complexas das novas amostras são obtidas, interativamente, tendo como base esses valores. 
Vale ressaltar que similar ao modelo capacitivo, o modelo de radiação também requer o deslocamento do plano de referência de medida BB' para o plano AA'. O Apêndice $\mathrm{K}$ apresenta o algoritmo de caracterização do modelo de radiação.

$$
\frac{Y}{Y_{0}}=K_{1}+K_{2} \varepsilon_{r}+K_{3} \varepsilon_{r}^{5 / 2}
$$

Para analisar as amostras de etanol combustível, foram utilizados os dois modelos apresentados. Ressalta-se que os melhores resultados foram obtidos com o modelo de radiação. Tal fato é confirmado em Berube et al. (1996), que demonstra melhores resultados nas caracterizações de amostras líquidas com o modelo de radiação nas frequências entre 2 a $5 \mathrm{GHz}$. Como linha de transmissão em aberto, foi utilizado uma transição (launcher) linha coaxial/linha de microfita empregando conector SMA fêmea com flange de quatro furos. A figura E.3 apresenta a montagem do aparato, com o recipiente para as amostras, o suporte de fixação e a transição coaxial/microfita SMA.

Figura E.3 - (a) Aparato para caracterização de amostras de etanol combustível através de linha coaxial em aberto; (b) perspectiva da transição coaxial/microfita SMA.

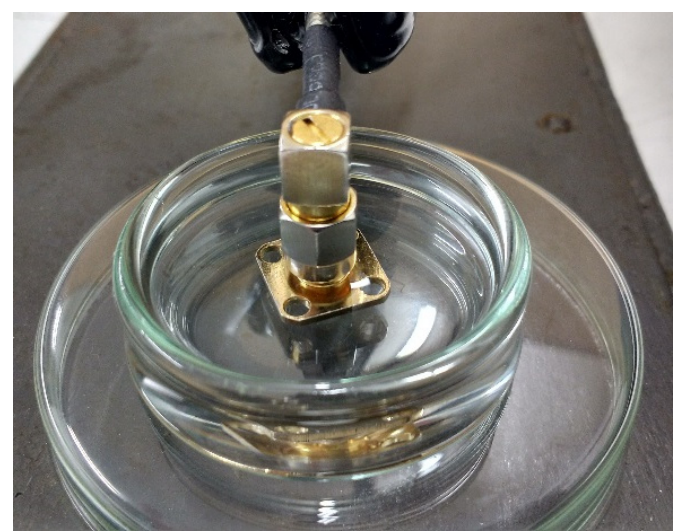

(a)

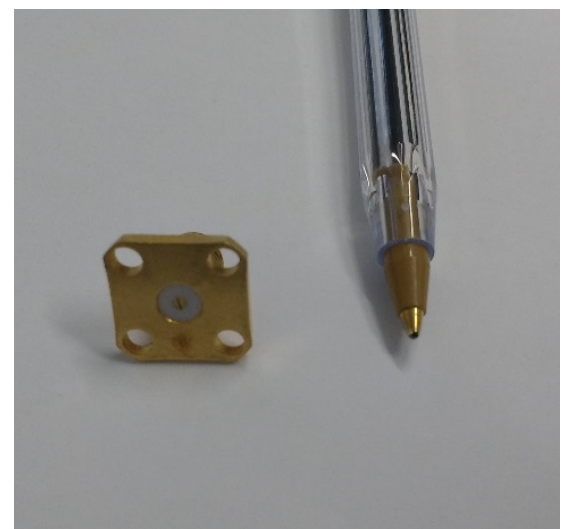

(b) 
Preliminarmente, foram realizados testes de tamanho do recipiente, volume de amostra, profundidade do conector e calibração do analisador de redes. Verificou-se insensibilidade das medidas para grandes tamanhos de recipiente, o que permitiu o uso de um recipiente de vidro com $40 \mathrm{~mm}$ de diâmetro. Diferentes volumes foram testados, e notou-se que mesmo para pequenos volumes o analisador não apresentava diferença de resultados, indicando que as linhas de campo da terminação do conector são concentradas próximas ao condutor central. Utilizou-se como referência de volume $10 \mathrm{ml}$ de água DI.

Os gráficos E.1 e E.2 apresentam os resultados da parte real e imaginária da permissividade complexa das amostras de etanol combustível.

Gráfico E.1 - Parte real da permissividade complexa de amostras de etanol combustível.

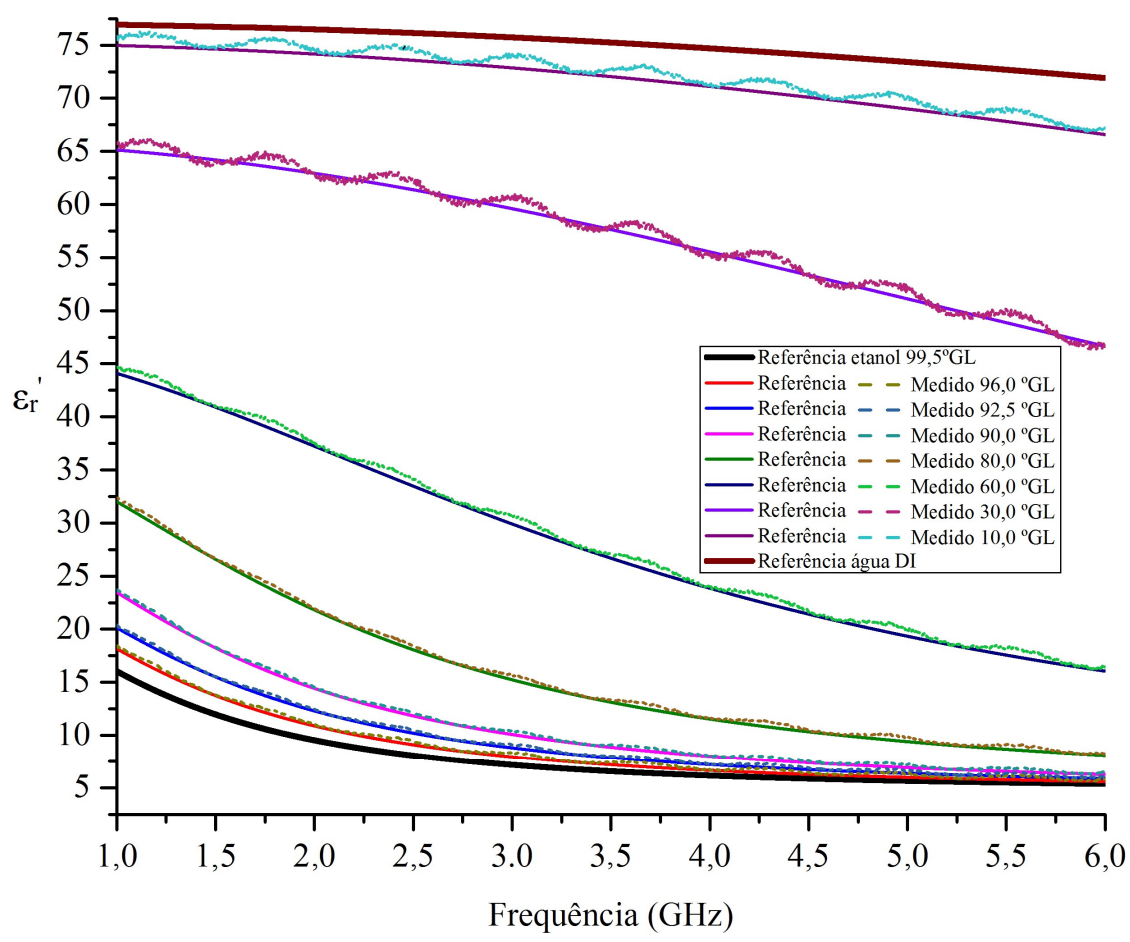

Foram utilizados como referência: água deionizada $(18 \mathrm{M} \Omega / \mathrm{cm})$, etanol absoluto (99, $\left.5^{\circ} \mathrm{GL}\right)$ e o ar. Dessa forma, constrói-se, para cada frequência discreta, um sistema com três equações e três variáveis. O analisador de redes vetorial foi calibrado no plano 
de referência do conector entre as frequências de $1 \mathrm{GHz}$ e $6 \mathrm{GHz}$ com 10001 pontos. Foram coletadas as partes reais e imaginárias do parâmetro $\mathrm{S}_{11}$. Os dados foram analisados utilizando a ferramenta simbólica (Symbolic Math Toolbox) do Matlab, que possibilita soluções analíticas de equações algébricas e diferenciais.

Junto aos valores medidos estão os dados de referência obtidos no capítulo 4, usando os parâmetros do modelo de Debye fornecidos por Bao et al. (1996) para etanol e água DI, modelados pelas regras de diluição. Nota-se que os valores medidos estão coerentes com a referência, o que permite afirmar que tanto as medidas como o modelamento estão adequados dentro da caracterização eletromagnética de materiais. As ondulações que aparecem juntos às medidas se devem, em larga medida, à calibração do analisador de redes.

Gráfico E.2 - Parte imaginária da permissividade complexa de amostras de etanol combustível.

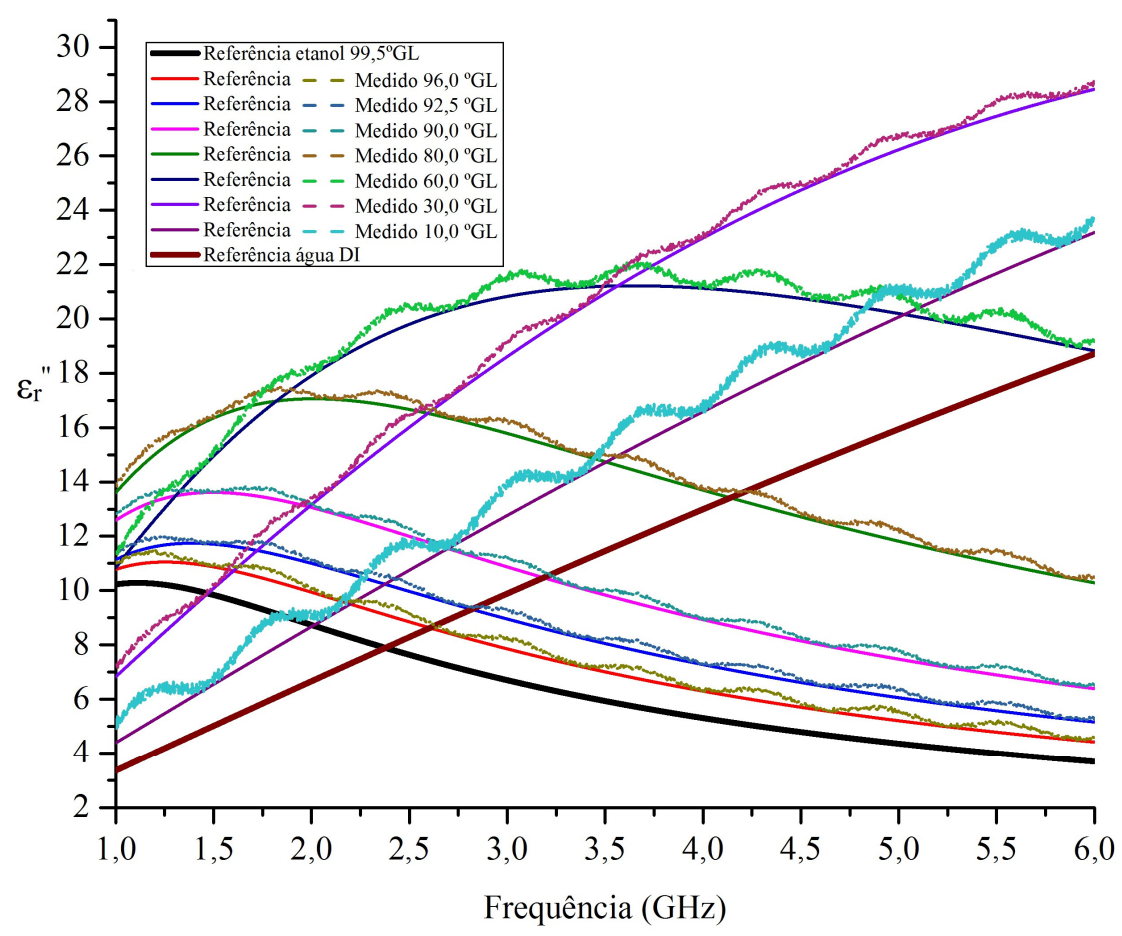




\section{APÊNDICE F - INSTRUMENTO VIRTUAL PARA INTERFACE COM O ANALISADOR DE REDES VETORIAL FIELDFOX N9912A}

Neste apêndice é apresentado o VI (Virtual Instrument) desenvolvido com o software LabVIEW para captura e análise de dados do analisador de redes vetorial FieldFox N9912A. A Figura F.1 apresenta o painel frontal e a Figura F.2 o diagrama em blocos do software. O objetivo desse instrumento virtual é realizar a aquisição dos valores de frequência de ressonância e do índice de mérito a partir da medida do coeficiente de reflexão.

Figura F.1 - Painel frontal da interface com o analisador de redes vetorial Fieldfox.

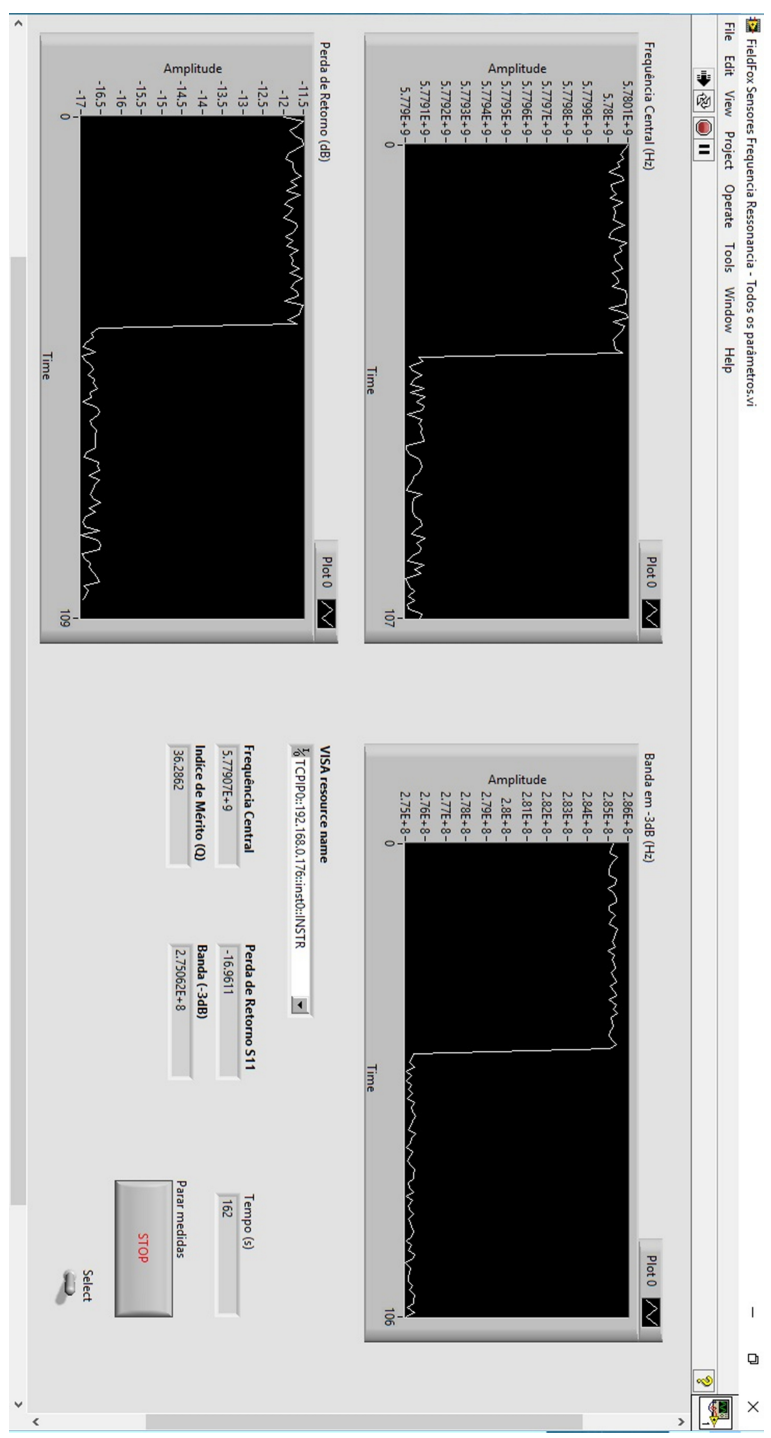


Figura F.2 - Diagrama em blocos da interface com o analisador de redes vetorial Fieldfox.
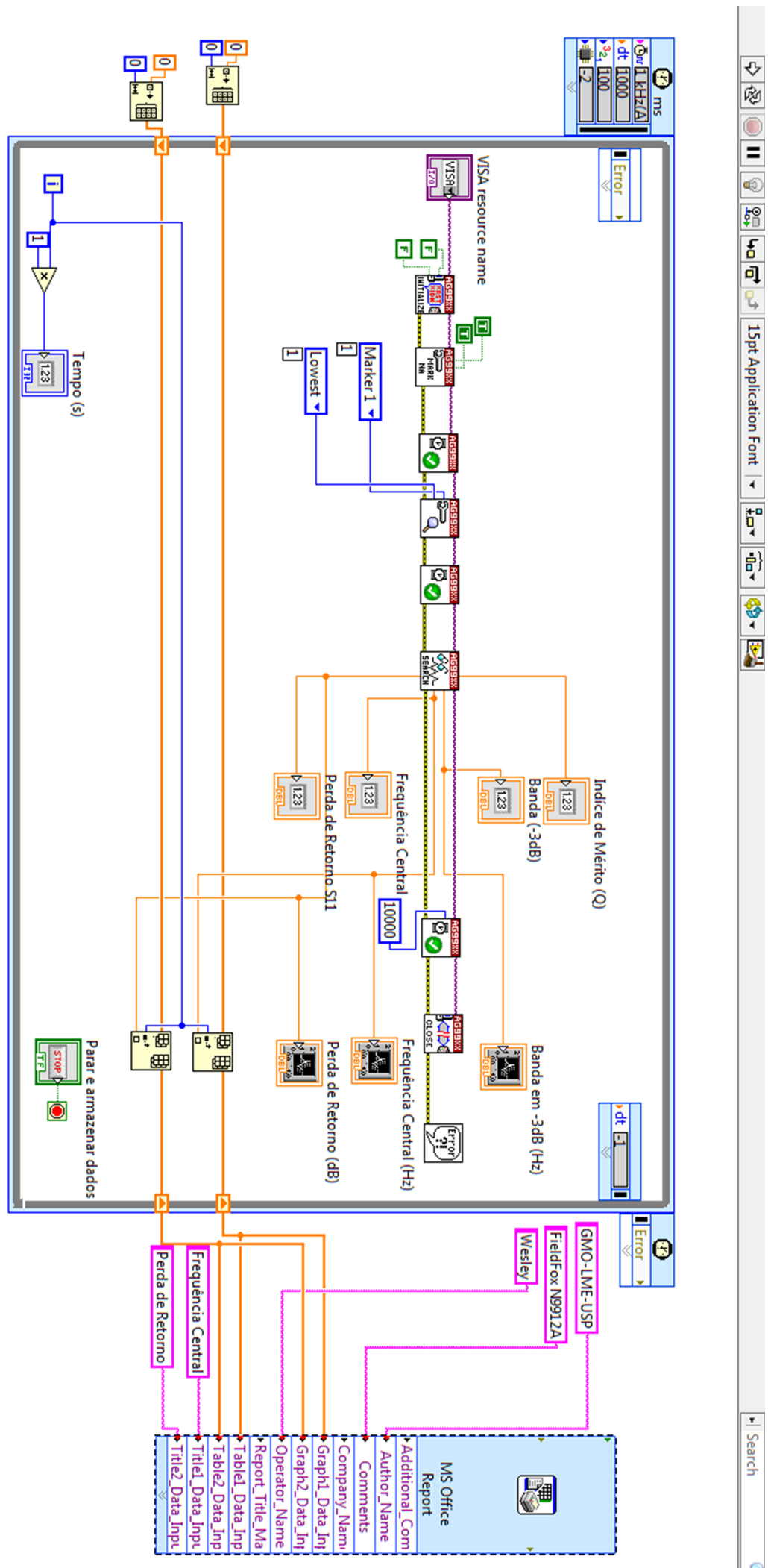


\section{APÊNDICE G - CURVAS DE FREQUÊNCIA DE RESSONÂNCIA E ÍNDICE DE MÉRITO EM FUNÇÃO DO TEMPO COM SWCNT DEPOSITADO SOBRE ANTENA DE MICROFITA}

Os gráficos G.1 e G.2 apresentam os dados obtidos durante o ensaio da antena de microfita com SWCNT na presença de água DI. Os dados crus demonstram o comportamento da frequência de ressonância e do índice de mérito durante as sucessivas injeções da fase vapor. Como demonstrado no subitem 4.2.1.2, o tempo de saturação do sensor foi medido em aproximadamente $40 \mathrm{~s}$ da injeção da amostra. Além disso, reafirma-se que o sensor não apresenta envenenamento dos CNTs, nem oxidação do metal.

Gráfico G.1 - Curva da frequência de ressonância ao longo do tempo para água DI.

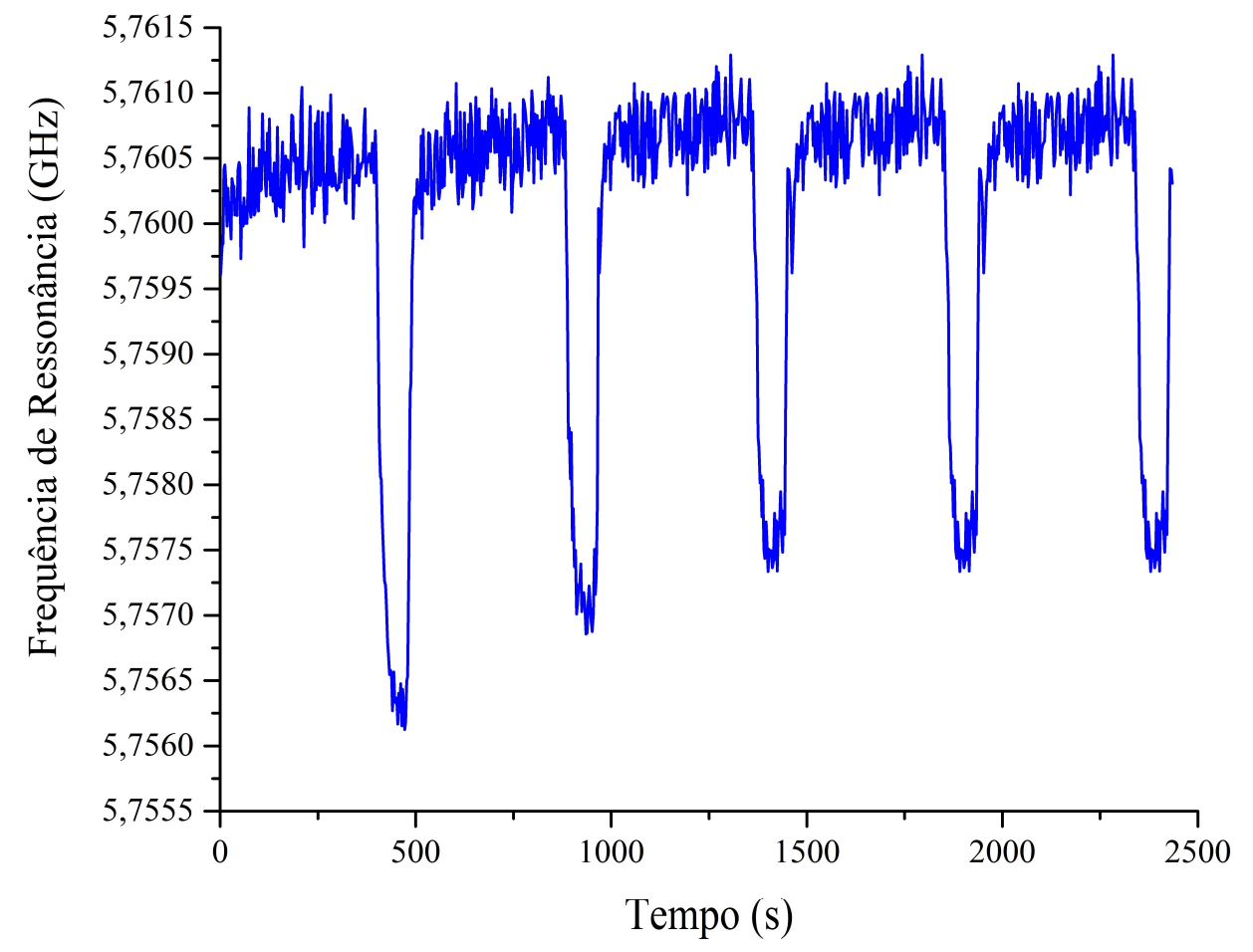

O Gráfico G.2 demonstra a necessidade do uso de um filtro para eliminar as oscilações da medida. Como mencionado no corpo do texto, foi utilizado um filtro de média móvel para a suavização de ruído. Esse filtro possui tamanho 8 , que é um valor de 
compromisso entre o desempenho do filtro e a capacidade de detecção dos picos das curvas da frequência de ressonância e de índice de mérito.

Gráfico G.2 - Curva do índice de mérito ao longo do tempo para água DI.

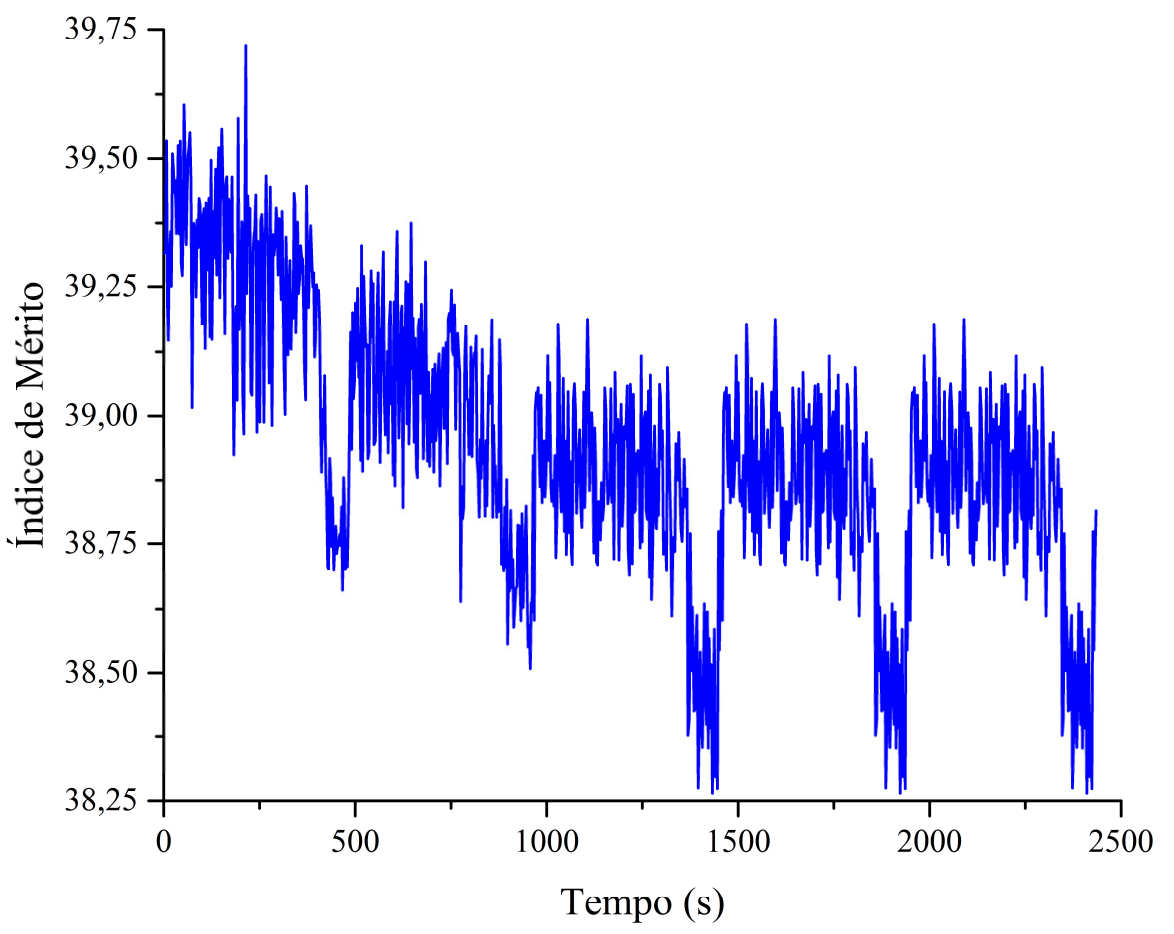




\section{APÊNDICE H - INSTRUMENTO VIRTUAL PARA CONTROLE DO FLUXO DE MASSA (MFC)}

Neste apêndice é apresentado o instrumento virtual para controle dos rotâmetros para as medidas de gases. A Figura H.1 apresenta o painel frontal e a Figura H.2 o diagrama em blocos do software. O instrumento virtual foi fornecido pelo GSIM (Grupo de Sensores do LME-USP) e otimizado para este trabalho. Nesse programa, são inseridas receitas que contém o tempo de duração e o fluxo para controle de dois MFCs. O primeiro controlador de fluxo é conectado diretamente a câmara de ensaios, permitindo a passagem do $\mathrm{N}_{2}$, gás inerte. $\mathrm{O}$ segundo controlador é conectado a um borbulhado que possui o material sob teste.

Figura H.1 - Painel frontal do sistema de controle dos MFCs.

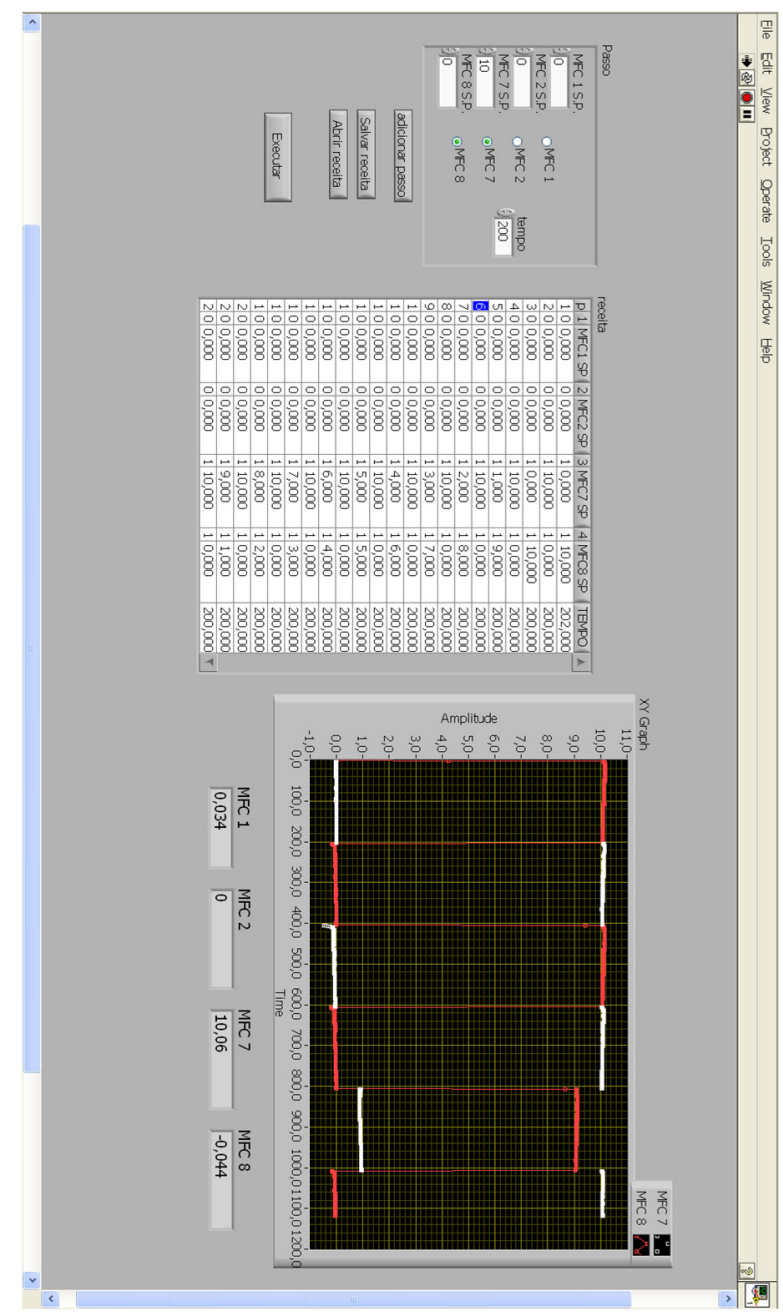


Figura H.2 - Diagrama em blocos do sistema de controle de MFCs.
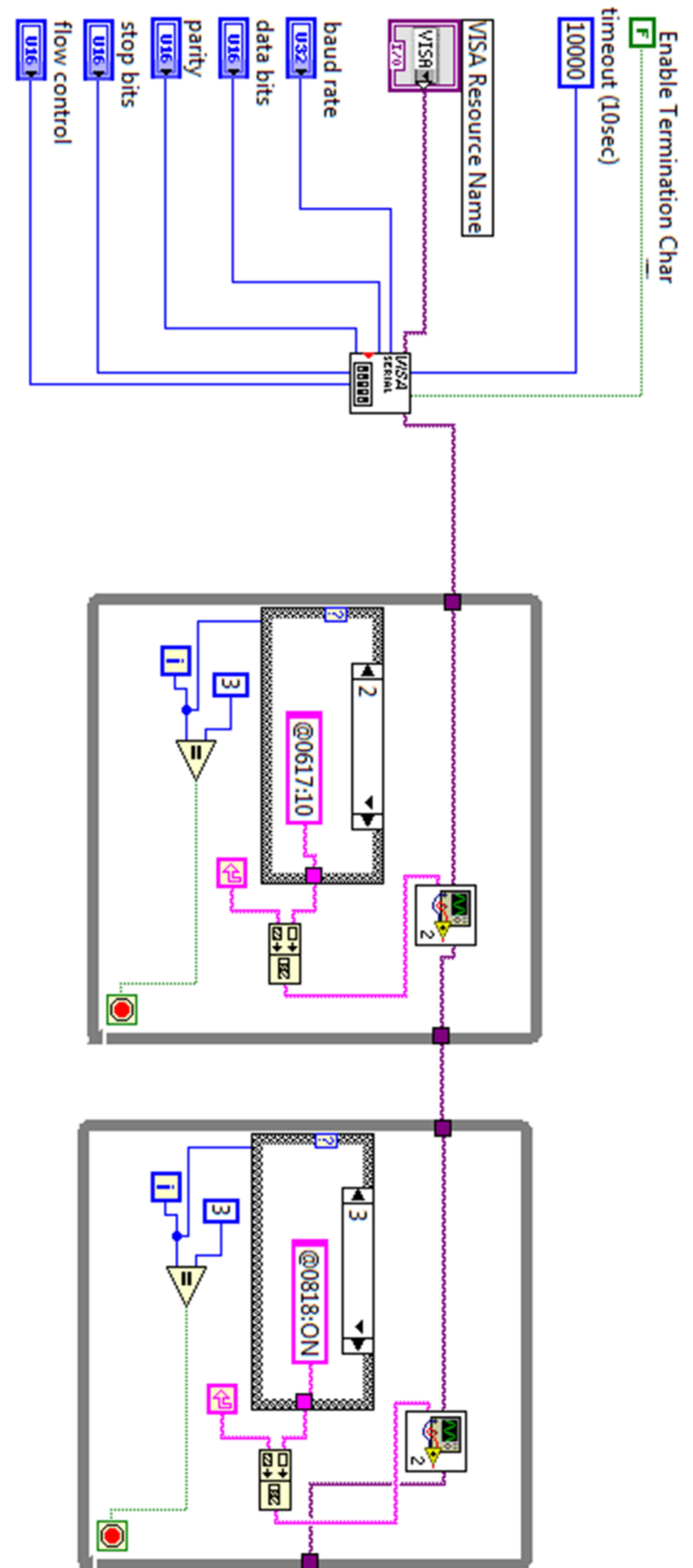


\section{APÊNDICE I - PERMISSIVIDADE ELÉTRICA COMPLEXA DA ÁGUA DESTILADA UTILIZANDO O MODELO DE DEBYE DE UMA E DUAS RELAXAÇÕES DIELÉTRICAS}

Neste apêndice é apresentado o script em Matlab para extração da permissividade elétrica complexa da água destilada utilizando o modelo de Debye de uma e duas relaxações dielétricas. Através da inserção da faixa de frequência de operação e dos valores do modelo de Debye, é possível obter a permissividade elétrica complexa da água destilada. Para exemplificar esse código, foram utilizadas as referências de valores do modelo de Debye obtidos nos trabalhos experimentais de Bao et al. (1996) e Buchner et al. (1999).

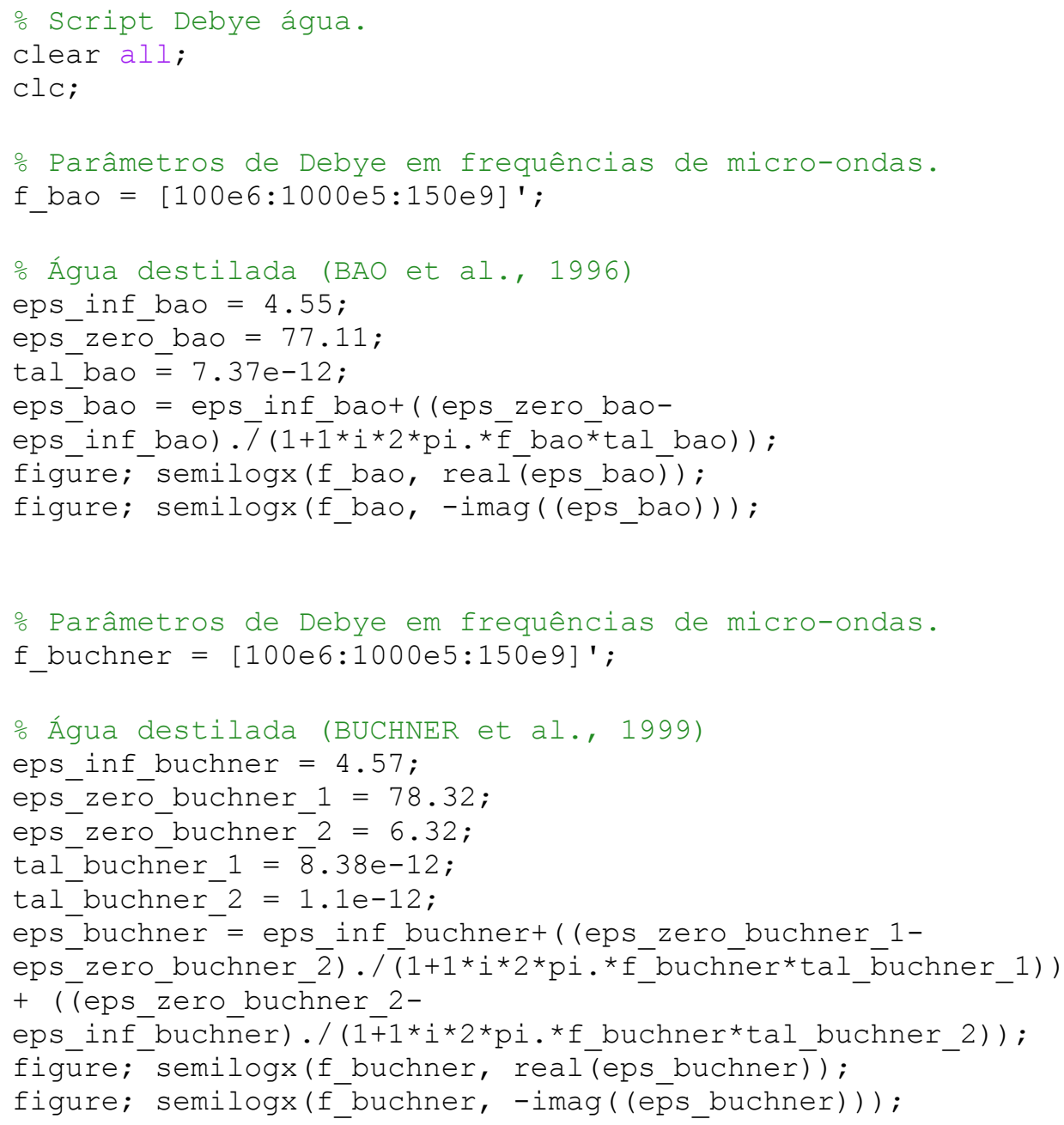




\section{APÊNDICE J - CÁlCULO DOS VALORES DE PERMISSIVIDADE ELÉTRICA COMPLEXA ATRAVÉS DOS MODELOS DE DEBYE PARA MISTURA - SCRIPT EM MATLAB}

Neste apêndice é apresentado o script em Matlab para cálculo dos valores de permissividade elétrica complexa utilizando os modelos de Debye e as regras de mistura. São valores de entrada: a faixa de frequência de operação; os valores do modelo de Debye para os materiais que compõem a mistura, no caso, água deionizada e etanol; a fração da mistura; e o coeficiente $a$, oriundo da equação ajustada de Bruggeman.

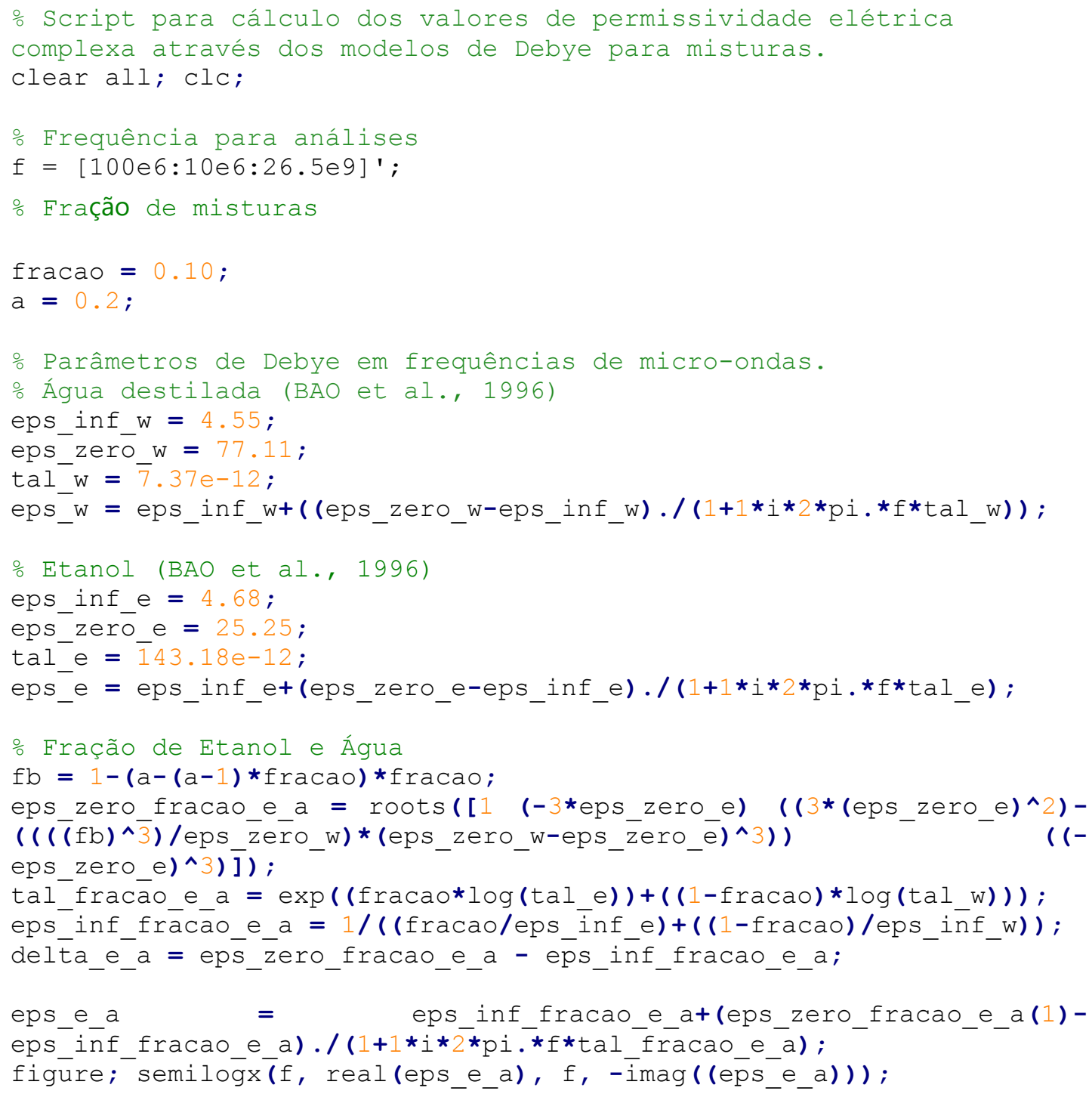




\section{APÊNDICE K - CARACTERIZAÇÃO DE MATERIAIS ATRAVÉS DE LINHAS EM ABERTO - SCRIPT EM MATLAB}

Neste apêndice é apresentado o script em Matlab para extração da permissividade elétrica complexa de materiais a partir do método da linha em aberto. São valores de entrada, os valores dos coeficientes de reflexão obtidos utilizando a linha de transmissão em aberto para três condições: no ar, na água (material de referência) e no etanol (material de referência). Também são dados de entrada, os valores de permissividade elétrica para as referências. Utilizando o modelo de radiação é possível obter os valores de permissividade elétrica complexa para valores intermediários da mistura de etanol em água, bem como de outros materiais.

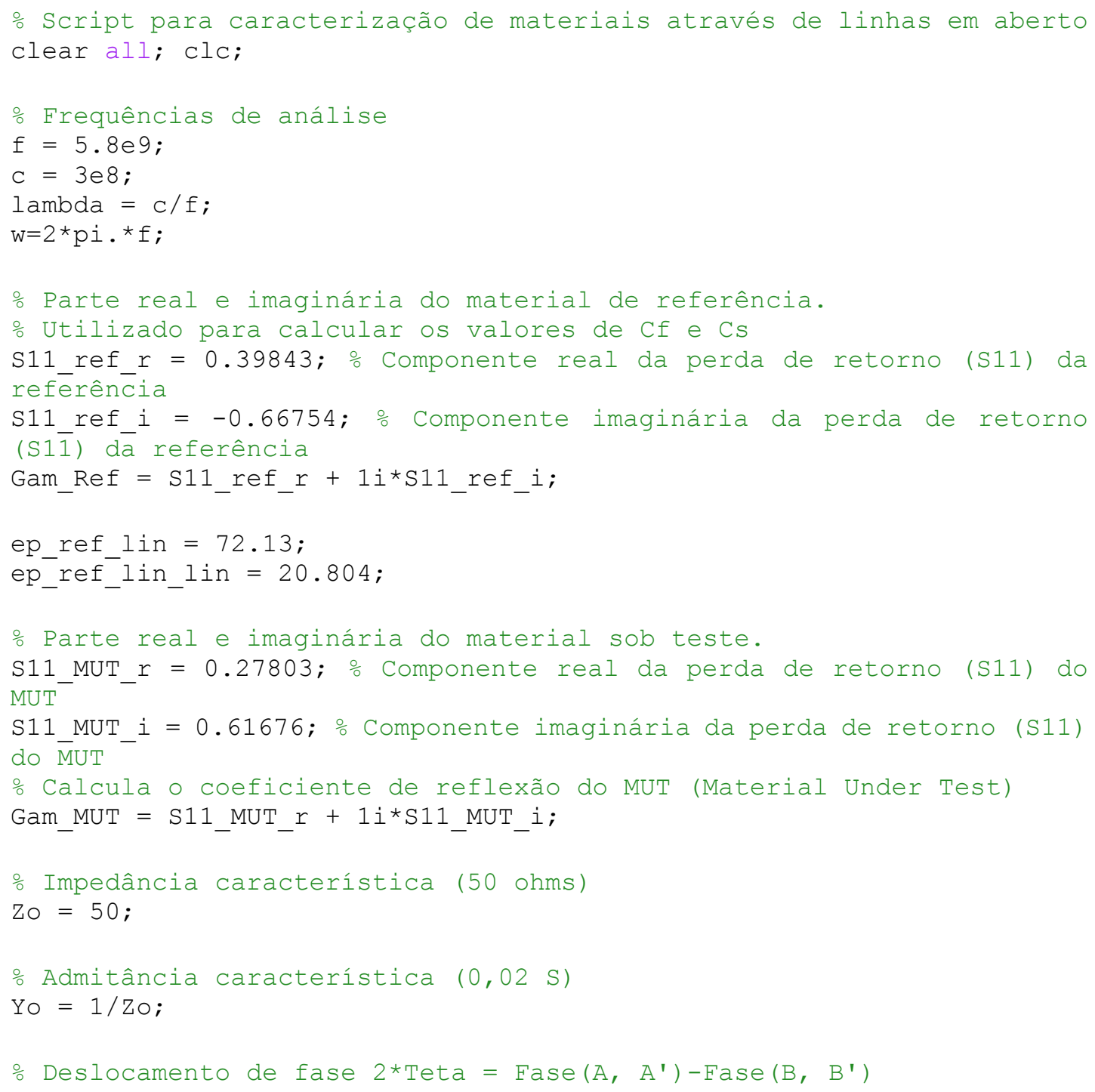




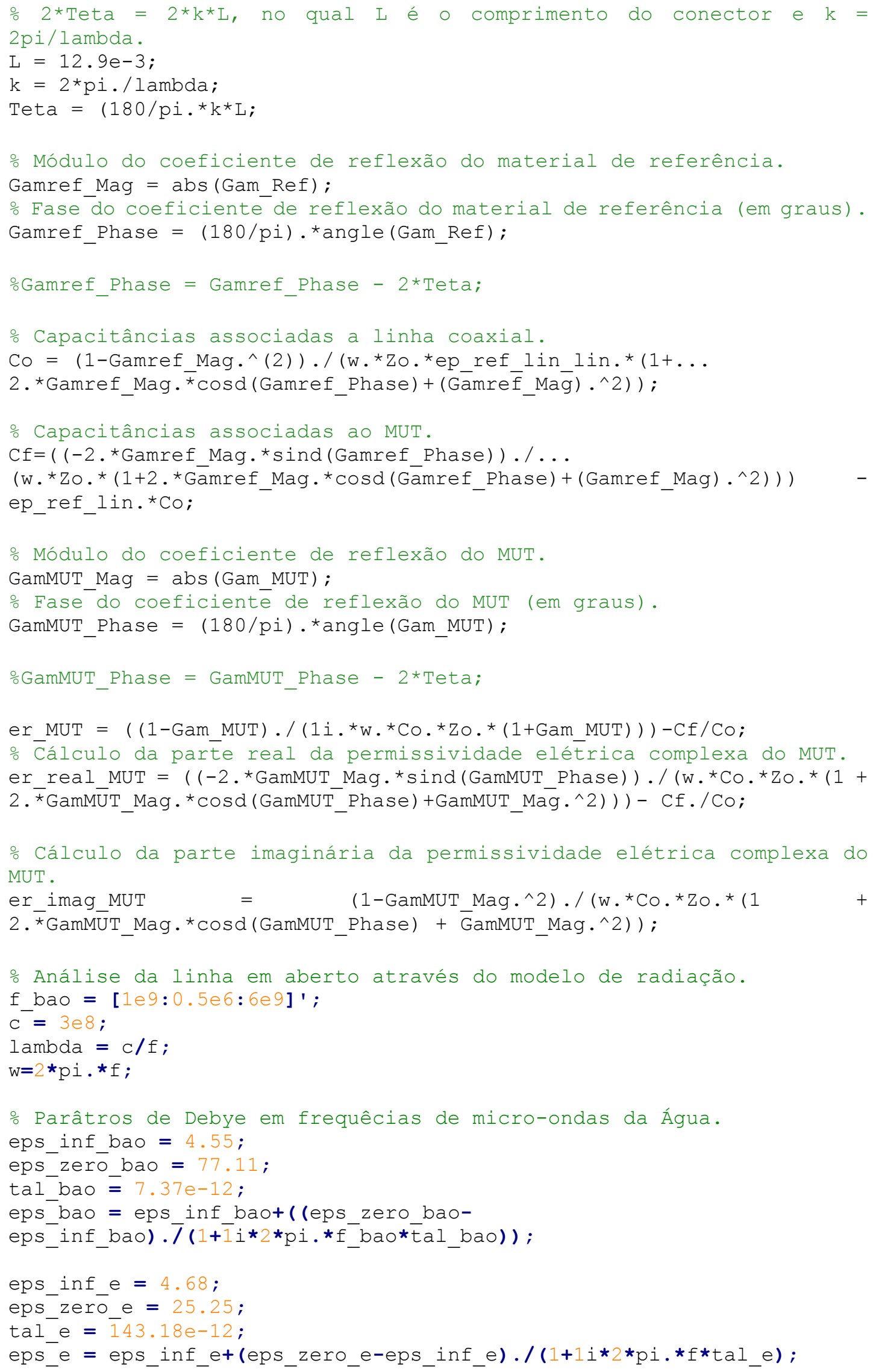




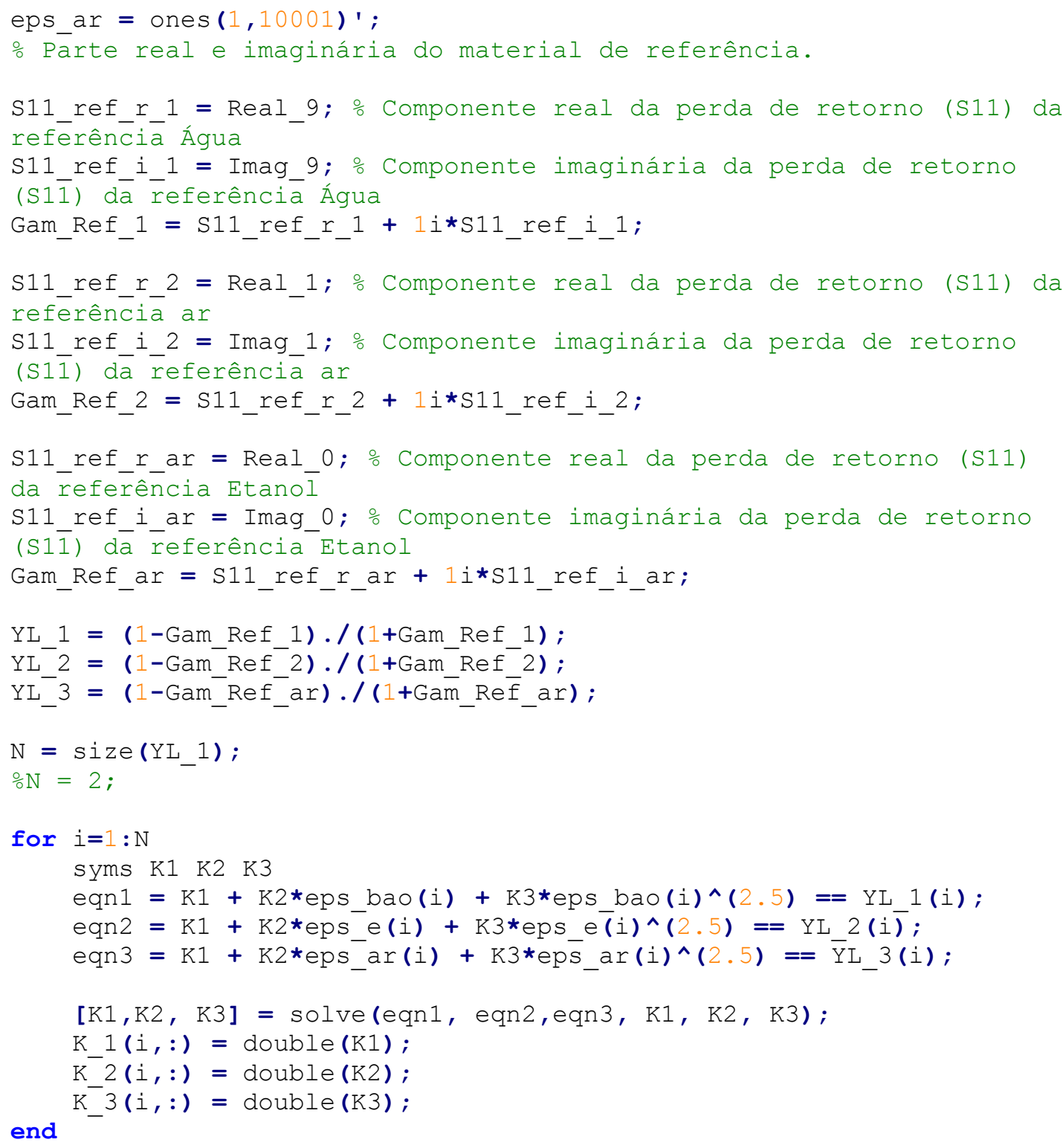

Parte real e imaginária do material sob teste. 


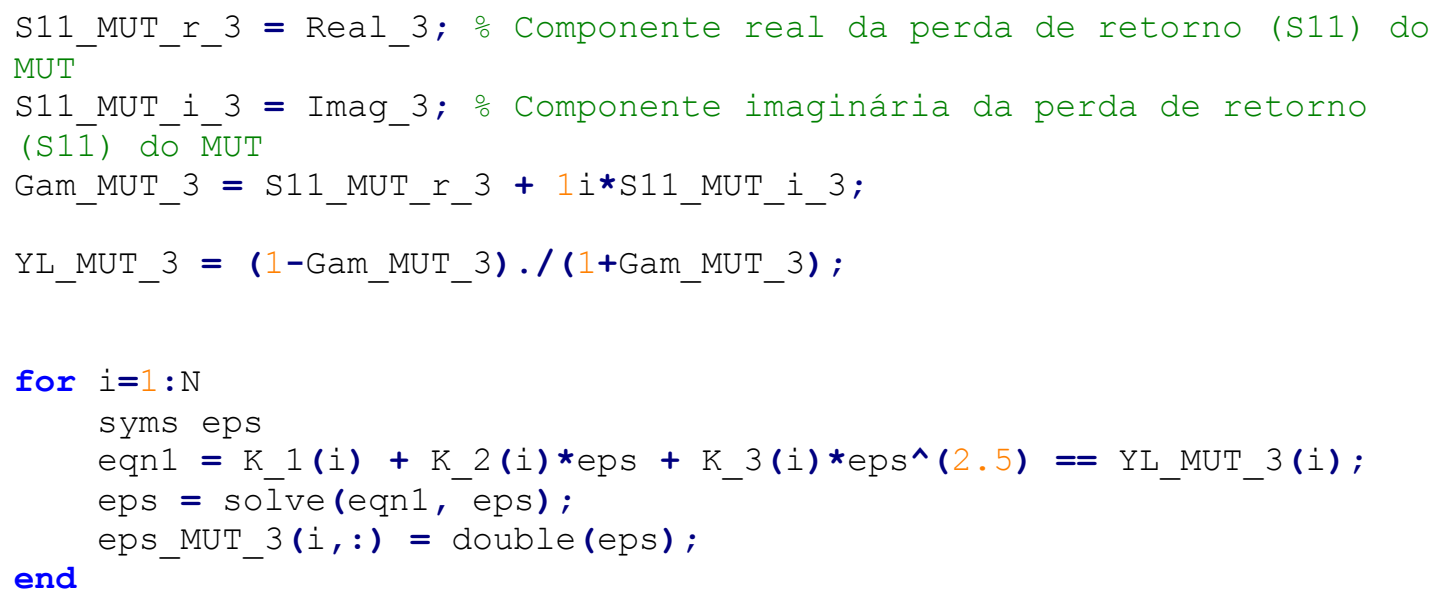

\% Parte real e imaginária do material sob teste.

S11_MUT_r_6 = Real_6; $\%$ Componente real da perda de retorno (S11) do MUT

S11 MUT_i 6 = Imag_6; O Componente imaginária da perda de retorno $(\mathrm{S} 1 \overline{1})$ do $\overline{\mathrm{MUT}}$

Gam_MUT_6 = S11_MUT_r_6 + 1i*S11_MUT_i_6;

YL_MUT_ $6=(1-$ Gam_MUT_6) $/ /(1+$ Gam_MUT_6 $)$; 


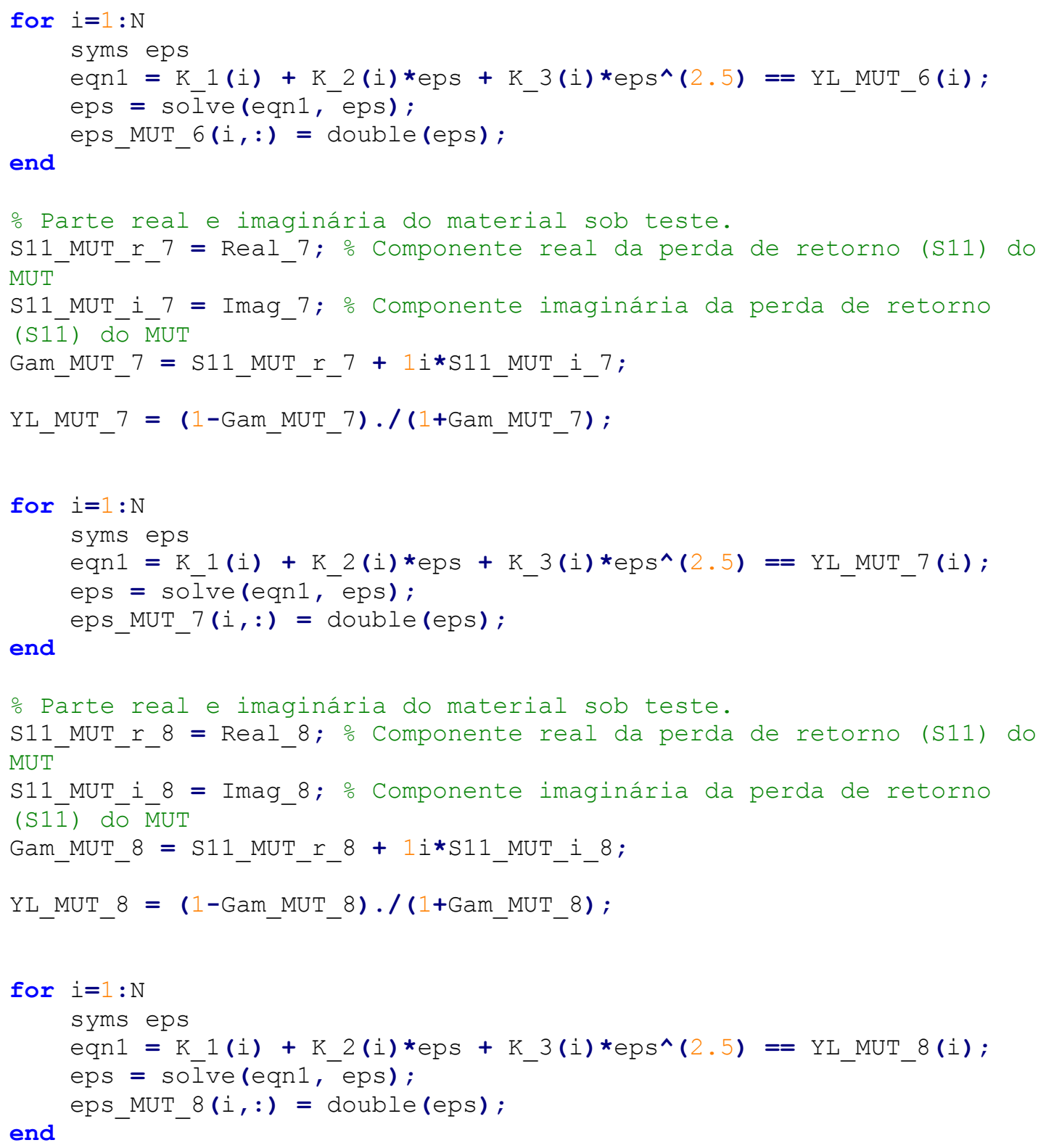




\section{APÊNDICE L - PROJETO DA ANTENA DE MICROFITA COM PLAQUETA RETANGULAR - SCRIPT EM MATLAB}

Este apêndice descreve as equações de projeto de uma antena de microfita com plaqueta retangular. São valores de entrada: a permissividade elétrica do substrato, a frequência de operação da antena e a espessura do substrato. A partir das equações são obtidos os valores de: largura da plaqueta retangular da antena de microfita, comprimento da plaqueta retangular da antena de microfita e posição do ponto de inserção da linha indentada.

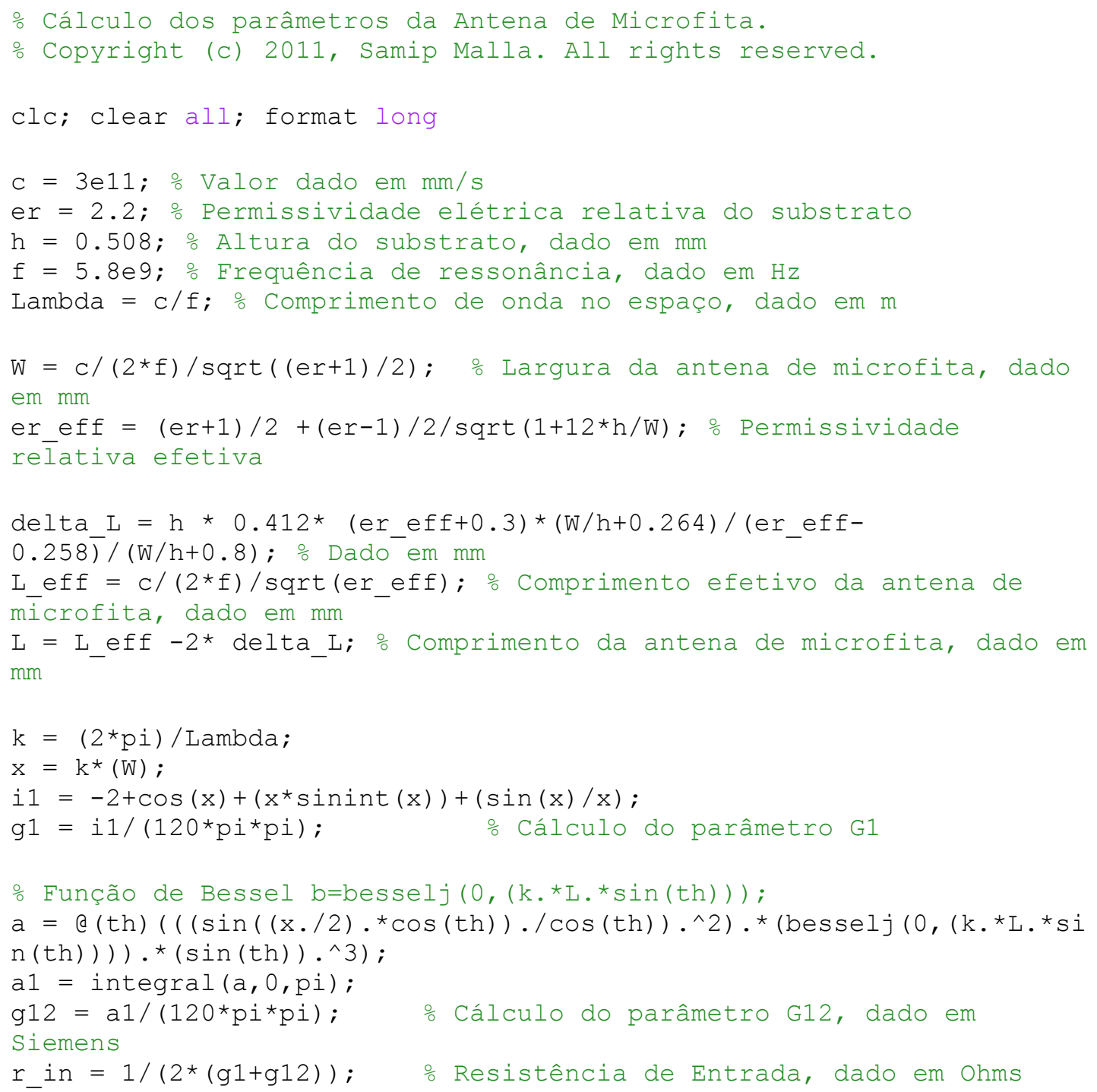


\% Posição do ponto de inserção para casamento de impedância em 50 Ohms

Inset $=(\mathrm{L} / \mathrm{pi}) *\left(\operatorname{acos}\left(\operatorname{sqrt}\left(50 / r_{-} \mathrm{in}\right)\right)\right) ; \quad \frac{\circ}{\circ} \mathrm{y} 0$, valor dado em $\mathrm{mm}$ 


\section{APÊNDICE M - CÁLCULO DAS DIMENSÕES DO GUIA DE ONDAS EM SIW - SCRIPT EM MATLAB}

Este apêndice descreve as equações de projeto do guia de ondas utilizando a tecnologia SIW. São valores de entrada: a frequência de corte do modo $\mathrm{TE}_{10}$, a permissividade elétrica do substrato, a distância entre furos e o diâmetro dos furos (postes). São obtidos através desta lista de comandos, o valor da seção transversal do guia SIW e a frequência de corte do segundo modo.

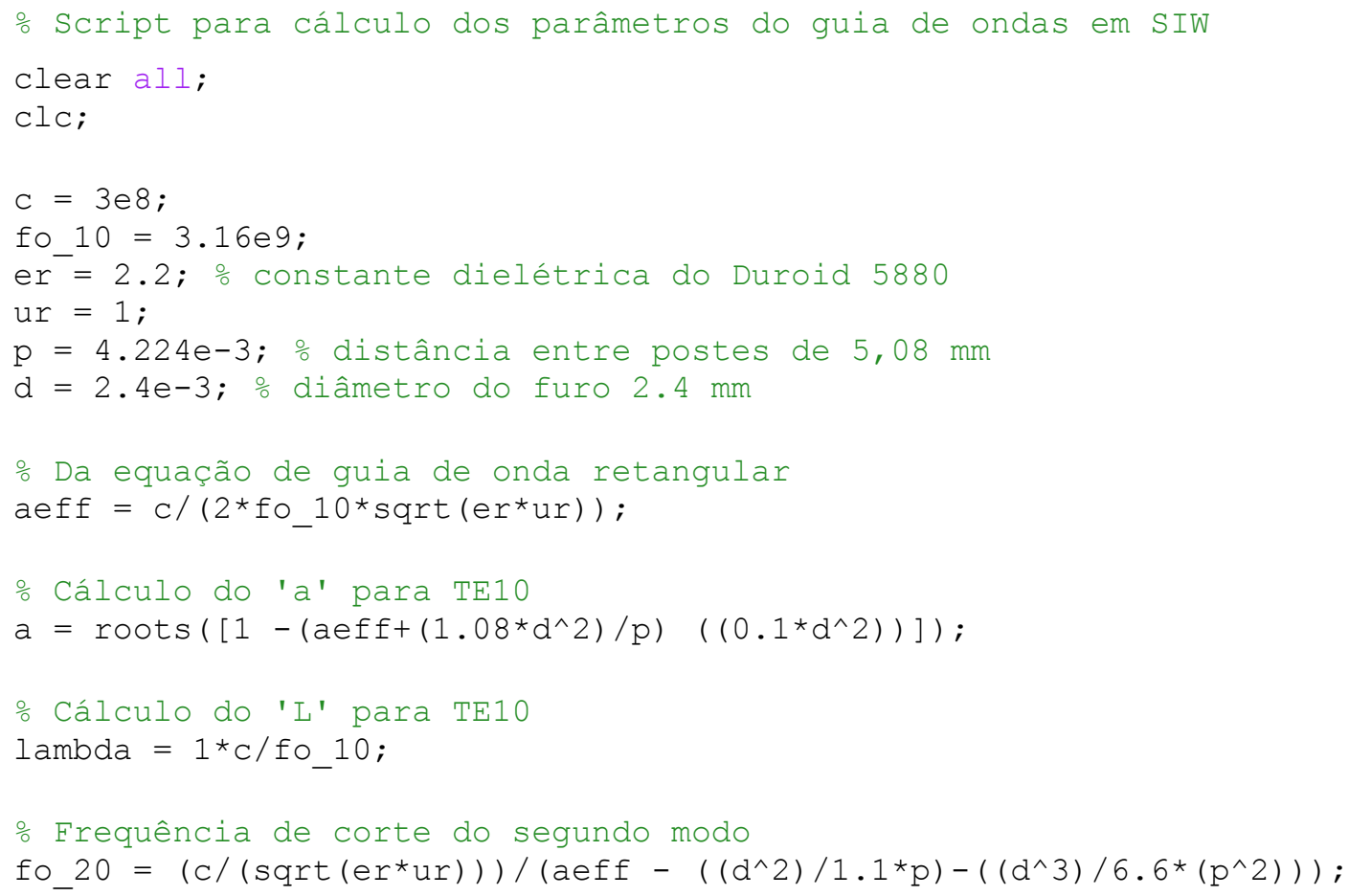




\section{APÊNDICE N - CÁlCULO DAS DIMENSÕes DA CAVIDADE RESSONANTE EM SIW - SCRIPT EM MATLAB}

Este apêndice descreve as equações de projeto das dimensões da cavidade de ressonante utilizando a tecnologia SIW. São valores de entrada: os modos de operação $m$ e $n$ da cavidade, a frequência de ressonância da cavidade, a permissividade elétrica do substrato, a distância entre furos e o diâmetro dos furos (postes). Como saída, são obtidos os valores das seções transversais da cavidade ressonante.

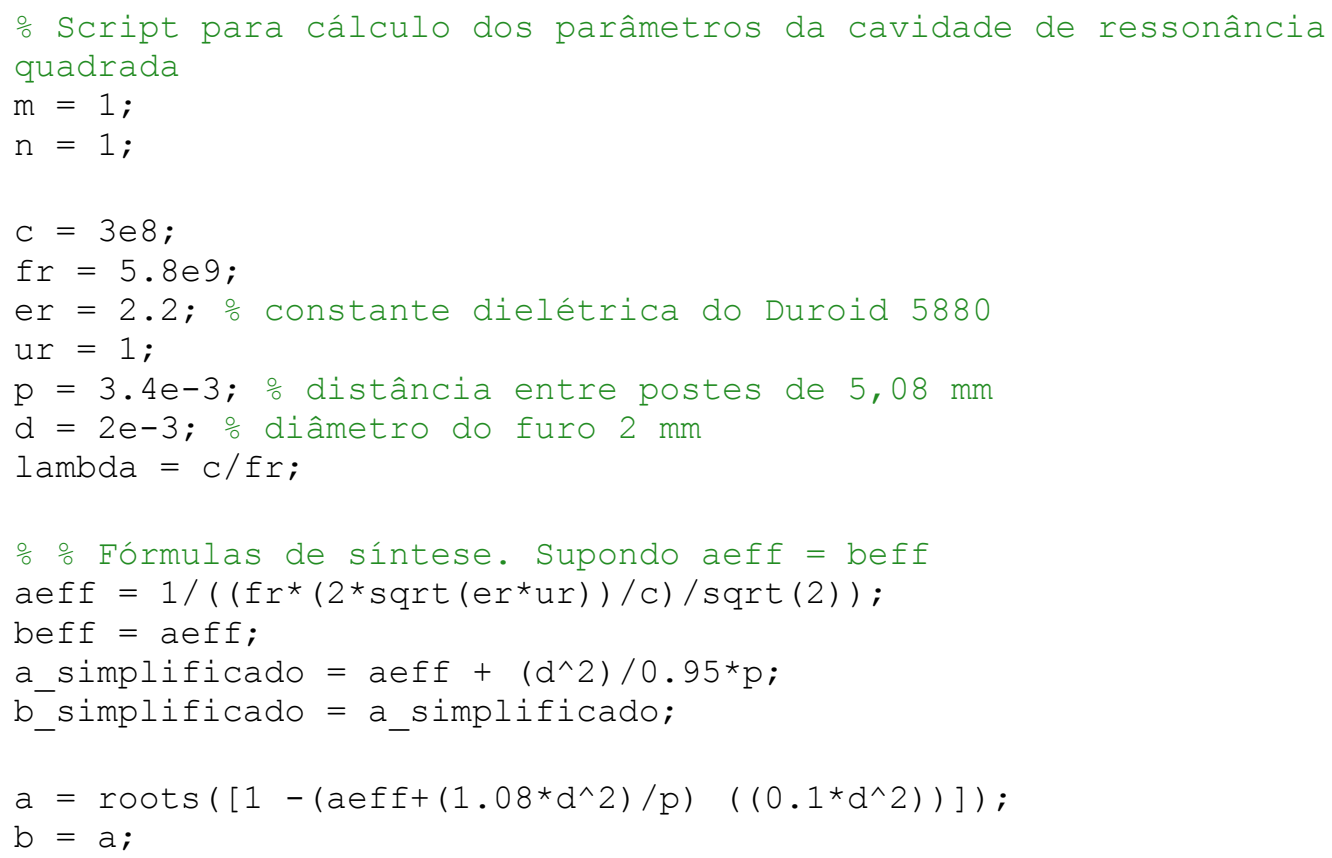




\section{APÊNDICE O - CÁLCULO DAS DIMENSÕES DO TAPER PARA O PROJETO DE GUIA DE ONDAS EM SIW E DA ANTENA COM CAVIDADE RESSONANTE EM SIW - SCRIPT EM MATLAB}

Este apêndice descreve as equações de projeto da linha cônica (taper), utilizada como circuito de casamento de impedâncias entre a microlinha de transmissão e o guia de ondas com tecnologia SIW. São valores de entrada: a permissividade elétrica do substrato, a distância entre furos, o diâmetro dos furos (postes) e a seção transversal do guia de ondas utilizando tecnologia SIW.

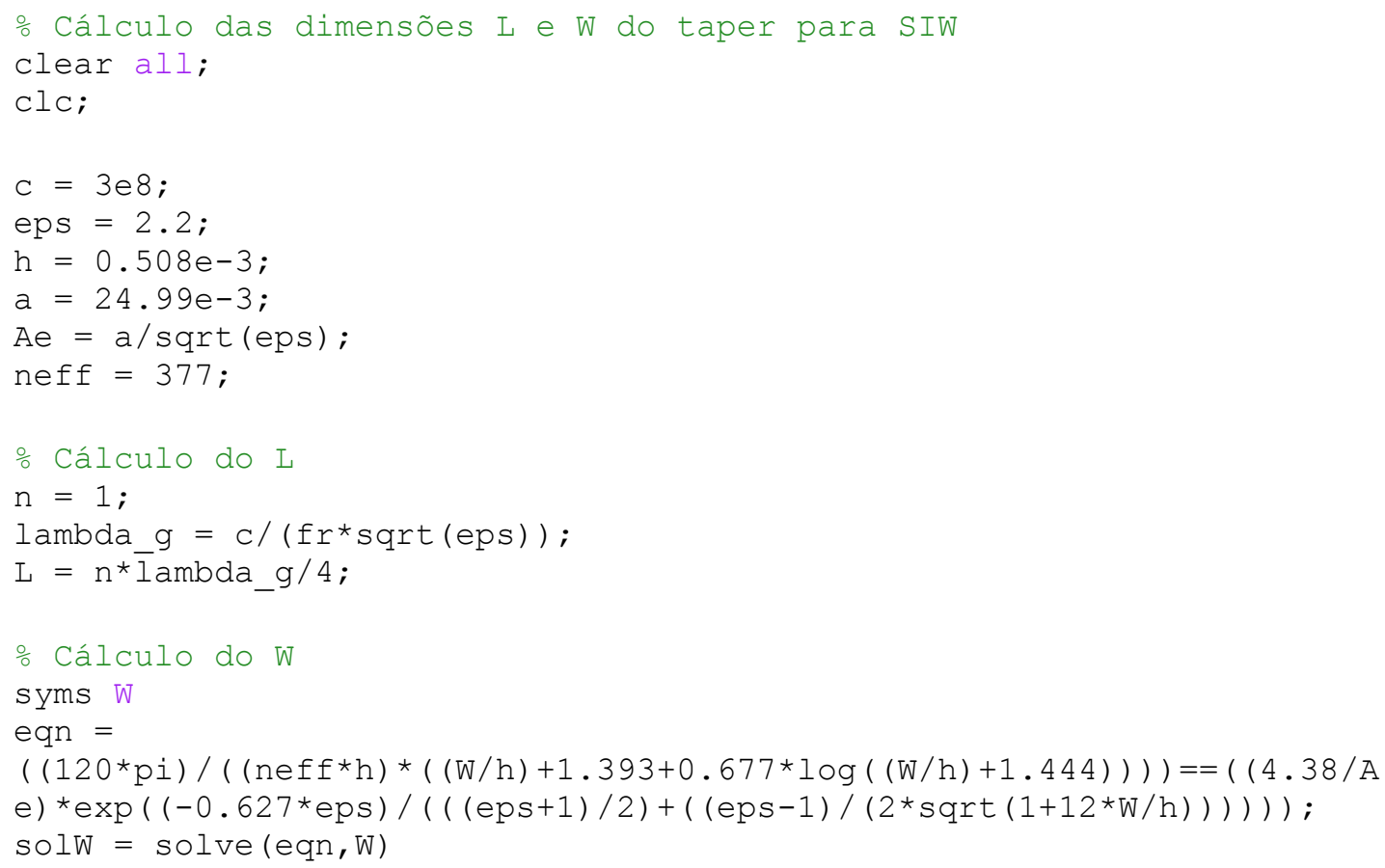




\section{APÊNDICE P - PERMISSIVIDADE ELÉTRICA EM FUNÇÃO DA TEMPERATURA PARA ANÁLISE DA FASE LÍQUIDA}

Todas as caracterizações e testes realizados nesse trabalho foram feitas à temperatura ambiente de $25^{\circ} \mathrm{C}$. Contudo é sabido que a temperatura é um parâmetro importante na caracterização eletromagnética de materiais. Em especial, os valores de permissividade elétrica são sensíveis às variações desse parâmetro (PONGSUWAN et al. 2014) (BERDEL et al., 2005) (JACOB et al., 2006) (TAKAHASHI et al., 1997). Para o caso de materiais polares o aquecimento ou o resfriamento modificam a polarizabilidade do material. Quando se aumenta a temperatura, aumenta-se a energia cinética das moléculas dos materiais e, consequentemente, a amplitude do movimento dessas moléculas fica maior. Com isso, torna-se mais difícil um campo elétrico externo ser capaz de alinhar os dipolos. Contudo, não se pode supor que o comportamento com temperatura ocorra da mesma maneira para todos os materiais, em especial, quando a estrutura do material é modificada com a variação da temperatura.

Foge ao escopo desse trabalho variar o parâmetro de temperatura em conjunto com as frações de etanol em água. No entanto, optou-se por realizar ensaios da fase líquida de água DI variando sua temperatura e analisando a resposta na antena SIW. Inicialmente, as curvas da permissividade elétrica complexa em função da frequência parametrizadas em temperatura foram modeladas com base nos trabalhos de Buchner et al. (1999) e Catenaccio et al. (2003). O Gráfico P.1 descreve a parte real da permissividade elétrica e o Gráfico P.2 apresenta a parte imaginária da permissividade elétrica.

Nota-se, do Gráfico P.1 que quanto menor a temperatura, maior são os valores da permissividade estática $\left(\varepsilon_{s}\right)$ e tempo de relaxação $(\tau)$. Esse resultado é esperado, pois nessas condições os dipolos da água são mais facilmente polarizáveis. Além disso, o maior tempo de relaxação explica o menor valor da parte real da permissividade elétrica da água para altas frequências. Um tempo de relaxação maior significa uma dificuldade maior do material ser polarizado com um campo elétrico externo (AGMON, 1996). 
Gráfico P.1 - Parte real da permissividade elétrica complexa em função da frequência para água deionizada em diferentes temperaturas.

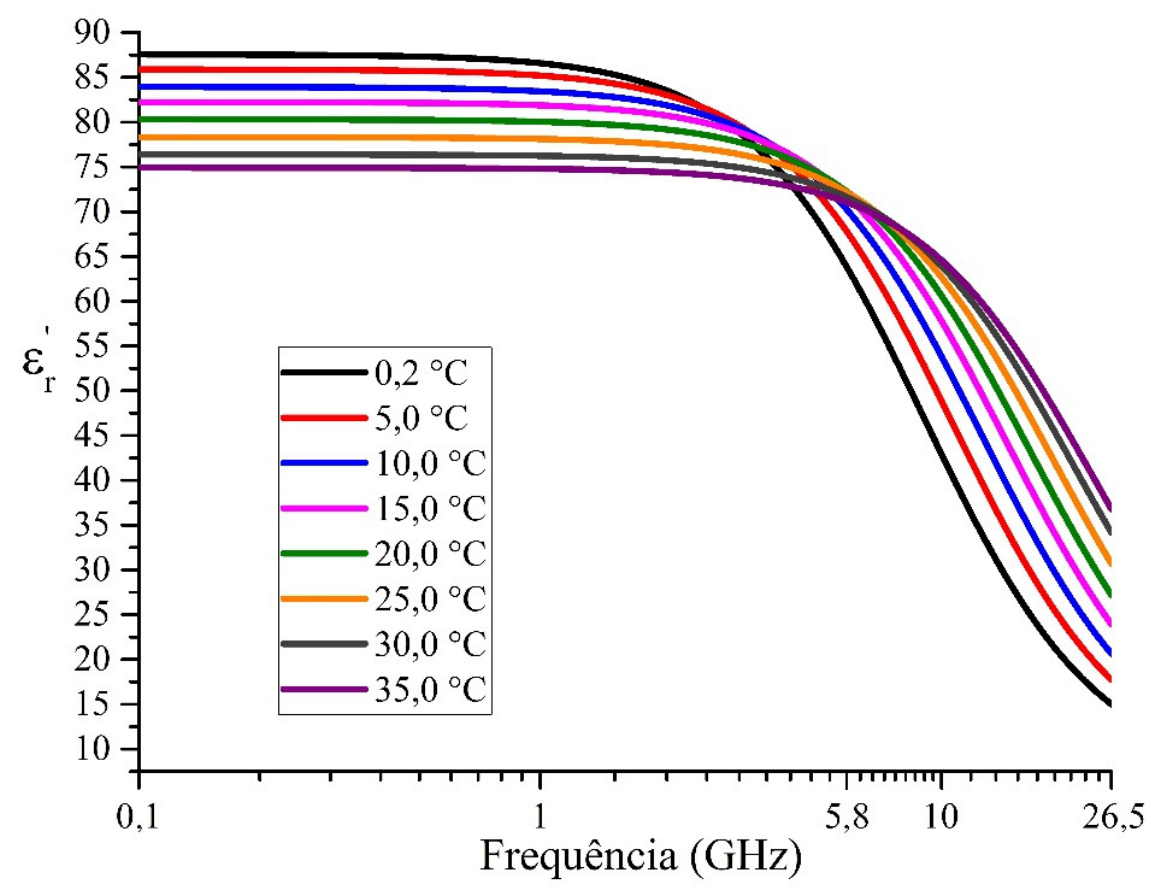

Gráfico P.2 - Parte imaginária da permissividade elétrica complexa em função da frequência para água deionizada em diferentes temperaturas.

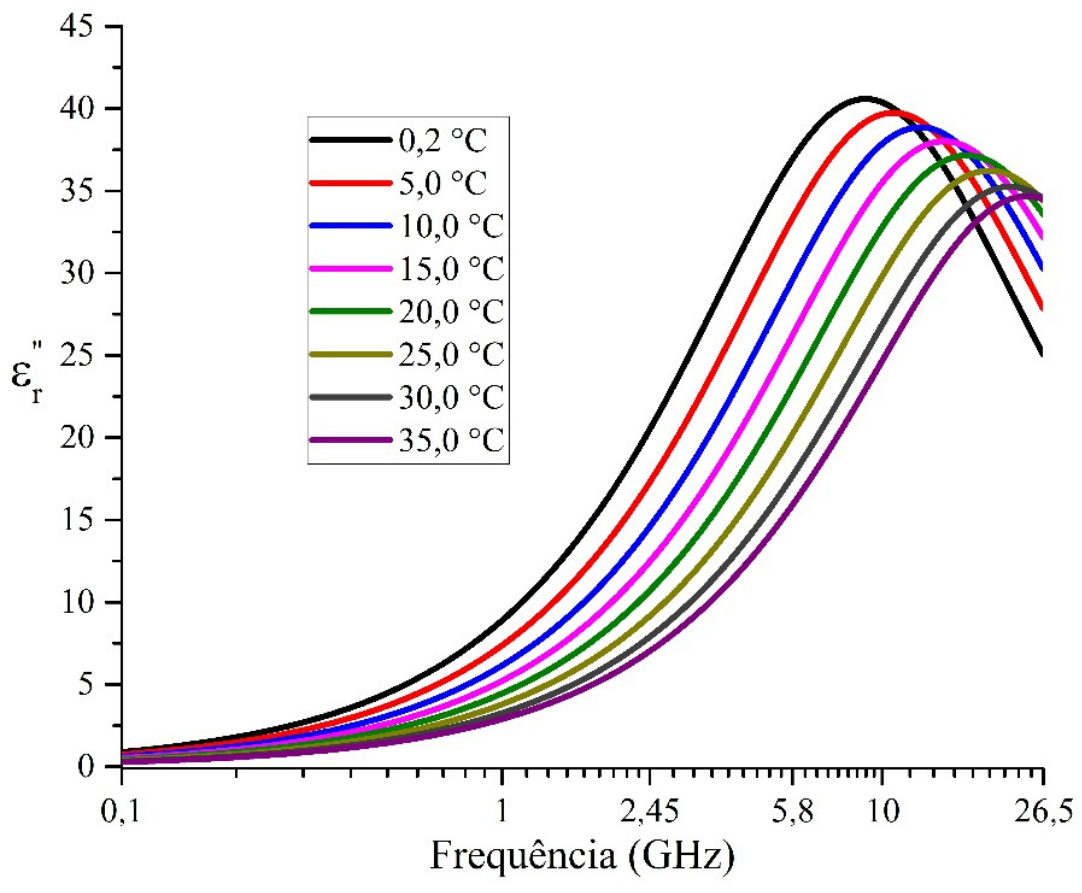


Do Gráfico P.2, nota-se pouca variação da parte imaginária da permissividade elétrica da água para baixas frequências. Para frequências entre $1 \mathrm{GHz}$ e $10 \mathrm{GHz}$ é verificável que quanto menor a temperatura, maior é o valor da parte imaginária. Nota-se também que a variação de temperatura influencia, em especial, as perdas do material na frequência de 5,8 GHz.

Utilizando a infraestrutura descrita na Figura P.1, os valores da permissividade elétrica complexa foram caracterizados para as diferentes temperaturas. Como foram utilizadas somente amostras de água, optou-se por inserir uma única gota na posição central da fenda traseira da antena SIW.

Figura P.1 - Aparato experimental para ensaio do sensor de fase líquida (antena SIW com fenda) para caracterização de água DI em diferentes temperaturas.

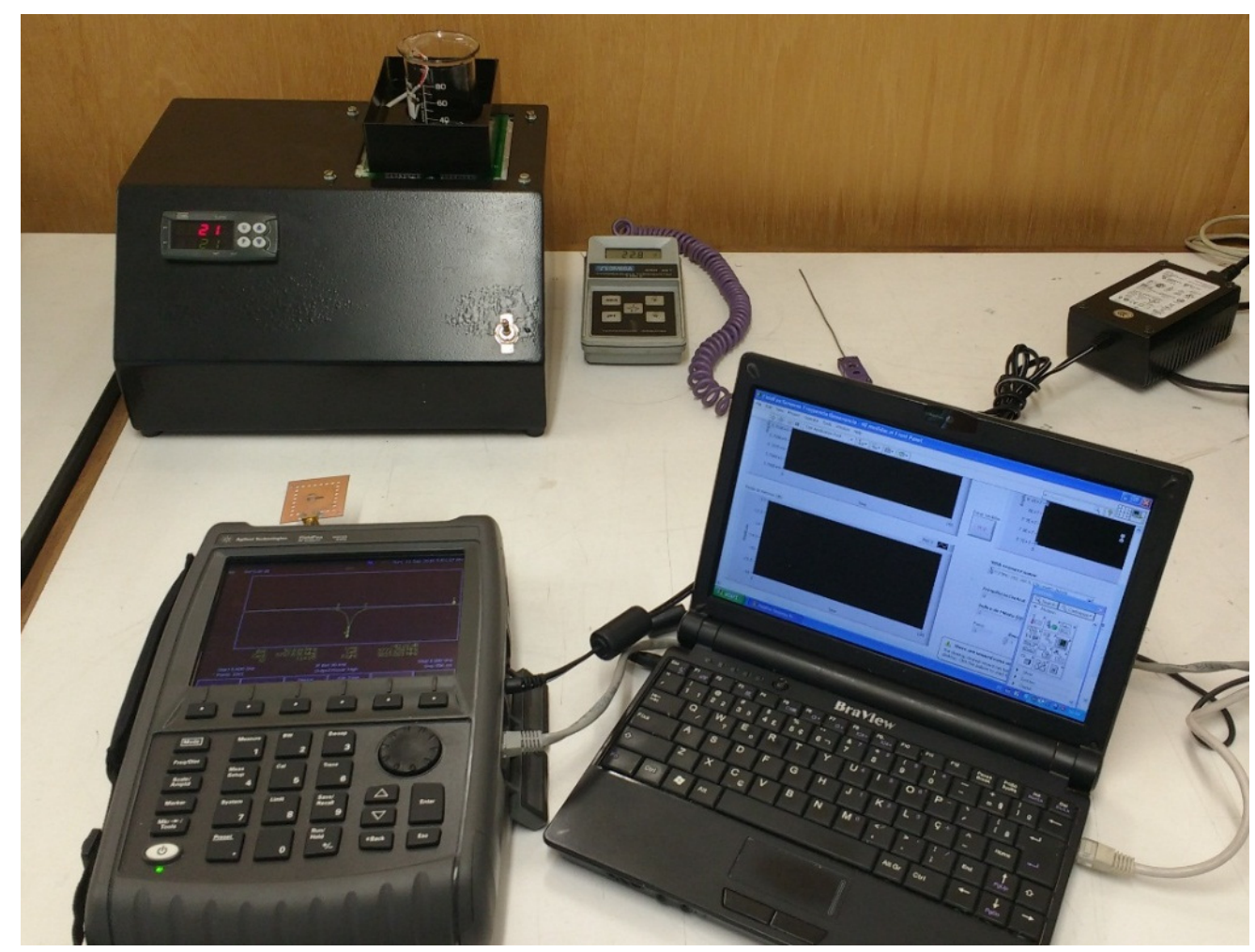


As amostras de água DI foram preparadas utilizando um sistema de controle de temperatura. Esse sistema possui um controlador TLK39 ${ }^{51}$, usado para ligar e desligar a alimentação de células Peltier e um sensor do tipo PT10052 isolado. Através de banho-maria foi possível manter a amostra de água DI nas temperaturas especificadas. As temperaturas das amostras foram medidas utilizando um termopar tipo E conectado a um indicador de temperatura Omega $450^{53} \mathrm{AET}$, com incerteza de $0,1^{\circ} \mathrm{C}$. A Tabela P.1 apresenta os valores da parte real e imaginária da permissividade elétrica complexa na frequência de 5,8 GHz em relação a sensibilidade da frequência de ressonância e das variações do índice de mérito da antena SIW com fenda traseira.

Tabela P.1 - Valores de permissividade elétrica complexa com os parâmetros de sensibilidade obtidos na antena SIW para as diferentes temperaturas analisadas.

\begin{tabular}{ccccc}
\hline $\begin{array}{c}\text { Temperatura } \\
\left({ }^{\circ} \mathrm{C}\right)\end{array}$ & $\begin{array}{c}\Delta f / f_{0} \\
(\text { Medido) }\end{array}$ & $\begin{array}{c}\text { Parte real da } \\
\text { permissividade } \\
\text { elétrica }(\varepsilon r) \\
\text { (BUCHNER et al., } \\
1999)\end{array}$ & $\begin{array}{c}1 / Q_{s .}\left(\Delta Q / Q_{0}\right) \\
(\text { Medido) }\end{array}$ & $\begin{array}{c}\text { Parte imaginária da } \\
\text { permissividade } \\
\text { elétrica }\left(\varepsilon r{ }^{\prime \prime}\right) \\
\text { (BUCHNER et al., } \\
1999)\end{array}$ \\
\hline 5,0 & 0,71007 & 67,83085 & 0,00438 & 33,30427 \\
10,0 & 0,73836 & 70,27996 & 0,00373 & 29,56902 \\
15,0 & 0,90422 & 71,77036 & 0,00286 & 26,19355 \\
20,0 & 0,94343 & 72,26049 & 0,00288 & 23,08917 \\
25,0 & 0,84829 & 72,17516 & 0,00174 & 20,18226 \\
30,0 & 0,80764 & 71,64845 & 0,00163 & 17,65517 \\
35,0 & 0,77507 & 71,05182 & 0,00156 & 15,88774 \\
\hline
\end{tabular}

O Gráfico P.3 apresenta a parte real da permissividade elétrica de água DI medida em diferentes temperaturas em função da sensibilidade da frequência de ressonância. Nota-se que é possível descrever o comportamento da sensibilidade da frequência de

\footnotetext{
${ }^{51}$ Controlador de temperatura TLK39: www.coel.com.br/produto/tlk39-controlador-de-temperatura.

52 Sensor de temperatura PT100: http://www.ecil.com.br/temperatura-industrial/sensores-pt100/

${ }^{53}$ Termômetro AET Omega 450: http://www.omega.com/pptst/450_HANDHELD.html
} 
ressonância da antena SIW em termos da variação da parte real da permissividade elétrica do material sob teste, tal como descrito no Apêndice B.

O Gráfico P.4 descreve a parte imaginária da permissividade elétrica de água para as diferentes temperaturas em função da variação do índice de mérito medido. Nota-se um crescimento monotônico dos valores de variação de índice de mérito de acordo com o aumento da parte imaginária da permissividade elétrica.

Gráfico P.3 - Parte real da permissividade elétrica em função da sensibilidade da frequência de ressonância para diferentes temperaturas.

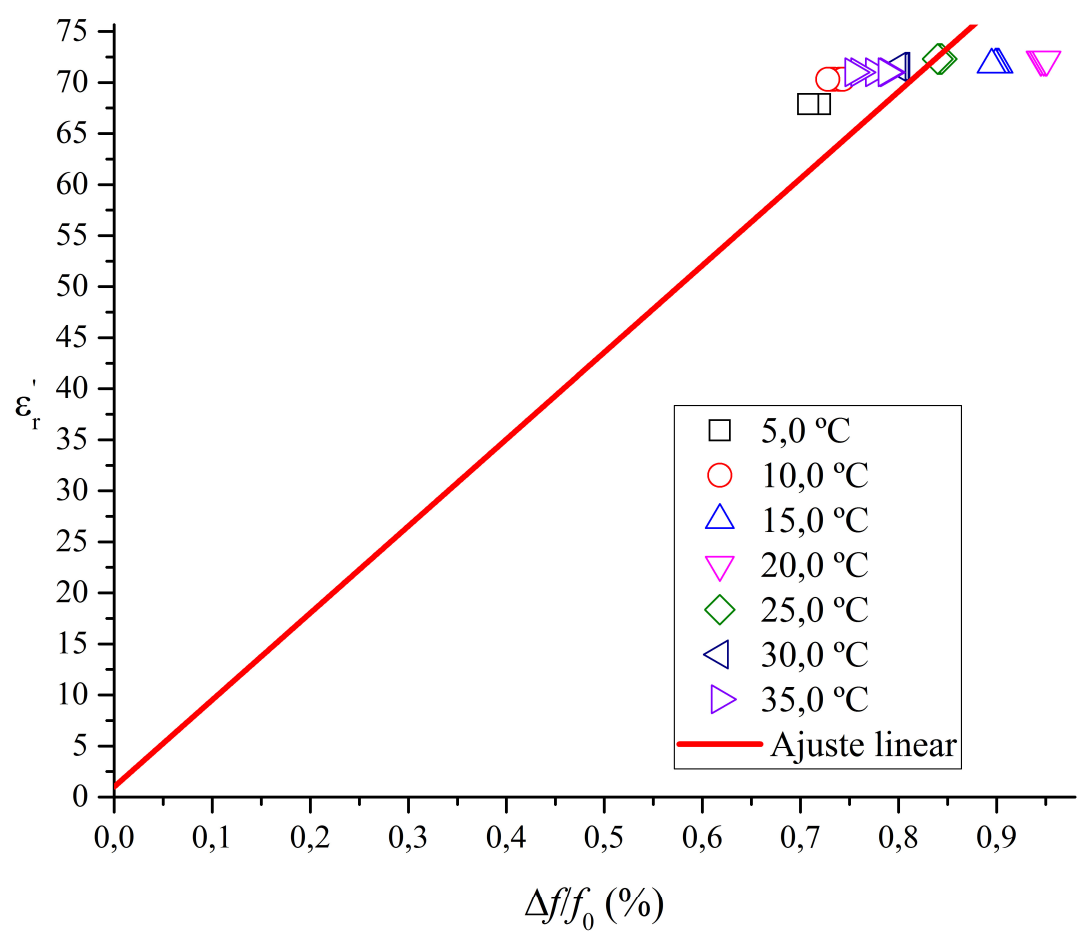

Para manter coerência com o modelo da teoria da perturbação da cavidade ressonante, os ajustes de primeira ordem dos Gráficos P.3 e P.4 são retas que passam, necessariamente, pelos pontos $(0,1)$ e $(0,0)$, respectivamente.

Conclui-se a partir das medidas, que seria possível realizar todos os testes descritos no corpo desse trabalho, variando, além das amostras e das frações, o valor da temperatura. O sensor testado é capaz de distinguir os efeitos da temperatura sobre as 
amostras. Cabe ressaltar que é necessário desenvolver um aparato de medidas que mantenha a temperatura da amostra constante durante o tempo de duração da medida.

Gráfico P.4 - Parte imaginária da permissividade elétrica em função da sensibilidade da frequência de ressonância para diferentes temperaturas.

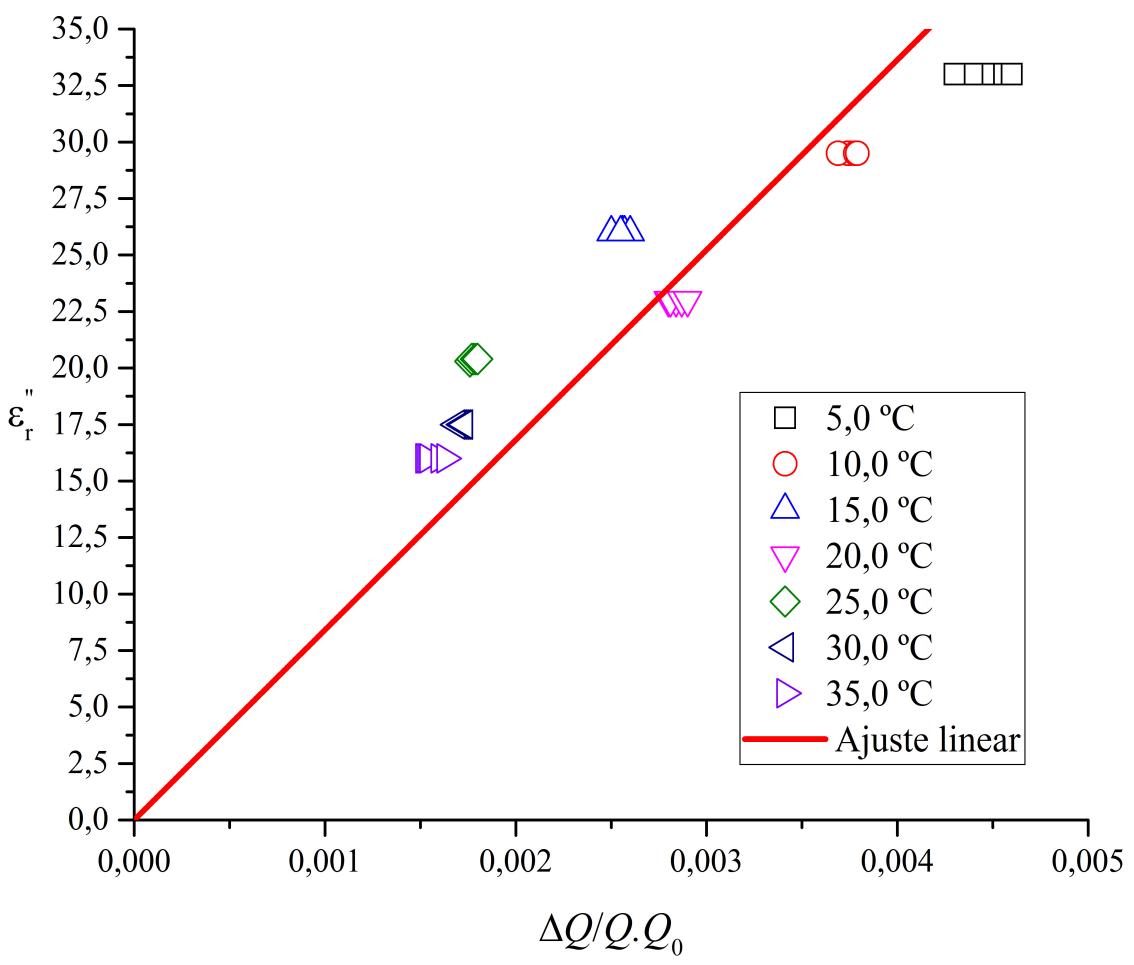




\section{APÊNDICE Q - ALGORITMO NRW PARA CARACTERIZAÇÃO DE AMOSTRAS COM O GUIA DE ONDAS SIW - SCRIPT EM MATLAB}

Este apêndice apresenta o algoritmo NRW utilizado para a caracterização de amostras com o guia de onda SIW (SOTODEH, 2014). São valores de entrada: a espessura da fenda e os parâmetros de espalhamento obtidos com o guia de ondas SIW com e sem o material sob teste. A saída do algoritmo é dada através das curvas de permissividade elétrica complexa.

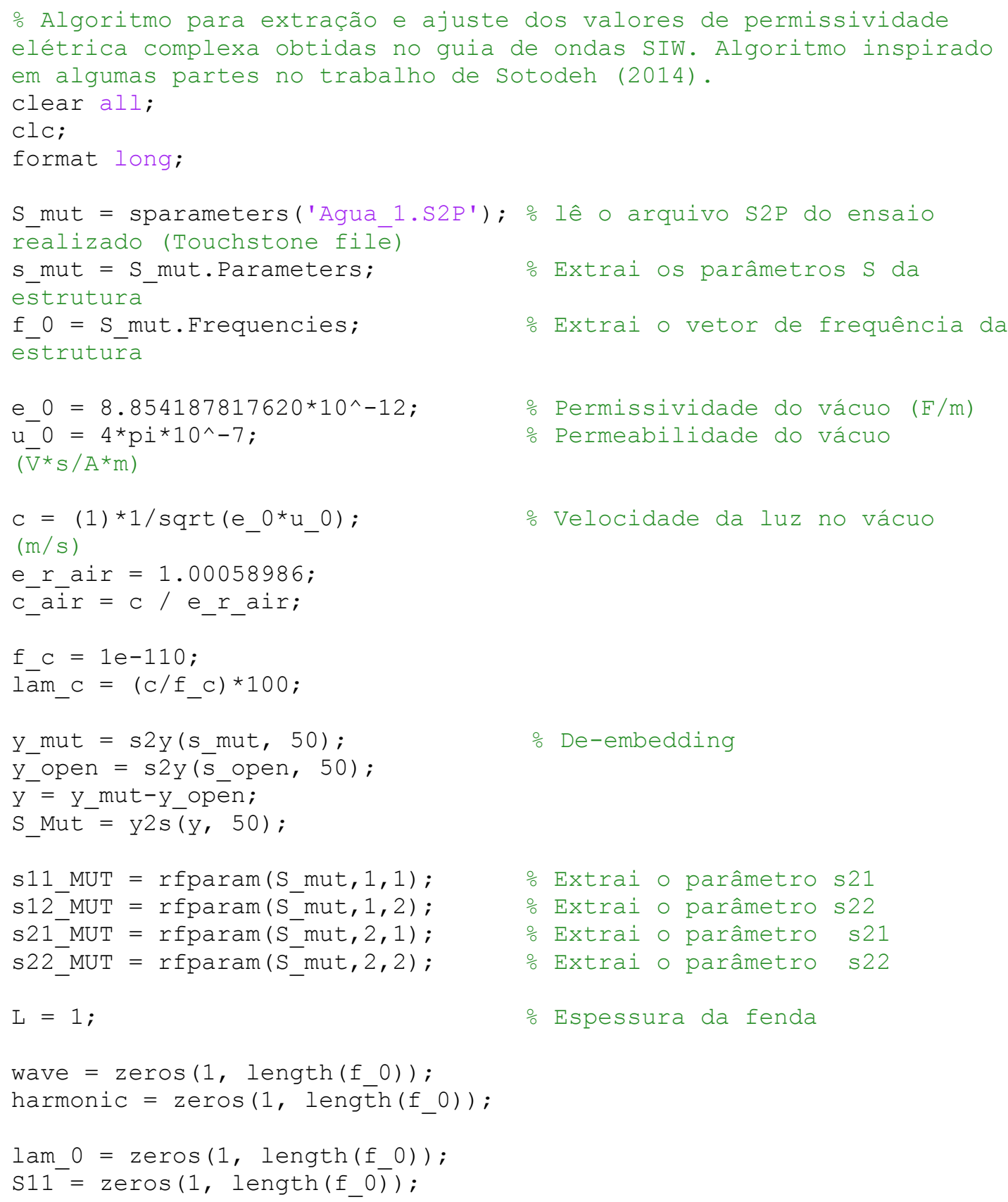




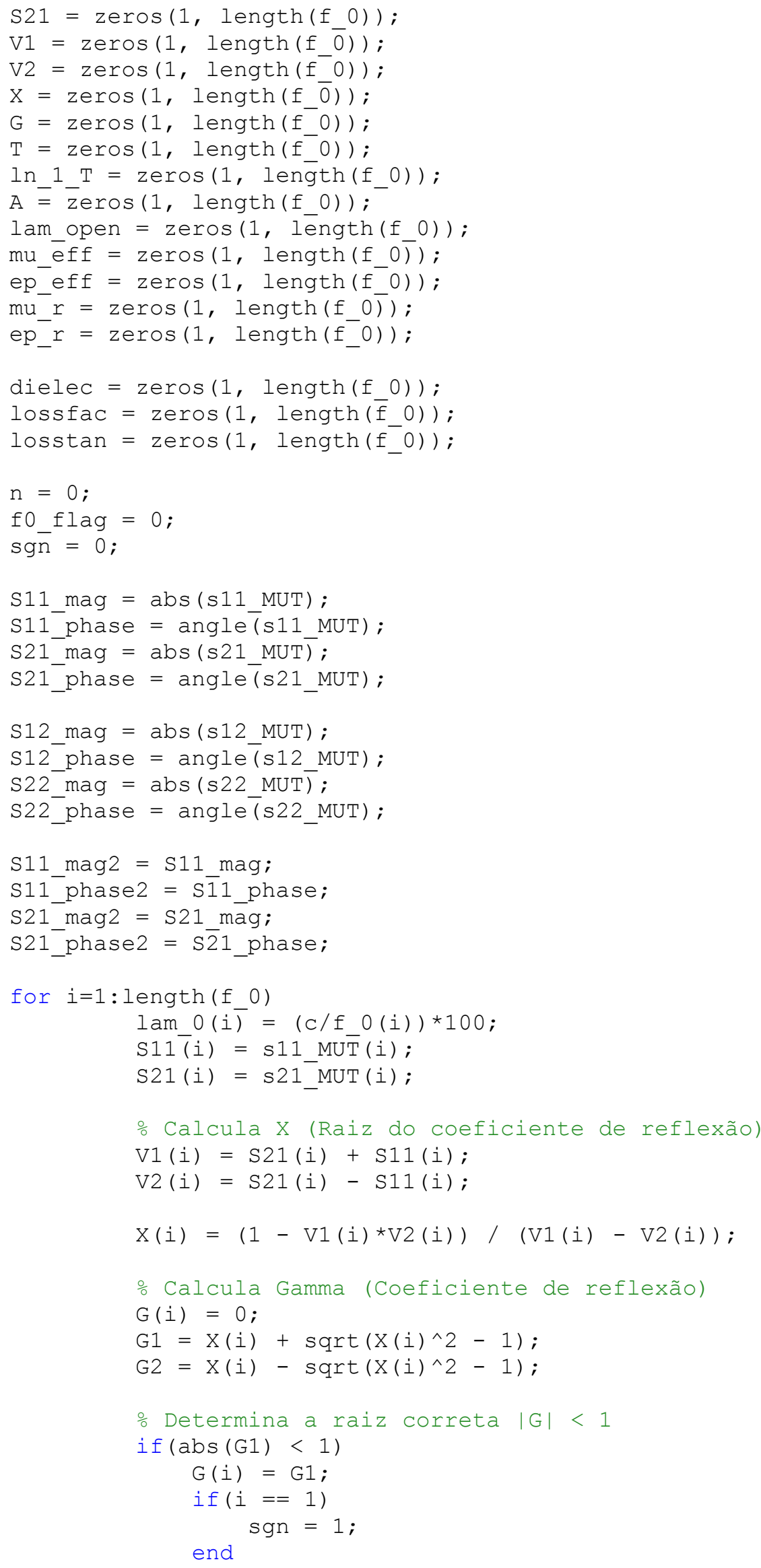




$$
\begin{aligned}
& \text { else } \operatorname{sgn}=1 ; \\
& \text { G(i) }=\text { G2; } \\
& \text { if }(i==1) \\
& \text { sgn }=2 ;
\end{aligned}
$$

end

$$
\operatorname{sgn}=2
$$

- Calcula T (Coeficiente de transmissão)

G(i)) ;

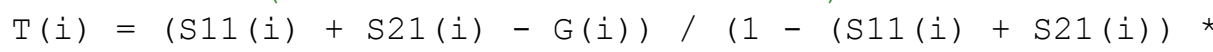

\% Resolve o problema da ambiguidade de fase if (i $\sim=$ length (f_o))

if ( (S21_phase2(i) $<0.00000$ \&\& S21_phase2(i) $>=$

$179.99000) \& \&($ S21_phase2 $(i+1)>=0.00000||$ S21_phase2 $(i+1)<-$ $179.99000))$ )

$$
\text { ln_1_T } \mathrm{T}(\mathrm{i})=
$$

complex $\left(\log \left(1 /\left(\operatorname{rea} \bar{l}(\bar{T}(i))^{\wedge} 2+\operatorname{imag}(\mathrm{T}(i))^{\wedge} 2\right)^{\wedge} 0.5\right),-\right.$

$1 * \operatorname{atan} 2(i \operatorname{mag}(\mathrm{T}(\mathrm{i})), \operatorname{real}(\mathrm{T}(\mathrm{i})))+2 * \mathrm{p} i * \mathrm{n})$;

$$
\mathrm{n}=\mathrm{n}+1 \text {; }
$$$$
\text { if } \mathrm{n}==1
$$$$
\text { f0_flag }=\text { i ; }
$$

end

$$
\begin{aligned}
& \text { else } \\
& \text { ln_1_T }(i)=
\end{aligned}
$$

complex $\left(\log \left(1 / \overline{(r e a l}(\mathrm{T}(i))^{\wedge} 2+\operatorname{imag}(\mathrm{T}(i))^{\wedge} 2\right)^{\wedge} 0.5\right),-$

$1^{\star} \operatorname{atan} 2(i \operatorname{mag}(\mathrm{T}(\mathrm{i}))$, real $\left.(\mathrm{T}(\mathrm{i})))+2 \mathrm{pi}^{\star} \mathrm{n}\right)$;

end

elseif( $i==$ length $\left(f_{-} 0\right)$ )

$$
\text { ln_1_T }(i)=
$$

complex $\left(\log \left(1 / \overline{(r e} a l(T(i))^{\wedge} 2+i m a g(T(i))^{\wedge} 2\right)^{\wedge} 0.5\right),-$

$1 * \operatorname{atan} 2(i \operatorname{mag}(\mathrm{T}(\mathrm{i})), \operatorname{real}(\mathrm{T}(\mathrm{i})))+2 * \mathrm{p} i \star n)$;

end

- Calcula o valor de A

$A(i)=1 / \operatorname{sqrt}\left(-\left(\ln { }_{-}{ }_{-} T(i) /(2 * p i \star L)\right)^{\wedge} 2\right)$;

lam_open(i) $=1 / \operatorname{sqrt}\left(1 / \operatorname{lam}_{-} 0(i)^{\wedge} 2-1 / \mathrm{lam}_{-} \mathrm{c}^{\wedge} 2\right)$;

o Considerando que o material é não magnético

mu_eff(i) $=1$;

ep_eff(i) $=($ lam_open (i)/A(i))^2 ;

mu_r $(i)=$ mu_eff(i);

- Calcula a permissividade efetiva e eff

ep_r(i) $=(1-1 \text { am_0(i)^2/lam_c^2 })^{\star} \overline{e p} \_$eff $(i)+$

( lam_0 (i)^2/lam_c^2)/mu_eff(i);

end

\% Extrai da curva a faixa de frequência entre $3.95 \mathrm{GHz}$ e $6 \mathrm{GHz}$ freq = f_o $(130: 224)$;

real_epr $=$ real (ep_r $(130: 224) . / 3.1)-75.45$;

imag_epr $=$ abs $\left(\right.$ imag $\left.\left(e p \_r(130: 224) . / 0.6\right)\right)-33.22$;

\% Realiza fitting da parte real da permissividade elétrica complexa. [xData, yData] = prepareCurveData ( freq, real_epr) ;

ft = fittype ( 'poly2');

[fitresult, gof] = fit( xData, yData, ft, 'Normalize', 'on' ); 
eps_r_fit $=$ fitresult (freq);

\% Realiza fitting da parte imaginária da permissividade elétrica complexa.

[xData, yData] = prepareCurveData ( freq, imag_epr) ;

ft = fittype( 'polyl');

[fitresult, gof] = fit ( xData, yData, ft );

eps_rr_fit = fitresult(freq); 


\section{ANEXO A - ESPECIFICAÇÕES DO ÁLCOOL COMBUSTÍVEL}

As especificações do álcool anidro e do álcool hidratado constam da tabela abaixo, do Regulamento Técnico n. ${ }^{\circ}$ 7/2005, anexo à Resolução ANP nº 19, de 15/04/2015:

Tabela A.1 - Especificações do álcool combustível.

\begin{tabular}{|c|c|c|c|c|c|c|}
\hline \multirow{2}{*}{ 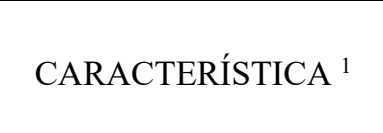 } & \multirow[b]{2}{*}{ UNIDADE } & \multicolumn{3}{|c|}{ LIMITE } & \multicolumn{2}{|c|}{ MÉTODO } \\
\hline & & EAC & EHC & $\mathrm{EHCP}^{2}$ & NBR & ASTM/EM/ISO \\
\hline Aspecto $^{3}$ & - & \multicolumn{3}{|c|}{$\begin{array}{l}\text { Límpido e Isento de } \\
\text { Impurezas (LII) }\end{array}$} & \multicolumn{2}{|r|}{ Visual } \\
\hline Cor & - & 4 & & 5 & & Visual \\
\hline \multirow{2}{*}{$\begin{array}{l}\text { Acidez total, máx. (em } \\
\text { miligramas de ácido } \\
\text { acético) }\end{array}$} & \multirow{2}{*}{$\mathrm{mg} / \mathrm{L}$} & \multirow{2}{*}{\multicolumn{3}{|c|}{30}} & 9866 & \multirow{2}{*}{ ISO 17315} \\
\hline & & & & & 16047 & \\
\hline $\begin{array}{c}\text { Condutividade elétrica, } \\
\text { máx. }^{6}\end{array}$ & $\mu \mathrm{S} / \mathrm{m}$ & \multicolumn{3}{|c|}{300} & 10547 & ISSO 17308 \\
\hline \multirow{2}{*}{ Massa específica a $20^{\circ} \mathrm{C}^{7}$} & \multirow{2}{*}{$\mathrm{kg} / \mathrm{m}^{3}$} & \multirow{2}{*}{$\begin{array}{l}791,5 \\
\text { máx. }\end{array}$} & \multirow{2}{*}{$\begin{array}{l}805,2 \\
\text { a } \\
811,2\end{array}$} & \multirow{2}{*}{$\begin{array}{c}799,7 \\
\mathrm{a} \\
802,8\end{array}$} & 5992 & \multirow{2}{*}{ D4052 } \\
\hline & & & & & 15639 & \\
\hline \multirow{2}{*}{ Teor alcoólico 7,8,9 } & \multirow{2}{*}{$\%$ massa } & \multirow{2}{*}{$\begin{array}{l}99,3 \\
\text { mín. }\end{array}$} & \multirow{2}{*}{$\begin{array}{c}92,5 \mathrm{a} \\
94,6\end{array}$} & \multirow{2}{*}{$\begin{array}{c}95,5 \mathrm{a} \\
96,5\end{array}$} & 5992 & \multirow{2}{*}{ - } \\
\hline & & & & & 15639 & \\
\hline $\begin{array}{l}\text { Potencial hidrogeniônico } \\
(\mathrm{pH})\end{array}$ & - & - & 6,0 & a 8,0 & 10891 & - \\
\hline Teor de etanol, mín. ${ }^{10}$ & $\%$ volume & 98,0 & 94,5 & 96,3 & 16041 & DD5501 \\
\hline \multirow{2}{*}{ Teor de água, máx. ${ }^{10}$} & \multirow{2}{*}{$\%$ massa } & \multirow{2}{*}{0,7} & \multirow{2}{*}{7,5} & \multirow{2}{*}{4,5} & 15531 & E203 \\
\hline & & & & & 15888 & E1064 \\
\hline Teor de metanol, máx. ${ }^{10}$ & $\%$ volume & \multicolumn{3}{|c|}{0,5} & 16041 & \\
\hline $\begin{array}{l}\text { Resíduo por evaporação, } \\
\text { máx. }{ }^{12,13}\end{array}$ & $\mathrm{mg} / 100 \mathrm{~mL}$ & \multicolumn{3}{|c|}{5} & 8644 & - \\
\hline $\begin{array}{l}\text { Teor de hidrocarbonetos, } \\
\text { máx. }{ }^{12}\end{array}$ & $\%$ volume & \multicolumn{3}{|c|}{3} & 13993 & - \\
\hline Ton drolora mó 14 & $m a / l_{0}$ & & & & 10004 & D7328 \\
\hline leor de cloreto, max. & $\mathrm{mg} / \mathrm{kg}$ & & 1 & & 10894 & D7319 \\
\hline Teor de sulfato máx 15 & $\mathrm{mo} / \mathrm{kg}$ & & 4 & & 10894 & D7328 \\
\hline & & & & & & D7319 \\
\hline Teor de ferro, máx. ${ }^{15}$ & $\mathrm{mg} / \mathrm{kg}$ & & 5 & & 11331 & - \\
\hline Teor de sódio, máx. ${ }^{15}$ & $\mathrm{mg} / \mathrm{kg}$ & & 2 & & 10422 & - \\
\hline Teor de cobre máx 16 & $\mathrm{mo} / \mathrm{kg}$ & & 0,07 & & & \\
\hline leor de cobre, max. & $\mathrm{mg} / \mathrm{kg}$ & & - & & 11331 & - \\
\hline & & & & & & D5453 \\
\hline Teor de enxofre máx ${ }^{17,18}$ & $\mathrm{mg} / \mathrm{kg}$ & & Anotar & & - & EN15485 \\
\hline & & & & & - & EN15486 \\
\hline & & & & & & EN15837 \\
\hline
\end{tabular}


1. A ANP poderá acrescentar características adicionais, métodos complementares ou impor novos limites às especificações dispostas nas Tabelas V e VI deste Regulamento Técnico, para o caso de Etanol Combustível produzido a partir de matéria-prima distinta ao caldo ou melaço de cana-de-açúcar ou a partir de processos distintos ao da rota fermentativa.

2. No Certificado da Qualidade deverá ser indicada a nomenclatura Etanol Hidratado Combustível Premium, quando os resultados das análises atenderem aos limites de especificação do EHCP.

3. O produto só poderá ser considerado reprovado no Aspecto, caso o parâmetro resíduo por evaporação estiver não conforme. Alternativamente, o parâmetro resíduo por evaporação pode ser substituído pelo teor de material não volátil, segundo a norma ABNT NBR 15559: Etanol combustível - Determinação do teor de material não volátil por evaporação, sendo aceito o limite de $5 \mathrm{mg} / 100 \mathrm{~mL}$.

4. Laranja após adição do corante especificado segundo a Tabela VII deste Regulamento Técnico.

5. Não pode apresentar as colorações laranja e azul, restritas ao EAC e à gasolina de aviação, respectivamente.

6. O Limite de $300 \mu \mathrm{S} / \mathrm{m}$ entrará em vigor a partir de $1^{\circ}$ de julho de 2015 . Até 30 de junho de 2015 , fica o valor máximo de $389 \mu \mathrm{S} / \mathrm{m}$.

7. Para o caso de EHC e de EHCP certificado após transporte dutoviário ou aquaviário e no caso de produto importado, o limite para massa específica e teor alcoólico deve atender os valores constantes na Tabela VI.

8. A unidade ${ }^{\circ}$ INPM é equivalente à unidade $\%$ massa para o teor alcoólico.

9. Para o cálculo do teor alcoólico, deve ser considerado o valor da massa específica com apenas uma casa decimal. Aplicar a regra de arredondamento determinada na norma NBR 5891.

10. Análise obrigatória para produto importado e quando houver suspeita de contaminação ou por solicitação da ANP.

11. A Norma ASTM E1064 somente poderá ser utilizada para o Etanol Anidro Combustível.

12. Análise obrigatória para produto importado e em caso de Etanol Combustível proveniente de transporte dutoviário ou aquaviário, o que não isenta de responsabilidade os agentes econômicos em atender o limite previsto na especificação nos casos em que o etanol não for transportado por estes modais.

13. No caso de Etanol Combustível aditivado, a determinação da característica resíduo por evaporação deverá ser conduzida conforme procedimento 2 da norma ABNT NBR 8644.

14. Análise obrigatória em caso de Etanol Combustível proveniente de transporte aquaviário por navegação marítima, o que não isenta de responsabilidade cada agente econômico que comercializa o combustível em atender o limite previsto na especificação ao longo de toda cadeia. 
15. Análise obrigatória para produto importado. No caso de produção nacional, análise de periodicidade mensal e obrigatória apenas para o EHC e EHCP, o que não isenta a responsabilidade por parte do Fornecedor de Etanol Combustível e demais agentes da cadeia em atender o limite previsto na especificação para o Etanol Anidro Combustível.

16. Análise obrigatória para produto importado. No caso de produção nacional, análise de periodicidade mensal e obrigatória somente quando o Etanol for produzido, armazenado ou transportado em equipamentos ou linhas que contenham ligas metálicas compostas por cobre.

17. Análise obrigatória para produto importado. No caso de produção nacional, análise de periodicidade trimestral.

18. A análise teor de enxofre passará a ser obrigatória a partir de $1^{\circ}$ de julho de 2015. 


\section{ANEXO B - BANDAS DE OPERAÇÃO NAS FAIXAS DE FREQUÊNCIAS DE MICRO-ONDAS E GUIAS DE ONDAS PADRÃO}

O espectro de micro-ondas pode ser divido em bandas de operação. Embora as aplicações mais comuns estejam dentro da faixa de 1 até $40 \mathrm{GHz}$, há interesse em desenvolver e estudar aplicações com frequências mais elevadas. As bandas de frequência de micro-ondas são mostradas na Tabela B.1.

Tabela B.1 - Faixas de frequências de micro-ondas.

\begin{tabular}{cc}
\hline Banda de operação & Frequência \\
\hline $\mathrm{L}$ & 1 a $2 \mathrm{GHz}$ \\
$\mathrm{S}$ & 2 a $4 \mathrm{GHz}$ \\
$\mathrm{C}$ & 4 a $8 \mathrm{GHz}$ \\
$\mathrm{X}$ & 8 a $12 \mathrm{GHz}$ \\
$\mathrm{Ku}$ & 12 a $18 \mathrm{GHz}$ \\
$\mathrm{K}$ & 18 a $26 \mathrm{GHz}$ \\
$\mathrm{Ka}$ & 26 a $40 \mathrm{GHz}$ \\
$\mathrm{U}$ & 40 a $60 \mathrm{GHz}$ \\
$\mathrm{V}$ & 50 a $75 \mathrm{GHz}$ \\
$\mathrm{E}$ & 60 a $90 \mathrm{GHz}$ \\
$\mathrm{W}$ & 75 a $110 \mathrm{GHz}$ \\
$\mathrm{F}$ & 90 a $140 \mathrm{GHz}$ \\
\hline
\end{tabular}

Fonte: Adaptado de (POZAR, 2005).

Os guias de ondas com seção retangular são tabelados e divididos em bandas de operação. Dessa forma, torna-se mais fácil selecionar um guia de acordo com a aplicação desejada. As dimensões de guias padrões e suas bandas de operação nas faixas de frequências de micro-ondas são descritas na Tabela B.2. Nessa tabela são apresentados os valores padronizados pela EIA (Electronic Industries Alliance) e sua equivalência com a padronização europeia. 
Tabela B.2 - Guias de ondas padrão.

\begin{tabular}{|c|c|c|c|}
\hline WR (EIA) & WR (Europa) & Banda [GHz] & Dimensões [pol.] \\
\hline 2300 & - & $0,32-0,49$ & $23,000 \times 11,500$ \\
\hline 2100 & - & $0,35-0,53$ & $21,000 \times 10,500$ \\
\hline 1800 & - & $0,41-0,62$ & $18,000 \times 9,000$ \\
\hline 1500 & - & $0,49-0,75$ & $15,000 \times 7,500$ \\
\hline 1150 & - & $0,64-0,96$ & $11,500 \times 5,750$ \\
\hline 975 & - & $0,75-1,12$ & $9,750 \times 4,875$ \\
\hline 770 & - & $0,96-1,46$ & $7,700 \times 3,850$ \\
\hline 650 & 6 & $1,12-1,70$ & $6,500 \times 3,250$ \\
\hline 510 & - & $1,45-2,20$ & $5,100 \times 2,550$ \\
\hline 430 & 8 & $1,70-2,60$ & $4,300 \times 2,150$ \\
\hline 340 & $9 \mathrm{~A}$ & $2,20-3,30$ & $3,400 \times 1,700$ \\
\hline 284 & 10 & $2,60-3,95$ & $2,840 \times 1,340$ \\
\hline 229 & $11 \mathrm{~A}$ & $3,30-4,90$ & $2,290 \times 1,145$ \\
\hline 187 & 12 & $3,95-5,85$ & $1,872 \times 0,872$ \\
\hline 159 & 13 & $4,90-7,05$ & $1,590 \times 0,795$ \\
\hline 137 & 14 & $5,85-8,20$ & $1,372 \times 0,622$ \\
\hline 112 & 15 & $7,05-10,00$ & $1,122 \times 0,497$ \\
\hline 102 & - & $7,00-11,00$ & $1,020 \times 0,510$ \\
\hline 90 & 16 & $8,20-12,40$ & $0,900 \times 0,400$ \\
\hline 75 & 17 & $10,00-15,00$ & $0,750 \times 0,375$ \\
\hline 62 & 18 & $12,40-18,00$ & $0,622 \times 0,311$ \\
\hline 51 & 19 & $15,00-22,00$ & $0,510 \times 0,255$ \\
\hline 42 & 20 & $18,00-26,50$ & $0,420 \times 0,170$ \\
\hline 34 & 21 & $22,00-33,00$ & $0,340 \times 0,170$ \\
\hline 28 & 22 & $26,50-40,00$ & $0,420 \times 0,170$ \\
\hline 22 & 23 & $33,00-50,00$ & $0,224 \times 0,112$ \\
\hline 19 & 24 & $40,00-60,00$ & $0,188 \times 0,094$ \\
\hline 15 & 25 & $50,00-75,00$ & $0,148 \times 0,074$ \\
\hline 12 & 26 & $60,00-90,00$ & $0,122 \times 0,061$ \\
\hline 10 & 27 & $75,00-110,00$ & $0,100 \times 0,050$ \\
\hline 8 & 28 & $90,00-140,00$ & $0,080 \times 0,040$ \\
\hline $7(6)$ & 29 & $110,00-170,00$ & $0,065 \times 0,0325$ \\
\hline 5 & 30 & $140,00-220,00$ & $0,0510 \times 0,0255$ \\
\hline 4 & 31 & $172,00-260,00$ & $0,0430 \times 0,0215$ \\
\hline 3 & 32 & $220,00-330,00$ & $0,0340 \times 0,0170$ \\
\hline
\end{tabular}

Fonte: Adaptado de (POZAR, 2005). 